\title{
Girl-Centered Program Design: A Toolkit to Develop, Strengthen and Expand Adolescent Girls Programs
}

\author{
Karen Austrian \\ Population Council \\ Dennitah Ghati \\ Population Council
}

Follow this and additional works at: https://knowledgecommons.popcouncil.org/departments_sbsr-pgy

Part of the Demography, Population, and Ecology Commons, Family, Life Course, and Society

Commons, Gender and Sexuality Commons, International Public Health Commons, and the Medicine and Health Commons

How does access to this work benefit you? Let us know!

\section{Recommended Citation}

Austrian, Karen and Dennitah Ghati. 2010. "Girl-Centered Program Design: A Toolkit to Develop, Strengthen and Expand Adolescent Girls Programs." Nairobi: Population Council. 
(1) Population Council

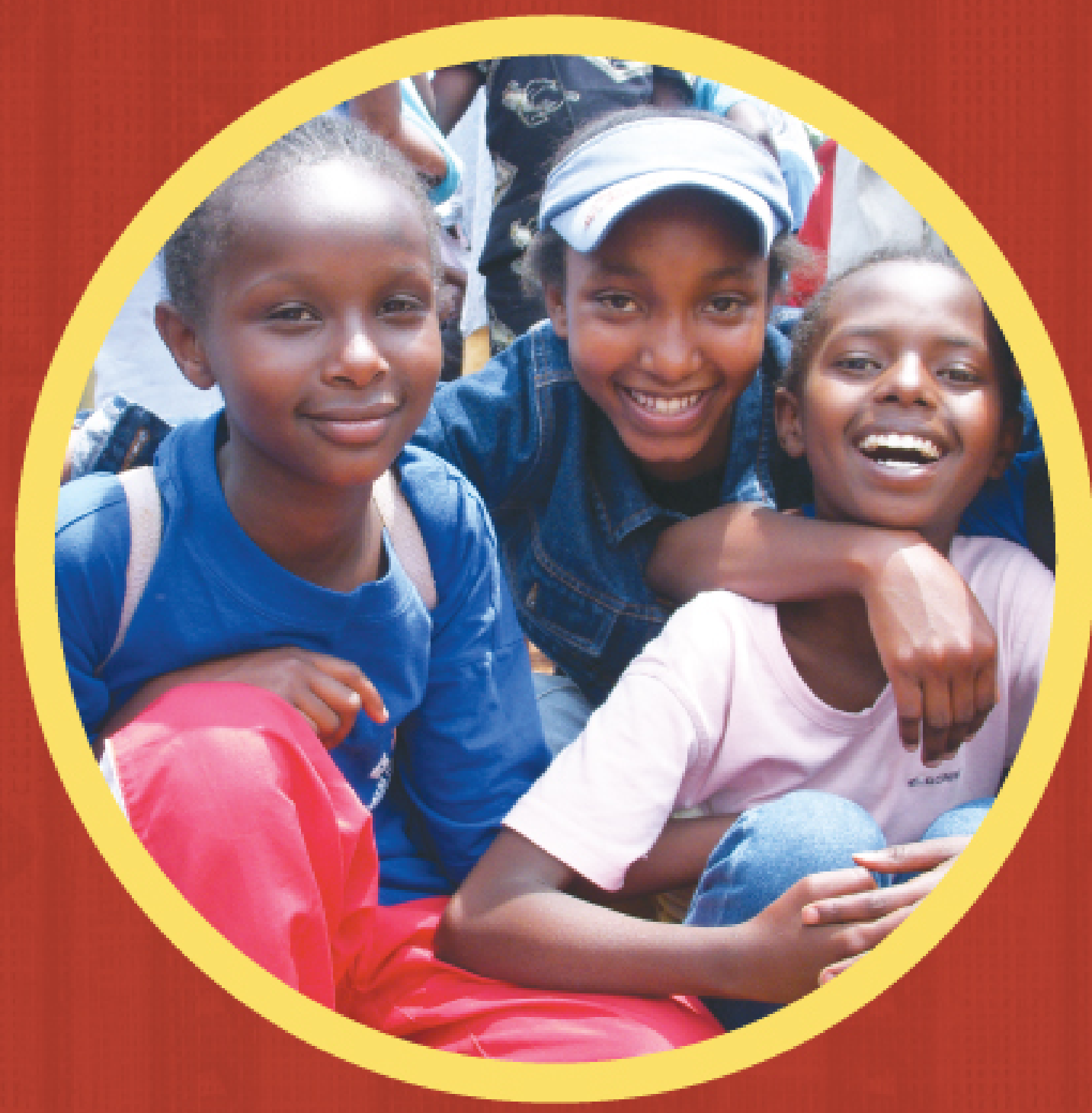

Girl-Centered Program Design

A Toolkit to Develop, Strengthen \& Expand Adolescent Girls Programs 



\section{(P) Population Council}

Research that makes a difference

The Population Council conducts research worldwide to improve policies, programs, and products in three areas: HIV and AIDS; poverty, gender, and youth; and reproductive health.

$\begin{array}{ll}\text { Population Council - Kenya } & \text { Population Council } \\ \text { PO Box 17643-00500 } & \text { One Dag Hammarskjold Plaza } \\ \text { Nairobi, Kenya } & \text { New York, NY 10017, USA } \\ \text { Tel: }+254-20-2713480 & \text { Tel: }+1-212-339-0500 \\ \text { Fax: }+254-20-2713479 & \text { Fax: }+1-212-755-6052\end{array}$

http://www.popcouncil.org

(c) 2010 The Population Council, Inc

Any part of this publication may be photocopied without permission from the publisher provided that copies are distributed without charge and that full source citation is provided.

The Population Council would appreciate receiving a copy of any materials in which the text is used.

ISBN 9966-956-74-3

Suggested Citation: Austrian, K. and Ghati, D. 2010. Girl Centered Program Design: A Toolkit to Develop, Strengthen and Expand Adolescent Girls Programs. Population Council.

Graphic design \& layout

Jacaranda Designs Ltd.

PO Box 1202-00606, Nairobi, Kenya

Tel: +254-20-374-6270 or Wireless +254-20-260-4433

Email: info@jacaranda-africa.com

Printed in Nairobi, Kenya

This toolkit was made possible with generous support from the Nike Foundation

\section{About the Nike Foundation, Nike, Inc. and the NoVo Foundation}

The Nike Foundation (www.nikefoundation.org) invests exclusively in adolescent girls as the most powerful force for change and poverty alleviation in the developing world. The Foundation's investments are designed to get girls on the global agenda and drive resources to them. The work of the Nike Foundation is supported by Nike, Inc. and the NoVo Foundation, a collaboration that has significantly broadened the impact of the Girl Effect.

\section{About girleffect.org}

girleffect.org tells the story of girls creating a ripple impact of social and economic change on their families, communities and nations. The work of the Girl Effect is driven by girl champions around the globe. The Nike Foundation created the Girl Effect with

significant financial and intellectual contributions by the NoVo Foundation and Nike, Inc. and in collaboration with key partners such as the United Nations Foundation and the Coalition for Adolescent Girls. 


\section{Girl-Centered Program Design}

A Toolkit to Develop, Strengthen \& Expand Adolescent Girls Programs 


\section{Acknowledgements}

This toolkit is based on the experiences of dozens of programs working with adolescent girls—and wouldn't have been possible to create without the willingness of many people to share their successes, stumbling points and expertise.

First, many thanks to the members of the Kenya Brain Trust: Your constant commitment, not only to our many meetings and learning conversations, but to reaching vulnerable adolescent girls with the highest quality of programs possible, is truly inspiring. Your willingness to learn from each other, help one another, and share both successes and failures has made us all better adolescent girls programmers. Thank you also to Everlyne Akinyi, Cyprian Amakalu, Anne Gitimu, Mumbi Kamuri, Nicole Khanali, Diana Moreka, Salome Munyendo, Pauline Mwangi, Daniel Nyawende, Mercy Nzioki, Emma Odundo, Monica Oguttu, Brenda Okumu, and Caroline Sakwa for reviewing the drafts of the toolkit and giving your wise input.

Also, a special thanks to Caroline Sakwa and the Binti Pamoja Centre for being a lead partner in the Kenya Brain Trust and for coordinating the activities of the Girls Committee. Thank you to Maureen Wandia,

Jacqueline Agwanda, and Kadesa Sylvia for leading the Girls Committee component of the Kenya Brain Trust-ensuring that our work stays grounded in the realities of the adolescent girls we are trying to serve.

Many thanks to Grace King' ori and Susan Scull-Carvalho of Jacaranda Designs for working closely with us on the design and layout. Without them the toolkit would not have its interactive and user-friendly feel.

Thank you also to Amy Babchek (Nike Foundation), Judith Bruce (Population Council), Jennifer Catino (Population Council), Sarah Engebretsen (Population Council), Lynn Renken (Nike Foundation), Cale Thompson (Nike Foundation), and Yohannes Wolday (Nike Foundation) for their careful review and thorough input into earlier drafts of the toolkit.

Thanks also to the multitude of colleagues at Population Council and beyond who work on adolescent girls programming and whose collective work and wisdom guided this writing: Sajeda Amin, Wendy Baldwin, Julie Bayiga, Martha Brady, Judith Bruce, Jennifer Catino, Monique Cohen, Alejandra Colom, Judy Diers, Sarah Engebretsen, Annabel Erulkar, Nicole Haberland, Kelly Hallman, Eva Roca, K.G. Santhya, Jennefer Sebstad Veronica Torres, and Adam Weiner.

Photographs in the toolkit were taken by Karen Austrian, Dennitah Ghati, Elizabeth Kariuki, Corrinne Ngurukie, and AMREF-Kenya.

Finally, our most important thanks are to the adolescent girls who bring to these programs their vibrancy and purpose. Your dedication to improving your lives, and the lives of those around you, is what inspires this work! 


\section{Table of Contents}

$\begin{array}{ll}\text { Introduction } & 7\end{array}$

Section 1 - Which Girls and Why 11

Chapter 1 - Which Girls Do You Want to Work With? 12

Chapter 2 - Needs Assessments - Understanding the Girls You Are Working With 22

Section 2 - Determining Program Structure $\quad 37$

Chapter 3 - Core Elements of the Safe Spaces Model - "Creating the Pot" 38

Chapter 4 - Recruitment - How Do You Get the Girls You Want into Your Program 52

Chapter 5 - Leadership Development and Mentoring 64

$\begin{array}{ll}\text { Chapter } 6 \text { - Working with Families and Critical Adults } & 78\end{array}$

$\begin{array}{lr}\text { Section } 3 \text { - Determining Program Content } & \mathbf{8 9}\end{array}$

Chapter 7 - The Asset Building Approach 99

Chapter 8 - Economic Strengthening Programming 102

Chapter 9 - Reproductive Health and HIV Information \& Clinical Services 116

Chapter 10-Addressing Sexual and Gender Based Violence 132

Chapter 11 - Reaching Extremely Vulnerable Groups of Adolescent Girls 146

Section 4 - Monitoring \& Evaluation $\quad 153$

$\begin{array}{ll}\text { Chapter } 12 \text { - Monitoring } & 154\end{array}$

$\begin{array}{ll}\text { Chapter } 13 \text { - Evaluation } & 164\end{array}$

$\begin{array}{lr}\text { Section } 5 \text { - Annexes } & \mathbf{1 8 5}\end{array}$

Tools/Handouts 186 

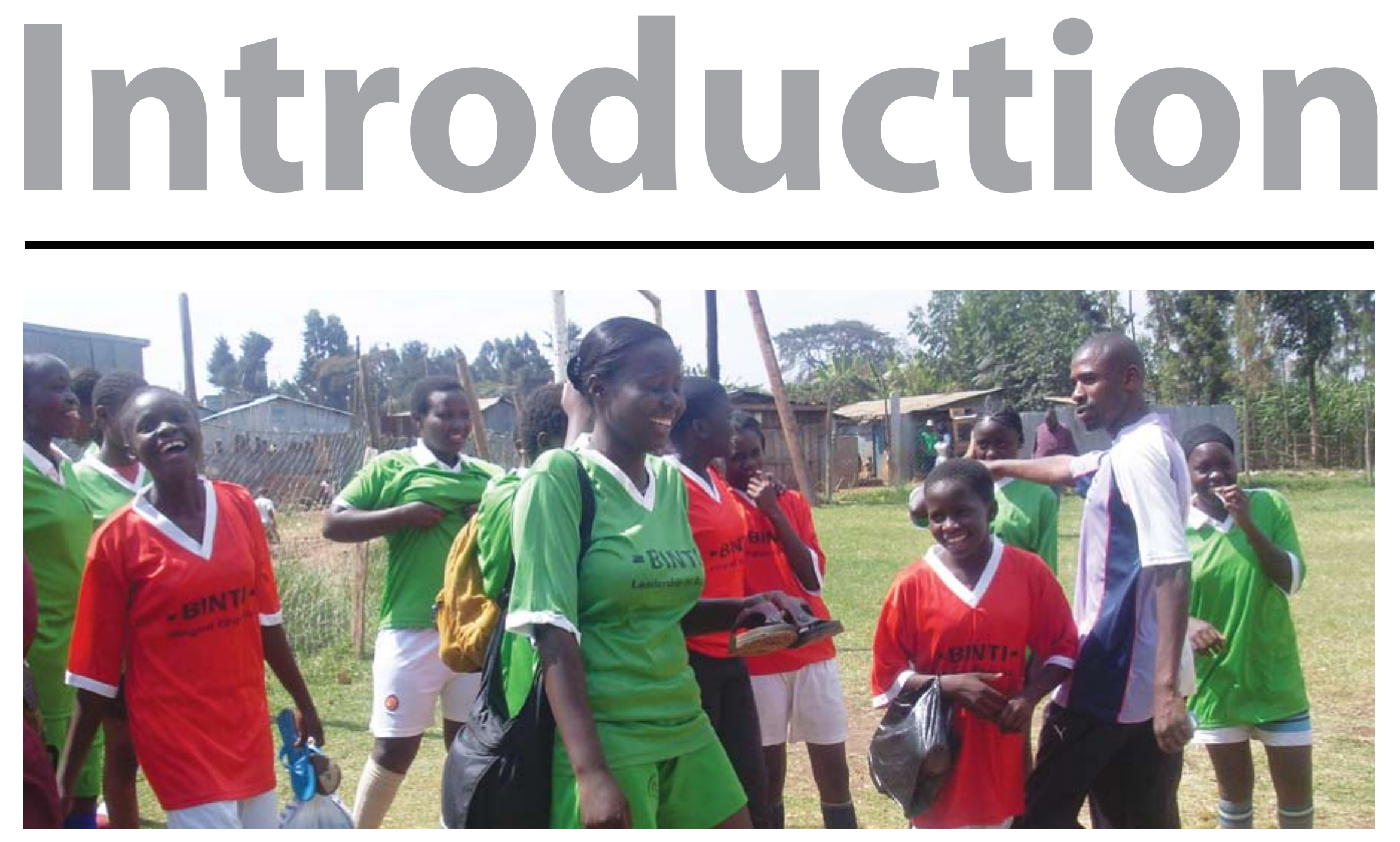


\section{Introduction}

As girls approach adolescence, they face the start of a narrow bridge. As they move through adolescence they must cross this bridge, emerging at the end as adult young women. However, the bridge through adolescence is a risky one for girls. They are significantly more vulnerable than their male counterparts and are more likely to fall off the bridge. Adolescent girls face poorer health outcomes, are more likely to become infected with HIV, more socially isolated, less likely to make the transition to secondary school or to complete it, and have fewer income-generating opportunities.

Logic might have it, then, that a lot of effort in these arenas is being made to reach these adolescent girls, to help them build social, health and economic assets and to provide them with the support and protection they need so that they do not drop out of school, get pregnant before they want to, or become infected with HIV or an STI. However, unfortunately, that is not the case. Typically, what is available are general youth programs that are meant to include adolescent girls, but in reality do not. Experience has shown that to reach adolescent girls, especially vulnerable adolescent girls, programs must be designed with them as the target audience. This toolkit will help you do that.

\section{How to use this toolkit}

The chapters in this toolkit build on each other. Chapters 1-6 focus on structuring a program that works with girls. The chapters address the various steps in preparing to set up the program and to start and run the girls' activities. Chapters 7-1 1 focus on the content of the programs - that is, how you decide what topics to cover and what kind of activities you do with the girls. Chapters 12-13 focus on monitoring and evaluation-how you keep track of what you are doing, who you are working with, and if your work is making a difference. At the end are lists of partners, donors and other resources for adolescent girls programs.

Within each chapter is an introduction to the topic, examples from existing programs for girls, and practical, user-friendly tools. In addition, the tools are available in the back pocket and in electronic files that you can edit on the enclosed CD and website: www.popcouncil.org/2010AdolGirlsToolkit. The hope is that you will take the tools, adapt them to meet your own needs and use them!

This toolkit is meant for anyone who is interested in working with adolescent girls ages 10-24'. It can be used by anyone who is designing or running a program, someone writing a proposal to work with girls, or staff working directly with girls who need fresh ideas on how to strengthen program activities. It can be used by people who are starting to work with girls in a targeted way for the first time, or those who already have a girls program but are trying to strengthen or expand it. 
The emphasis of this toolkit is on programs that are for girls only. Girls tend to receive the maximum benefit when the programs they participate in are girl-only because they feel free to open up, express themselves, ask any questions and take on leadership roles that they might not otherwise. Additionally, girls have significantly less access to safe public space in a community as compared with boys. As puberty starts, girls' lives typically become more restricted to the domestic sphere whereas boys' worlds start to expand. Girls tend to not feel as safe, comfortable, or in control in public spaces or in mixed company as their male agemates - and often culture dictates that they defer to males. Therefore, a girls program provides girls with a place to gather, learn and grow that they do not otherwise have access to. Also, experience has shown ${ }^{2}$ that programs that are meant for youth in general tend to be populated by young men ages 18-25. Therefore, existing youth programs do not create an environment that is appropriate or enabling for girls, especially the younger ones, and then girls attend less, the participant profile becomes more male and the cycle continues.

Some programs or organizations are committed to working with both boys and girls or do not have the ability, for a diverse range of reasons, to be girl-only. This toolkit is still relevant for you for two main reasons. First, many of the program structure and content suggestions are simply good practice and can be used to strengthen programs that work as well with boys, or with boys and girls. Second, even if you work with boys and girls together, there will still be times when it is appropriate to segregate the boys and the girls and use gender-based program strategies. For example, the recruitment methods that ensure vulnerable girls join your program (chapter 4), the need to engage critical adults (chapter 6) or the different assets that girls will need by certain ages (chapter 7) will be different from boys. So, even a program with boys and girls together can still be committed to addressing the unique needs of adolescent girls. This toolkit can help you with the information and tools to enable you to do so effectively.

\section{Kenya Brain Trust}

The Kenya Brain Trust comprises over 20 organizations that work with vulnerable adolescent girls in Kenya. It has two chaptersone in Nairobi, the capital city, and one in Kisumu, the third largest city in Kenya, located in the west on the shores of Lake

Victoria. The Brain Trust was formed to gather best practices in programming for girls from a dedicated group of practitioners and the girls they serve, and to create a community of practice.

The group met monthly from January 2008 to December 2009, and the content of this toolkit is based in part on the knowledge captured during these meetings. The members were a committed and diverse group of practitioners with expertise in a variety of areas including girls with disabilities, refugees, nomadic youth, savings, sports programming, faith-based programming, financial 
education, clinical services, vocational training, day programs, weekend programs, residential programs, urban programs and rural programs. The richness of their experience and their advice to each other is captured here in this toolkit.

Because of the association of this toolkit with the Brain Trust, the vast majority of examples and case studies in this toolkit are from members' programs. However, much of the lessons learned and program structures and strategies recommended transcend the Kenyan context. As you go through the toolkit and ask yourself the questions posed throughout the chapters, keep your specific cultural context in mind. Perhaps where you are working there are additional profiles of vulnerable girls or different categories of adults that will be important to work with. Perhaps the community or government structures in place and resources available will be somewhat different. However, the main principles will remain the same.

As you dive into this toolkit, it is my hope that you will use the practical tools and meaningful insight provided to transform your passion for and dedication to empowering vulnerable adolescent girls in your communities into concrete, successful programs. Girls are the future of our communities, cities and countries. Investing in them now is critical.

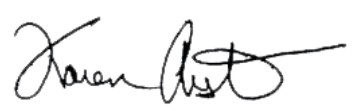

Karen Austrian

Population Council

Poverty, Gender, and Youth Program 


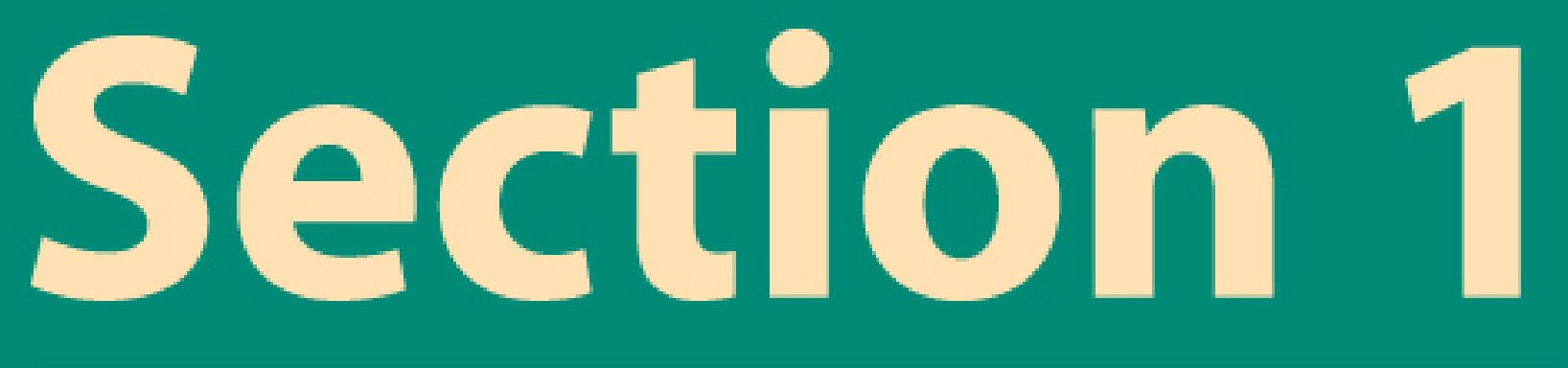

\section{Which Girls and Why}

Chapter 1

Which girls do you want to work with

\section{Chapter 2}

Needs assessments

Understanding the girls you are working with

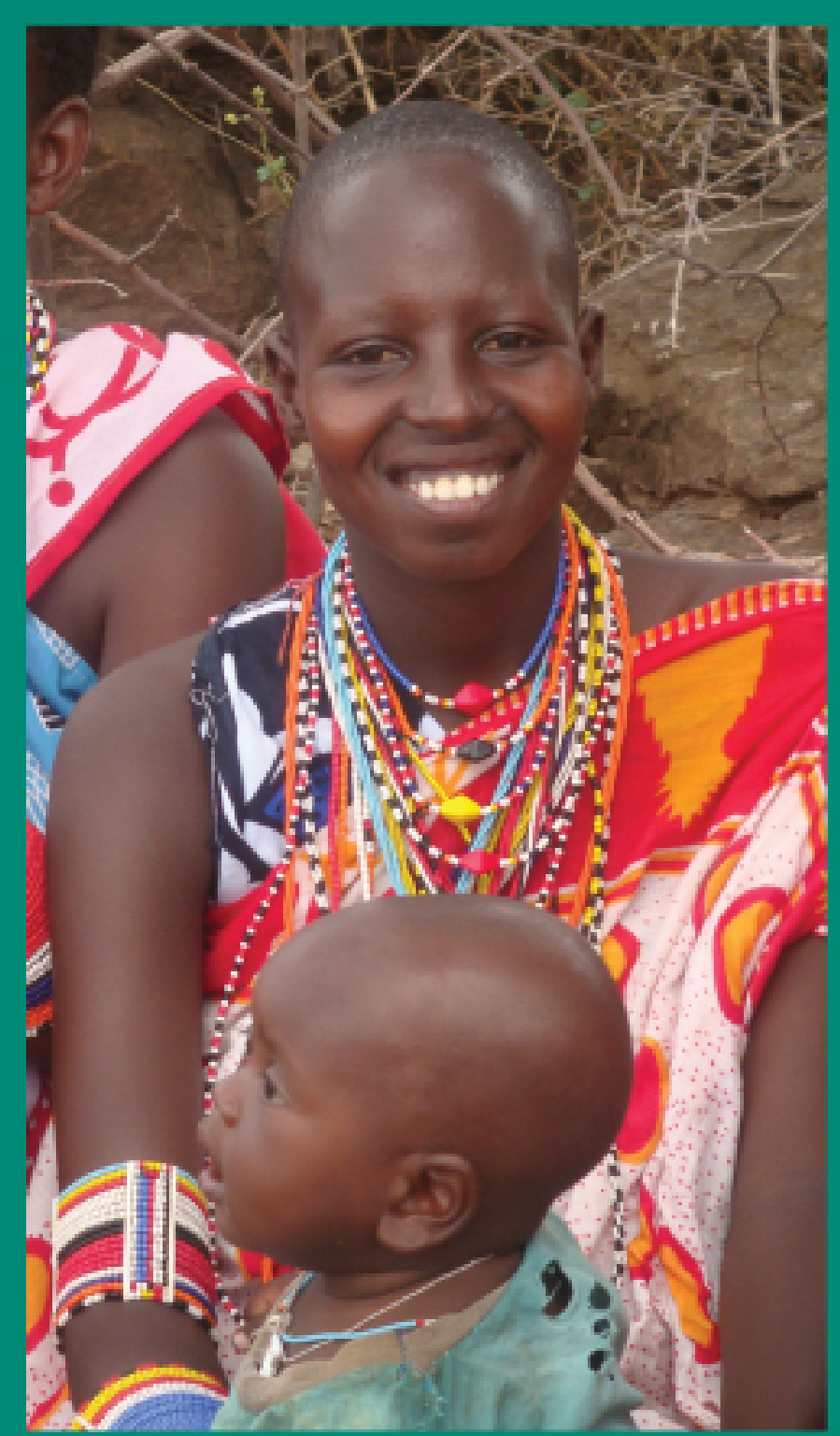




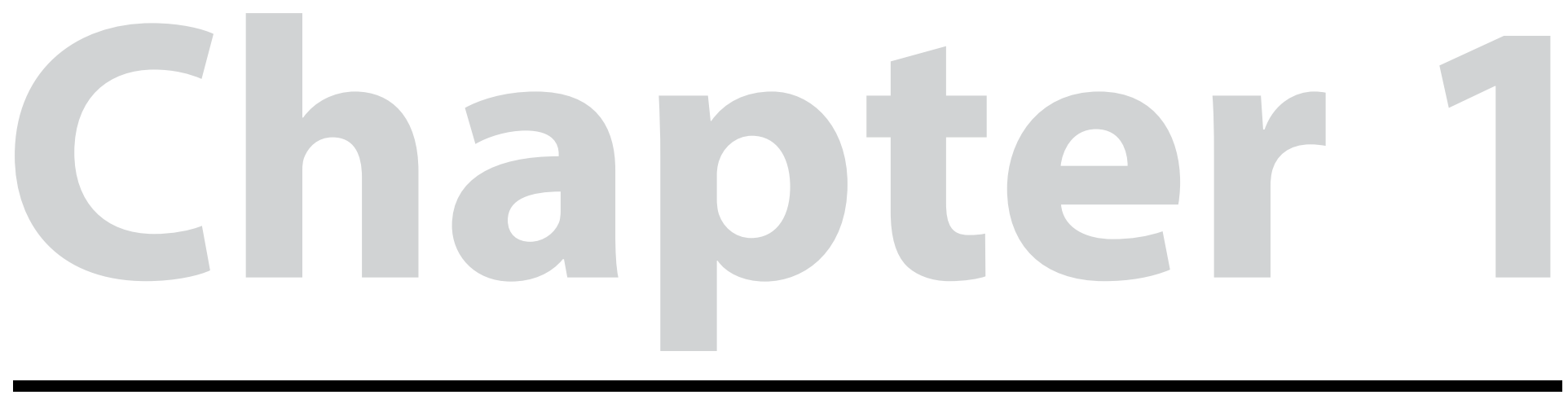

\section{Which girls do you want to work with}

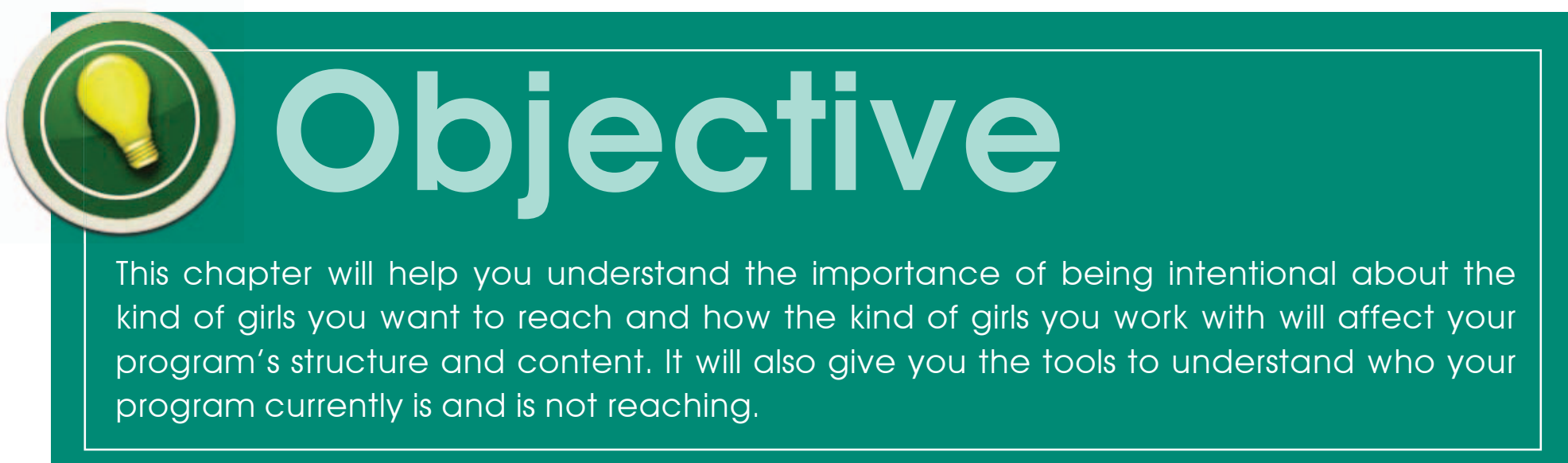




\section{One of the first questions that you will have to ask yourself when designing a girls program is "Which girls do I want in my program?"}

If you are thinking about how to strengthen or expand your girls program, you will need to ask yourself two questions:

"Who am I reaching?" and "Are they the girls I want to be reaching?"

Why is this a critical first step? Not all adolescent girls are the same and the issues that girls face will be specific to their age, where they live, their culture and other life circumstances. Many parts of your program plan will depend on the answer to this question. Let's think for a minute about some of the differences between adolescent girls:

- younger girls, ages 10-14

- older girls, ages 15-19

- young women, ages 20-24

- in-school girls

- out-of-school girls

- domestic workers

- girls with disabilities

- refugees or internally displaced girls

- married adolescent girls

- orphan girls

- migrant girls who are living apart from their family

- young mothers

- lesbians

- commercial sex workers

- nomadic girls/highly mobile girls

Not all adolescent girls are the same. The issues that girls face will be specific to their age, where they live, their culture and other life circumstances. 
This is not to say that a program should work with only one, or with all, of these types of girls, but it is important to be aware of the differences, because you will then need to plan your program structure and content accordingly.

What are the program structure components that might change, depending on which girls you want in your program?

- Times and days of the week the girls are available and for what duration

For example, in-school girls likely can meet only after school or on weekends while out-of-school girls might be able to meet during the week; often, domestic workers are available only on Sundays, their off day.

- Where to meet the girls

For example, younger girls might be more restricted in their mobility as it is harder for them to walk long distances to reach the program (see chapter 3).

- Kind of adults that you will need to talk with to get permission for the girls to participate in the program

For example, married adolescents may need the permission of their husband or mother-in-law; domestic workers may need permission from their employer-especially if they are asking to be released during the week to participate (see chapter 6).

- How you will recruit the girls

For example, if you are trying to reach in-school girls, you could go to the school setting; the very vulnerable and hard-to-reach groups will likely need more intensive and direct recruitment methods if they are truly going to be reached (see chapter 4).

- Who the people are that girls look up to

For example, if you are incorporating a mentoring element to your program (see chapter 5), it will be important to understand what characteristics are important for girls; for example, girls that do not have any parental figures in their lives may need someone who is a bit older and can fulfill that parent/advocate role, whereas girls who are living with one or both parents perhaps need someone who is a bit closer in age that they can identify with and with whom they can feel free to discuss their problems and ask questions. 
What are some content related issues that might change depending on which girls are in your programs?

Reproductive health/HIV The content in teaching 10- or 12-year-old girls about reproductive health issues will be different from that for 17- or 18-year-olds. Younger girls will likely be most concerned about menstruation, puberty and hygiene. Older, sexually active girls might be more concerned about family planning, emergency contraception and HIV/STD testing.

Economic empowerment For younger girls, it may be more appropriate to focus on financial education and basic savings activities. As girls get older, their needs and interest may lie more in the area of business training, vocational skills building or small loans. Young domestic workers are already earning an income and may need help with money management-or perhaps they want help to explore other employment opportunities.

Age appropriateness Typically, girls prefer being in groups of similar ages. In addition, it makes it easier for you to adapt the content to the right age group. For example, younger girls 10-14 like being together with others their age and feel free to discuss their issues and ask questions without worrying what the older girls think. Sometimes when older girls aged 16-18 are together in groups with younger girls, the older girls get tired of participating with "those little ones". So whenever possible, structure your program to deliver content to groups of girls that are similar in age so that the girls have the most in common as possible.

This toolkit provides you with tools that will help you to build a structure and select content and methodologies that are appropriate for the girls you want to reach-and is based on the assumption that you have decided the profile of girls you are working with. You will see that in the coming chapters there is more information on each of these topics mentioned above-recruitment, working with critical adults, economic empowerment programming, etc. You will be able to make the best use of this information if you are working with a specific profile in mind. 
"Who am I reaching?"

"I work with girls 10-24 throughout the Eastlands area of Nairobi."

"Our program is for all girls of ages 10-19-in-school and out-of-school."

These are commonly heard descriptions of program reach because programs often describe themselves and honestly aim to reach many of the girls in the specific place where they are working. However, on close examination, more often than not, their reach is not as wide as what they describe. Therefore, "who are we reaching?" is a question you should ask periodically to validate that the structure and content of your program is reaching and retaining the profile of girls you intended it for.

This is also a larger problem of the general "youth" programs that were thought to be a good place for girls. However, after documenting which girls, if any, were served by general "youth" programs, the answer revealed-not many.

So even in our own girls programs, we must be careful to understand who we are reaching and who we are not reaching so that we can responsibly report our target group and make adjustments to our programs so that we can indeed reach the profile of girls that we want.

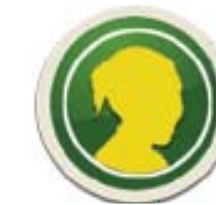

The Binti Pamoja Centre is a program for adolescent girls in the Kibera slum of Nairobi, Kenya, that wanted to reach girls from the 12 or more villages in Kibera. Binti Pamoja also described their program as one that reached girls from all Kibera villages. However, they had never actually tracked which villages the girls came from. When a systematic survey was done of girls who were members of the program, it turned out that the majority came from only a third of the villages. This information allowed Binti Pamoja to make a special effort to recruit girls from new villages and now there is a more equal distribution of girls.

- Decide which kinds of girls you are trying to reach in your program

- Use the coverage exercise tools to find out who you are currently reaching

\section{Don't}

- Assume who you are reaching, in terms of gender, age and other profile elements 


\section{The Coverage Exercise Tool}

\section{Purpose}

This tool will help your program document who is being reached and how to use that information to assess if you are reaching your target goals.

This tool can be used to do a quick scan of your current participants or a new group of participants that have just joined. It is important because it can help you to understand the basic characteristics of who is and is not coming to your program. As in the case study above, after Binti Pamoja conducted a similar coverage exercise, it became clear that girls from several villages in Kibera were not being reached. This tool has also been used with youth programs to better understand the breakdown between boys and girls and then make adjustments after understanding that they are not reaching the profile of adolescent girl that they want.
Directions

Step 1. Pick the critical elements of the girls' profile that you would like to collect.

- For example, if you are working with only school-going girls, you want to ask, "What grade are you in at school?" However, if you are working with a mix of in-school and out-of-school girls, it might be better to ask, "Are you in school?"

- Another example-if you are working with teenage mothers, maybe you want to ask, "How many children do you have?" but if you are working with a mix, you can ask, "Do you have children?"

- If you are trying to reach a certain geographical rangesuch as four neighbourhoods in one area-you can ask, "Where do you live?"

- If you work with both boys and girls, you may want to note if they are a boy or a girl. But if your program is all girls, clearly you wouldn't ask this question.

Step 2. Create a simple questionnaire that captures all the critical profile elements that you'd like to ask (sample attached).

Step 3. Add up the results in a chart (sample attached).

Step 4. See what you have learned and make program changes accordingly.

Note The coverage tool as presented here is a tool to analyse a program. It can also be used in a whole community with all the youth-serving organizations, or in an entire city or even country. The larger analysis of these results would provide an understanding of what profile of youth is being reached by the "youth-serving organizations" - and the youth that are not. This can be helpful for planning at a range of levels from neighbourhood to nation. 


\section{Sample coverage exercise}

Remember, you must choose the profile information that is important for your own program.

\begin{tabular}{|c|c|c|c|c|c|}
\hline & Male/female & Age & \begin{tabular}{|l}
$\begin{array}{l}\text { In school/out of } \\
\text { school }\end{array}$ \\
\end{tabular} & $\begin{array}{l}\begin{array}{l}\text { Neighbourhood that } \\
\text { you live in }\end{array} \\
\end{array}$ & $\begin{array}{l}\text { Do you live with one or } \\
\text { both of your parents? }\end{array}$ \\
\hline 1 & & & & & \\
\hline 2 & & & & & \\
\hline 3 & & & & & \\
\hline 4 & & & & & \\
\hline 5 & & & & & \\
\hline 6 & & & & & \\
\hline 7 & & & & & \\
\hline 8 & & & & & \\
\hline 9 & & & & & \\
\hline 10 & & & & & \\
\hline 11 & & & & & \\
\hline 12 & & & & & \\
\hline 13 & & & & & \\
\hline 14 & & & & & \\
\hline 15 & & & & & \\
\hline 16 & & & & & \\
\hline 17 & & & & & \\
\hline 18 & & & & & \\
\hline 19 & & & & & \\
\hline 20 & & & & & \\
\hline 21 & & & & & \\
\hline 22 & & & & & \\
\hline 23 & & & & & \\
\hline 24 & & & & & \\
\hline 25 & & & & & \\
\hline 26 & & & & & \\
\hline 27 & & & & & \\
\hline 28 & & & & & \\
\hline
\end{tabular}

In this coverage exercise tool you will learn about boys vs. girls, age, if they are in or out of school, where they live and with whom they live. You will not learn at what level they are in school, if they work, if they have children, and more. If you want to get different information, you will have to change the characteristics listed in this table. 
Sample coverage exercise-summary sheet

This table can be used to summarize the information collected with the coverage tool

\begin{tabular}{|c|c|c|c|c|c|c|c|c|}
\hline & \multicolumn{2}{|c|}{ Schooling status } & \multicolumn{2}{|c|}{ Living status } & \multicolumn{4}{|c|}{ Location* } \\
\hline & In school & $\begin{array}{l}\text { Out of } \\
\text { school }\end{array}$ & $\begin{array}{l}\text { One or both } \\
\text { parents }\end{array}$ & $\begin{array}{l}\text { Neither } \\
\text { parent }\end{array}$ & Area 1 & Area 2 & Area 3 & Area 4 \\
\hline Girls 10-14 & & & & & & & & \\
\hline Girls 15-19 & & & & & & & & \\
\hline Girls $20+$ & & & & & & & & \\
\hline Boys 10-14 & & & & & & & & \\
\hline Boys 15-19 & & & & & & & & \\
\hline Boys $20+$ & & & & & & & & \\
\hline
\end{tabular}


Sample completed coverage exercise

\begin{tabular}{|l|l|l|l|l|l|}
\hline & $\begin{array}{l}\text { Male/ } \\
\text { female }\end{array}$ & Age & $\begin{array}{l}\text { In school/out of } \\
\text { school }\end{array}$ & $\begin{array}{l}\text { Neighbourhood that you } \\
\text { live in }\end{array}$ & $\begin{array}{l}\text { Do you live with both of } \\
\text { your parents? }\end{array}$ \\
\hline 1 & M & 19 & Out & Area 1 & No \\
\hline 2 & F & 17 & In & Area 1 & Yes \\
\hline 3 & F & 18 & In & Area 3 & No \\
\hline 4 & M & 24 & Out & Area 3 & No \\
\hline 5 & M & 20 & Out & Area 1 & No \\
\hline 6 & M & 14 & In & Area 2 & Yes \\
\hline 7 & F & 15 & In & Area 1 & Yes \\
\hline 8 & M & 16 & In & Area 3 & Yes \\
\hline 9 & M & 18 & Out & Area 4 & No \\
\hline 10 & M & 19 & Out & Area 1 & No \\
\hline 11 & F & 16 & In & Area 4 & Yes \\
\hline 12 & M & 22 & Out & Area 3 & No \\
\hline 13 & F & 20 & Out & Area 3 & No \\
\hline 14 & M & 17 & In & Area 2 & Yes \\
\hline 15 & M & 18 & Out & Area 1 & Yes \\
\hline 16 & F & 13 & In & Area 1 & Yes \\
\hline 17 & M & 21 & Out & Area 4 & No \\
\hline 18 & M & 18 & Out & Area 1 & No \\
\hline 19 & M & 18 & In & Area 3 & Yes \\
\hline 20 & F & 18 & Out & Area 3 & Yes \\
\hline 21 & F & 16 & In & Area 3 & Yes \\
\hline 22 & M & 22 & Out & Area 4 & No \\
\hline 23 & F & 20 & Out & Area 1 & No \\
\hline 24 & M & 14 & In & Area 1 & Yes \\
\hline 25 & M & 15 & In & Area 1 & No \\
\hline 26 & F & 14 & In & Area 3 & Yes \\
\hline 27 & F & 15 & In & Area 3 & \\
\hline 28 & M & 17 & In & Area 2 & \\
\hline & & & & & Y \\
\hline
\end{tabular}

Remember, you must choose the profile information that is important for your own program.

Note-this is a program that aims to reach youth 10-24 who are living in all four neighborhoods that make up a particular municipality. The mandate is to reach in-school and out-of-school youth, with a special focus on younger, vulnerable adolescent girls who are out of school.

In this coverage exercise tool you will learn about boys vs. girls, age, if they are in or out of school, where they live and with whom they live. You will not learn at what level they are in school, if they work, if they have children, and more. If you want to get different information, you will have to change the characteristics listed above that you are collecting information 


\section{Sample coverage exercise-summary sheet}

This summary reflects the information collected from the chart in the page 20

\begin{tabular}{|c|c|c|c|c|c|c|c|c|}
\hline & \multicolumn{2}{|c|}{ Schooling status } & \multicolumn{2}{|c|}{ Living status } & \multicolumn{4}{|c|}{ Location* } \\
\hline & $\begin{array}{l}\text { In } \\
\text { school }\end{array}$ & $\begin{array}{l}\begin{array}{l}\text { Out of } \\
\text { school }\end{array} \\
\end{array}$ & $\begin{array}{l}\text { Both } \\
\text { parents }\end{array}$ & $\begin{array}{l}\text { One or neither } \\
\text { parent }\end{array}$ & Area 1 & Area 2 & Area 3 & Area 4 \\
\hline Girls 10-14 & 11 & & 1 & 1 & 1 & & 1 & \\
\hline Girls 15-19 & 州 & I & 州 1 & 1 & II & & IIII & \\
\hline Girls $20+$ & & 11 & & 11 & 1 & & 1 & \\
\hline Boys 10-14 & II & & II & & 1 & 1 & & \\
\hline Boys 15-19 & 州 & 州 & 州I & III & WK & II & 11 & 1 \\
\hline Boys $20+$ & & H & & $4 k$ & 1 & & $\|$ & $\|$ \\
\hline
\end{tabular}

* Personalize this based on the area where you are working

If this was your program, what would you learn?

- there are a total of 17 boys and 11 girls-over $60 \%$ of your participants are boys

- very few (only 2 girls and 2 boys) are under the age of 14

- most of your participants are boys age 15 and above (15)

- you have a mix of in-school and out-of-school youth

- almost all of your school-age girls are in school

- you are not reaching many youth from area 2 or area 4

- most of your girls (7) live with both their parents

\section{What questions would this raise for you?}

- how can I reach more girls? what changes do I need to make to my program so girls feel safer?

- do I want to reach more younger girls or boys?

- why aren't out-of-school girls ages 10-19 coming to my program?

- why aren't youth from areas 2 and 4 coming to my program? what can I do to reach out to them?

- what can be done so that we can do a better job of reaching the youth in our mandate, especially the younger, very vulnerable out-of-school girls—or does our mandate need to be changed? 


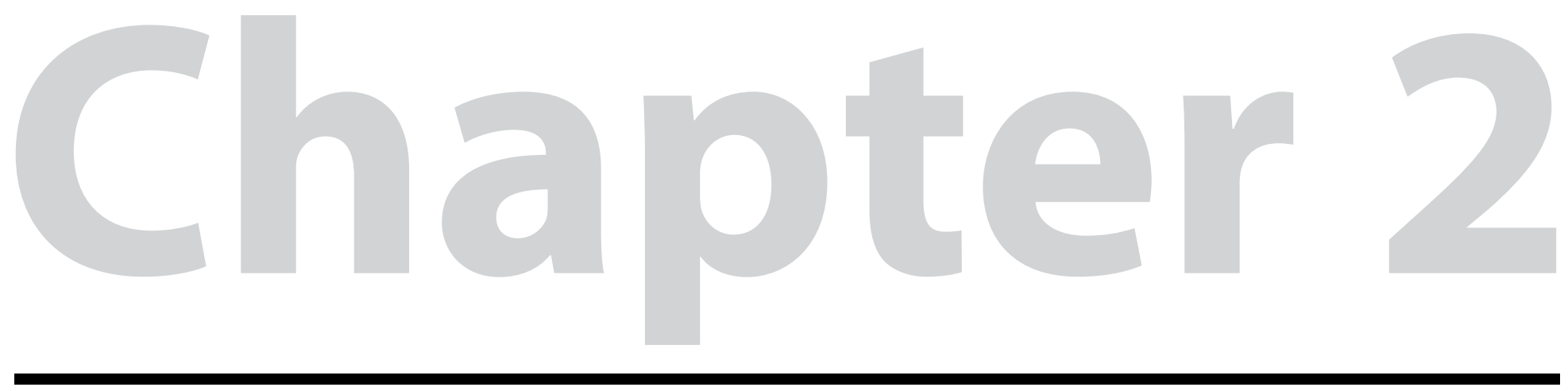

Needs assessments-Understanding the girls you are working with

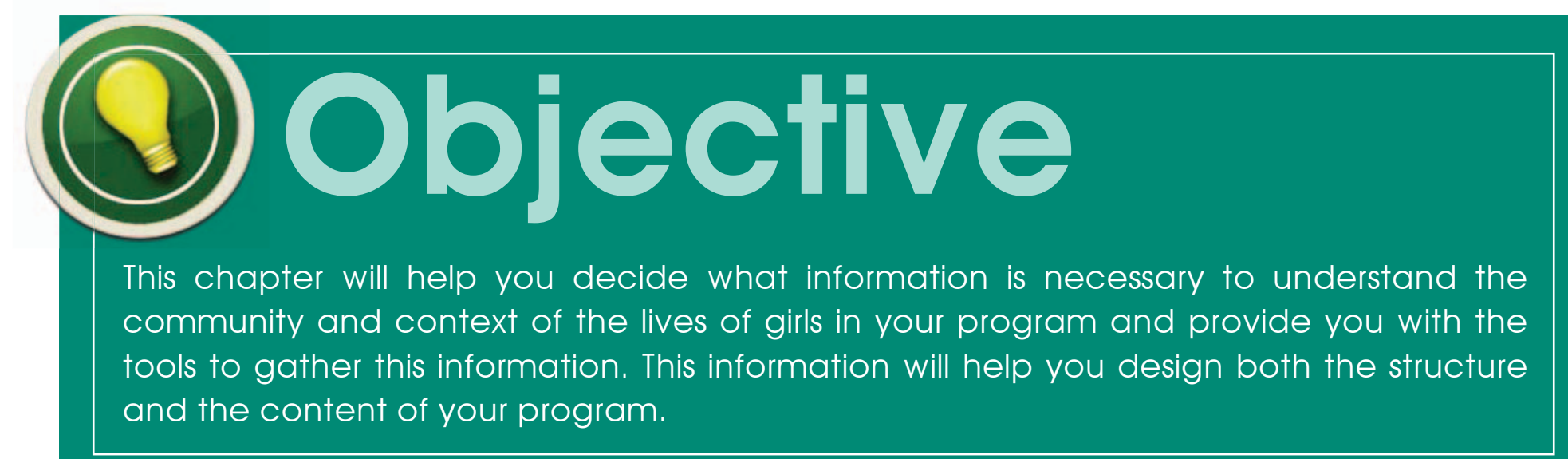


Once you have clarified which girls you will be working with, the next step in designing your program is to understand the needs of those girls and the community that they live in.

While girls do face common challenges, if you do not ask the girls themselves what are the critical issues that they face, you will likely make incorrect assumptions that will set your program back. As covered in the last section, not all adolescent girls are the same; the issues facing the girls you work with will be specific to their age, where they live, what cultural context they are living in, and their life-cycle stage. For example, if you are working with girls who are mothers, income generation and child care might be a priority. If you are working with married adolescents, they may be concerned about how to engage with their mothers-in-law. If you are working with younger, in-school girls, basic information about puberty and menstruation might be their top concern. 
Conduct needs assessments You need to ask the right questions to find out what current issues are a priority for the girls you work with. These questions are an important first step towards getting your program content and structure right.

Needs assessments can be done to develop both structure and content:

Structure How your program should be delivered-location, days of the week, hours, what adults in the community need to be engaged, etc.

Here is a list of the key structure-related questions that you need to answer for your program:

- Where in your community is a safe place to meet?

- Where in your community is a place to meet that is safe to get to?

- At what hours is it safe for girls to meet?

- At what hours are girls able to meet?

- On what days of the week can girls meet?

- How many times a week and for how long do girls realistically have time to meet?

- From which adults in girls' lives do they need permission to come to group meetings?

- To whom do girls go for advice and support in times of difficulty?

Content What are the topics that you will cover in your program.

Following are some of the key content-related questions that you need to answer for your program:

- What are the most common challenges facing the girls you are working with?

- What are some of the topics that the girls want to talk about?

- What are key topics that interest girls that they are not already receiving information on (especially if you are thinking about how to improve your program)?

- What are the kinds of activities that are most engaging for the girls you want to work with?

- What do you want to build up within the girls themselves (such as self-esteem, knowledge on different topics, certain skills)? 
Often, the easiest way to find out the answers to some of these questions is to talk to the girls themselves! Many of the tools included in this chapter are designed so that you can get many of these answers from the girls directly, and often in a more creative and interactive way than simply sitting and asking them (although that works sometimes too!). That information, combined with your knowledge and experience of working with girls, or other similar programs, should give you a strong base from which to develop, or make changes, to your program.

\section{Girls can be your researchers}

If you are looking to get information about or from the community, consider engaging the girls in your program as research assistants. With some training and simple survey tools, they can go out into the community and collect information about a range of resources_-including health services, schools, safety and youth programs. There are multiple advantages to this: 1) the girls in your program will have access to their community and knowledge about it that outsiders will not have; 2) the girls will feel stronger ownership of the program that results from the information they collect; and 3 ) it will develop important leadership and technical skills in the girls.

\section{CASE STUDY}

The Binti Pamoja Centre in the Kibera slum has engaged girls as researchers. Before starting an expansion phase of the program, the alumni members (girls ages 16-21) gathered information about existing youth-serving programs in Kibera, whether there were girls in those programs, and if the places where activities were held were safe for girls. Ten alumni, working in pairs, were able to collect information on over 125 groups. That information was used to create a map of where there were programs for girls in Kibera-and also areas that had no programs. This newly created map was used to guide Binti Pamoja's expansion. The same alumni who conducted the research used the map to determine where to establish new girls groups in the unreached communities. 


\section{Ongoing needs assessments}

While it is critical to conduct various kinds of needs assessments at the start of a program, there will also be times during its course that it will be wise to gather information about a certain topic or situation. In general, conducting a needs assessment about once a year (unless unique circumstances arise) will keep you up to date with the current issues for the girls in your program without overburdening your staff.

The nature of adolescence is transitory. As girls grow through adolescence, they are constantly changing in terms of their needs and their priorities. A 10-yearold is different from a 15-year-old, who is different from a 19-year-old. As girls grow through your program, or new girls come in and go out, you might have to make adjustments to its content and structure.

Living in volatile situations or locations tends to make girls vulnerable. Dynamics like political violence external to your program, or changes in the lives of individual girls like migration, schooling or marital status, might also require you to adapt the content and structure of your program.

\section{CASE STUDY}

In late December 2007, post-election violence raged in Kibera for over a month. Many girls in the Binti Pamoja Centre program were displaced, their guardians lost their source of income, and ethnic tensions were high. The program decided to conduct a needs assessment in January 2008 to understand the most critical issues for the girls at that moment. Binti Pamoja used the findings to temporarily adjust their focus to relief and conflict resolution work.

Also within Binti Pamoja, for several months there seemed to be an increase in the number of members getting pregnant. A needs assessment was conducted to better understand the causes of the trend, as well as to develop a plan for how to reintegrate the young mothers back into the program. The needs assessment resulted in an adapted program design with slightly different content and structure specifically for girls who were mothers so that they could get together to discuss their issues and provide support for one another. 
Do

- Conduct a needs assessment at the start of a program and at critical turning points (current events, when a problem arises in the program or community)

- Conduct ongoing needs assessments about once a year

- Engage girls in your needs assessments, as both collectors and providers of information, and make the sessions as interactive as possible (see tools below)

\section{Don't}

- Assume you know what girls need or think

- Assume what the priority issues and concerns are for girls and their communities 


\section{Community Safety Mapping Tool}

Purpose

This tool will help you understand the community where the girls you work with live, including where are the safe and unsafe locations, what determines safety and how those locations compare relative to one another. This is an example of a participatory tool and an activity that you can do with the girls that you want to join your program, or at the very start of your program to learn more about the community the girls come from and to help answer some of the structural questions listed above.

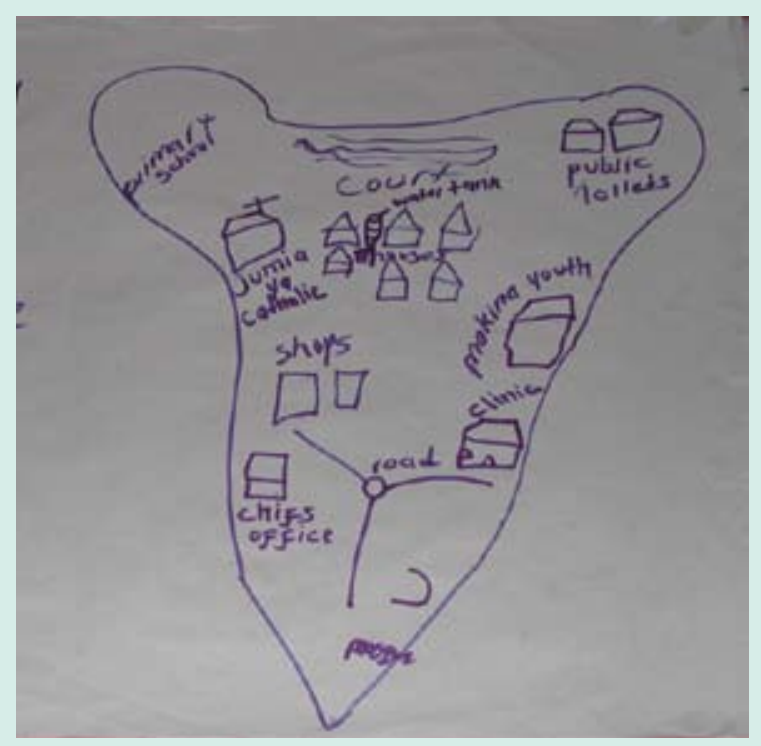

Directions

Step 1. Divide girls into groups of $4-5$ each. Give each group a sheet of flip chart paper and a marker. Give them 15 minutes to draw a map of their community. Tell them to start with drawing the outline, and then to fill in with all of the major landmarks (schools, churches, mosques, markets, clinics, bus stages, railroad tracks, roads, etc.).

Step 2. Give each group nine note cards and tell them to write the name of one location in the community on each note card.

Step 3. Hand out another sheet of flip chart paper to each group. Ask the girls to prioritize each place in the community according to safety for girls like themselves. They should put the cards in a diamond shape, with most safe on the top and least safe on the bottom.

Step 4. Have each group present their map, describe the locations in the community they identified, and then have them share their safety ranking diamond.

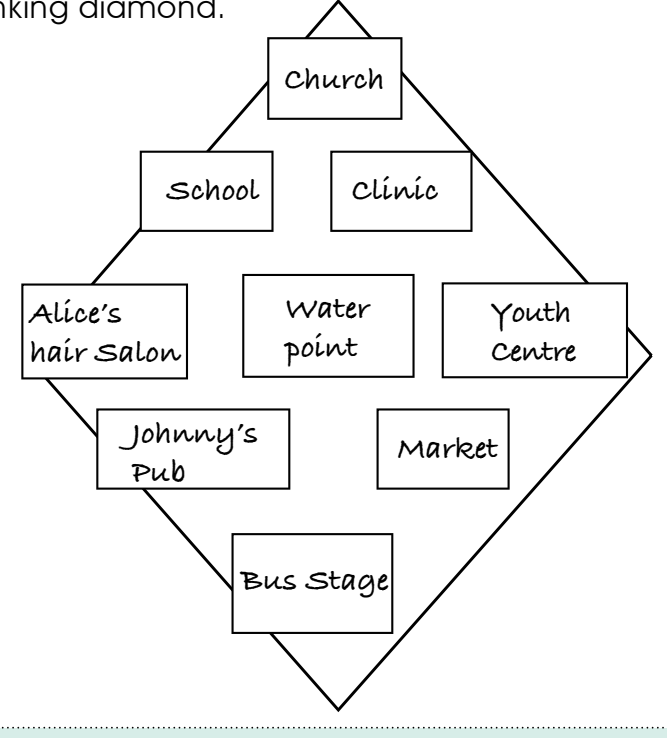


Step 5. Probe for discussion, asking the following questions:

- What makes "xxx" safe?

- What makes " $x x x^{\prime}$ unsafe?

- What would make "xxx" safer?

- Are there certain times of the day when a place is safe and other times when the same place becomes unsafe? When? Why?

- Are there certain times of the week/ seasons/ years when a place is safe and other times when the same place becomes unsafe? When? Why?

- In which of these places can we have our group meetings?

If groups had different safety rankings for the same places, ask them to defend their positions.

Step 6. Continue to meeting logistics. Transit the conversation to a discussion in which you agree on meeting and program logistics. For example, "Given these different safe and unsafe locations, for your specific program, where is a good place to meet? When, at what hours? How many times a week?" Alternatively, you could discuss with the girls what their strategies are for avoiding unsafe locations or for being safe at the unsafe locations they identified.

In summary, this exercise is helpful in two areas:

1) it allows you to gain an understanding of the geography of the community in terms of safety for girls, and also their reasoning behind what makes places safe or unsafe, and

2) it helps you gain critical information about the ideal operating location, days and times for the program.

\section{Variations on the tool}

With parents and community members If you are having a meeting with parents or other stakeholders before beginning a program, you can have them do the same exercise, leading to an agreement on where would be an appropriate place in the community for girls to meet.

Safety for girls vs. boys You can do the ranking a second time, focusing on the safety for boys instead of girls. Alternatively, you can give out circle stickers in four different colours and have them label the locations:

$$
\begin{aligned}
& \text { 1-safe for girls } \\
& \text { 2-unsafe for girls } \\
& \text { 3-safe for boys } \\
& \text { 4-unsafe for boys }
\end{aligned}
$$




\section{Ranking Tool}

Purpose

This tool can be used on a diverse range of topics to understand to what degree a certain topic is important or common. For example, not only can you use this tool to understand what locations are the safest and the least safe but also which challenges are most common for the girls or which people they talk to the most about their problems.

This diamond-shaped ranking that was done in the community mapping tool above can also be used as a tool on its own when ranking of any sort would be helpful to gather information-such as most common $v$. least common, most important $v$. least important, most acceptable $v$, least acceptable.

For example, there was a program that struggled to get married girls to attend, and although they were reaching out to the parents, they began to realize that perhaps there were other adults in these girls' lives that needed to be engaged. They used the ranking tool with girls to understand, first, who are the types of important adults in their lives, and second, which ones have the most influence. For married girls, it turned out that the mothers-in-law were more influential than their own mothers.
Directions

Step 1. Distribute cards to girls and have them write one answer on each card for any topic that you would like to learn more about. Then have them arrange the cards in the diamond shape with regard to a particular priority.

Questions that can be used with the ranking tool (this is by no means all of them, be creative! ):

- Where do girls get information about HIV and AIDS?

- Who do girls like yourselves talk to about sexual and reproductive health?

- What do girls do between 4 pm and 6 pm?

- What kinds of worries are common for girls your age to have?

- What kinds of adults have influence on girls' lives?

Example: What kinds of adults influence girls' lives?

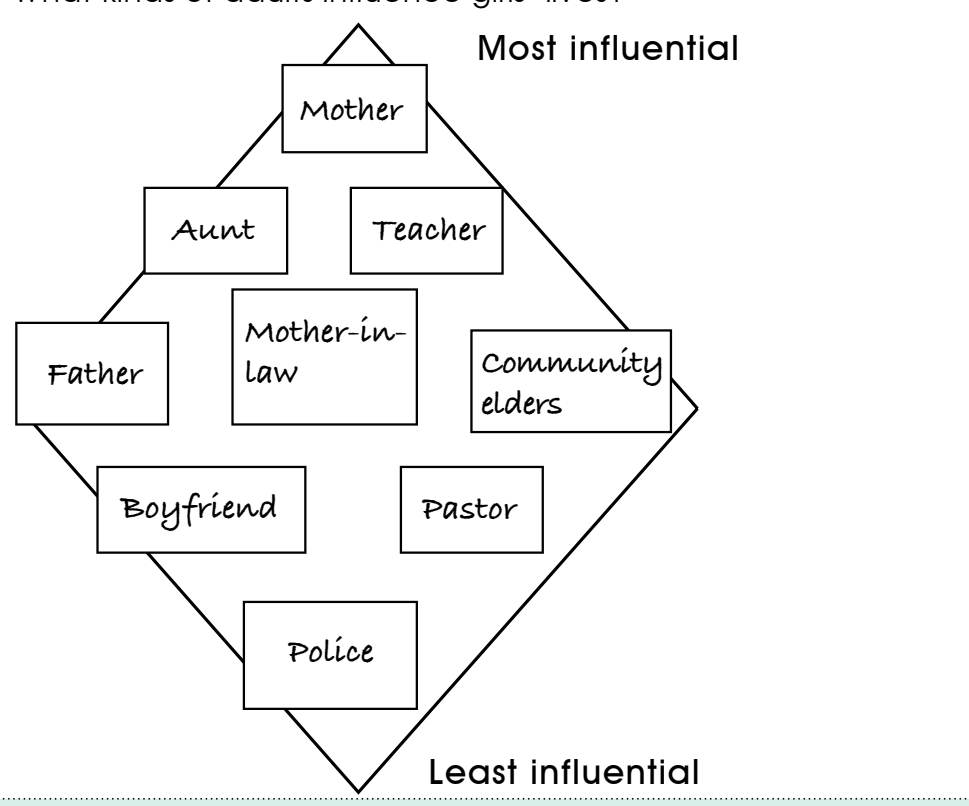


You might want to do several rounds, each round asking about a different kind of girl-in-school, out-of-school, 10-14year-olds, 15-19-year-olds, 20-24-year-olds, married, teenage mothers, domestic workers, etc. Then you can compare the similarities and differences.

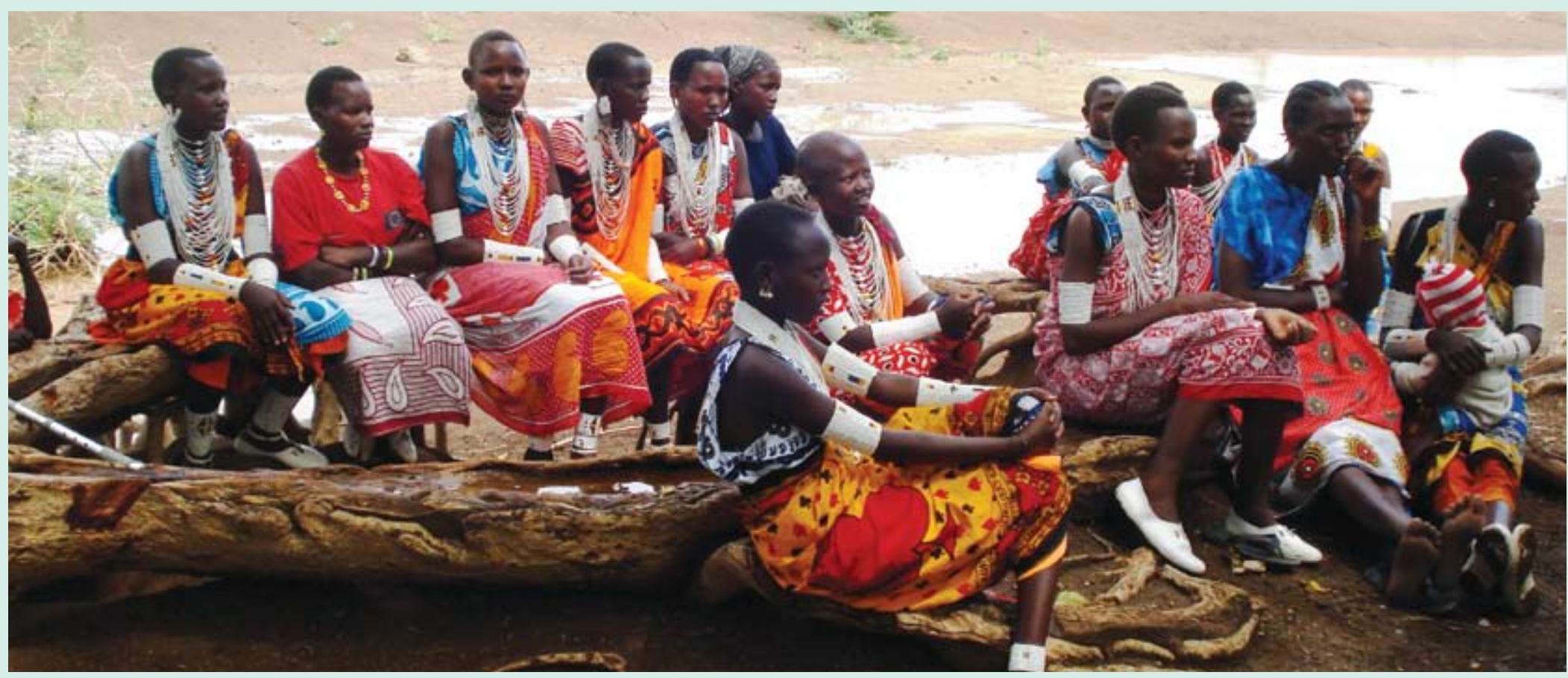




\section{"In and Out" or Cash Flow Tool}

\section{Purpose}

This tool allows you to understand where girls get their money and what they spend it on. It can also be used to understand other behaviours that involve resources coming in and going out, such as what kind of support girls need to become leaders and what they can give as leaders.

This tool can be used to gather information about a particular issue in girls' lives. It typically asks girls to think about two elements of an issue and can be used on a variety of topics. Examples include where girls get their money and what they spend it on; the kind of support girls need and what they can give back to their community or program; challenges that girls face and behaviours that they engage in to respond to those challenges. The tool can also focus on specific topics like financial responsibilities, teenage pregnancy, drug and alcohol abuse.
Directions

Step 1. Ask for a volunteer to draw on a flip chart a picture of a typical girl in their community.

Step 2. Ask for another volunteer to give the girl a name.

Step 3. Pass out note cards to the girls (preferably cards of two different colours). Assign a colour of card to each category or question (for example, where do girls get money? = yellow card; what do girls spend their money on? = blue card).

Pose the first question and ask them to start by writing their answers, one answer on each card. You can limit the number of responses or answers by giving each girl only three cards of each colour.

Step 4. Invite the girls to tape their cards about the first question on the left side of the girl in the picture.

Step 5. Repeat step 3 for the second category or question (for example, what do girls spend their money on? = blue card).

Step 6. Have the girls tape their second set of responses on the right side of the girl.

Step 7. As the facilitator, work with the girls to move the cards on the left side into common categories.

Step 8. Depending on the topic, work with the girls to rank the categories from most common to least common, or along another characteristic based on the topic.

Step 9. Repeat steps 7 and 8 with the categories on the right side. 
For example, before developing a savings product for adolescent girls, the Population Council and MicroSave used this tool as part of a broader market research assessment to understand from girls of different ages and profiles the different ways they got money and what they used their money for. Further, they looked at which were the most common and least common in each category. This information was helpful in designing the savings product and accompanying financial education correctly, as well as to reassure the banks and parents that girls did indeed have money to save and it was not going to influence their behaviour in a negative direction.

Materials needed: Flip chart paper, markers, notecards, tape.
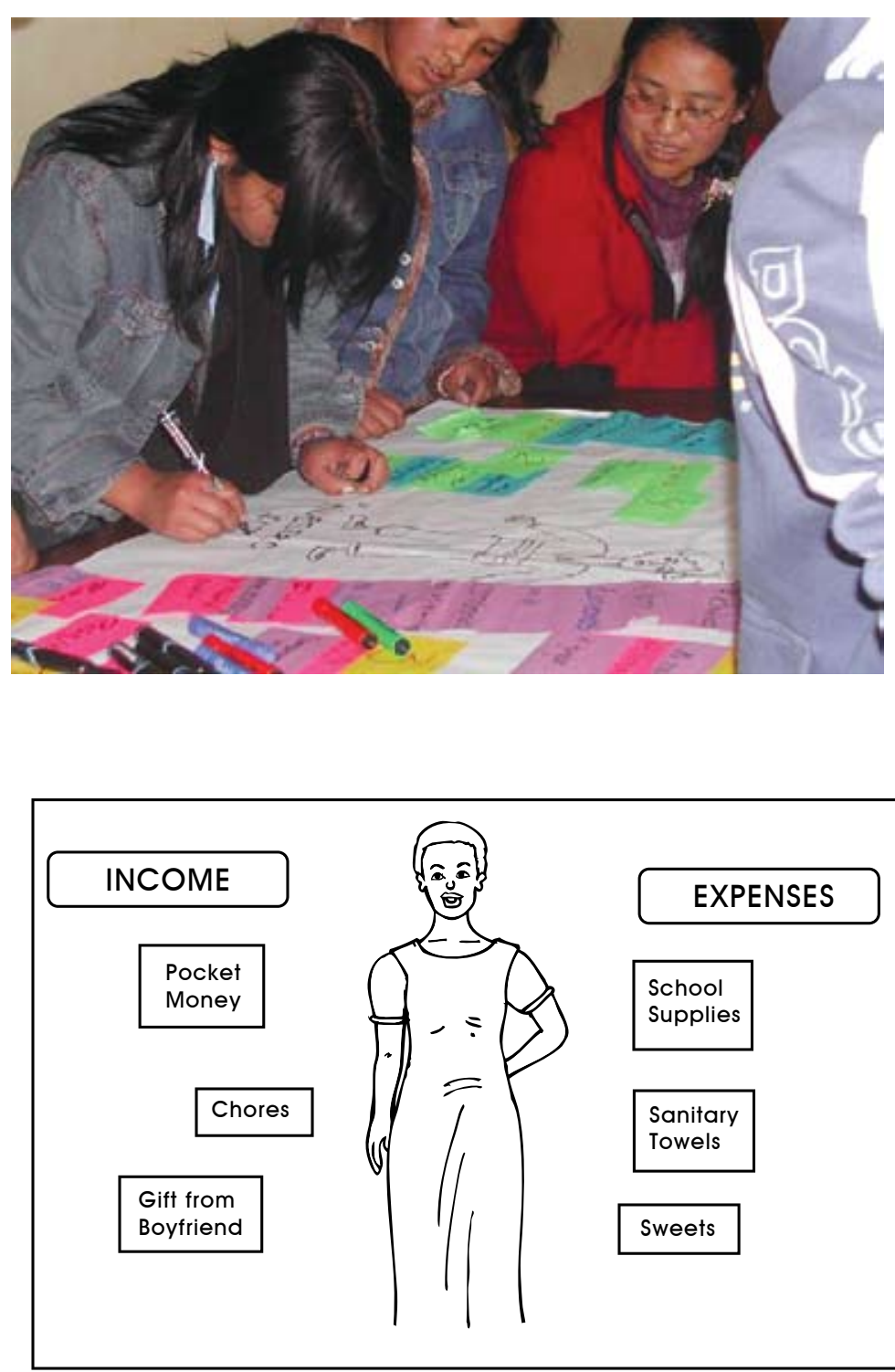


\section{"A Day in the Life" Tool}

\section{Purpose}

This tool will help you understand the typical life of a girl in your program, including how her time is spent, the challenges she faces, and her likes and dislikes. Once you know what logistics or structure will work for the girls in your program, it is important to start to understand the context of their lives. Doing so will help you to better understand the girls and create appropriate content for your program. Having a good understanding of the girls' lives helps you understand who you might need to engage in the program, indicates examples you can use in your teaching, and lets you anticipate some of the challenges that may come up. Also, as adults, we often tend to make assumptions about what is most important to girls. For example, while the core content of many youth programs is on HIV prevention, for many girls (not all!), an unwanted pregnancy is a much more present and pressing worry. Understanding the priorities of girls and how they see the wide range of issues before them can help you decide how and in what order to present the different topics.

"A Day in the Life" is a tool you can use to guide your initial conversations with girls.
Directions

Step 1. Start by asking girls to describe a typical day in the life of a girl (it is best to give her a name) in their community. Splitting girls into small groups to come up with a daily schedule will probably get girls engaged and talking. Also, it is important to do this exercise in the third person so that girls talk about a "typical girl," not themselves. This helps them to open up and speak freely.

Step 2. Probe using the following questions:

- What does she like about her day?

- What does she dislike about her day?

- How is her day different from her brother's? Older sister's? Younger sister's?

- Where does she go during her day, and who is she with?

- What are some of the typical problems or challenges she might come across in that day?

- If she could change one thing about her day, what would it be? How could she change it? 


\section{Variation}

If your program has funding to support this, you can buy disposable cameras and have the girls go out into the community and take pictures of "A Day in the Life" of a typical girl in that community. Then you can use the photos to discuss, asking what issues are shown in the pictures, why they are problems, what the girl in the picture can do about them.

Note Community members are often sensitive about having their photos taken, so make sure that girls are prepared to explain why they are taking photos and that they do not take photos of people who do not agree.

Listen carefully to what the girls are telling you, as the information is based on their own lives and lives of girls they know. The challenges they raise are likely those you should try to address in the course of your program.

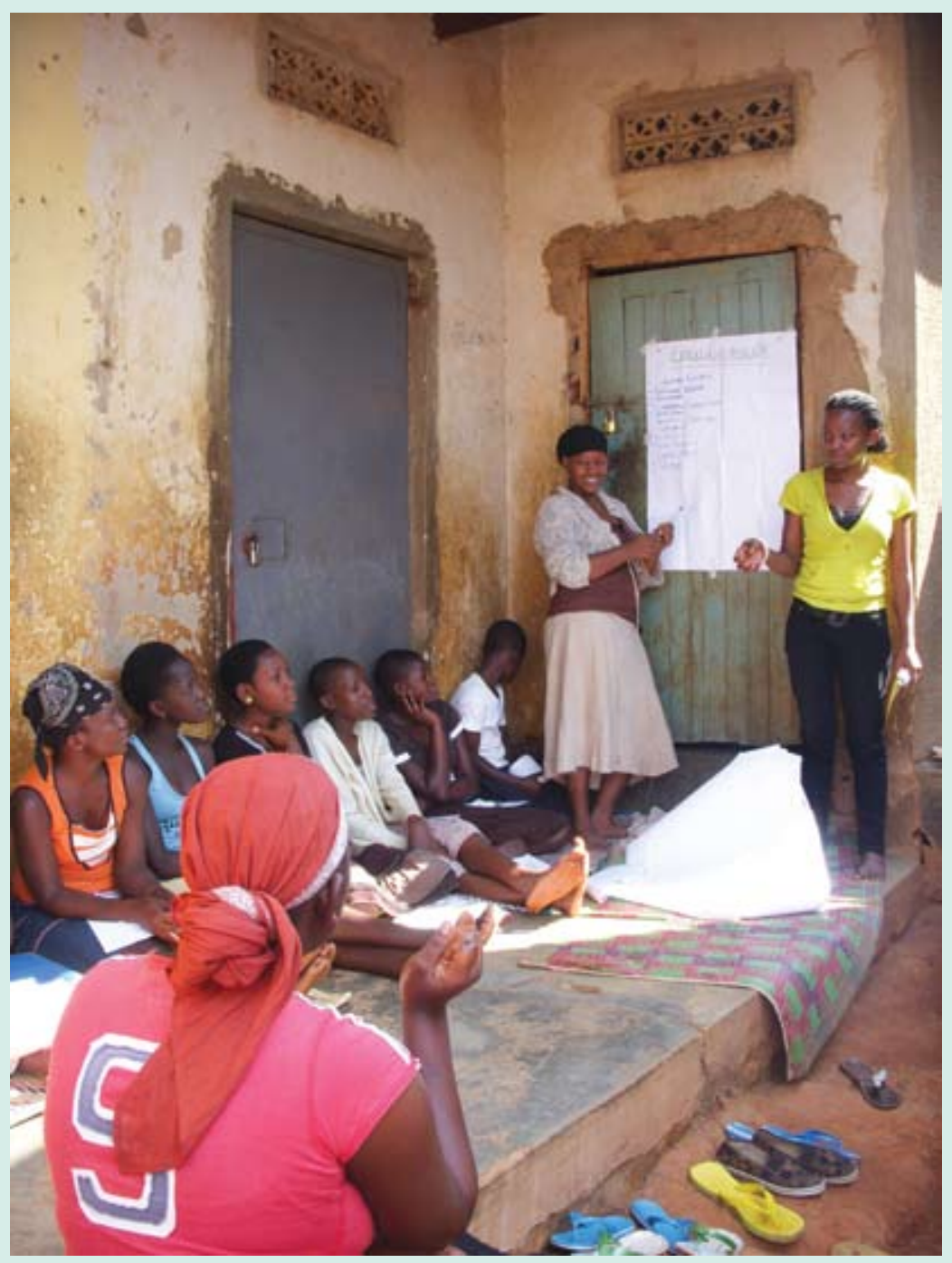




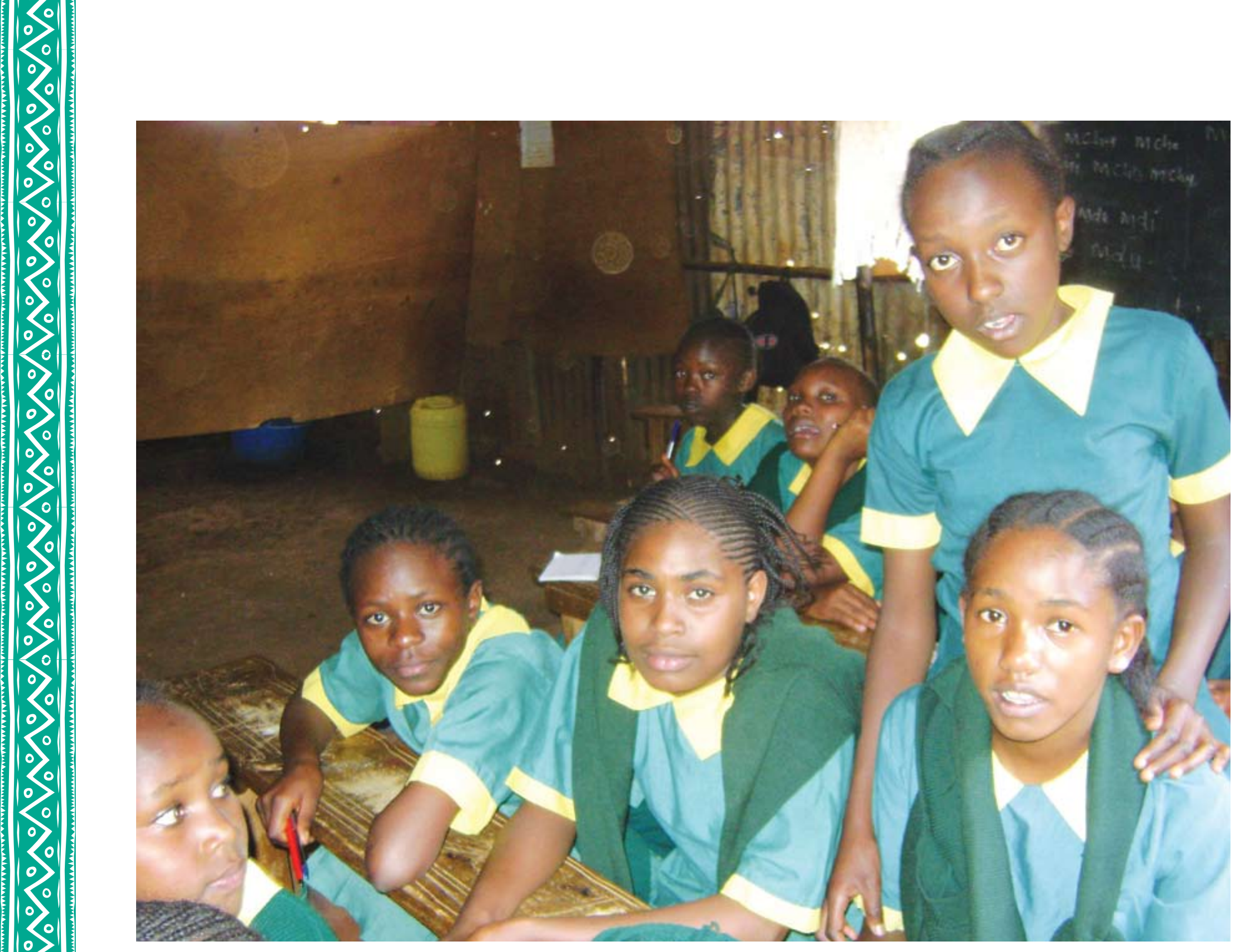




\section{Program Structure}

Chapter 3

Core elements of the Safe Spaces Model

"Creating the pot"

Chapter 4

Recruitment

How do you get the girls you want into your program

Chapter 5

Leadership development and mentoring

Chapter 6

Working with families and critical adults

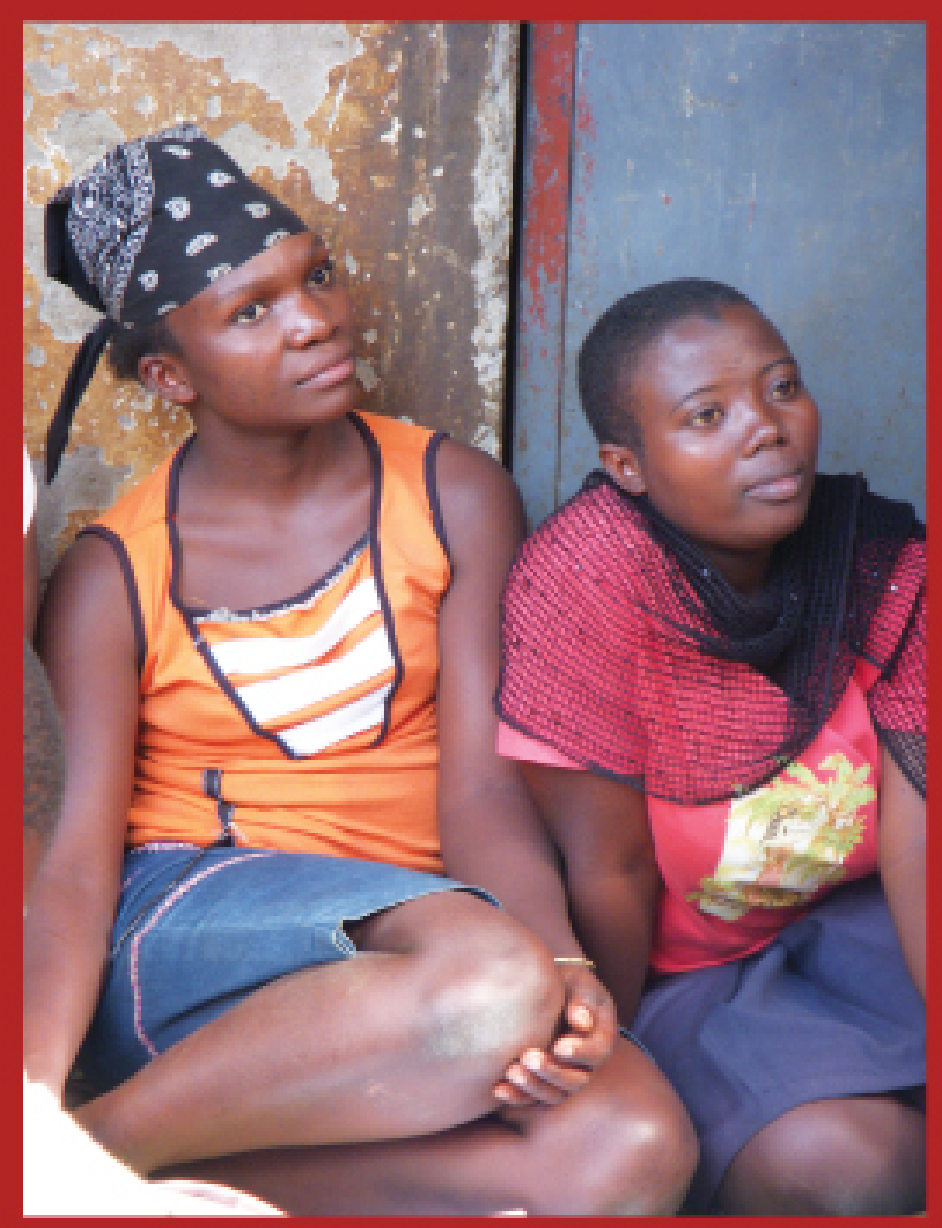

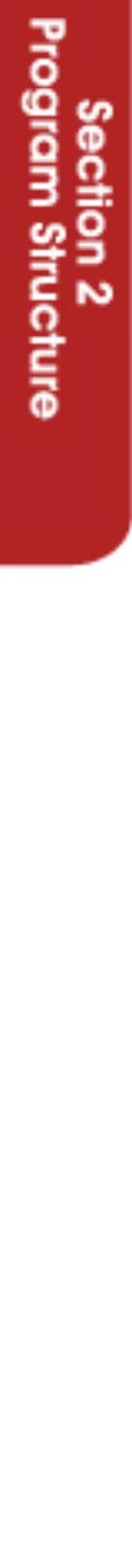




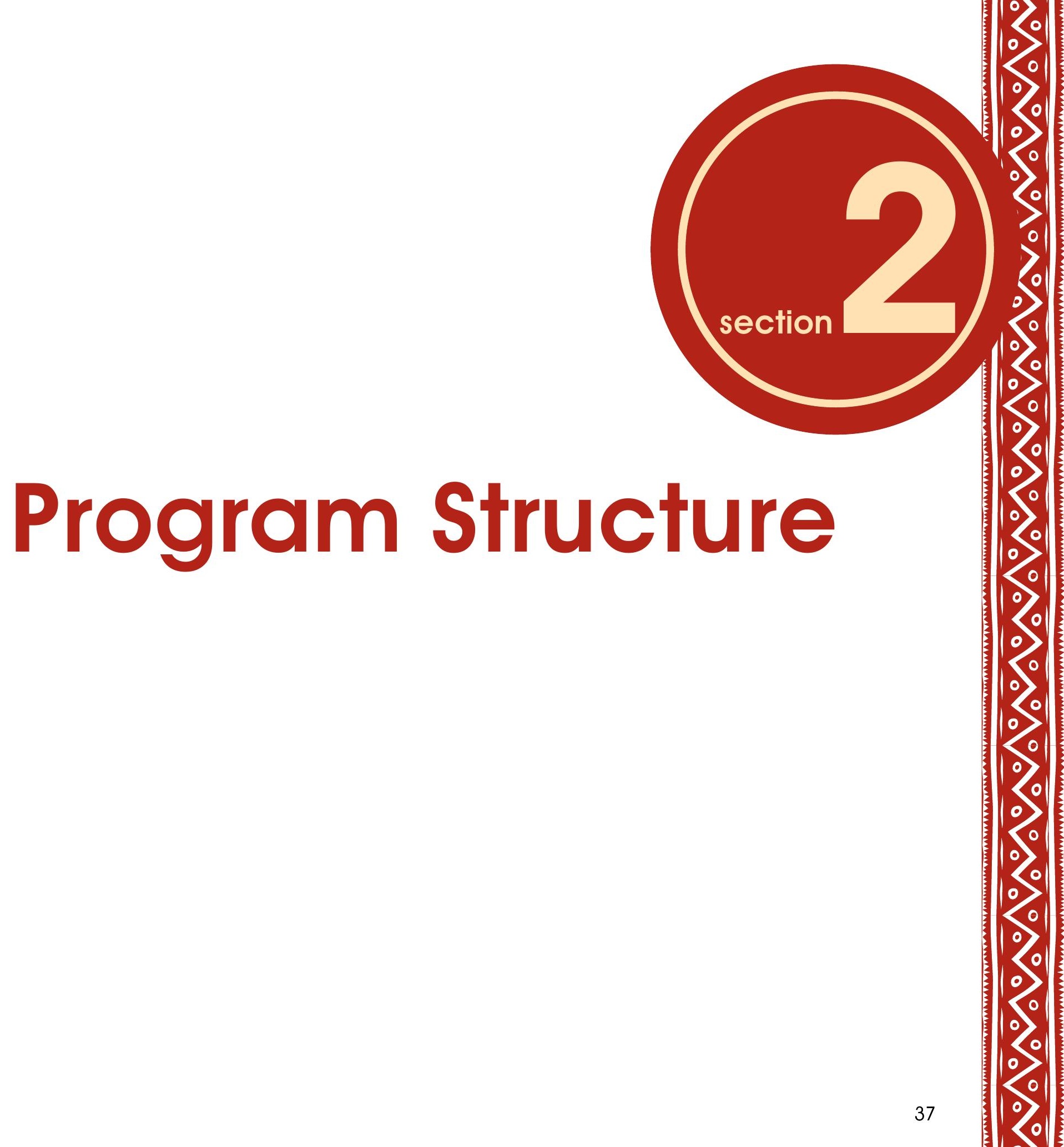




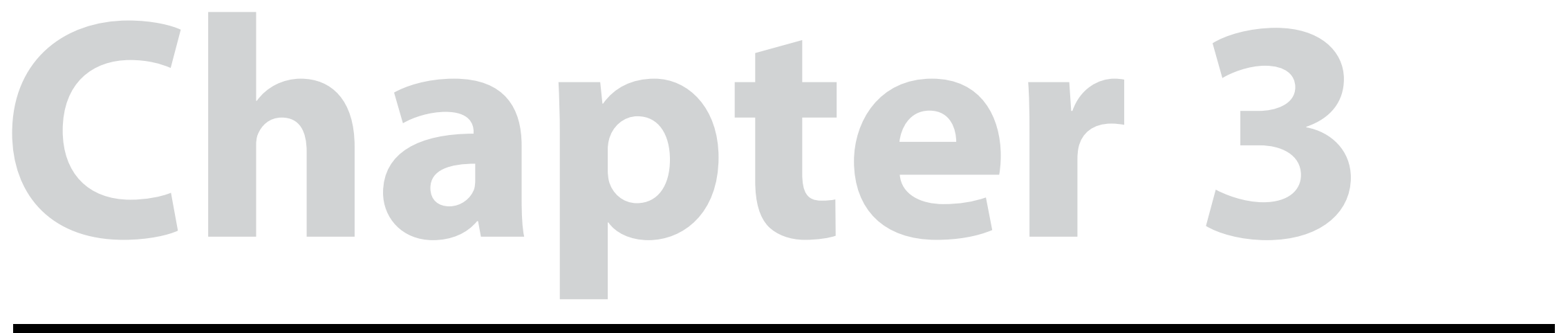

\section{Core elements of the Safe Spaces Model-“Creating the pot"}

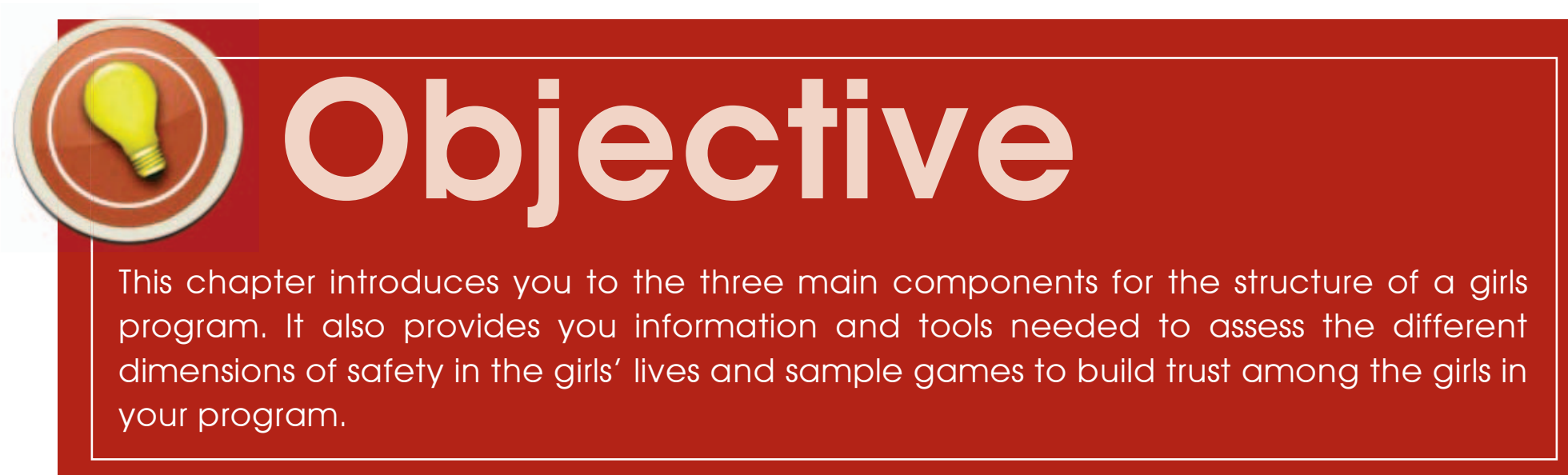




\section{Safe place, friends and a mentor-the pot}

\section{Before you begin to think about the content of your program, or about the kinds of topics that you want to teach the girls and the kinds of activities that you are going to plan, you must first create the proper structure within which you will deliver the program.}

Think of this structure as "the pot" The ingredients in the stew are the topics and the activities. Unless you have the appropriate pot, it will be impossible to adequately serve the stew. So first you must create the proper pot that will hold your girls program.

The "Safe Spaces Model" is a term that can be used to describe the three core elements of the structure of an adolescent girls program: safe place, friends and a mentor. These three program components have been the backbone of strong and successful adolescent girls programs across the globe-urban and rural, Africa and Asia, religious and non-religious societies, covering health and economic empowerment.

The "Safe Spaces

Model" is a term that can be used to describe the three core elements of the structure of an adolescent girls program: safe place, friends and a mentor. 
Safe space. While it may seem obvious, you should identify a space where girls can meet regularly-that is, the same place each week, or each day, as often as your program meets. This should be a place that is considered safe and appropriate by the girls as well as their guardians. Use the Community Mapping tool in chapter 2 and the Safety Scan tools in this chapter to help.

These spaces exist in a variety of structures_including, but not limited to, schools, churches and mosques, community halls, hair salons and residence compounds. The space could be a general public space, in which case it would be important to get the community or structure owner to allow only girls to meet there on specific days. In some settings it may be necessary to rent the space for a fee from the owner. In other settings (especially in rural areas), the space can be a contribution from the community. When this is the case it is good to create a formal contract with the community to acknowledge the designation of the space as a girlsonly space at the agreed upon times; in some cases you may be able to post that information publically.

One thing to keep in mind is location of the space.

While it might be safe inside, if girls have to pass through unsafe locations to get there, it is not necessarily appropriate.

\section{CASE STUDY}

A girls program in Kisumu, Kenya, established their meeting place inside a compound with several other businesses and organizations, including two bars and a body-building gym. As a result, they faced a significant challenge with participation rates and later had to change their location to better serve girls.

Population Council staff met with community leaders in Tema, Ghana, as part of the planning phase of a new girls program. The leaders suggested that the program be located in an open-air community meeting space. The leaders assured the program planners that they would designate the space as girls-only during the times when the groups met. The planners asked to visit the open-air community meeting place and found about a dozen young men in the space, drinking beer and playing card games. An additional dozen men were lingering about on the outside, just watching. Planners talked with the community leaders and suggested that the girls might not feel comfortable in a place where they were likely to be watched or heard by the community during their meetings. Leaders then suggested that the program use an empty classroom during non-school hours. The headmaster agreed and the program has met there ever since. 


\section{CASE STUDY}

The African Medical and Research Foundation (AMREF) is implementing a four-year Nomadic Youth Reproductive Health Project whose goal is to improve the reproductive health and rights of the nomadic youth in Kenya, Tanzania, and Ethiopia. After two years of project implementation, AMREF realized that nomadic girls (aged 10-15 years) could not be adequately reached and supported through the conventional reproductive health programming since they are largely a 'hidden' population due to cultural institutions that place them beyond ready reach. AMREF adopted the Safe Space intervention model for mothers and girls because, while boys have the 'moran' peer institution and men who have the 'age set' and elder's forums as cultural institutions that allow them to freely meet, socialize, and discuss boys' and men issues, girls and women have no such institutions that allow them forums where they can meet in a gender segregated space and discuss girls' and women issues.

With a safe spaces model that includes components of a safe place to meet, friends and a mentor, AMREF has created over 40 safe spaces or girls forums that meet every month at sessions led by older girls and women who have been trained on RH and Female Genital Cutting. The safe spaces have lead to transformational changes among participants, girls' access to safe spaces in the community has increased, their sources of support grew, they have gained confidence and self esteem, and they have learned new skills. In addition, communities' attitudes about girls' involvement in public activities has become more positive and supportive and parent-teen communication has been observed to improve.

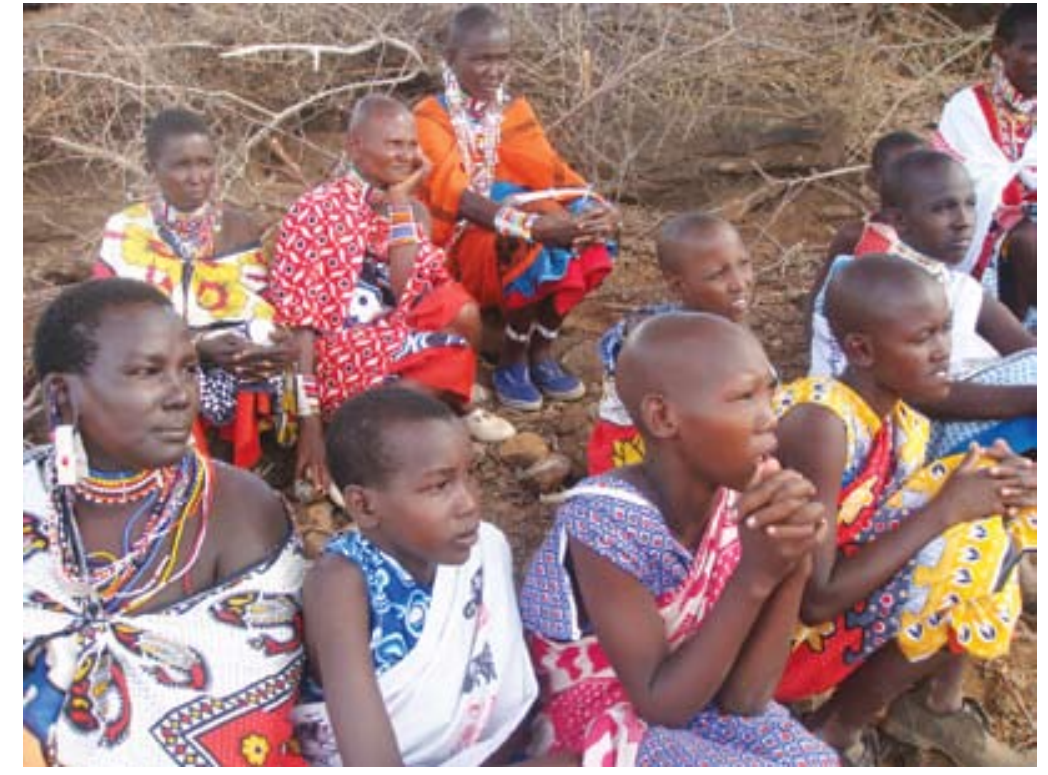

Young nomadic girls (10-15 years) with their mothers in one of the forums on RH 
Generally, girls are socially isolated, even in the most dense urban slum settings. Once they near and enter puberty, their social world begins to contract and they are confined to the domestic setting more and more. There are few places that they are able to go, either because they are at risk of harassment or violence, including sexual violence, or it is socially unacceptable. The available places for youth are generally more appropriate for their male age mates. Therefore, a critical role that your program will play is to create space within a community that is considered safe and specific for girls to meet (see note on safety below).

Friends Due to girls' social isolation, simply creating a space where a group of girls, around the same age and from the same community, can meet regularly, build relationships and begin to trust and share with each other, is a critical component of the program structure. Relatively easy to do, it just means that you create regular opportunities for girls to meet with the same girls. These social networks are critical, as girls with stronger social networks are less likely to be victims of sexual harassment and violence ${ }^{3}$.

Mentors Girls need mentors-a young woman who is a little older so that girls can look up to her, but not so old that they can no longer identify with her (that is, females aged 18-35) from the same community as the girls. For instance, getting a young woman from the local university to come and volunteer and "mentor" girls once a month may not be a good idea because she will rarely be someone the younger girls can identify with. Chapter 5 will further explore how you develop young women within vulnerable communities to be mentors and leaders, but having someone older who can guide the girls in the program is important-someone who will be there in the community if the girl is having an emergency, someone she can go to for advice when she has a problem or to share her successes. 


\section{A word about safety}

Consider what "safety" means for adolescent girls. The term "safe spaces" is used quite frequently, but what qualifies and what does that mean for the girls who want access to those spaces?

As discussed above, a safe space is a safe physical place, in this case, a place where girls can regularly meet friends who are close in age, from the same community and have access to a mentor. But, within that safe place to meet it is also important to create safety in two ways:

- Physical safety The girls should be free from physical harm within the place they are meeting, and the space should be located in an area that is easy and safe for them to get to. If it is unavoidable that there will be relatively unsafe places for girls to pass through (for example, many urban slum areas have generally high levels of violence throughout), help the girls come up with a plan for how to get to the program site, for example, walking in pairs or making sure the program ends early enough so they can walk home before dark. Again, the Community Mapping exercise shared in chapter 2 can help you understand the general safety situation in the community where you are working.

- Emotional or mental safety Many girls are socially very isolated, and the group or program that they will participate in will be one of their only social networks. Creating a girls-only space, whether it be girls-only all the time or in certain elements of your program, is a critical first step in creating a "safe space" for girls. In addition, it is important to build good group dynamics and trust between members of the group so that all girls feel free to share their thoughts and ask any questions. One good way to start building good group dynamics is through setting ground rules at the very start. Allow girls to set their own ground rules for their group - that way they are making an agreement with each other on how to act instead of being told by an adult. There are also many examples of trust-building games that can be done during program activities to get girls working together, used to each other and beginning to trust one another. A series of trust-building games are explained in the Tools section of this chapter. 
However, no matter how much the girls trust each other and how strong the group dynamics are, there will be conflicts and disagreements because of their young ages. Be prepared to mediate conflicts-ranging from personality clashes, girls gossiping about each other outside the program to family disputes, problems with boyfriends, and more. It is important to address these issues as they arise so that they do not become a barrier to implementing your program activities. Use your judgement on when conflicts need to be addressed on an individual level (between you and the girl), with all parties involved (you and all the girls in conflict with each other), or with you and the whole group of girls (perhaps because it has spread over into the group, already affecting group activities and dynamics).

One final strategy for creating safety is for the girls to feel ownership of the program. When girls have input into the content of the program, get to play a role in choosing the kind of activities they do, or are put into leadership positions or given responsibilities, it strengthens not only their personal development but also their overall sense of safety and belonging in the program.

Do

- Hold your program in a physical and emotional space safe for girls

- Hold girls meetings regularly at the same time and place each week

- Provide girls in your program with access to a mentor who is a young woman from the same or similar community

\section{Don't}

- Put your program in a location that is unsafe for girls to access 


\section{Safety Scan Tools ${ }^{4}$}

\section{Purpose}

Following are a set of tools that you can use with the girls in your program. You don't have to do all the activities; pick the ones that best suit your needs. They will help you better understand the times, conditions and situations in which the girls feel safe or unsafe.

Depending on your goal, these tools can be used in a more formal research style where staff or interviewers sit with a girl individually and ask her these questions, and then the information is compiled by the staff-that is, not in an interactive fashion. Alternatively, they can be used in a participatory fashion. You may take the charts from the tools below, rewrite them on flip chart paper and have girls work in small groups to fill them out. For the tools that ask girls to rank "never", "sometimes", or "always", you can mark three corners in a room and have girls go stand in the appropriate corner when you call out the location/day/time/ season.

Overall, you can use these tools as discussion starters with girls, or to gain information about things your program might want to work on. For example, if your program discovers that a certain school is known for a lot of sexual abuse of girls, you may want to mobilize the community to raise the issue or to act on it.
Safety by time of day (pg 46) Allows girls to identify where they are throughout the day and in which of those places they face potentially unsafe situations.

Safety in different places in the community (pg 47) Allows girls to assess the safety of the different places in their community and their degree of safety.

Safety accessing services and opportunities (pg 47) Identifies common situations that girls find themselves in and allows them to identify which are unsafe. You could use this information to help girls develop safety strategies when engaging in the more unsafe situations (for example, waiting for a bus).

Safety nets (pg 48) Assesses the strength of girls' social networks. It can help to identify gaps that you might want to fill through your program (such as no one to turn to when they have a health problem).

Safety by season (pg 48) Identifies particularly unsafe times for girls during the year. You might want to then adjust your programming to help protect girls during unsafe seasons. For example, if holidays are an unsafe time, be sure to plan activities during that period so that girls are not left alone and vulnerable.

Safety by situation (pg 49) Allows girls to identify certain situations (such as being stopped by a policeman) that makes them feel safe or unsafe. You can use the information to help girls develop safety plans for what to do in these situations, or how to avoid the situations altogether, although that is not always possible.

Safety by day (pg 49) Analyses girls' feelings of safety over the different days of the week. This could also help you decide which days would be most strategic for holding your program activities. 
Safety by time of day

Fill out where you are during all 24 hours of the day. Then next to each time slot, check off one of the three columns.

\begin{tabular}{|c|c|c|c|c|}
\hline Hour & Place & I never feel safe there & $\begin{array}{l}\text { I always feel safe there on } \\
\text { my own }\end{array}$ & $\begin{array}{l}\text { I feel safe there if ... (fil } \\
\text { in the condition) }\end{array}$ \\
\hline \multicolumn{5}{|l|}{ 6:00 am } \\
\hline \multicolumn{5}{|l|}{ 7:00 am } \\
\hline \multicolumn{5}{|l|}{ 8:00 am } \\
\hline \multicolumn{5}{|l|}{ 9:00 am } \\
\hline \multicolumn{5}{|c|}{ 10:00 am } \\
\hline \multicolumn{5}{|c|}{$11: 00 \mathrm{am}$} \\
\hline \multicolumn{5}{|c|}{$12: 00 \mathrm{pm}$} \\
\hline \multicolumn{5}{|l|}{ 1:00 pm } \\
\hline \multicolumn{5}{|l|}{ 2:00 pm } \\
\hline \multicolumn{5}{|l|}{ 3:00 pm } \\
\hline \multicolumn{5}{|l|}{ 4:00 pm } \\
\hline \multicolumn{5}{|l|}{ 5:00 pm } \\
\hline \multicolumn{5}{|l|}{ 6:00 pm } \\
\hline \multicolumn{5}{|l|}{ 7:00 pm } \\
\hline \multicolumn{5}{|l|}{ 8:00 pm } \\
\hline \multicolumn{5}{|l|}{ 9:00 pm } \\
\hline \multicolumn{5}{|c|}{ 10:00 pm } \\
\hline \multicolumn{5}{|c|}{ 11:00 pm } \\
\hline \multicolumn{5}{|c|}{$12: 00 \mathrm{am}$} \\
\hline \multicolumn{5}{|l|}{ 1:00 am } \\
\hline \multicolumn{5}{|l|}{ 2:00 am } \\
\hline \multicolumn{5}{|l|}{ 3:00 am } \\
\hline \multicolumn{5}{|l|}{ 4:00 am } \\
\hline \multicolumn{5}{|l|}{ 5:00 am } \\
\hline & & Total hours: & Total hours: & Total hours: \\
\hline
\end{tabular}


Safety in different places in the community

\begin{tabular}{|l|l|l|l|}
\hline Places & Never feel safe & Always feel safe & Sometimes feel safe \\
\hline Market & & & \\
\hline School & & & \\
\hline Home & & & \\
\hline Police station & & & \\
\hline Church, mosque & & & \\
\hline Clinic & & & \\
\hline Bus station & & & \\
\hline Friend's home & & & \\
\hline
\end{tabular}

Safety accessing services and opportunities

For situations where you sometimes feel safe, indicate what would make you feel safer.

\begin{tabular}{|l|l|l|l|l|}
\hline Situation & $\begin{array}{l}\text { Always safe to use, } \\
\text { access }\end{array}$ & $\begin{array}{l}\text { Sometimes safe to } \\
\text { use, access }\end{array}$ & $\begin{array}{l}\text { Never safe to use/ } \\
\text { access }\end{array}$ & $\begin{array}{l}\text { What would make } \\
\text { it safer? }\end{array}$ \\
\hline $\begin{array}{l}\text { Taking public } \\
\text { transportation }\end{array}$ & & & & \\
\hline Taking taxis & & & & \\
\hline Health service & & & & \\
\hline Going to school & & & & \\
\hline Going to the bank & & & & \\
\hline Going to the post office & & & & \\
\hline On a football pitch & & & & \\
\hline At the salon & & & & \\
\hline Church, mosque & & & & \\
\hline
\end{tabular}


Safety nets

\begin{tabular}{|l|l|l|l|l|}
\hline $\begin{array}{l}\text { In an emergency, do you } \\
\text { have ... }\end{array}$ & Yes & No & Not sure & Comment \\
\hline $\begin{array}{l}\text { Five non-family female } \\
\text { friends? }\end{array}$ & & & & \\
\hline $\begin{array}{l}\text { A place to meet female } \\
\text { friends at least once a } \\
\text { week? }\end{array}$ & & & & \\
\hline $\begin{array}{l}\text { Someone to turn to if you } \\
\text { have a sensitive personal } \\
\text { problem -your own or } \\
\text { someone else's? }\end{array}$ & & & & \\
\hline $\begin{array}{l}\text { Someone from whom you } \\
\text { can borrow money? }\end{array}$ & & & & \\
\hline $\begin{array}{l}\text { A safe place to stay for the } \\
\text { night? }\end{array}$ & & & & \\
\hline $\begin{array}{l}\text { Someone to turn to if you } \\
\text { have a health problem? }\end{array}$ & & & & \\
\hline $\begin{array}{l}\text { Someone to turn to if } \\
\text { you have an economic } \\
\text { problem? }\end{array}$ & & & & \\
\hline
\end{tabular}

\section{Safety by season}

\begin{tabular}{|l|l|l|}
\hline Seasons that bring risk & Does the season bring risk? Why? & What can be done to reduce risk \\
\hline Harvesting & & \\
\hline Rainy season & & \\
\hline Migration for work & & \\
\hline School fees are due & & \\
\hline Holidays & & \\
\hline School is in session & & \\
\hline Other (describe) & & \\
\hline Other (describe) & & \\
\hline Other (describe) & & \\
\hline
\end{tabular}


Safety by situation

\begin{tabular}{|l|l|l|}
\hline Situations that bring risk & Does the situation bring risk? Why? & What can be done to reduce risk \\
\hline Getting stopped by a policeman & & \\
\hline In a shop by myself & & \\
\hline Asking for a grade & & \\
\hline Being kept after school & & \\
\hline Negotiating to sell something & & \\
\hline Other (describe) & & \\
\hline Other (describe) & & \\
\hline Other (describe) & & \\
\hline
\end{tabular}

Safety by day

\begin{tabular}{|l|l|l|}
\hline Days of the week & $\begin{array}{l}\text { Times of the week I feel most safe and } \\
\text { relaxed }\end{array}$ & $\begin{array}{l}\text { Times of the week I feel least safe and } \\
\text { relaxed }\end{array}$ \\
\hline Monday & & \\
\hline Tuesday & & \\
\hline Wednesday & & \\
\hline Thursday & & \\
\hline Friday & & \\
\hline Saturday & & \\
\hline Sunday & & \\
\hline
\end{tabular}




\section{Trust-building games}

These games can be played with the girls to help build trust and develop comfort and openness within the group. As discussed in the section above, creating emotional and mental safety among the girls is critical to their building social networks, developing friendships, learning how to trust, and then being able to open up, share and grow together. These games can be used as ice breakers or energizers to start or spice up a training session, or at the close of a group meeting to end on a positive, team-building note.

\section{The Human Knot}

Have all the girls stand in a circle. Tell them to put their right hand into the circle and grab the hand of someone else, but not the people standing right next to them. Then have them repeat with the left hand. Now, without letting go, they have to figure out how to unknot themselves.

Variation. Have the girls get into the knot but have one girl remain outside the circle and then try to unknot them herself. Give her about 3 minutes. Then give the group the same amount of time to unknot themselves without letting go. Most likely, the group will get further in the process than the girl on her own. The lesson learned? Groups working together, who are in the problem together, will do a better job of solving the problem than a lone individual from the outside.

\section{Concentration}

Start a clapping beat of two claps and two snaps. Following the beat, say, "Concentration. Is the name. Of this game. Starting with. ." Choose a category that they will have to list things in, such as girls' names, boys' names, musicians, cities, countries. Go around the circle and on the claps, each girl has to list something in the chosen category. If she doesn't respond on her turn, she is out.

\section{Sevens}

Everyone stands in a circle. Girls count off in order. Any number that is a multiple of 7 or has a 7 in it (that is, 14, 17, 21) the girl should clap instead of saying the number out loud. If she does something incorrect she is out and sits down 
Additional resources for trust-building games:

- http://www.businessballs.com/ teambuildinggames.htm

- http://www.unssc.org/web/_private/ files/30.pdf

- http://www.go2itech.org/ HTML/TTO6/toolkit/delivery/print/ TrngMethods/100Energizers.pdf

\section{Trust Fall}

Have girls pair up (try to have them be similarly sized). One girl in the pair stands with her feet firmly planted and her arms in an " $X$ " across her chest. Her partner stands very close behind her with her hands up at shoulder level. They exchange the following words:

Girl in front: "Ready to fall"

Girl in back: "Ready to catch"

Girl in front: "Falling"

Girl in back: "Fall away"

The girl in front falls back slowly, with her feet still firmly on the ground, and her partner catches her. Each time the "catcher" takes one small step back so the falling girl falls a little bit more each time, building trust with each step.

\section{Group Sit}

Have all the girls stand in a circle. Have them get as close to each other as possible so they are standing shoulder to shoulder. Then have everyone turn to the right. Again, have them move in so they are as close and tight as possible. Tell the group that on the count of 3 they all should sit down slowly at the same time. They will sit down onto the lap of the person behind them. If they do it all at the same time and speed, no one will fall. Once they succeed, tell them to stand on the count of 3 . When they get really good at this, once they are in the sitting position they can try to walk around the circle a few steps.

\section{Trust Walk}

For this game, you will need space to walk around, with a small amount of obstacles in the way. If you can go outside, great. If not, you can set up an indoor area. Put girls in pairs, give each pair a cloth for a blindfold and have one girl in each pair tie it over her partner's eyes. Then lead the pairs on a walk. The "seeing" girl will be the guide of the "blind" girl-needing to tell her where to turn, when to step over something, go around something. Afterwards, ask the girls, "How did it feel to have to trust someone else to lead you around?" "How did it feel to be responsible for someone else?" 


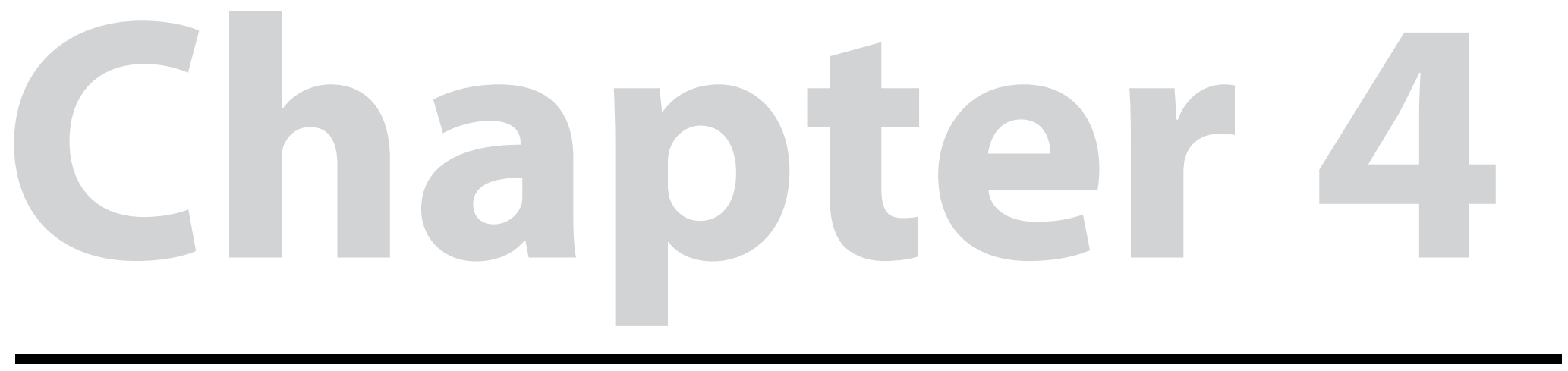

Recruitment-How do you get the girls you want into your program

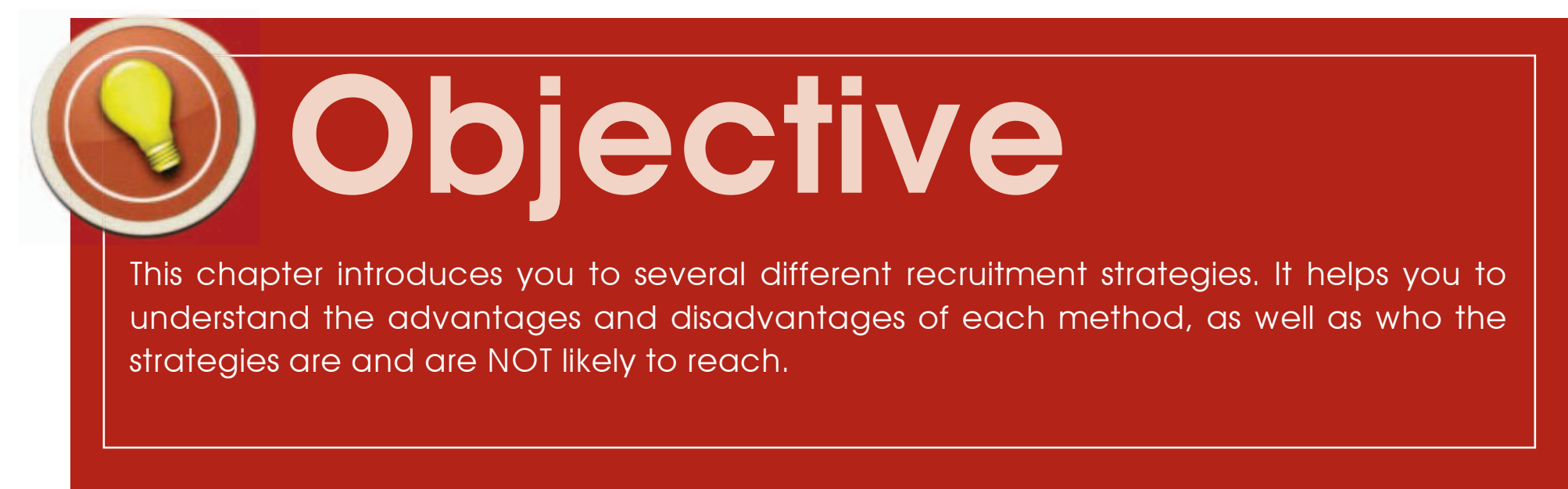


Once you clarify which girls you would like in your program (see Chapter 1), you will have to develop your recruitment strategy to ensure those specific girls are reached. The challenge usually lies in finding the girls you want_-not getting them to join.

The key point to remember about recruitment, and thinking about different recruitment methods, is that each method will attract a slightly different kind of girl. Equally important, each method will likely NOT reach some kinds of girls.

To be sure you reach the girls you want, you most likely will have to use a combination of recruitment methods.

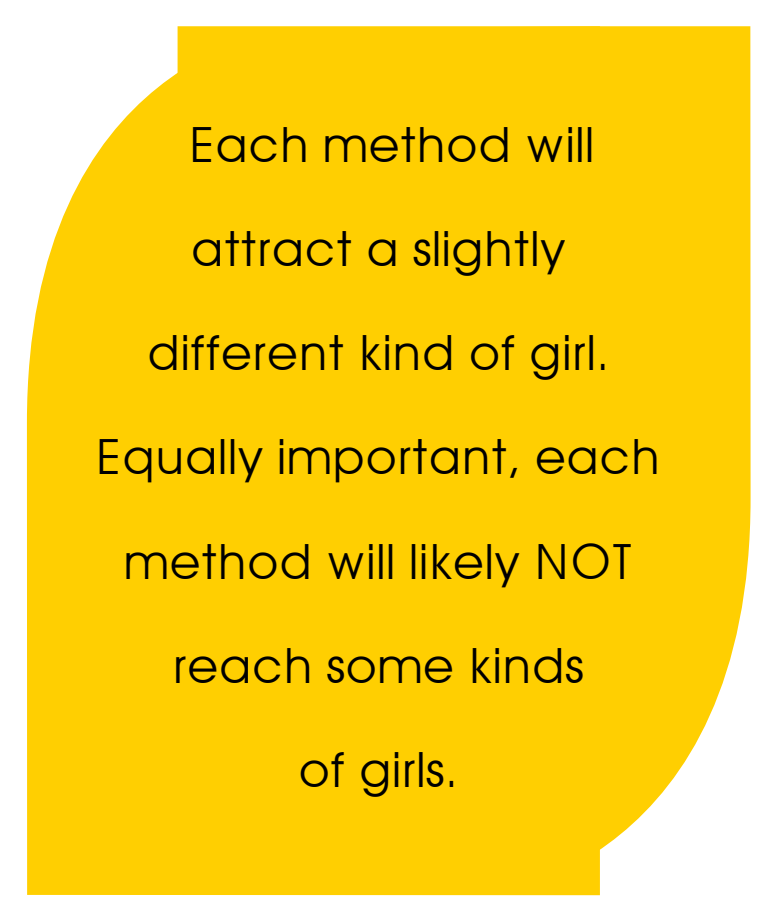


Let's explore a few main recruitment methods and look at their pros and cons, as well as which girls they reach-and which they do NOT reach.

\section{Word of mouth}

\section{How do we do it?}

The "word of mouth" strategy relies on girls that are already in your program bringing in additional girls that they know, are friends with, are neighbors or relatives of, etc. Current members, or staff, tell the people who they know, who tell the people that they know, and so on, that the program is recruiting new members and those who are interested should show up.

PROs

\section{CONs}

- get a linked group of girls

- does not cost money

- hard to expand membership beyond existing network

- does not take a lot of time

- relies on others to do the recruitment

- use of local resources and connections

\begin{tabular}{|l|l|}
\hline & \\
\hline Who is reached & Who is NOT reached \\
\hline $\begin{array}{l}\text { - girls who are already connected to program members } \\
\text { Or staff }\end{array}$ & $\begin{array}{l}\text { - girls who do NOT have a friend or relative in the } \\
\text { program } \\
\text { - girls who are more socially isolated }\end{array}$ \\
\hline
\end{tabular}




\section{Through parents}

\section{How do we do it?}

The core element of this strategy is to go through parents. Calling a meeting in the community of parents of adolescent girls in the age range you are targeting is one way to do this. At the meeting, you can explain the program and encourage them to enroll their daughters. Another way is to use the other methods listed (fliers, doorto-door) but targeted at parents.

PROs

\section{CONs}

- parental buy-in from the start of the program

- only get girls whose parents approve from the start

- a way to get parents' input at the very start

- high support and ownership of program by parents

\begin{tabular}{|l|l|} 
& \\
\hline Who is reached & Who is NOT reached \\
\hline $\begin{array}{l}\text { - girls whose parents approve of the program } \\
\text { girls whose parents are networked enough in the }\end{array}$ & $\begin{array}{c}\text { girls whose parents do not want her to participate in } \\
\text { the program } \\
\text { girls whose parents are not linked to recruitment efforts }\end{array}$ \\
\end{tabular}




\section{Through community leaders}

\section{How do we do it?}

Recruiting through Community Leaders involves approaching the recognized leaders in the community-whether

they be the chiefs or elders, local level government administrators, religious leaders, head masters of schools,

directors of community organizations, etc.-and either meeting with them one-on-one or calling a meeting.

Sometimes you will need to do both; sometimes the leaders will request an invitation or information in writing. You will need to explain the program to the community leaders, describe the kinds of girls that you would like in the program, and ask them to identify appropriate girls in the community.

PROS

\section{CONs}

- gain buy-in and support from community leaders at

- community leaders might not agree with you on who the very start of the program

- can be cost effective the "right" girl for the program is

- sometimes community leaders have their own interest in supporting a program and will ask for something in exchange for allowing the program to run

\section{Who is reached}

- girls seen as appropriate in the community

- girls chosen are typically the "shining stars" - i.e. those already succeeding and seen as 'worthy' of participating in a special program

\section{Who is NOT reached}

- girls who are not known by community leaders

- girls that community leaders dismiss as "unfit" for the program (even if you are specific about the profile of girl you want) 


\section{Through schools}

\section{How do we do it?}

Recruiting through schools involves contacting the schools in the community, often starting with a meeting with the head teacher (sometimes after sending a formal letter of introduction). You might want to ask the teachers to announce the new program in their classroom and inform interested girls of how to join the program. You can ask permission to go and speak in the classrooms yourself. You can distribute fliers in schools.

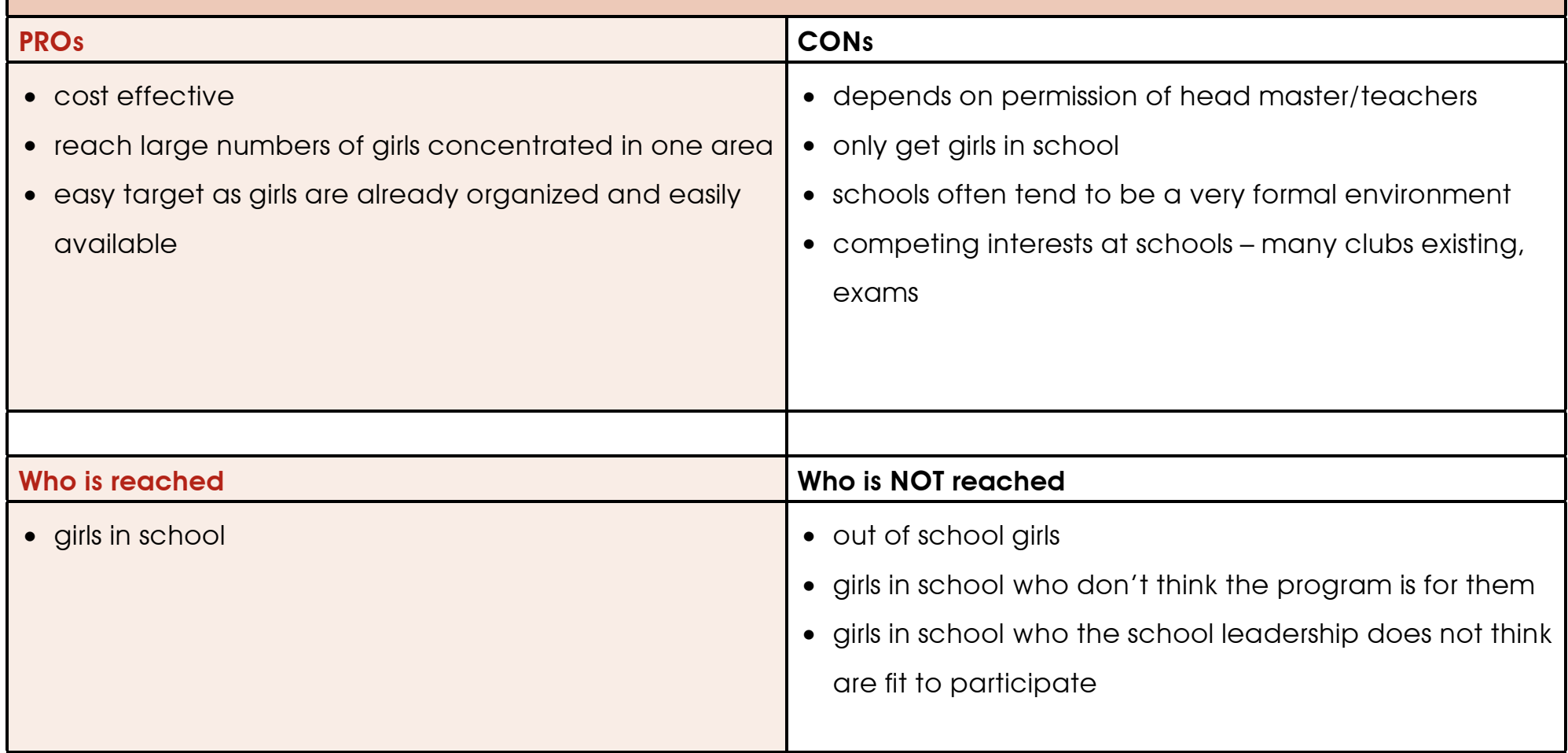




\section{Fliers}

\section{How do we do it?}

Recruitment by using fliers involves developing a one page or half page flier with basic information about your program, the characteristics of the girls you are trying to recruit, and what girls who are interested should do (i.e. should they come to your office? On a certain day?). You can paste fliers throughout the community, and also in strategic places where you might find girls - schools, markets, churches/mosques, etc. You can also distribute the fliers to people who you would like to spread the word for you.

\begin{tabular}{|l|l|}
\hline PROs & CONs \\
\hline $\begin{array}{l}\text { - Iow cost to make copies of flier } \\
\text { not that time consuming }\end{array}$ & $\begin{array}{l}\text { - fliers get torn down } \\
\text { you do not have a lot of control over what happens } \\
\text { to the fliers and who reads them once they are } \\
\text { distributed }\end{array}$ \\
\hline - girls who can read & $\begin{array}{l}\text { girls with an existing desire to join a program } \\
\text { Who is Not reached }\end{array}$ \\
& $\begin{array}{l}\text { girls who do not have the self-esteem to see the flier } \\
\text { and feel that they are good enough to be a part of } \\
\text { the program }\end{array}$ \\
\hline
\end{tabular}




\section{Radio}

\section{How do we do it?}

Recruitment through the radio involves approaching the local community radio station and requesting them to air an advertisement or announce your recruitment. You would have to work with them to make sure the information and tone are correct. Perhaps you could even be interviewed on the radio, describing the program and announcing that you are recruiting more girls.

\begin{tabular}{|l|l|}
\hline PROs & CONs \\
\hline radio can reach a large number of people & $\begin{array}{l}\text { - not very targeted } \\
\text { - dependent on people listening at the right time } \\
\text { - can be costly to produce and air the announcements } \\
\text { - dependent on a radio station with a targeted audience }\end{array}$ \\
\hline gho is reached with access to a radio & $\begin{array}{l}\text { Who is NOT reached } \\
\text { - girls without access to the radio } \\
\text { - girls without the self-esteem (or that have other } \\
\text { obstacles) to hear the announcement and then take } \\
\text { the necessary steps to join the program }\end{array}$ \\
\hline
\end{tabular}


Door-to-door

How do we do it?

Door-to Door recruitment involves program staff and/or volunteers going to every house in the target area of your program and asking if there are adolescent girls eligible for the program in that household. If there are, it will be important to talk to the adults in the house, as well as the girl, to explain the program, its benefits, and why the girl should attend. Then you can leave information for when and where the girls should come if they want to join.

\section{PROs}

- reach vulnerable, isolated girls who would not automatically think a program is for them, or be reached by the other recruitment strategies

- have a chance to talk to adults in the household

\section{CONs}

- time consuming

\begin{tabular}{|l|l|} 
& \\
\hline & \\
\hline Who is reached & Who is NOT reached \\
\hline - very vulnerable girls & $\begin{array}{l}\text { - girls who aren't home } \\
\text { - very isolated girls }\end{array}$ \\
$\begin{array}{l}\text { - girls in the catchment area you are targeting } \\
\text { girls with the characteristics you are looking for }\end{array}$ & \\
\hline
\end{tabular}


In reality, you will likely use a combination of recruitment methods. For example, you might put up fliers advertising an introductory meeting for the program that interested girls should come to, as well as go around door-to-door in certain areas to invite girls to that same meeting. As stated earlier, the most important thing to consider is what kind of girls you are trying to reach, and then identify an appropriate recruitment strategy to reach them.

Remember, some of the most vulnerable girls will be very hard to reach. You will need to convince their guardians, employers, mothers-in-law or husbands. You will also have to convince the girl herself that she is worthy of and welcome to participate in your program. This will take time and planning and is a critical step in the development of your program.

\section{A note about attendance}

Sometimes, while programs are successful in their recruitment efforts, they can later struggle with attendance and retention. Drop out can be high or attendance irregular. Some common reasons leading to attendance problems are:

- problem with the day/time in which meetings are held (clash with school or other responsibilities)

- group meetings or program duration are too long or they occur too frequently (or not often enough)

- parents or other critical adults are not supportive of the program (see Chapter 6)

- girls need child care for their babies or younger siblings that they have to take care of

- the program is not meeting the needs of the girls/the girls are bored

When programs are designed with girls needs in mind (Chapter 2), these problems tend to be minimized. However, if you are experiencing a drop in attendance, that is a sign that it is time for a needs assessment. Organize some sessions with the girls, use the interactive tools provided in Chapter 2, and find out what are the barriers to attendance. 


\section{CASE STUDY}

Fortress of Hope Africa (FOHA) is a program for adolescent girls in the Dandora neighborhood of Nairobi. Dandora is divided into four phases and FOHA has an office located in Dandora Phase 4. As FOHA was planning to implement a new program component, they looked at the current girls that they were reaching and realized that they were not reaching girls from Dandora Phase 2, or any girls in the area that had disabilities. Therefore, as they were recruiting, they went door-to-door in Phase 2, looking for girls with disabilities, as well as talking to girls in general, reaching out to other $\mathrm{CBO}$ in that area, in order to find the girls that met the criteria they were looking for.

Population Council, in partnership with MicroSave Consulting Ltd., manages a program that is developing and rolling out savings accounts for girls. Faulu-Kenya, a partner microfinance institution who offers the Princess Account for girls aged 10-19 years aimed to mobilize 500 girls to open accounts and join savings groups during the pilot period. Faulu used a mix of recruitment strategies - holding meetings with community leaders to announce the product and asking them to send girls who were interested, gaining approval of religious leaders and then advertising the program after the religious service, meetings with current clients who were parents of adolescent girls, going to other youth serving organizations, churches/mosques, and schools in the area, and finally, going door-to-door to talk with girls and their guardians about joining savings groups. Even when the formal recruitment stopped, through word-of-mouth, existing Princess Account holders would bring their friends to the group meetings to open accounts themselves.

The Sisterhood for Change Program (SFC), a girls program within a larger organization called Kisumu Medical and Education Trust, is a vocational training and empowerment program for vulnerable adolescent girls. In order to ensure that they took the most vulnerable girls into their program, program staff screened interested girls at intake to see if they were out-of-school, teenage mothers, orphans, or HIV-positive and if they resided in the urban slums. They publicized the program in the community through sensitization forums on the magnitude of the problem and challenges faced by these disadvantaged girls, and the objectives of SFC. This was done in different forums e.g. the churches, Chief's baraza, schools, etc. 

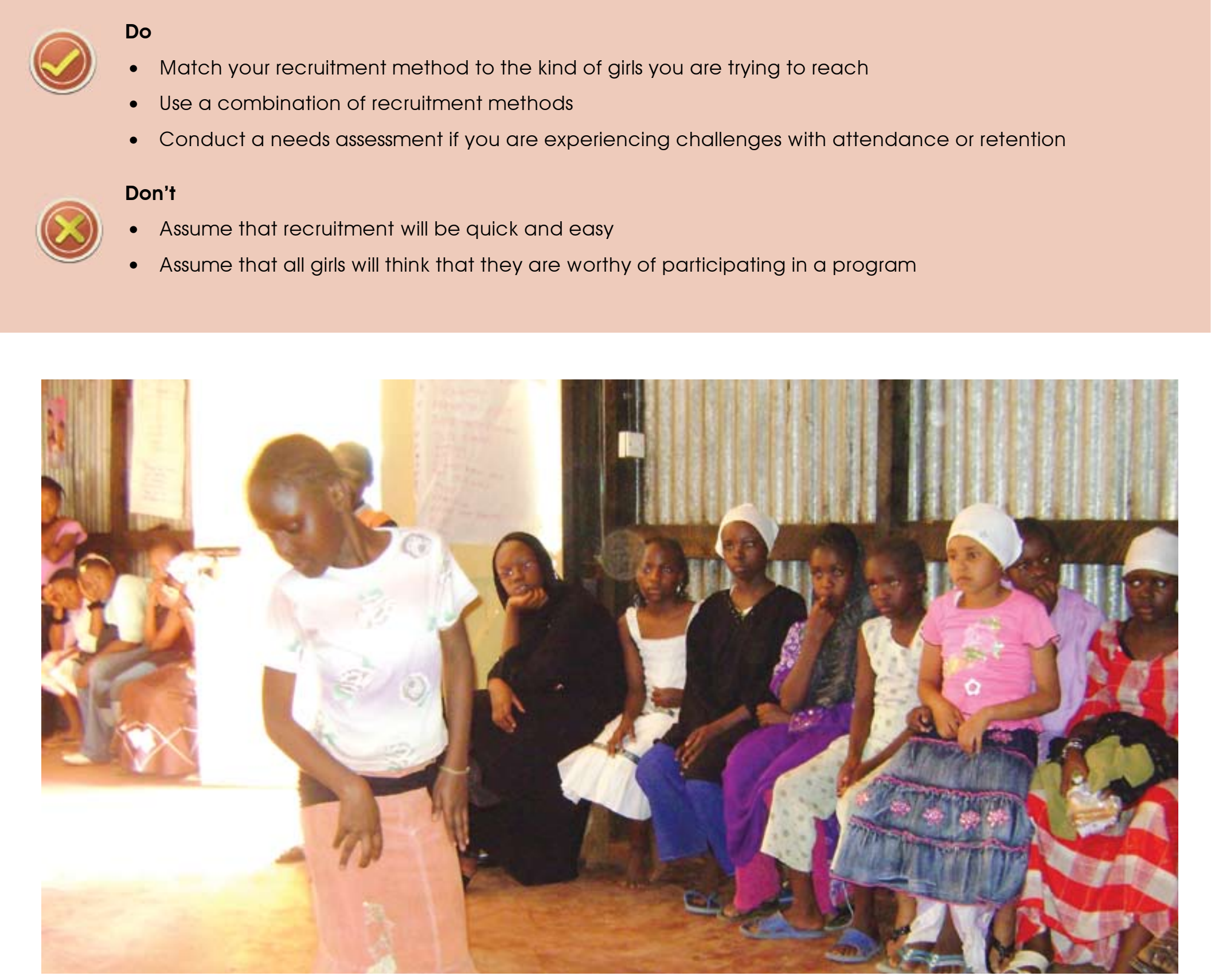


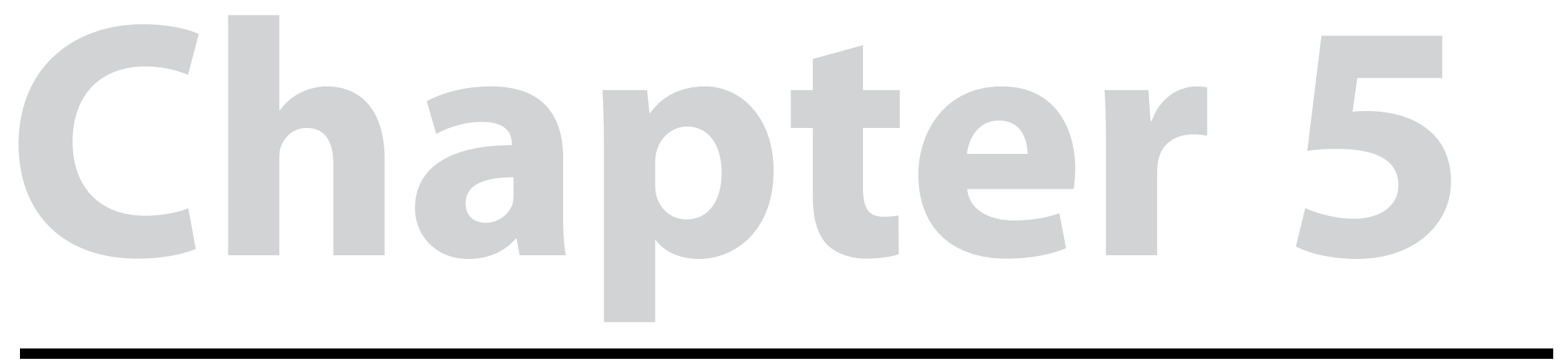

\section{Leadership development and mentoring}

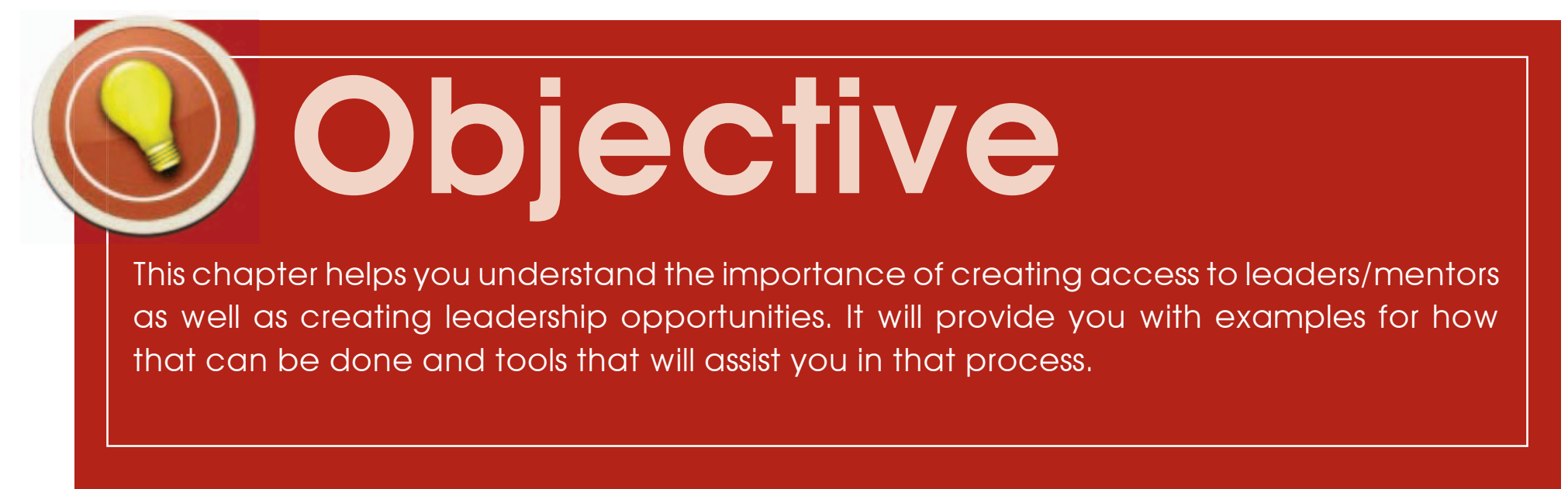




\section{As you develop your program, it is important to think about developing leadership in three specific ways:}

- providing girls with access to female leaders and mentors

- helping the girls in your program to develop leadership skills

- creating leadership opportunities for girls as they grow up through your program

These three elements can be linked through program design by including different levels of leadership opportunities within your program. Creating these leadership opportunities is critical for girls to practice the skills they have been developing and learning how to apply what they have been learning in the context of a safe space with other girls.

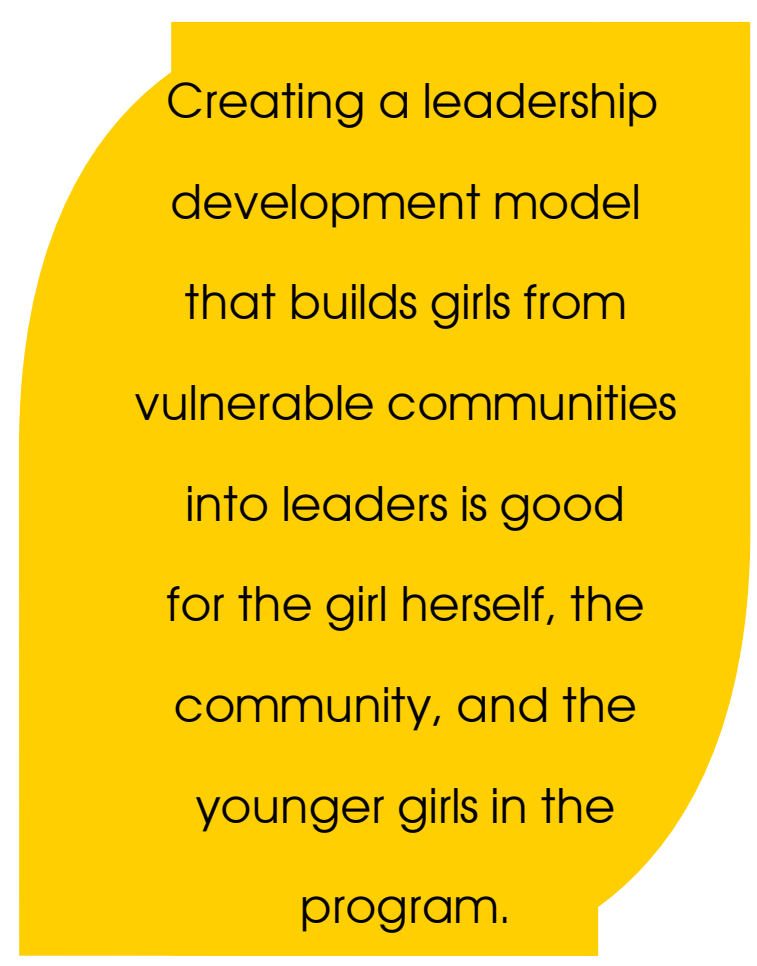


In Chapter 3 we discussed the three core elements of developing a girls program, with the third being a mentor. Often people think of a mentor as a role model—someone much older who a girl takes as an example for "what she wants to be when she grows up" or a hero in her life like Mother Teresa, the first lady, or a local female musician. However, our definition of a mentor in our programs is a bit broader, a bit closer to the girls themselves and the community/reality that they live in. A mentor can be an older adolescent girl, even someone who graduated from the program a few years before, who can assist in facilitating group meetings, planning activities, and simply developing a regular relationship of trust and support with the girls.

Developing young, female leaders within the community that you are working is important. Often, when programs want to provide mentors, leaders or role models they make the mistake of thinking that that talent must be imported. Often they ask university students or young women professionals to volunteer. However, creating a leadership development model that builds girls from vulnerable communities into leaders is both good for the girl herself, the community, and the younger girls in the program, who will have mentors and strong young women living right there in their own communities, girls with similar background. 


\section{Cascading Leadership}

One model of leadership development that we have seen work in many settings throughout the world is where older adolescent girls from the community you are working in are trained to mentor the younger girls in those communities.

Sometimes this can happen over a longer time period where girls go through the program course, graduate, and are trained to take on increasingly higher leadership positions, running groups for the new girls coming into the program. In most cases, there may not be enough time at the beginning of the program to allow the girls to go through the leadership development program, and it will be necessary to train a group of older adolescent girls to serve as your initial mentors.

So what is the major premise of Cascading Leadership? It is working with older adolescent girls or young women to be leaders and run programs for younger adolescent girls.

- one way is to take a group of promising, older girls, but from the same disadvantaged community and put them through an intense training to prepare them to be mentors.

- another way is building girls up through programs to take on leadership responsibilities - but that also takes time.

One critical thing to note is that these mentors and group leaders should be compensated for their time and treated as if they are doing a job (which they are!). Ideally they should be paid a small stipend that is appropriate for the number of hours they are involved, and the amount can be linked to similar compensation for other jobs in the community - i.e. a day care worker, a primary school teacher, a health outreach worker, etc. If that is not possible, they should be compensated with training, opportunities, or other incentives that you have agreed upon with them. However, in our experience, a monetary stipend is the best way to ensure quality work, commitment and sustainability.

Another critical component of the model is that the mentors will also need ongoing supervision and support. This can take the form of monthly mentors meetings, one-on-one meetings, or site visits, depending on the geographic spread of your program. However, regardless, we recommend some form of gathering that allows the mentors to interact, share successes and challenges, exchange ideas and learning, and build their own social networks 


\section{CASE STUDY}

Here are two examples of the Cascading Leadership Model - one that happened organically through program growth and another that was built into the structure of the program from the start.

The Binti Pamoja Centre - Binti Pamoja is a program for adolescent girls ages 10-19 years in the Kibera slum of Nairobi, Kenya. The program started with a core group of 15 girls that then grew to two groups of girls. As these girls grew together with the program, it became clear after a couple of years that they were ready to "graduate" and take on leadership roles, and the program was ready to expand into the community. In 2006, the initial group of graduates went through a training of trainers program that strengthened their skills on facilitation, group development, communication, and conflict resolution. Then the groups worked in pairs to form their own girls groups that met in the community. The responsibility of the mentor/alumni was to recruit girls into the group, locate a place in the community to meet, plan and facilitate the weekly meetings, provide support and guidance to the girls in their group, and spend the monthly group budget appropriately. Alumni are provided with a small stipend, and meet all together monthly for supervision meetings with the Binti Pamoja staff.

Within a year the "Safe Spaces Program" at Binti Pamoja had grown to 20 alumni and 10 groups. As this became too large for the two program staff to handle, two alumni were hired as part-time field officers to monitor and support the alumni and safe spaces groups. With each year, the Safe Spaces Program continued to grow as more girls finished Binti's core program, became alumni and started their own girls groups in the community. By 2009 the program had grown to include over 50 alumni and 25 groups - too much for two field officers to supervise. Therefore, another leadership level was implemented in between the alumni/group leaders and the field officers-the Village Coordinators. The five village coordinators are each responsible for a specific geographical area in Kibera and monitor 4-6 groups each. They help the alumni in their area with recruitment, identifying spaces to meet, monitoring group content, and planning events and trainings.

Therefore, through a cascading leadership model, Binti Pamoja has been able to grow from a program of 40 girls meeting in one location in Kibera to a program of over 1,000 girls, 30 groups (15-25 girls per group), 75 alumni in some leadership capacity, and a reach into every village within Kibera. 


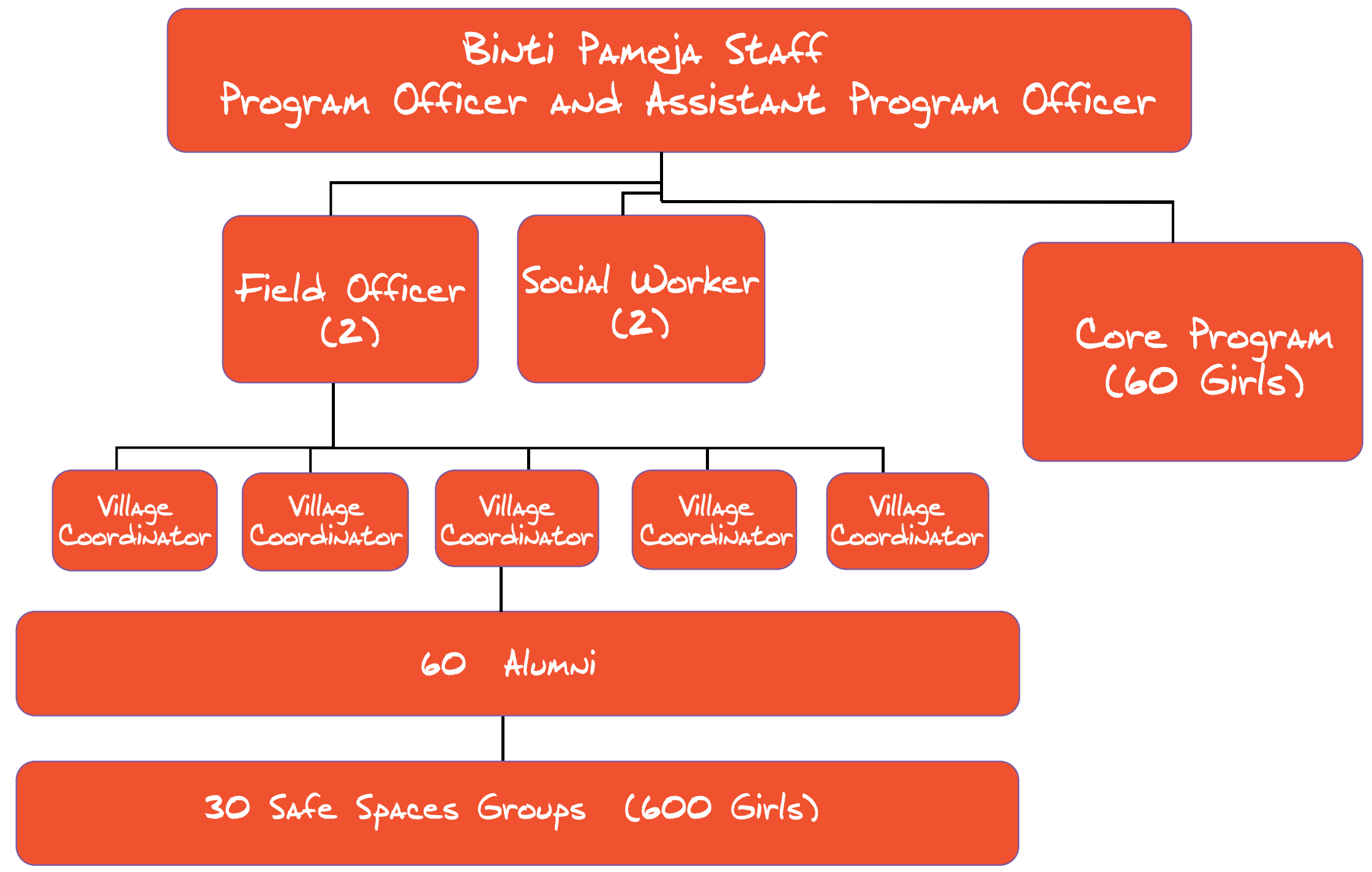




\section{CASE STUDY}

Safe and Smart Savings for Vulnerable Adolescent Girls This project-managed in partnership by Population Council and MicroSave Consulting, Ltd., together with financial institution partners Faulu-Kenya and K-Rep Bank in Kenya plus Finance Trust and FINCA-Uganda in Uganda-aims to provide adolescent girls with formal savings accounts. The accounts are delivered using the "Safe Spaces Model" as the girls are organized into groups that meet each week in a place provided by the financial institution. Each group has a mentor who is a young woman from the community, chosen by the girls, who helps with running group meetings and facilitating financial transactions.

This is an example of cascading leadership that did not grow organically because there was no time to wait for the girls in the savings groups to grow and then become mentors. However, now that the program has been running for over a year, older girls who turn 18 or 19 and are eligible for adult savings accounts are encouraged to take on the mentor role in new savings groups that are forming.

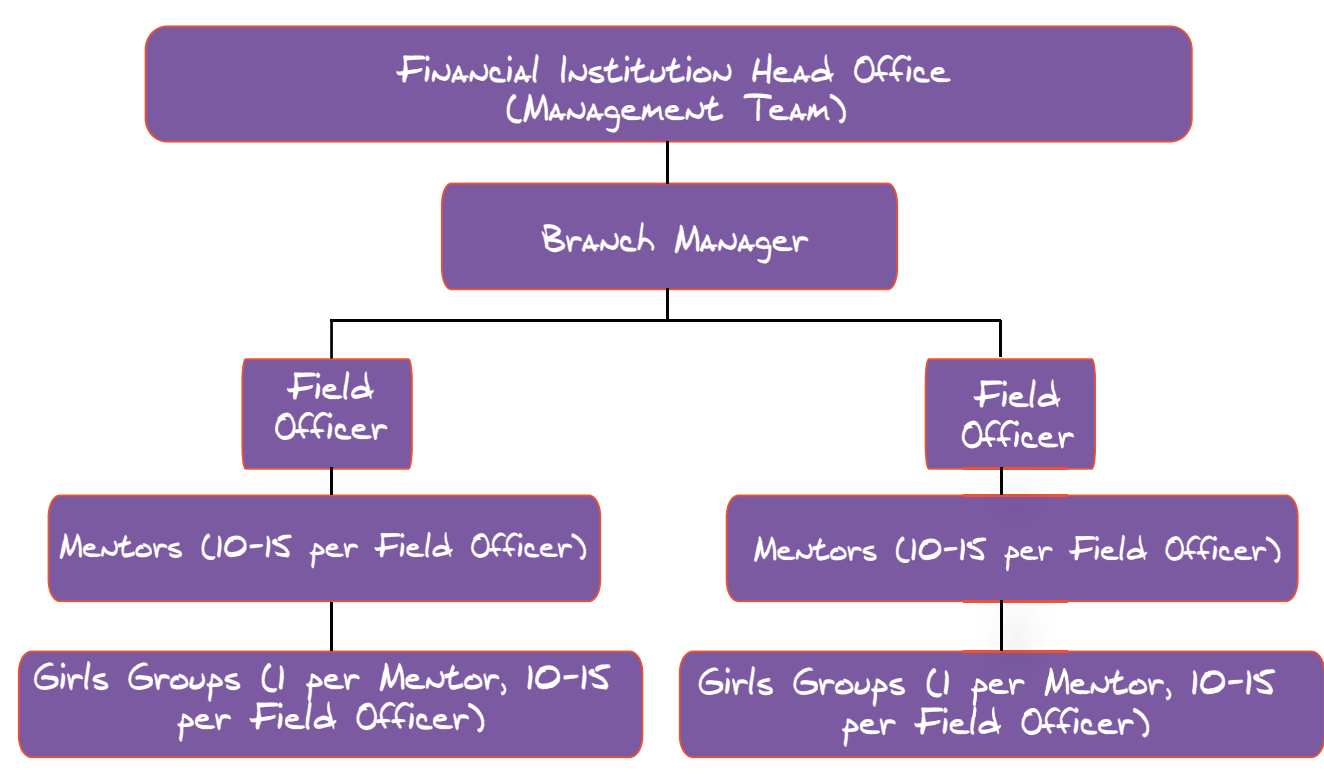




\section{A word about mentoring vs, peer education}

The words 'mentor' and 'peer educator' are commonly used interchangeably. However, they are actually two different models that serve different purposes. Mentors/Cascading Leadership involves older girls mentoring younger girls, so that even though all of them might be adolescent girls, there is an age difference, for instance a 24 year old running a girls group of 12-14 year olds, or a 15 year old training a 9-year old. However, what is critical is that it gives the older girls a leadership role and set of responsibilities, and the younger girls an example of what they can be in the future (i.e. something to work toward). On the other hand, peer education implies youth of the same age transferring information to their age mates. This model has been found to have benefits for the peer educators themselves, but less so for program participants ${ }^{12}$. This model also tends to elevate the less vulnerable youth into leadership positions, as those that are selected to be the peer educators are often already outstanding. Finally, peer education does not build a lasting structure of leadership and girls program delivery infrastructure, as peer educators move through the program cycle and move on.

\section{Do}

- Provide access to mentors and leaders for girls in your program

- Ensure that leaders are females from the community that the girls can relate to and that are a good fit for the specific girls in your program

- Create leadership opportunities within your program for girls to grow into

\section{Don't}

- Assume that only women from outside the community can serve as mentors or leaders

- Underestimate the ability of the girls in your program to take on responsibility 
The following is a sample schedule for a five-day training of trainers course that can be used to build a training to prepare older adolescent girls or young women to be mentors in your program. It includes sessions on how to structure groups and trainings, facilitation and group management skills, and time to practice training.

Depending on the content focus of your program, you will want to focus sessions on that specific area and have the participants use those topics for their practice training session. For example, a very similar schedule was used to train older adolescent girls ages 18-25 to become group leaders in a financial education program. Therefore, the afternoon of Day 3 was an overview of the financial education curriculum, which was what was used for their practice learning sessions on Days 4 \& 5.

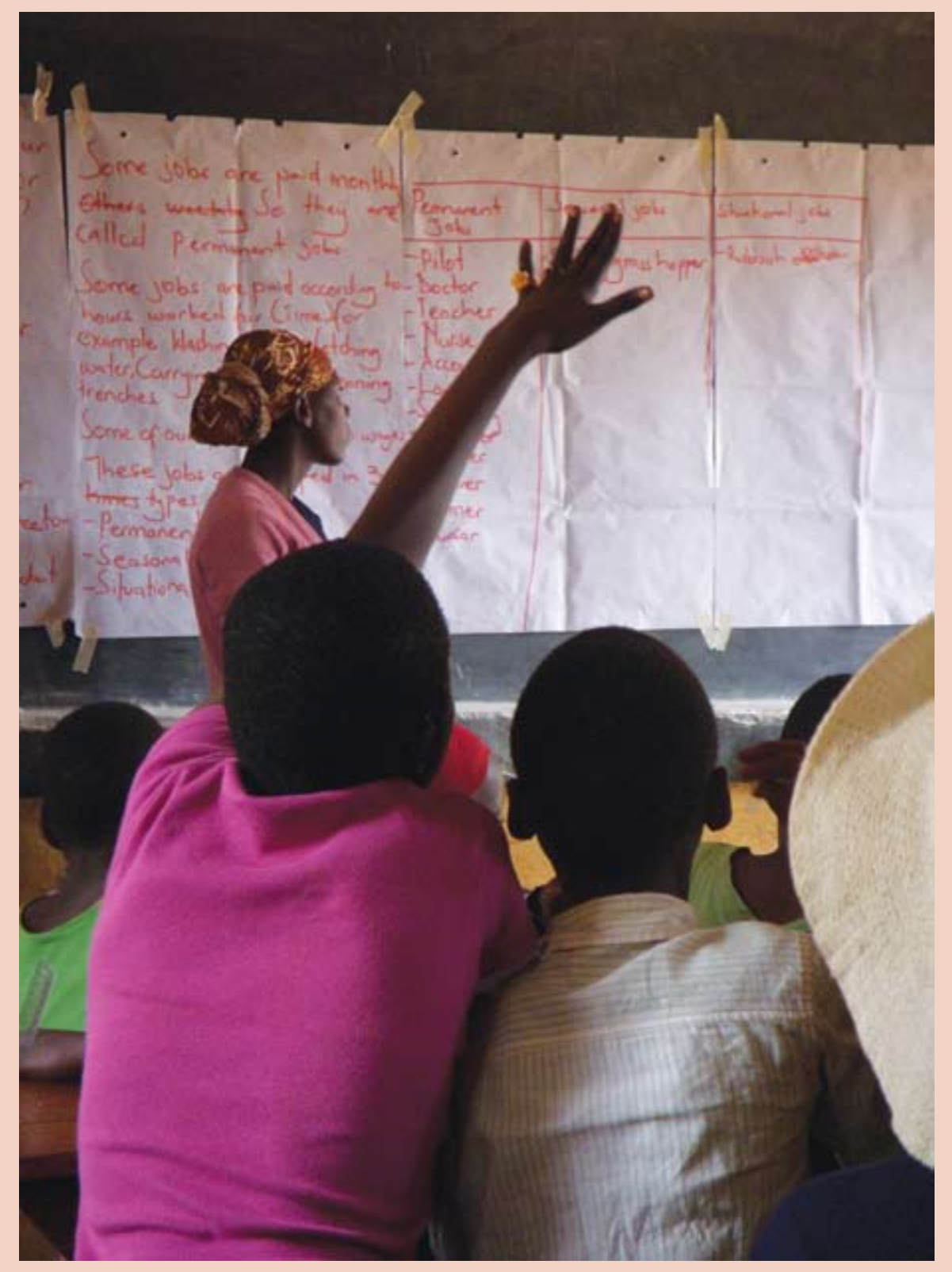


SAMPLE SCHEDULE FOR A "HOW TO BE A TRAINER/GROUP LEADER" TRAINING

Note This schedule can and should be changed to meet your needs, what the girls you are training to be facilitators

need the most focus on, and how much time you have.

Day 1.

9:00am - 4:00pm

Morning

- Introductions/Expectations

- Ground Rules

- Go over outline of TOT

Objectives

- introduce the training

- explain expectations for the training - especially an emphasis on the point that this training is preparing them to be facilitators, they must increase their seriousness and look at the material from the perspective of someone who is going to be teaching $\mathrm{SRH} / \mathrm{HIV} /$ Economic Empowerment to others

- present the schedule for the course of the training

- explain techniques for opening a training (Introduction, Expectations, Ground Rules/Norms) why they are important and share different methods

- introduce concept of energizers and icebreakers share examples

- introduce concept of daily feedback teams

Note This session serves both as an introduction to the training - including expectations, group norms, ice-breakers, daily feedback teams - as well as informative for the participants about how to start a training, why the various components of an introduction are necessary, and a modeling and brainstorm of the different techniques that can be used for the different components of an introduction. It is by nature a very fun,

interactive morning with a lot of energizers, moving around, etc
Afternoon

- Engagement/Experiential Learning/Small Group work

- Safety

- Affirmation

- Open Question

Objectives

- introduce the concept of fully engaging participants - "Tell me...l forget, show me...I remember, involve me...I understand" (engagement)

- discuss the advantages of small group work and share techniques to making small groups work better (engagement)

- help participants think about the principle of safety in the context of learning/training and how to create a safe learning environment for members in their trainings/groups (safety)

- have participants develop a list of techniques they can use to promote a safe place for learning for the groups with which they work (safety)

- help participants understand the power of affirmation and consider how to more consistently provide it to their groups (affirmation)

- practice giving and receiving praise (affirmation)

- listed appropriate ways to give praise during group learning sessions (affirmation)

- explain the difference between open and closed questions and help participants to understand the important of using open questions as a facilitator (open questions)

- practice changing closed ended questions into open ended questions (open questions)

Note This session covers the components of "Creating a Safe Learning Environment." 
Day 2.

9:00am - 4:00pm

Morning

- Team/trust building

- Methods of facilitation - role play, small group work, lecture, games

Objectives

- start a process of team building in the workshop (team building)

- allow participants to understand the important of team building in training (team building)

- give participants experience with appropriate teambuilding techniques (team building)

- explain the benefits of using a variety of teaching methods while training (methods)

- identify the different types of teaching/facilitation methods and discuss the pros and cons of the different methods and when different methods may or may not be appropriate (methods)

- brainstorm the pro's and con's of different teaching/ facilitation methods - (methods)

- present techniques for using role play effectively, including examples - (methods)

- present techniques for using games effectively, including examples - (methods)

Afternoon

- Values Clarification

- Reading an audience

- Adapting a curriculum to suit your audience

Objectives

- discuss the role of personal values as a facilitator/ trainer and the need to stay objective (values)

- provide participants with experience in techniques that explore values and attitudes (values)

- discuss the importance of being able to read your audience (reading an audience)

- identify techniques to assess the audience and respond appropriately (reading an audience)

- practice responding to various "problem participants" (reading and audience)

- identify the importance of adapting the learning session so they are relevant to participants (adapting)

- review techniques/methods for adaptation (adapting)

Note This day focuses on facilitation skills - including different methods of facilitation, team building, how to read an audience and how to adapt a curriculum. 
Day 3.

9:00am - 4:00pm

\section{Morning}

- Public Speaking

- Co-facilitation

\section{Objectives}

- help participants identify and practice their skills in public speaking (public speaking)

- give participants techniques on how to improve their public speaking skills (public speaking)

- highlight important aspects of co-facilitation, including do's and don'ts (co-facilitation)
Afternoon

- Review the content from which they will be trained

\section{Objectives}

- provide participants with a content refresher of the training materials

Note This is a time to make sure that the participants have the core grounding in the content of what they will be training on. For example, if they will be training girls on financial education, you would want to review the basics of financial education and the curriculum that they will be using. If the content of the groups will focus more on sexual and reproductive health or HIV, then you would review those topics. 
Day 4.

9:00am - 4:00pm

Morning

- Further review of training content/curricula (depending on what they will be training girls on)

- Prepare for learning session presentations

\section{Objectives}

- review elements of curriculum that participants identified as needing review

- clarify any confusing components of the curriculum

- explain to participants that they will each facilitate a session and assign session topics

- assign learning sessions to be facilitated

- give time for preparation of facilitation

- discuss key principles of giving and receiving feedback

Note This is time to further review the content of what they will be training on and clarify and questions that the participants may have. One of the final components of the TOT is that each participant facilitates a session. During this time, participants should be assigned a session/topic to facilitate and be given time to prepare (i.e. review the content, decide her lesson plan, prepare flip charts, etc.)

\section{Afternoon}

- Presentation of sessions by participants with feedback

\section{Objectives}

- have participants practice facilitating skills with sessions from relevant curriculum

- have participants give and receive feedback on presentation

Note This is a very important experience for the girls to actually use the curriculum, get up in front of the group, and get and receive feedback. One way to do this is for each girls to have a session. Another way is for them to co-facilitate. If there are many girls, they can be split into two for time sake so everyone gets a chance to facilitate. 
Day 5.

9:00am - 4:00pm

Morning

- Continuation of presentation of learning sessions with feedback

\section{Objectives}

- have participants practice facilitating skills with learning sessions from relevant curriculum

- have participants give and receive feedback on presentation
Afternoon

- Develop a Plan of Action

- Closing Ceremony

Objectives

- identify plan of action for how the participants will now begin working with girls in the program

- celebrate the completion of the TOT

Note Setting aside some time for a plan of action is important because it gives the participants some time to outline a schedule for how they will start interacting with their girls groups, what the next steps are, etc. It ensures that the training doesn't just end, but that it ends with a plan in place to implement what was taught and discussed at the training. 


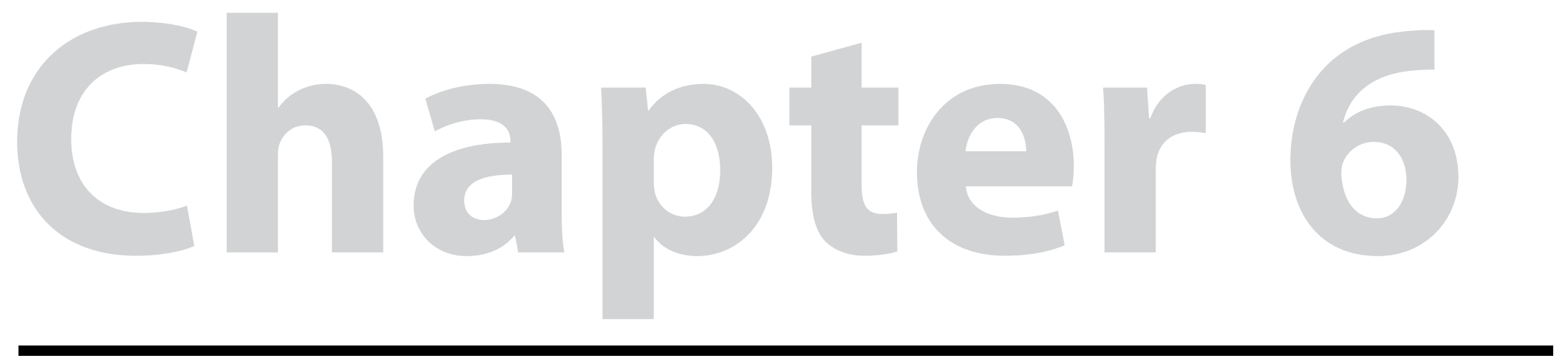

\section{Working with families and critical adults}

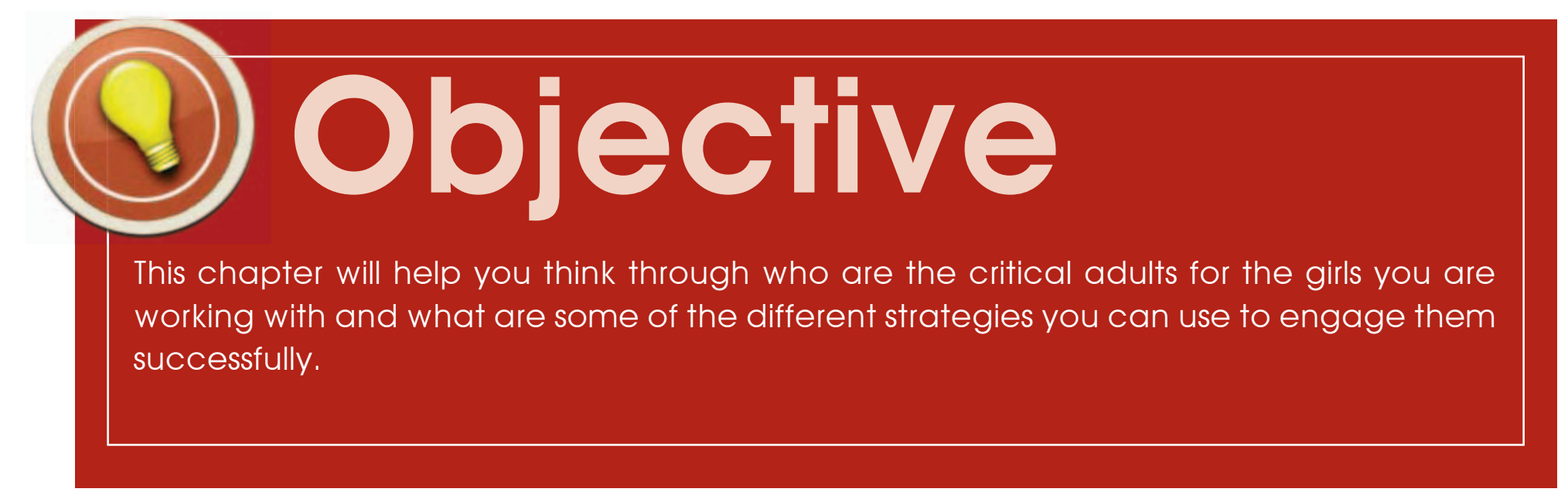


You will need to secure program approval and support from the girls' parents, guardians, relatives or other adults. These adults are often the ones who will give girls the permission to attend your program, or who can be the barrier that keeps girls away. Their level of support is an important factor in the success or failure of your program.

The first question that you have to ask yourself is:

"For the girls that I am trying to reach, who are the critical adults in their lives?"

Depending on which girls you are trying to reach, and the cultural context in which you are working, the kind of adults will be different. Let's look at some examples. This list is not exhaustive, but should get you thinking in the right direction:

Girls living with their parents/guardians $\rightarrow$-Parents/guardians

In-school girls $\rightarrow$

Domestic workers $\rightarrow$

Married adolescents $\rightarrow$

Girls in a rural community $\rightarrow$
-Teachers, Head Teachers

-Employers

-Husbands, Mothers-in-law

-Village elders'
The first question

that you have to ask

yourself is:

"For the girls that I

am trying to reach,

who are the critical

adults in their lives?" 
Also, in some settings girls' brothers will be important, particularly in more socially conservative settings where it is the responsibility of the male relatives to maintain the family honor; in other settings mothers will be most important and fathers will have a minor role. In other communities, fathers will be the ones to give permission for girls to attend the program.

Note How you approach these adults is another important factor in whether or not you are able to gain their support. If you treat them as barriers or obstacles to your program, they may behave as barriers. If you approach them as important assets to your program, however difficult it may be to engage them, you are more likely to win their approval. How you approach them, what you say and how you say it will make a difference in if they approve or support your program.

\section{Strategies for engaging adults}

There are many different strategies that you can use to engage parents and other adults?:

Involve parents and other critical adults in needs assessments

At the start of your program, or at critical moments in the program's development (such as before adding a new component), bring a group of parents together and have a small focus group discussion to get their input. For instance, ask them questions about how they view the issues and challenges that girls are facing, their suggestions for how to address those issues, and run some ideas by them about your program activities to make sure there is general approval.

Parents will appreciate this because they will feel a part of the program, and you can avoid challenges in the future by hearing their concerns upfront. 


\section{CASE STUDY}

Before Binti Pamoja integrated financial education into its curriculum, program staff did a series of interviews with mothers of girls in the program to understand how they viewed girls' financial responsibilities, as well as to hear how they felt about introducing money management training into the program. It was interesting for the staff to learn the difference between how girls expressed their financial responsibilities and how their mothers viewed them. For instance, girls thought they had more financial responsibilities than what their mothers expressed. However, money can be a sensitive topic and it was very beneficial for the parents to approve of the activities ahead of time. In addition, some of the mothers were later able to ask their daughters about what they were learning and were able to integrate some of those lessons in their own money management behaviors.

Cheshire Services Kenya runs a residential vocational training program for girls with physical and mental disabilities. One challenge the program faced was that at the end of the program, when girls received a sewing machine to take home to help start up their business, the parents/ guardians of the girls would often sell the machine and send the gir back to the centre or the streets. With the new financial education program that Cheshire implemented, the parents were included to learn how to support the girl in identifying a good market for her products in the community, and to understand that the girls' income could also be of benefit to the family. The parents became very supportive as they understood the benefit to the girls and their families.

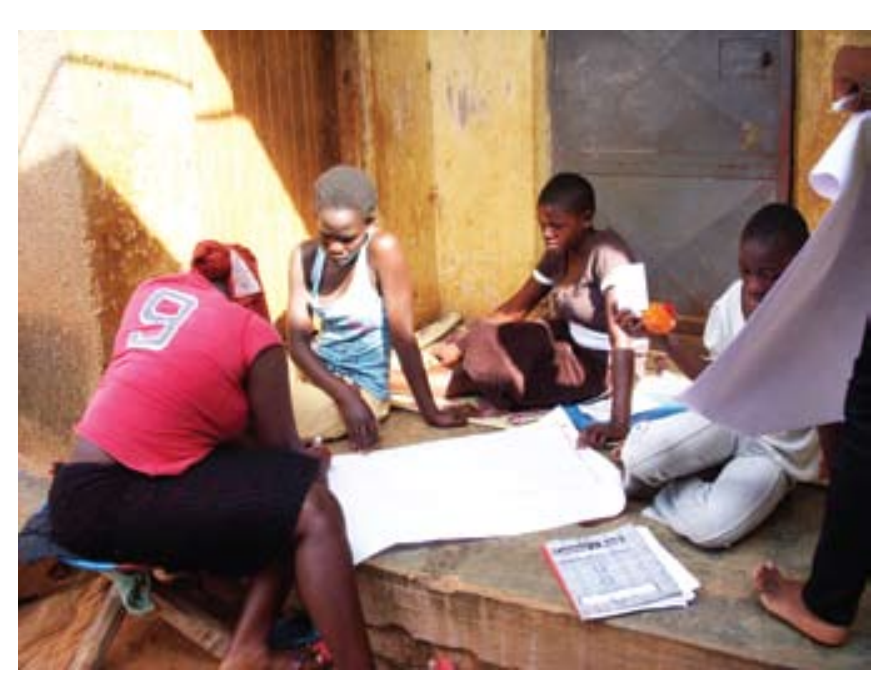




\section{Family Events}

Another strategy is to hold events for parents that bring them together at your program. This can be done on a quarterly, semi-annual or annual basis, although it is probably best to engage them often. These events give you a chance to address the parents, tell them what has been going on in the program, and to hear their questions and concerns. The events also give the girls in the program a chance to show their leadership skills and to facilitate the meeting or share what they have learned. This kind of event is important because parents become familiar with the setting of the program, what the girls do and who the staff are that run the program. It is also a chance to improve communication between parents and daughters.

One variation of this kind of event is using it as an opportunity to train the parents themselves. FauluKenya, as part of their Princess Account girls' savings program, has meetings for the parents of account holders where they discuss what the girls are doing in their savings groups, and provide some financial education training for the parents as well. Several parents have opened up their own savings accounts with Faulu following such meetings.

\section{Home Visits}

Visiting the homes of the girls in program on a one-on-one basis is another way of both building relationships with their parents/critical adults, as well as understanding the girls' home environments. Home visits are some of the best ways to strengthen relationships with parents, but the major drawback is that they are quite time consuming. As your program grows, you might not have time to visit each home. You will need to make strategic decisions about who to visit. There is an added risk of entering into some uncomfortable family dynamics in the home - for instance, the father might be drunk, or members of the family might demand certain things in return for a girls participation. 


\section{Sending Home Information}

For many families, simply receiving a letter informing them of the activities, trainings, field trips, etc. makes them feel involved and that they know when and where their girls will be. If the girl herself forgets to tell her parents where she is going, and then is away for a day-long training, the parent may start to complain about the program.

\section{Giving Ownership of and Responsibilities within the Program}

It is important for the parents to see themselves as partners in the program - not beneficiaries. In certain contexts, it can be appropriate to ask the parents or families of the girls in your program to take on responsibilities within the program. For example, you can ask them to prepare a meal during a training; you can ask families with space in their compound to host meetings; you can ask them to spread the word about various family events. In the case of a program that gives in-kind support to girls (i.e. pays school fees) - you can do so in a way that ensures that the families will also make their own contributions.

This strategy has both its pros and its cons. If successful, this can build a strong sense of ownership and support for the program. The families, and in turn the community, can begin to feel that the program belongs to them. However, if you depend on the families, and they do not follow through, you can be left without food, without a place to meet, etc. This requires continued follow up with the parents. Also, it requires familiarity with the community you are working in - it might not be appropriate to ask for this kind of support in certain circumstances. 


\section{CASE STUDY}

Fortress of Hope Africa (FOHA) asks the families to contribute small amounts of ingredients that are used to prepare lunch for their day program

Heshima-Kenya, who works with unaccompanied refugee minors, allow girls to identify foster parents in the community and then the program does a home visit to assess the foster family before the girl joins their home.

Cheshire Services Kenya, which runs a residential vocational training program for girls with disabilities, used to run the program year-round.

However, they saw that parents would just leave the girls at the school and let go of all responsibility. Therefore, to get the parents to take a more active role in their girls' lives and share the responsibility together with Cheshire Services, they shifted to a school calendar model where the girls come to the boarding school for three months and then go home for a month during the holiday months.
Note Keep in mind that your primary focus is the girl. Some girls may not have informed their parent/guardian that they are participating in your program for several reasons.

For example, perhaps a girl lives with both her parents, and her mother knows and approves of her participation, but her father does not approve. If care is not taken and a letter is sent home or a staff comes to the house, the father might become very upset and there may be negative consequences for both the girl and the mother. Therefore, any contact with parents or a guardian once the girl is already in your program must be done with the girl's awareness and consent. 


\section{Community contracts}

Many programs have found it a successful strategy to enter into a formal agreement or contract - often written - with a certain community before setting up a girls group there. The process of working with communities (usually through community-recognized leaders) to develop these agreements provides the opportunity to establish and build relationships between the program and the community and establish commitment by the community to work with and for girls.

"Community contracts" can include documentation of what the community has committed to, both on the value level (e.g. supporting girls education) and on the logistical level (e.g. providing girl-only space at certain days/times in the local primary school, village hall or community). Agreeing on these terms ahead of time can later smooth the work with the community and other critical adults. Further, these agreements can be updated and modified as the program evolves and the communities become more engaged, increasing the role and support the community provides to the girls' activities. This strategy has been effective when the initial commitments start small and when the local leaders and community boundaries are clearly defined.

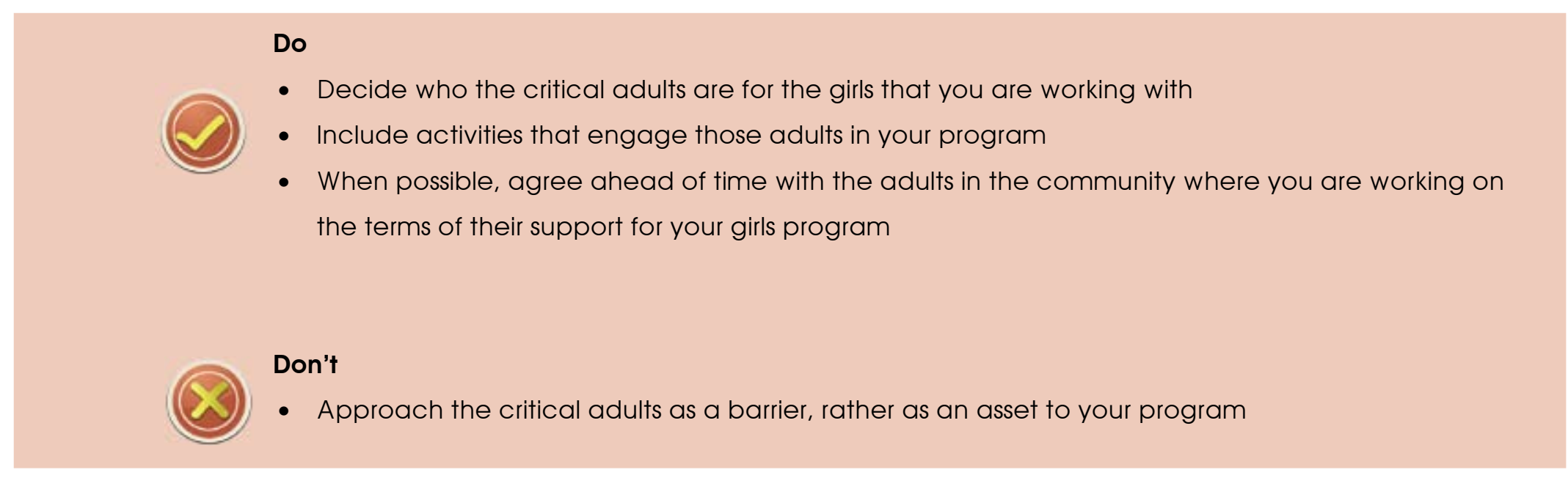


Sample agenda for a parents' meeting

10:00 - Introduction and welcome from the Program Director

Introduction and welcome by two of the girls on behalf of all the program members

10:15 - Welcome and explanation of the program components

10:45 - Performances by the girls

11:15 - Question and answer period - time for parents to ask general questions about the program

12:00 - Sample training session for parents on relevant topic (financial education, HIV prevention, business planning, etc. - so that they are exposed to what their girls are learning)

1:00 - Closing and refreshments 
Sample topic guide for a focus group discussion with parents (before program starts)

Facilitator: Hello, my name is XXXX, from program XXXXX. We're in the process of starting a program for adolescent girls ages 10-15 in this community and we wanted to get your thoughts about these girls, how they can be reached, the topics we'd like to address with them, and more.

1. Just to get started, can you tell me a little bit about the adolescent girls that live in your household? How old are they, do they go to school, what are some of their hobbies?

2. Tell me a bit about the typical day for a girl who lives in this community. Where does she spend her time? What activities does she do? What challenges might she face?

3. Let's focus specifically on health for now. When it comes specifically to health issues - what would you say are the three biggest challenges that girls face?

Probe - For each challenge, what could a program for adolescent girls to do to help address this challenge?

4. Now, let's talk about financial matters for a few minutes. Do adolescent girls in this community have opportunities to make money? If so, how do they make money?

5. Sometimes people can put money aside, or save for the future. Is this realistic for adolescent girls in this community? Tell me a bit about that

6. Overall, what kind of decisions about her daily life do girls need to get permission for, and which ones, can she make on her own.

7. As a parent, what kinds of things would you like to see a girl learn in a community based program?

Probe - Where do you think is a safe place for the girls to meet for the program?

Probe - How many days a week do you think girls can meet and during what times?

8. Are there any questions that you want to ask us, or final words you like to tell us as we go about planning the program? 
Sample topic guide for a focus group discussion with parents

(During a program - example of trying to get more information before starting a entrepreneurship program.

You will need to change the question based on the topic that you are exploring)

Hello everyone, my name is XXXXX from XXXXX program.

I want to thank you all for coming today and taking the time to participate in this discussion. As you know XXXXX program works with adolescent girls ages 14-18 here in this community and we mainly focus on teaching the girls about different health issues - like hygiene, HIV, and others - and also help them to develop strong leadership and communication skills. One thing that we've noticed is that as girls get older, they take on more financial responsibilities and have a greater need to be involved in some kind of income generating activity. We are thinking about how we can change or add to our program to accommodate some of these needs.

1. Tell us a bit about the different kind of financial responsibilities that adolescent girls in your community have? -Financial responsibilities in the household?

Personal financial responsibilities?

2. What kind of things do girls spend money on? What are the different sources from where girls get their money? Note - if you want this to be interactive, you can use the Cash Flow Tool located in Chapter 2

3. What are the different income generating activities that girls are involved in? Which of these are positive? Which of these are risky? Why?

4. What do you see as some of the challenges for girls in getting involved in different income generating activities?

5. What kinds of businesses could girls run in this community?

6. What would girls need in order to start a business? In order to successfully run a business?

7. What risks are there for girls to start a business? What do you worry about when you think about your own daughter/ niece/granddaughter starting a business?

8. As a program, what do you think we can do to prepare and help girls become successful business women?

Note If you have program ideas - now would be a good time to share the different program components that you are proposing to add and get feedback from the parents.

9. That's all of our questions - do you have any questions for us?

Once again, thank you for your time and your input. This will be very helpful for us in designing the best entrepreneurship program that we can. 


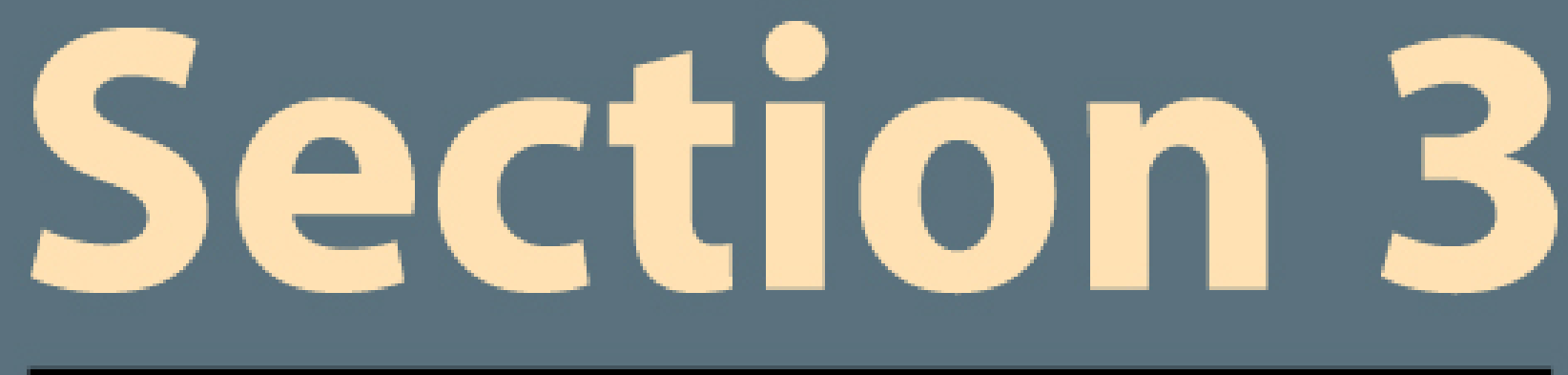

\section{Program Content}

\section{Chapter 7}

The asset building approach

Chapter 8

Economic strengthening programming

Chapter 9

Reproductive health and HIV information \& clinical services

\section{Chapter 10}

Addressing sexual and gender based violence
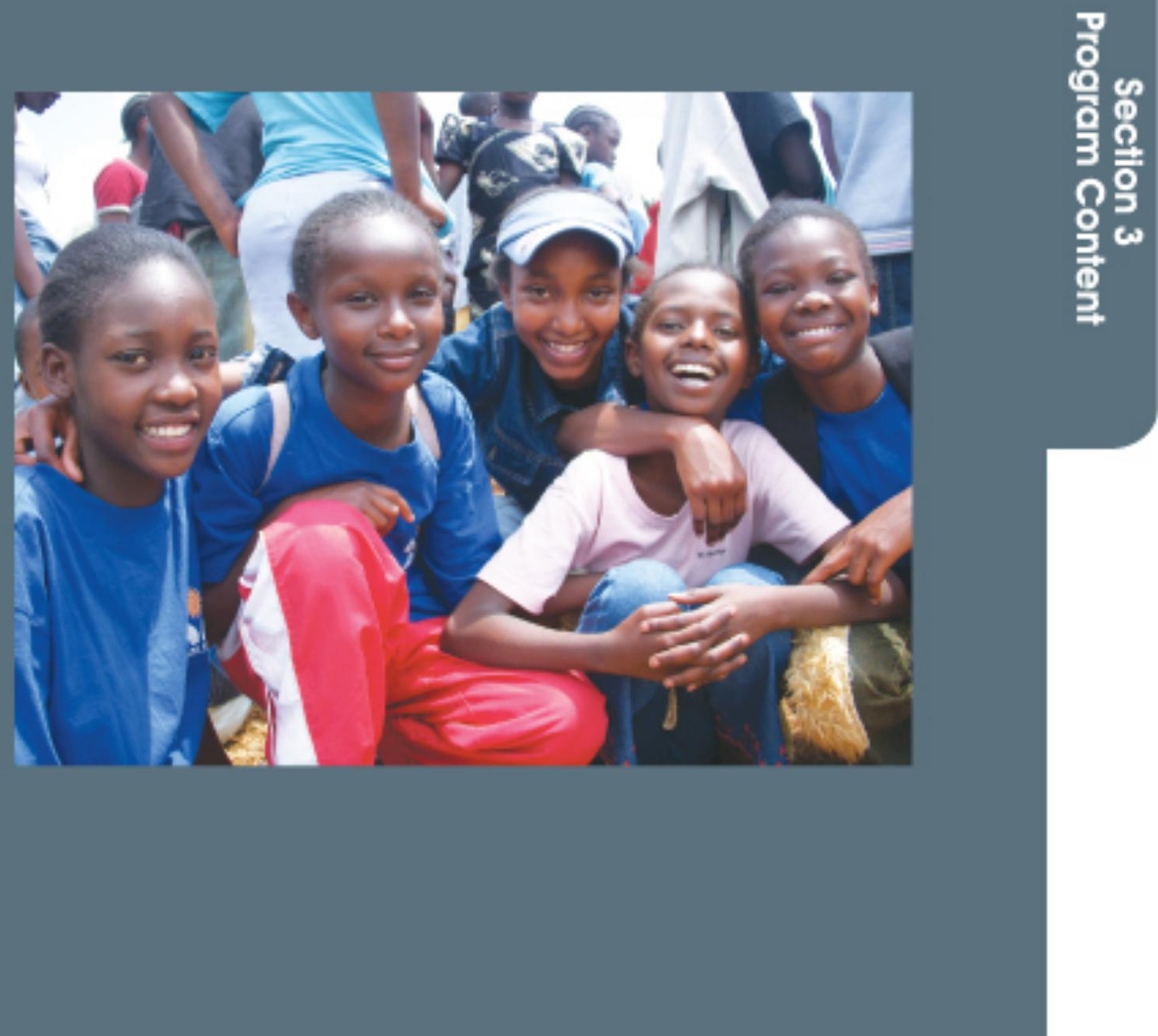

Chapter 11

Reaching extremely vulnerable groups of

adolescent girls 


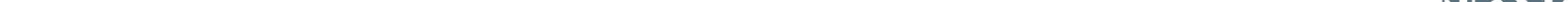




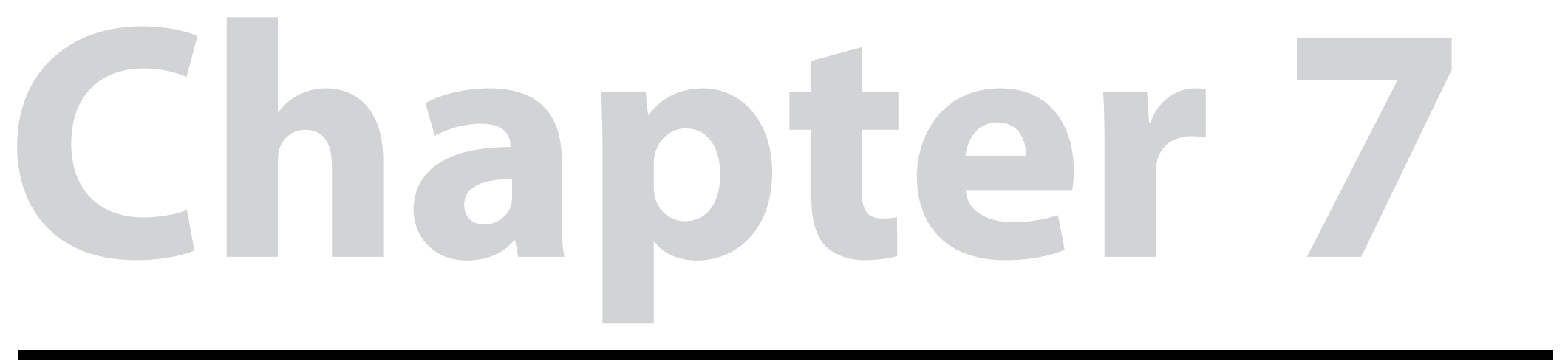

\section{The Asset Building Approach}

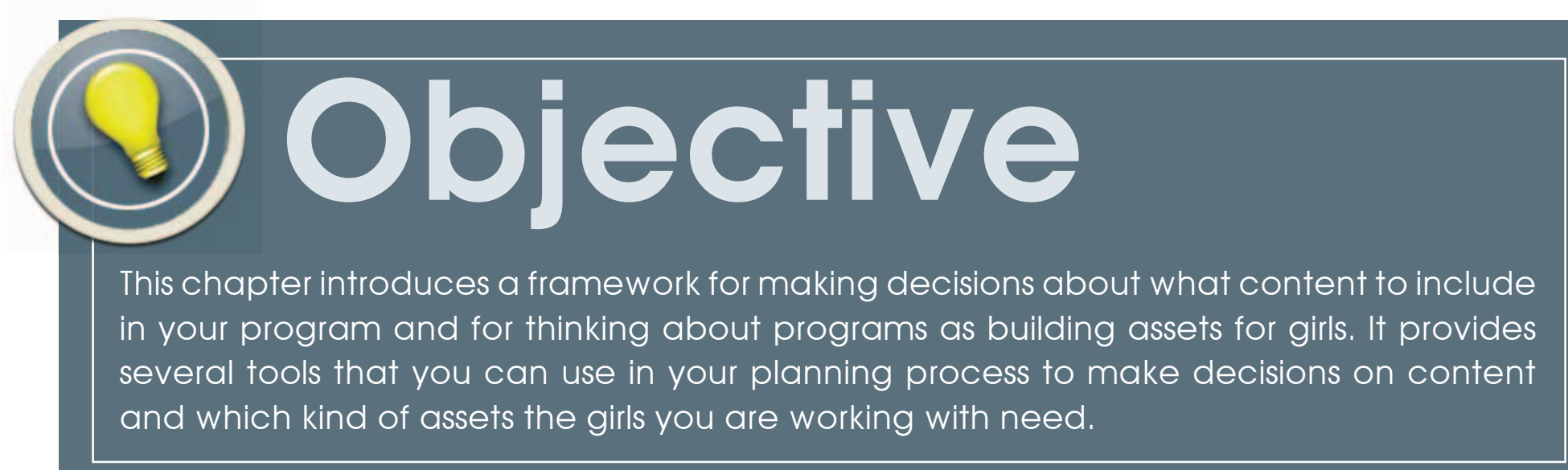


This chapter will introduce an overarching framework that can guide your thinking about content_-to help focus your thinking on what girls need, what topics they need to be trained on and through what kind of activities. Then the following chapters will focus on the different content areas.

The previous chapters in this toolkit were focused on developing the structure of your program - or how you create a high quality program for adolescent girls. They focused on how you create 'the pot' that is going to hold your program activities, or 'the stew' if you will! This chapter, and the next several chapters, shift to focusing on the content of your program - what kind of stew will you make that will be served in the pot?

One strategy that can be helpful is to think first and foremost of what girls need or what they should have, as opposed to thinking about the problem that girls face. 


\section{Moving on to Content...}

Now that you have a good pot, what are you going to put in it? To be honest, you do not always have full choice on the content of your program. Often programs are pre-designed or limited to activities included in a proposal. However, often you can make decisions within those limitations about what to specifically focus on, what else to include, with what age-group and in what order you will introduce the topics. However, often you can make decisions within those limitations about what to specifically focus on, what else to include, with what age-group and in what order you will introduce the topics.

One strategy that can be helpful is to think first and foremost of what girls need or what they should have, as opposed to thinking about the problem that girls face. For example, "What does a girl need in order to grow into a young woman without getting HIV?" instead of "What do girls need to know about HIV?"

To guide you in this process, we will share with you the "Asset Building Framework'," which helps you to think about all the different assets - or valuable things - that a girl needs in order to make a healthy transition into adulthood. This approach is not a specific activity, but a way of thinking about girls programs.

What is an asset? An asset is a store of value, something that girls can use to:

- reduce vulnerabilities

- expand opportunities 
For example, self-esteem is an asset. A girl can draw on her self-esteem to negotiate for safer sex (reduce vulnerabilities) or to excel at a job interview (expand opportunities). Another example of an asset is savings. A girl can use her savings in the case of illness in the family to get the money to pay the hospital bill instead of getting the money in a risky way (reducing vulnerabilities). Savings can also be used to pay for a vocational training course (expand opportunities).

We can think about assets in different categories:

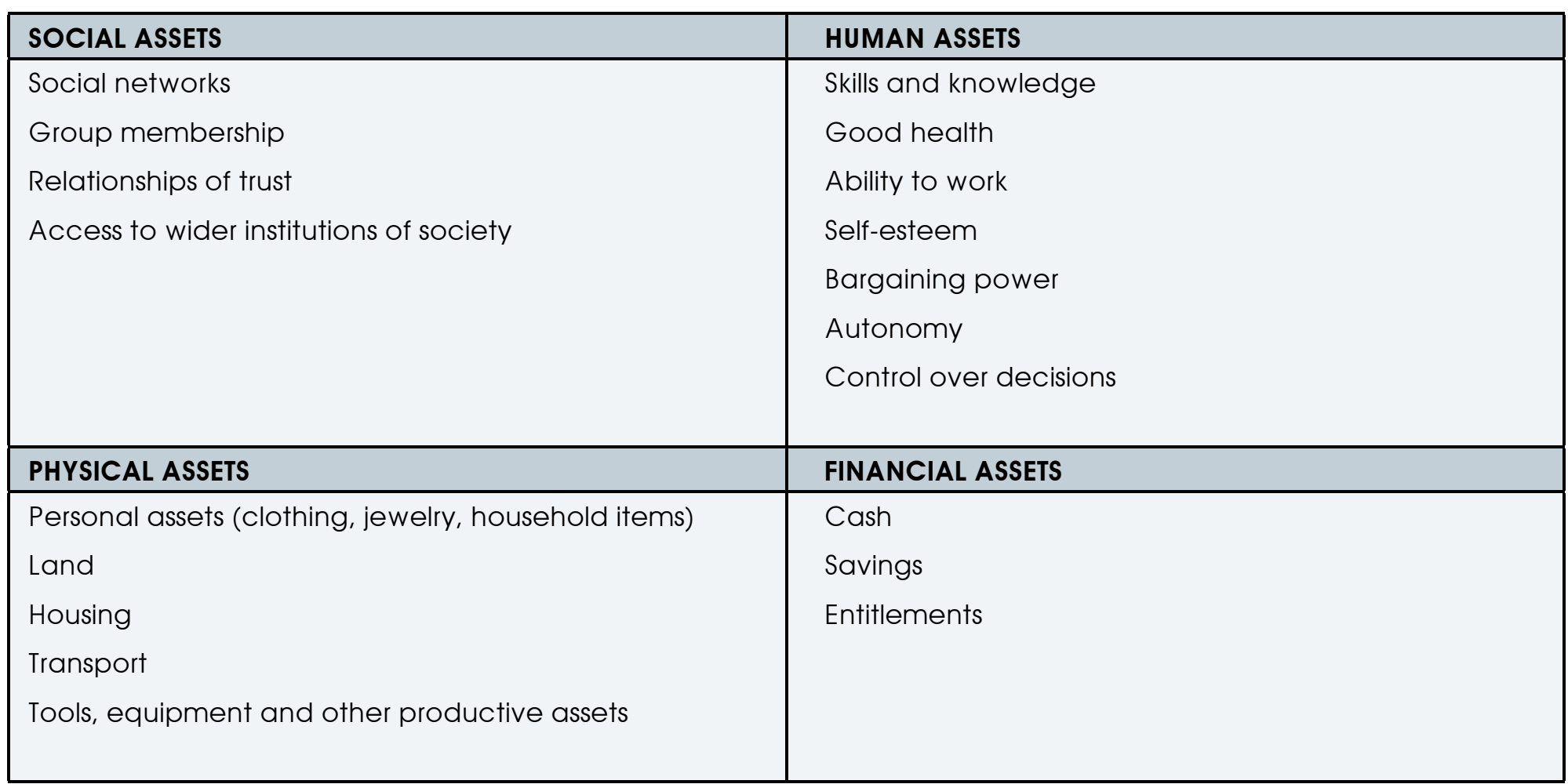


Once you understand assets, the next step is to think about building assets along an age timeline. If you close your eyes and picture a 10-year old girl and a 22-year old girl - are they the same? Clearly the answer is no; girls at different ages have different needs, which means that they will need different assets, different program approaches and content.

The tool at the back of this chapter provides a long list of assets that have been compiled over time ${ }^{2}$. Use this tool to decide which assets you think the girls in your program should have by which age. Then, keeping in mind the girls in your program, you can match activities to build the corresponding assets.

With this information, decide the kind of program activities that will help you achieve those goals. Here is a sample of program activities that build assets across the four categories:

\begin{tabular}{|l|l|}
\hline PROGRAM ACTIVITIES THAT BUILD: SOCIAL ASSETS & PROGRAM ACTIVITIES THAT BUILD: HUMAN ASSETS \\
\hline Group formation & Life skills training \\
Social support & Health education \\
Development of social networks & Literacy programs \\
Mentoring & Financial education \\
& Rights education \\
& Employability training \\
& Vocational/skills training \\
& Business development training \\
& Business internships/attachments \\
\hline PROGRAM ACTIVITIES THAT BUILD: PHYSICAL ASSETS & PROGRAM ACTIVITIES THAT BUILD: FINANCIAL ASSETS \\
\hline Access to tools or equipment for businesses & Savings \\
Safe physical space to meet & Credit \\
Safe place to work & Remittance services \\
& Other financial services \\
\hline
\end{tabular}

${ }_{2}^{2}$ Initial list developed by Microfinance Opportunities with contributions by Karen Austrian, Judith Bruce, Sarah Engebretsen, Catherine Maternowska, and Ghislaine Ouedraogo. 
These program activities are general. You will have to plan much more in detail while keeping in mind the kind of assets that you would like to build.

Do

- Go through the process of thinking about which assets the girls you work with need, by what age, and which ones your program can help to build

- Think about, and then implement accordingly, the order in which different assets should be built and how that translates into the order of program activities

Don't

- Assume that girls of all ages need the same things 
Asset building across the life cycle of an adolescent girl

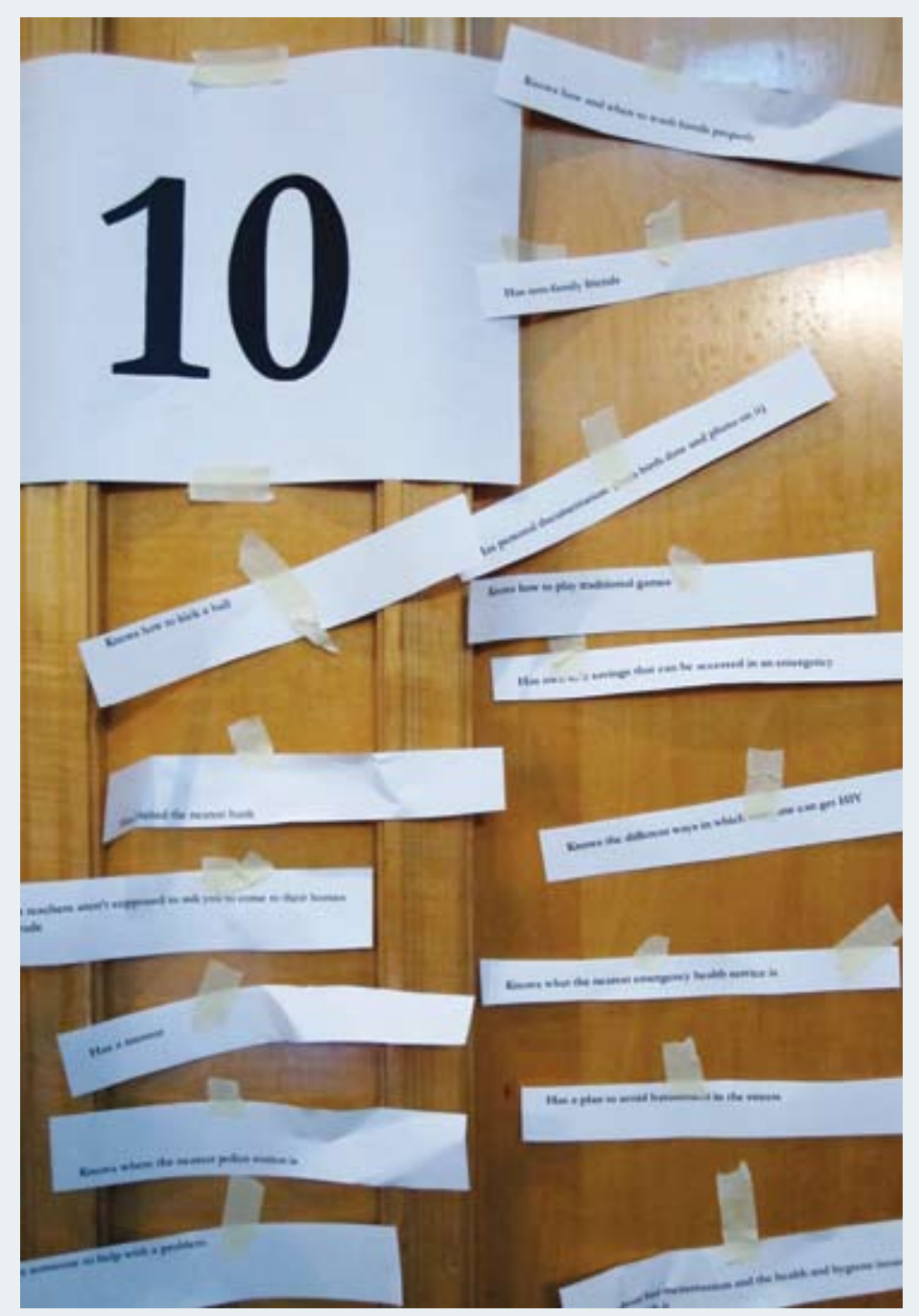

\section{Directions}

Below is a list of assets that programs can build within adolescent girls. Look through these assets and decide by what age a girl should have each asset. Then, think about the girls in your program, and what age they are, and what program activities you will need to have so that they can build these assets. Feel free to add your own assets to the list as well!

Method 1 (More interactive): Use the asset cards at the back of the toolkit (photocopy and cut out), or print out the list of assets and cut them into strips with one asset on each strip. Then, on a wall you can put up signs with the numbers 10, 12, 14, 16, 18, 20, 22 (ages). Distribute the assets cards/strips among the people participating and have each person tape the asset under the age by which they think is appropriate. Then, as a group, discuss each asset's placement, move the assets around, etc.

Once as a team/program you have decided on which assets you'd like the girls to have and by what age, use this as a program planning tool - a list of indictors, or things you would like girls in your program to have achieved through participating. Next, develop program activities that will build the assets according to the list you created.

\section{Variation}

- You can also do this activity with the girls themselves and get an understanding for their point of view.

- You can also do this exercise with a specific kind of girl in mind (e.g. young mothers or domestic workers) and then compare across the different profiles. 
Method 2 (Less interactive): Use the asset list below, and the worksheet that follows. Sit in a group and decide by what age each girl in your program should have that asset. Once you have decided write it in under the appropriate age on the worksheet

Once as a team/program you have decided on which assets you'd like the girls to have and by what age, use this as a program planning tool - a list of indicators, or things you would like girls in your program to achieve through participating. Next, develop program activities that will build the assets according to the list you created.

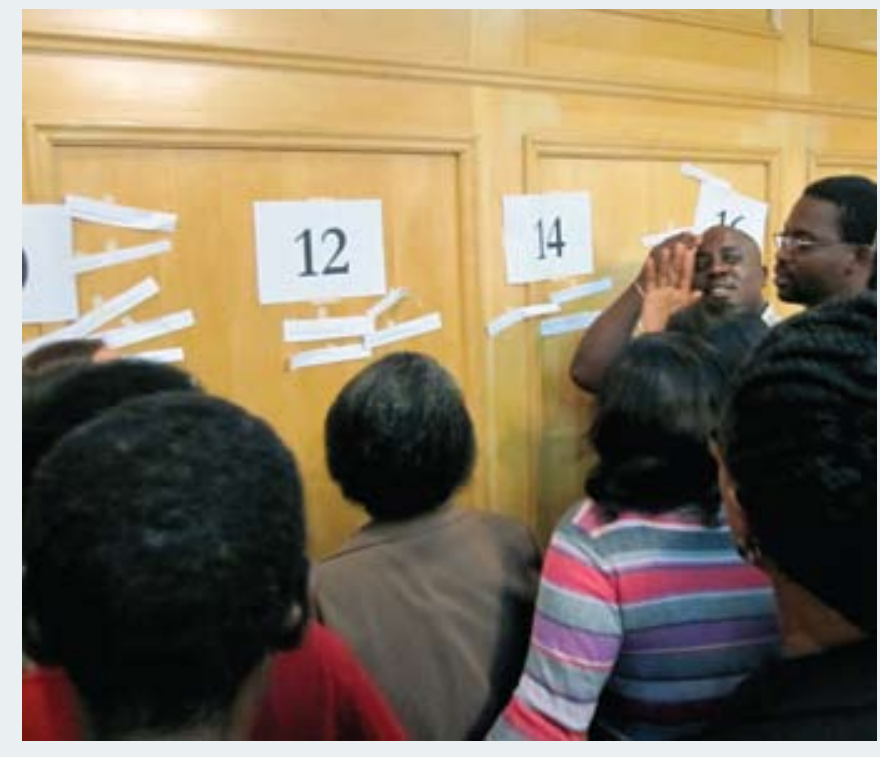


ASSET LIST

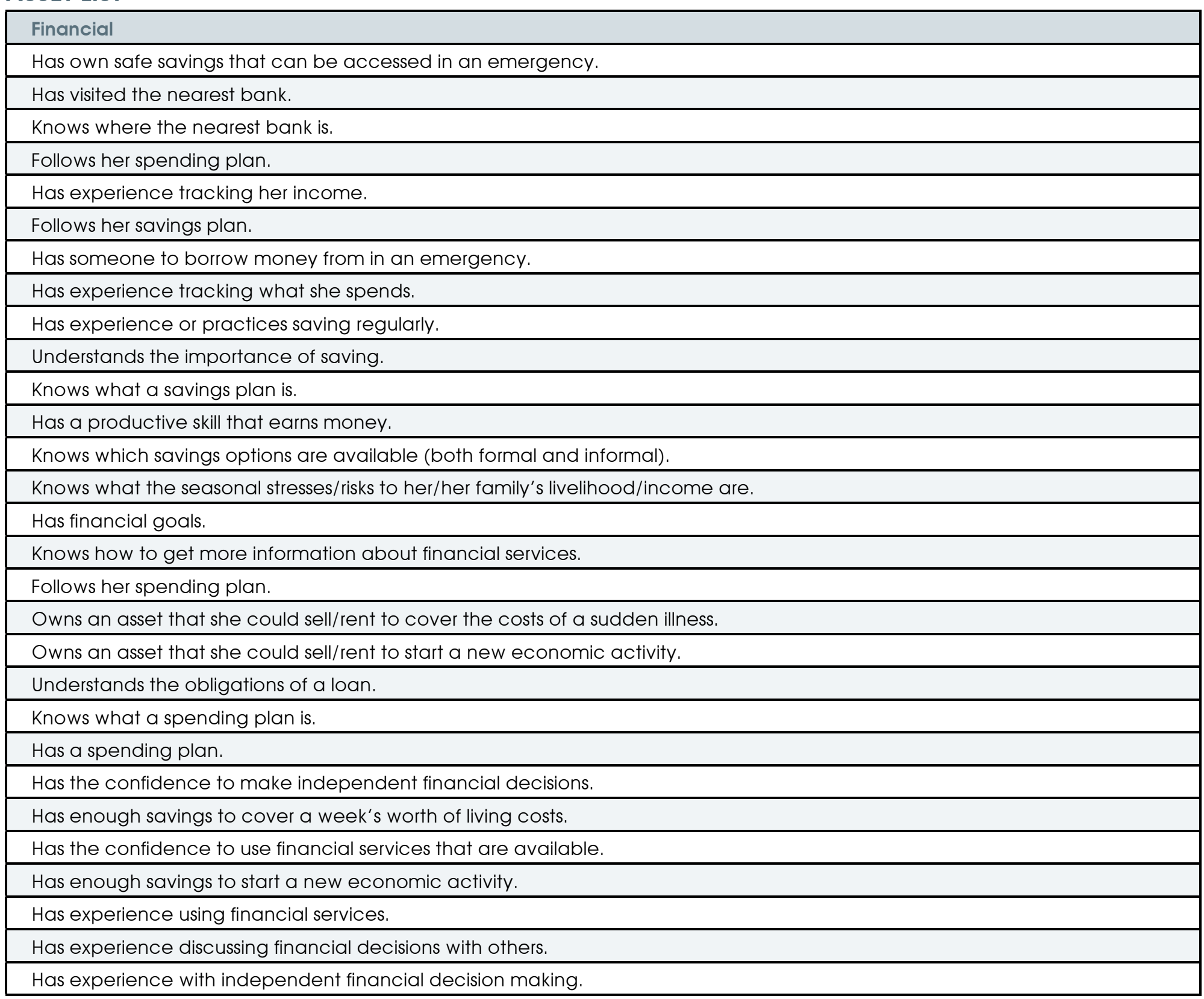


Health

Knows about her menstruation and the related health and

hygiene issues.

Knows how and when to wash hands properly

Knows what the nearest emergency health service is.

Knows the different ways in which someone can get HIV.

Understands the risks associated with certain types of unsafe

work

Knows the danger signs in pregnancy

Knows the danger signs in delivery.

Knows where to go to get an HIV test.

Knows when emergency transport should be called for a

woman who is in labor

Knows the signs of diarrhea in a child and how to treat it

Knows about different kinds of family planning.

Knows what a condom is/does and how to use it.

Safety

Has a plan to avoid harassment in the streets

Knows that teachers aren't supposed to ask you to come to

their homes to get a grade.

Knows where the nearest police station is

Knows when most girls are circumcised customarily

Has a safe place to spend the night away from home if she needs to.

Knows where to go if she is being threatened with an illegal marriage.

Knows to ask for a female police officer if she is uncomfortable with a male.

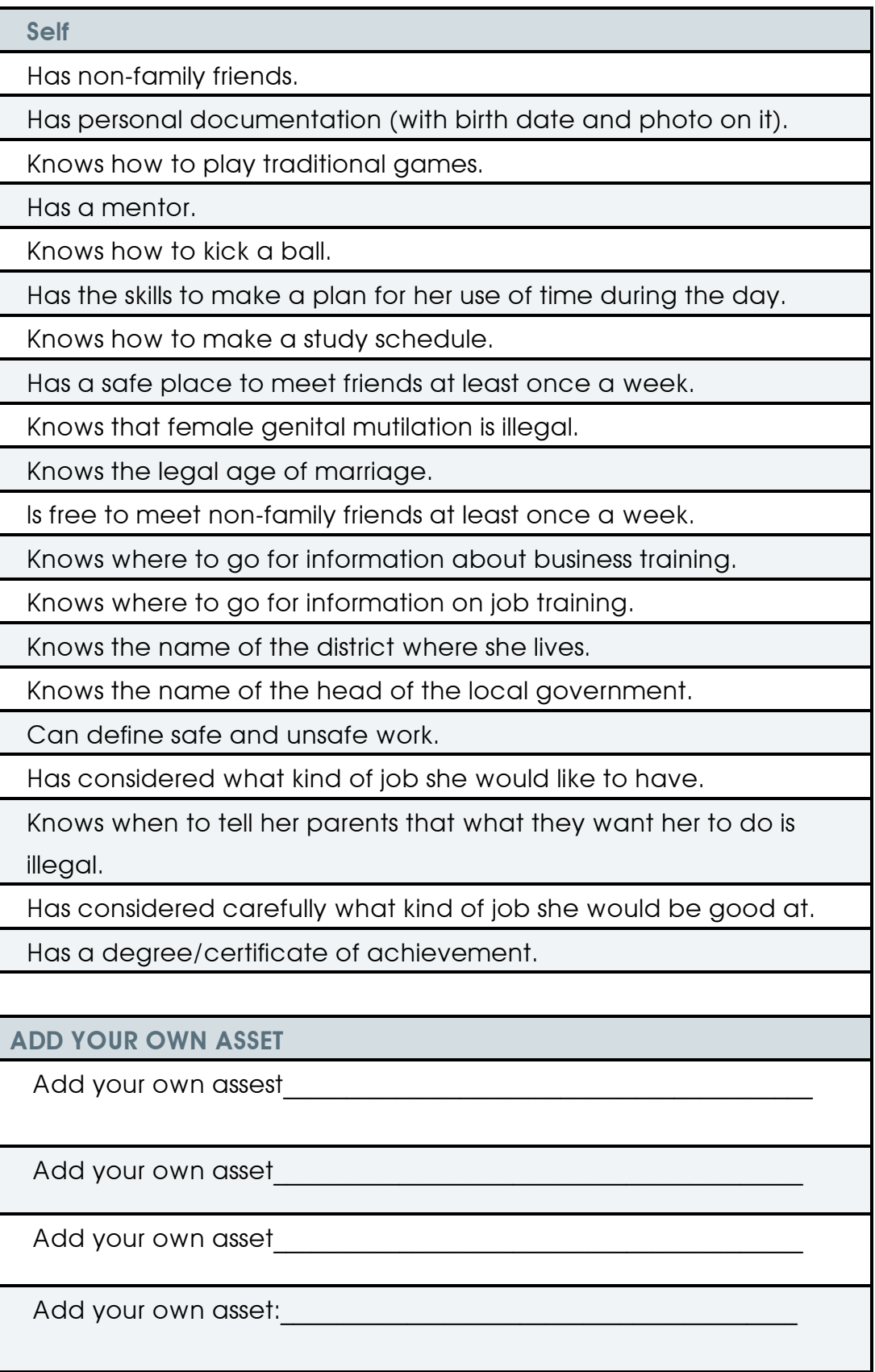




\section{AGE CATEGORIES}

Put each asset listed above under the age by which you think a girl in your program should have this asset.
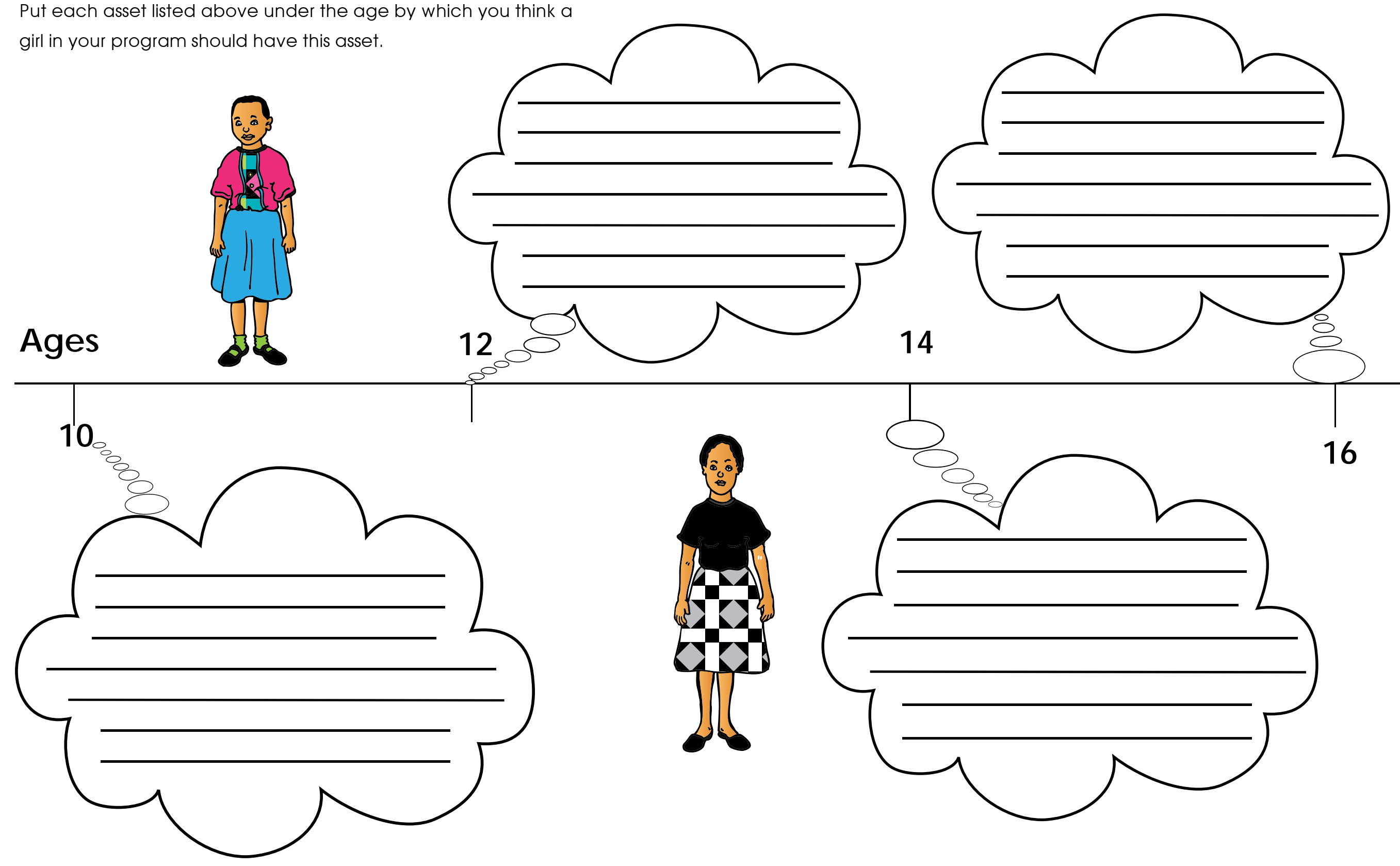


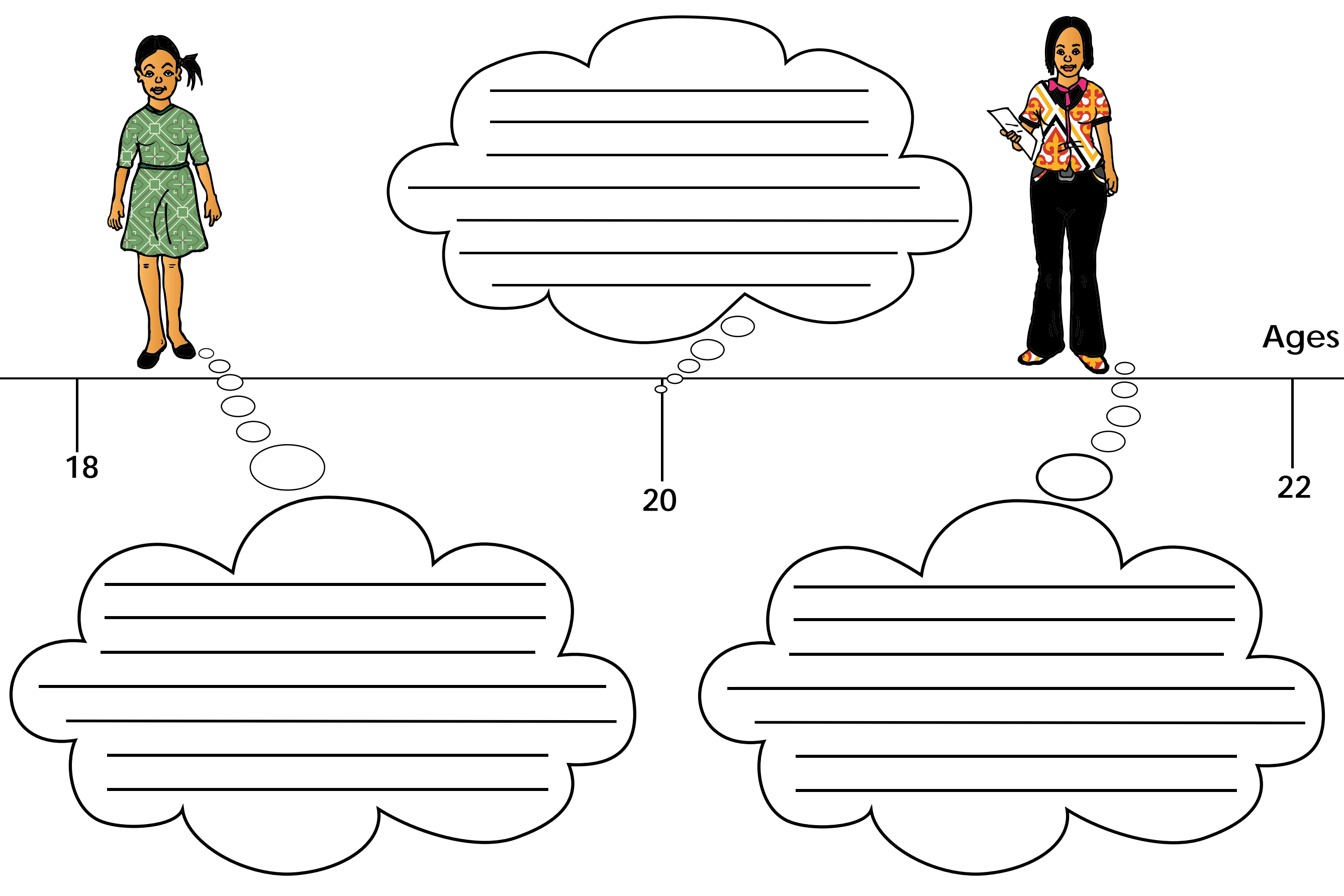




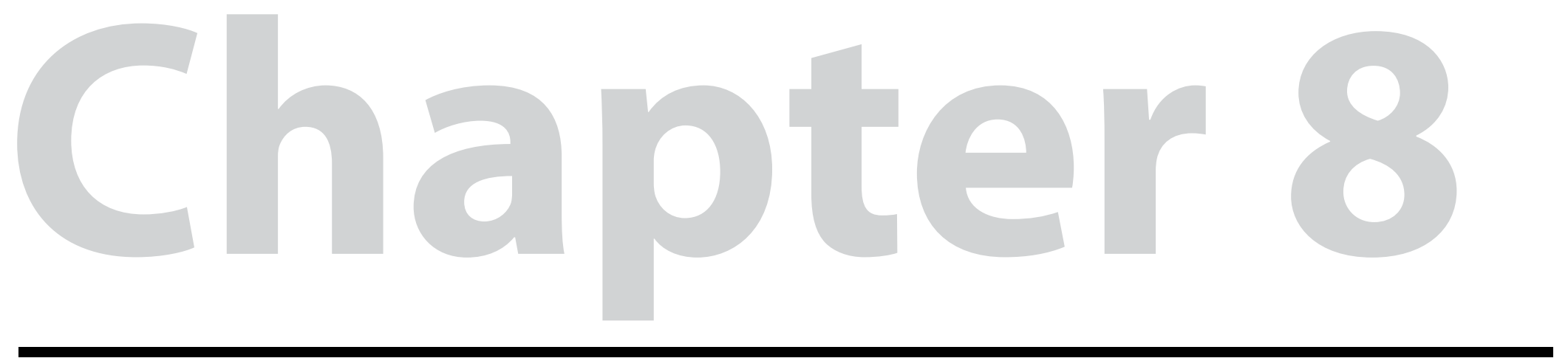

Economic strengthening programming

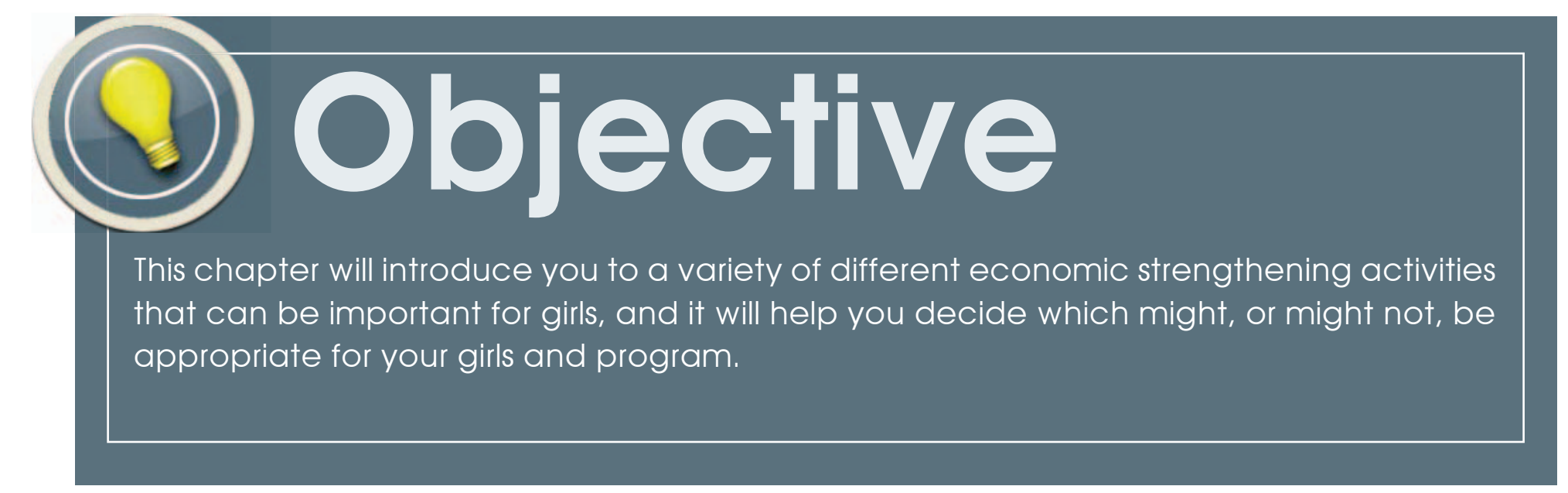



on specific vocations.

Economic empowerment programs help girls to practice skills and develop some financial independence-a critical factor in helping girls make healthy and productive transitions into adulthood.

What is more, some programs have begun to realize that there is a strong link between economic independence and health behavior. Programs that focus on HIV or reproductive health help girls gain the knowledge they need in these areas, and to build their leadership skills and self-esteem, but eventually realize that girls still have trouble putting that health knowledge into practice. Often this is not because they did not have the knowledge, but because their economic situation led them to a risky health behavior.

Some programs have begun to realize that there is a strong link between economic independence and health behavior. 
For example, in many African countries it is common for adolescent girls to have relationships with older men that involve some transactional dependence. The older man may help her to pay school fees, or he may provide her with gifts of clothing or food. A girl may know that unprotected sex puts her at risk of HIV, STIs or pregnancy, but it is hard for the girl to negotiate safer sex because she needs the money that the man will give her for having a sexual relationship with him - and he may not want to practice safer sex. Therefore, economic strengthening, or livelihood, programming is critical for not only economic outcomes, but also a diverse range of positive outcomes for girls, including health.

You can decide on the kind of economic strengthening activities you want to be part of your program by considering three factors: which girls you work with, your organization's competencies, and possible partnerships or linkages with other programs. Whole toolkits can be written about each kind of economic strengthening program (and some already have been!). Therefore, in this toolkit we will provide a short summary of the different kinds of economic empowerment programs with some questions that you can ask yourself as you decide how to proceed. You will have to make the decision if, and what, economic strengthening activities you want to include in your program.

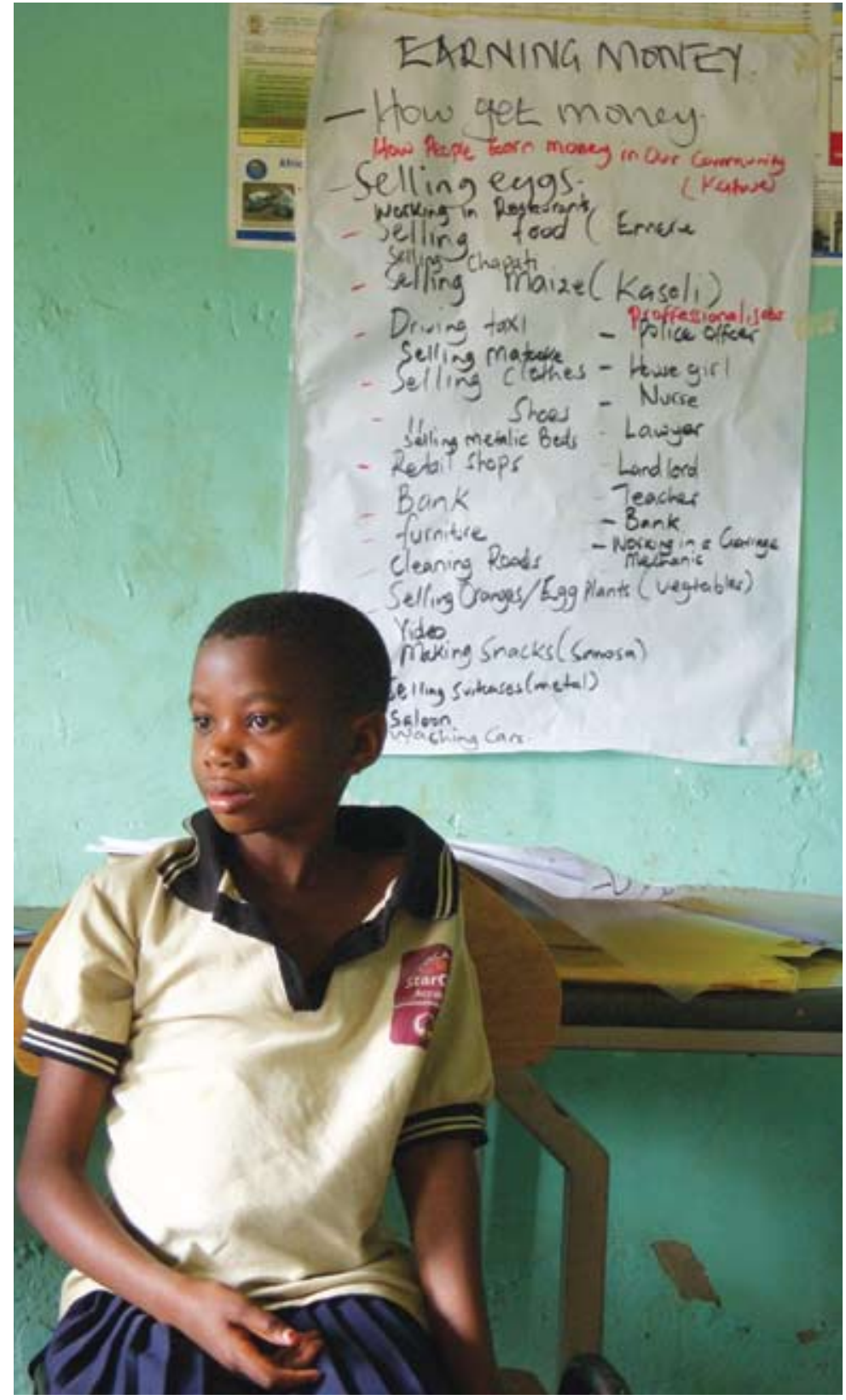


Also, remember, your program does not have to do everything. You can develop a strong system of referrals to other programs so that you can send girls from your program to a partner program in your community. A great example of this is vocational programming. It might not be the best option for you to start offering a tailoring course within your own program, even though many girls in your program are interested in it. A good alternative would be to locate several tailoring schools in your area, build relationships with them, and refer the girls who are interested there.

As you read the brief summary of the various economic strengthening program options, keep in mind the list of assets that you developed (see Chapter 7) and what you decided was appropriate and important for the girls you work with. Also be honest with yourself about your own organization's capabilities and whether or not you are ready to add an economic strengthening component. This will help you choose the right kind of economic empowerment program given the girls' age, context, and previous experience and exposure to economic empowerment activities.

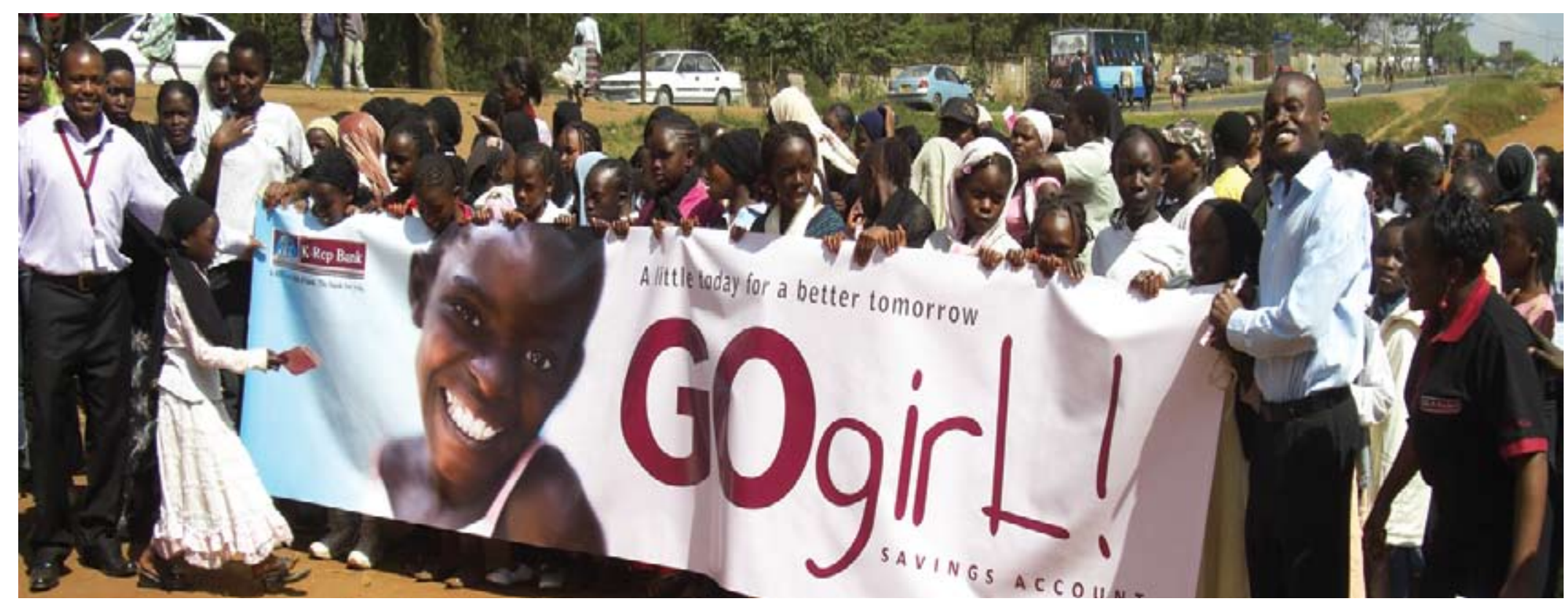




\section{Financial Education'}

Financial Education focuses on concepts of money and how to manage it well. It teaches knowledge, skills and attitudes that people can use to:

- Adopt good money management practices;

- Make decisions about earning, saving, spending and borrowing money and the use of financial services; and

- Set financial goals, budget money, track expenses, and save for the future.

Financial education is important for adolescent girls because it can be a good entry point for working with girls. In addition, the skills taught in financial education are easy to exercise and results can be seen fairly quickly. Typically both adolescents and parents like financial education and it is a good base or compliment to other livelihood interventions.

Good financial education will ideally lead girls to become financially literate. Financial literacy is the competence or capability to engage in economic transactions. It is a capability that helps girls to manage their money (through making wise spending decisions, saving and budgeting), prepare for life cycle events, manage risk, and take advantage of opportunities.

Other strengths of financial education are that it promotes awareness of personal financial issues and choices, encourages the development of financial goals, promotes a savings culture, and, in short, provides a basic life skill. Girls who are financially literate very quickly start to save - even if the amounts are quite small.

Financial education is a basic life skill - as important as communication, self-esteem, and basic health knowledge. Many of the life skills developed through health education programming - such as decision making, goal setting, and negotiation - are also taught through financial education.

Adolescence is a time when individuals form habits and become set in their ways. It is an important time to introduce financial education, especially when so many of adolescent girls' decisions are influenced by the power and financial dynamics in their relationships. Financial education can help them develop knowledge and change their practices at an early age to facilitate their transition into financial independence and therefore have a positive impact in many other arenas in their lives. If you look at the list of assets from Chapter 7 - many of them are built through basic financial education. 


\section{CASE STUDY}

sos Children's Village in Kenya is an example of a program where financial education provided a base from which they developed a more comprehensive livelihoods program for their girls. SOS in Kenya runs a Youth Centre that is open to youth from the surrounding slum communities. Upon realizing that they were not properly reaching adolescent girls from these areas, they started the "SOS Ladies Club." For the first few years the Ladies Club focused on HIV and SRH training. But the program soon realized that they needed to address the girls' poor economic situations as well and financial education was introduced into the training curricula. The girls became so enthusiastic about savings that sos helped them to form a savings club. Once the girls had money to invest from their savings, sos introduced entrepreneurship training, disbursement of small loans and a setting up group businesses. These elements were introduced one step at a time, starting with financial education and building on that base.

\section{Savings}

Savings activities tie very closely to financial education, as savings behavior is one of the key behaviors highlighted in financial education. Savings has incredible potential to change the lives of girls because it changes their perspective, from thinking only about today, or the present, or about daily survival, to thinking about and planning for the future. Many girls have said that simply having savings, even if they do not use them, makes them feel more secure and stable because they know that if something bad happened, they would be able to deal with the situation.

Savings activities can take a wide range of forms you have to think carefully about what is appropriate and available for your girls, as well as what you as a program or organization are willing to take on. One option is simply to encourage informal savings - for girls to save at home, in some form of a homebank/ piggy bank and for the program not to be directly involved. The program could create a register that tracks deposits and withdrawals and keep the 
money at the office (this takes on a level of risk and responsibility for the program). The program could open a group account at a local bank, but maintain the records in a register that is managed by the program. In this option it is possible to give girls responsibilities in maintaining the register, going to the bank to make deposits, etc. Another option is to help girls open formal savings accounts at local banks or micro-finance institutions. In reality, very few financial institutions offer savings accounts that girls under 18 can operate on their own. Most banks have a child savings account that a guardian operates on behalf of the minor.

Again, the format of savings activity will depend on the context of the girls in your program and the community you are working in:

- age of girls

- availability of formal financial services in the area

- the level of safety in the community (i.e. is girls' money safe in their own home)

If you are interested in pursuing savings as a program activity, the best approach is to discuss with the girls about where they feel comfortable keeping their savings, and then to explore the savings options in the community where you are. Then you can decide if you want to partner with a formal financial institution or do something more informa at your own organization.

For example, as girls who were becoming financially literate in the Kibera slum started to save, the insecurity in that community led them to request a more secure place to put their savings. Population Council and Microsave Consulting, Ltd. partnered with two formal financial institutions - K-Rep Bank and Faulu Kenya - to develop formal savings accounts for the girls so that they could have that security. For more information on that project go to: http://www.popcouncil.org/projects/48SafeSmartSavingsVulnerableGirls.asp 


\section{VSLA/ROSCA/Merry-Go-Round}

One variation on the savings activities are to help girls in your program organize a form of rotating savings - called different names in different settings (Village Savings and Loans Associations, Rotating Savings and Credit, Merry-GoRound, and many more - especially in each local language!). While there are many variations on the model, the general concept are that girls meet regularly in groups and commit to each contributing a certain amount of money each time. The money is collected, kept safe - often by a group treasurer or in a box locked with multiple keys - and then either given to one girl each week or given out as small loans. These groups not only help girls develop savings skills and accumulate lump sums of money, but also create a good "safe spaces" structure in that the girls meet each week and develop their social networks. The group meetings can also be a time for financial education or training on other basic topics of interest for the girls.

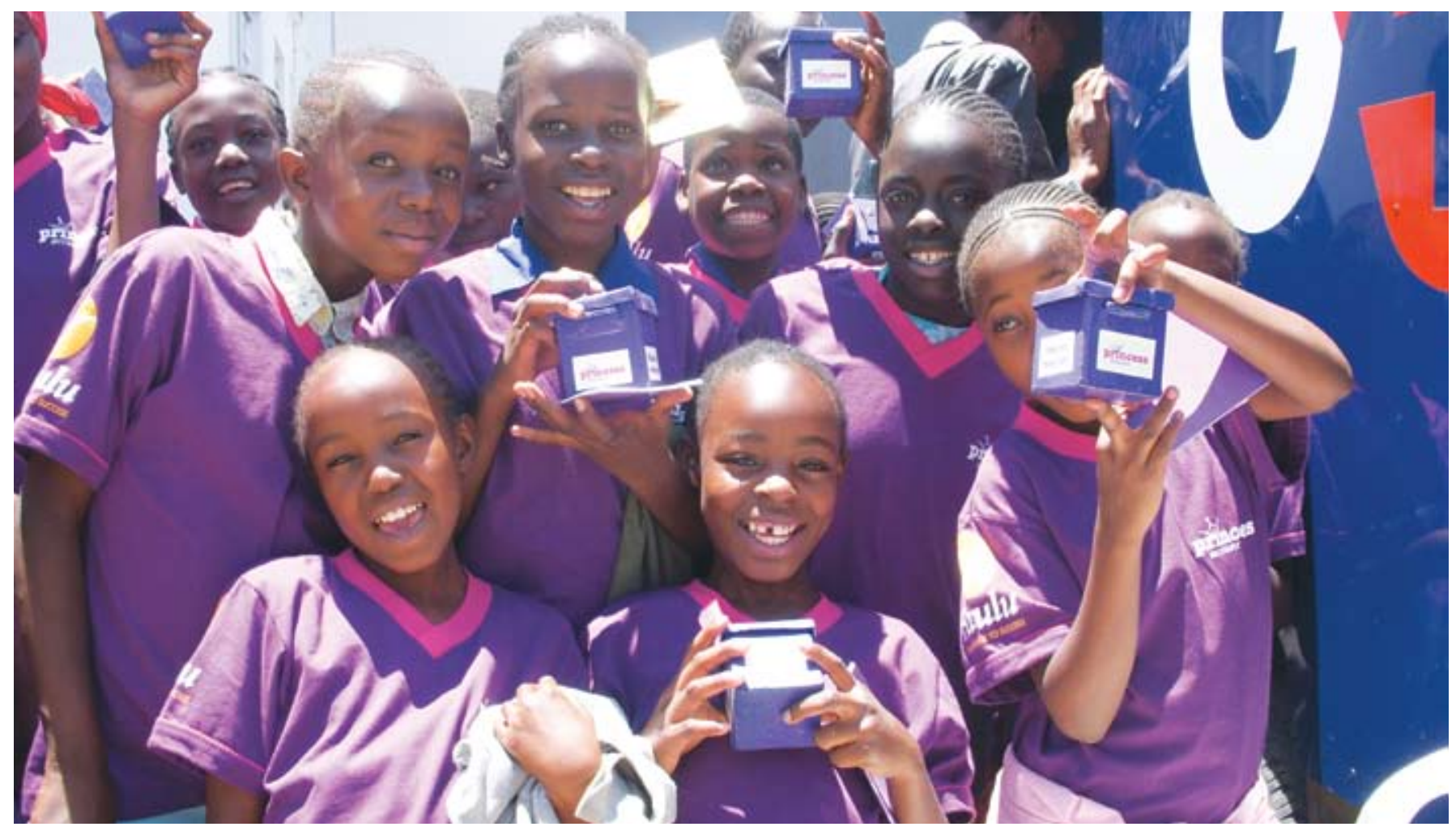




\section{Vocational Training}

Vocational training involves providing girls with a skill in a certain field of employment-for example computer skills, web design, tailoring, carpentry, counseling, hairdressing, car mechanics, etc. Providing vocational training is a very time- and resource-intensive venture because it requires equipment, trainers who are skilled in the profession, space, and more. However, many programs do offer vocational training.

The most common challenge for vocational training programs are around over-saturating the market and gender norms. First, programs often train girls in skills without first determining whether there is need for more people with that specific skill. It is very common to find programs that will train 30 girls at a time in hairdressing-but the question is, after they finish, are there 30 jobs for hair-dressers in that community? Take those issues into careful consideration because the overall goal is not just for girls to have the skill, but to actually be able to translate that into an income generating activity. The second challenge is the issue of gender norms, and tending to stick closely to the "acceptable" skills for girls_tailoring, dressmaking, hairdressing, catering, etc. One problem, already mentioned, is that there may not be enough jobs for all girls with the same skill. Secondly, it could be beneficial for girls to move into fields that are typically considered male, which often have more job opportunities and higher wages. Move carefully into this area as the girls will need support and supervision - the last thing you want to do is put them in a more vulnerable position!

One additional challenge is that girls need more than vocational training. If you refer back to the list of assets, a productive skill was only one of many assets that would help girls make a healthy transition into adulthood. So, whose responsibility is it to provide those other program activities? Many vocational training programs provide additional life skills training. You can use them as a referral program, knowing that the girls will get more holistic programming at your program, and the vocational skill at another. There is no right answer to this, except to be aware of these challenges and maneuver the situations accordingly. 


\section{CASE STUDY}

The Kibera Girls Centre, a program of the Kenya Girls Guides Association, is a vocational skills training centre for out-of-school adolescent girls ages 15-19. The program runs for one-year and the beneficiaries are trained in all the elements of tailoring, financial education, catering, life skills, sexual and reproductive health, crafts, environmental studies, entrepreneurship and guiding. Through years of experience, KGGA realized that one of the major challenges was that not all graduates of the program could secure employment. They therefore sourced for funds and opened a garment production unit on site at the centre that girls could be employed at to produce uniforms for Kenya Girl Guides association members, for one year post graduation from the program. The production unit has expanded to a rental house outside the centre from where beneficiaries of the program are working. Seeing the success of the production unit also led the program to obtain funds to open a bakery for program graduates who were not benefiting from the garment production unit to have a source of income generation in the one year transition period after the vocational training.

Another example of how a program addressed the need for vocational training is the Safe Spaces program which works with girls from the Kariobangi and Maili Saba slums in the Eastlands area in Nairobi. Some of their older girls expressed an interested in developing a vocational skill in a nontraditional area. The program linked the girls to a school for car mechanics and enrolled them in the program. They also provided them with the emotional support to enable them stay in a program that was not considered typical for women. Through their persistence and skill, the girls quickly became accepted in the school and are now planning to open a female-owned garage upon graduation 


\section{Entrepreneurship}

Entrepreneurship training teaches girls the skills of developing and running a successful business. Often referred to as business development skills, these trainings help girls learn how to develop a business plan, decide what kind of business will do well, how to price their product, how to manage the income and expenses of the business, and how to market their product to clients and more. Some entrepreneurship programs then help girls with start up funds for their business or link them to loans.

However, girls typically have a wider range of needs than just business development skills, and programs will have to make the decision on whether they should also train girls on various health topics, life skills, financial education, leadership, etc.

One critical piece of a good entrepreneurship program is also helping girls to decide if they want to be entrepreneurs. Not everyone has the right personality for, or the desire to be a business owner. Girls must understand what the pros and cons to starting a business are and then make their decision accordingly. Often there is a tendency to assume that everyone wants to start a business, and that it is the only income generating opportunity available. That can be a mistake.

EMpower published a toolkit specifically on this topic in 2010. The Girls Entrepreneurship ToolKit, "It's Her Business: A Handbook for Preparing Young, At-risk Women to Become Entrepreneurs" can be found at www.itsherbusiness.org.

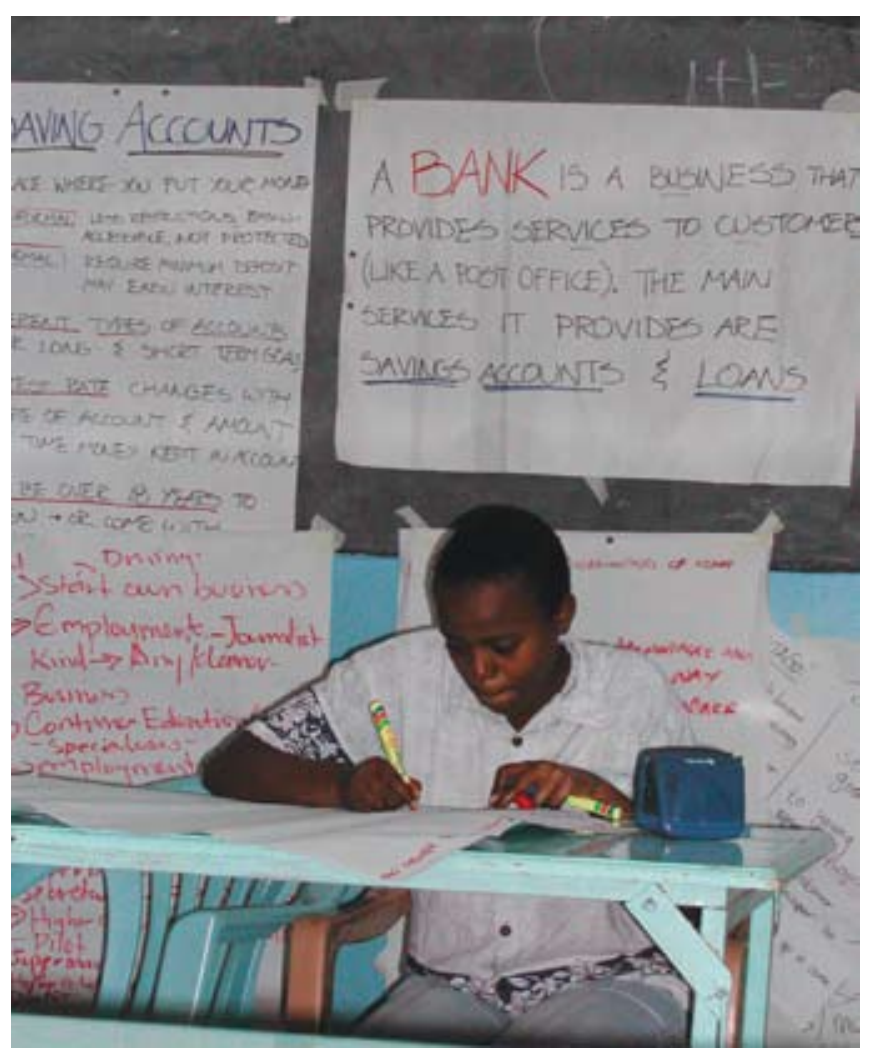




\section{CASE STUDY}

One example of a successful entrepreneurship program for adolescent girls is Technoserve Kenya's Young Women in Enterprise program. The Young Women in Enterprise (YWE) program teaches business and life skills to more than 3,000 adolescent girls and young women both in and out of school, ages 15 to 22, in low-income urban areas. It helps them to steer clear of problems such as HIV/AIDS and to thrive by creating or finding work within employment-generating businesses that can support Kenya's communities. The YWE program comprises four components: training on using tools to plan, implement, and manage a small business - including business plan competitions which identify promising business ideas and enable talented entrepreneurs to further advance their businesses; links to financing, with an emphasis on the importance of savings; mentorship guided by leading women entrepreneurs, among others; and, internship/employment preparation and placement.

The YWE program started in 2006 with a pilot that equipped 300 girls with business skills. In the expansion of the program, to help girls move their business ideas to reality, the program introduced a savings component upon realizing girls had no money to start businesses and they were afraid of borrowing. YWE also introduced an experiential business component where girls in groups of five receive small grants to experiment on a business idea. During the pilot period, over $70 \%$ of the girls were only interested in finding employment and not starting their own business, therefore, employability training was added to equip them with basic job application and interviewing skills to increase their chances of finding and keeping jobs.

Girls who join the program are 15-22 years, with 8 or more years of formal education. The training helps girls discover their entrepreneurial potential and develop it. Girls are also recruited through vocational training institutions because those who have a skill are more likely to start a business than those without. 


\section{A cautionary word about credit and seed capital}

Loans or grants to start businesses have the potential to be very positive for adolescent girls - ONLY if they are given to girls who are old enough, skilled enough, ready to run a business and fully understanding of all the obligations for their loan, grant and business.

If you are considering a small loan or seed grant program, proceed with caution. Make sure the girls are prepared. Make sure only the girls who are prepared take loans. Make sure that they have a strong background of financial education, personal money management, and savings experience before venturing into the world of credit and business management. Make sure that they have the proper ongoing mentoring and support that will ensure their success and help them to work through the challenges they will surely face.

Do

- Strongly consider including basic financial education training

- Assess the economic empowerment needs of the girls in your program based on their age, situation, and economic opportunities

- Assess the ability of what your own organization can realistically deliver yourselves, and what needs to be referred out

- Build networks with other organizations in your community that offer economic strengthening activities

\section{Don't}

- Add an economic strengthening component if you don't have the capacity to run it yourself 


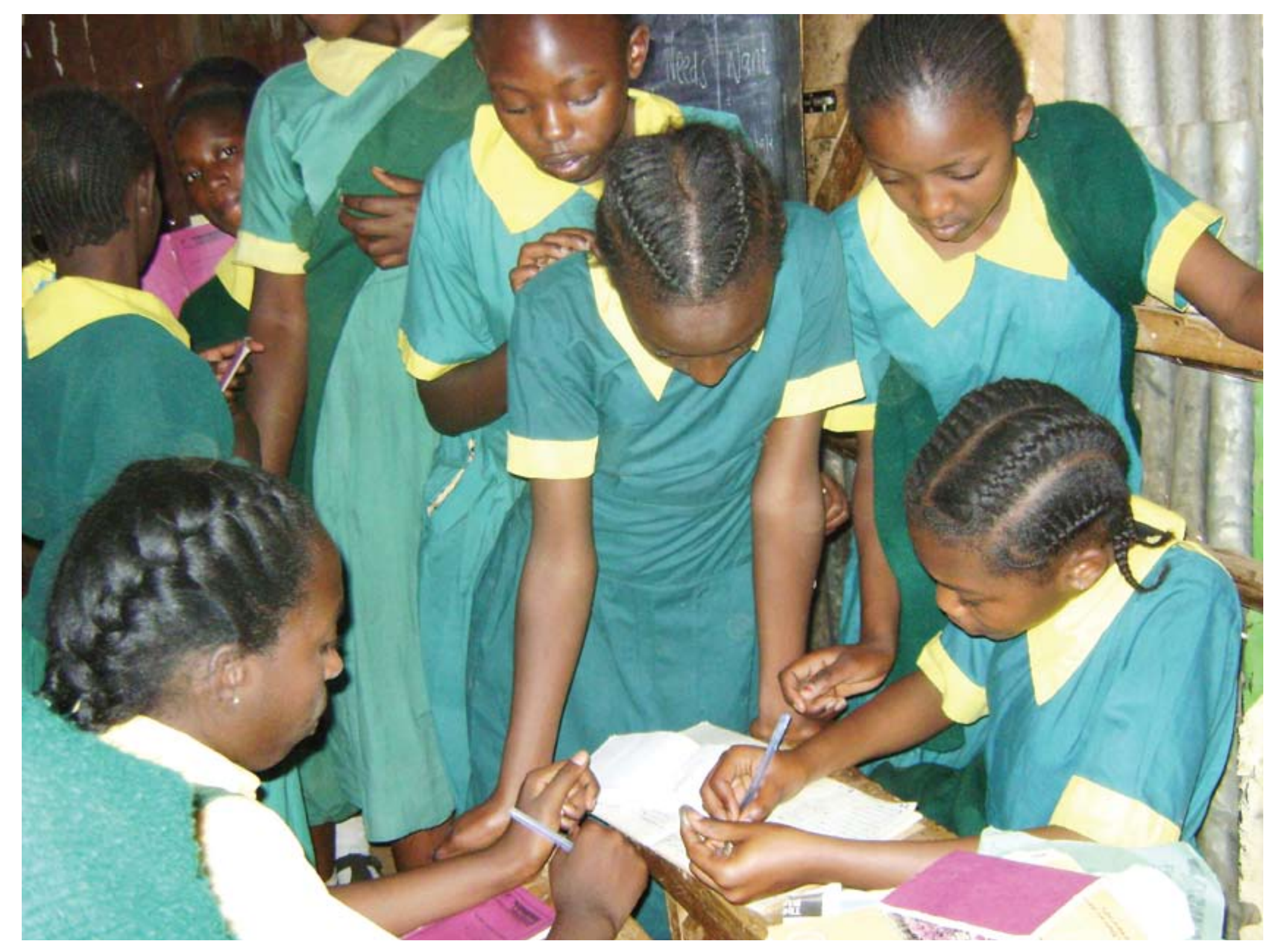




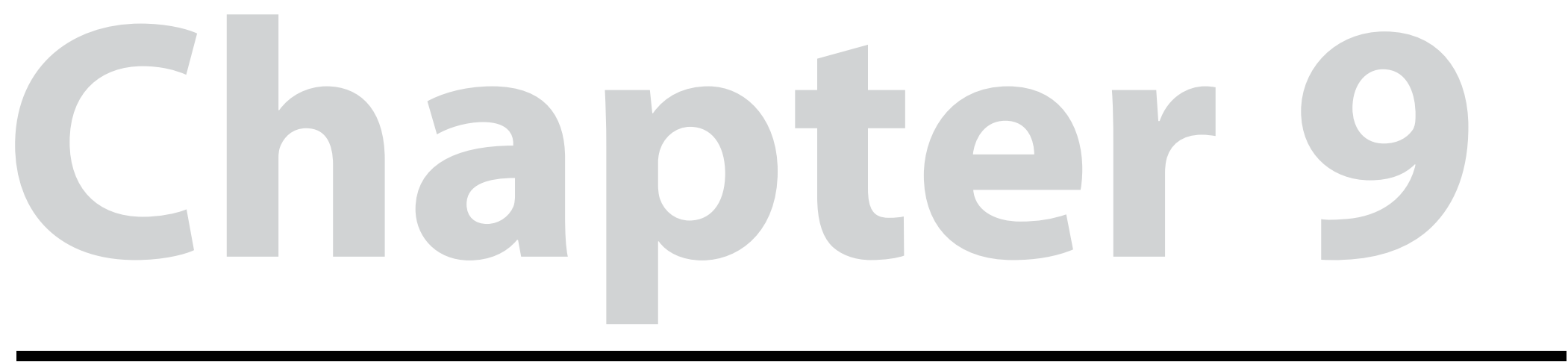

Reproductive health and HIV information $\&$ clinical services

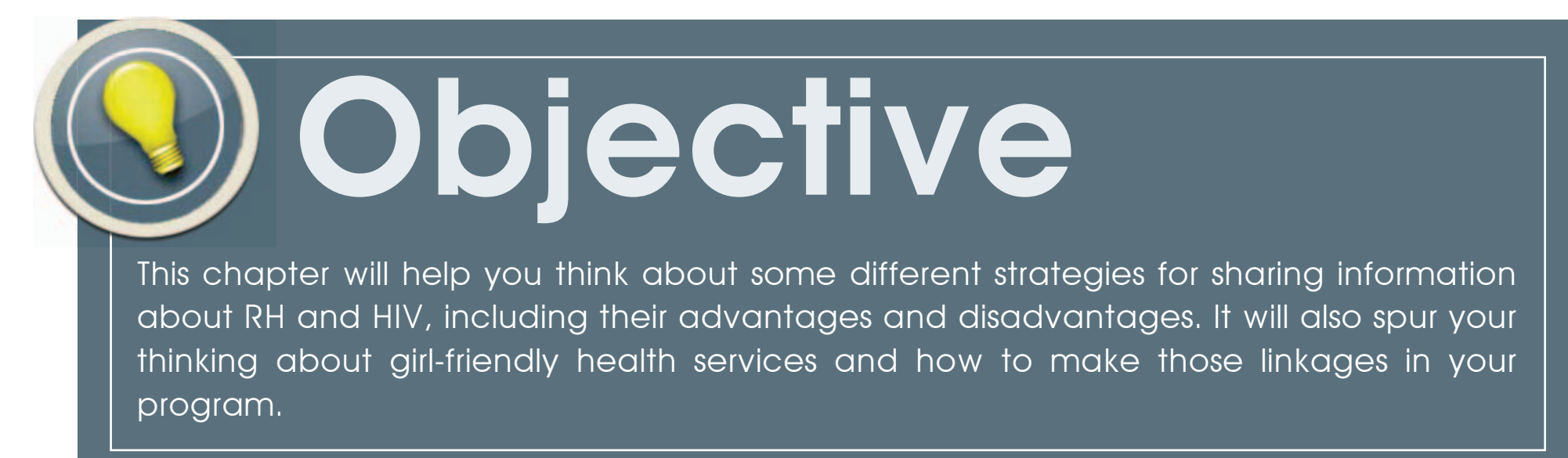


Health education is a critical topic for adolescent girls. Knowledge about their bodies — how to understand their bodies, how to protect themselves from various diseases and how to take control of their health-is important.

For many girls, their body is an asset that is used for a wide range of activities-getting grades, getting attention and getting support.

Many programs that work with girls focus mainly on reproductive health issues. You will have to make the decision if, and what, health-related education or linkages to health services you want to include in your program.

This chapter will give an overview of the various health-related topics that are beneficial for girls and some of the ways through which the information can be delivered. We will also highlight issues surrounding girl-friendly clinical services.

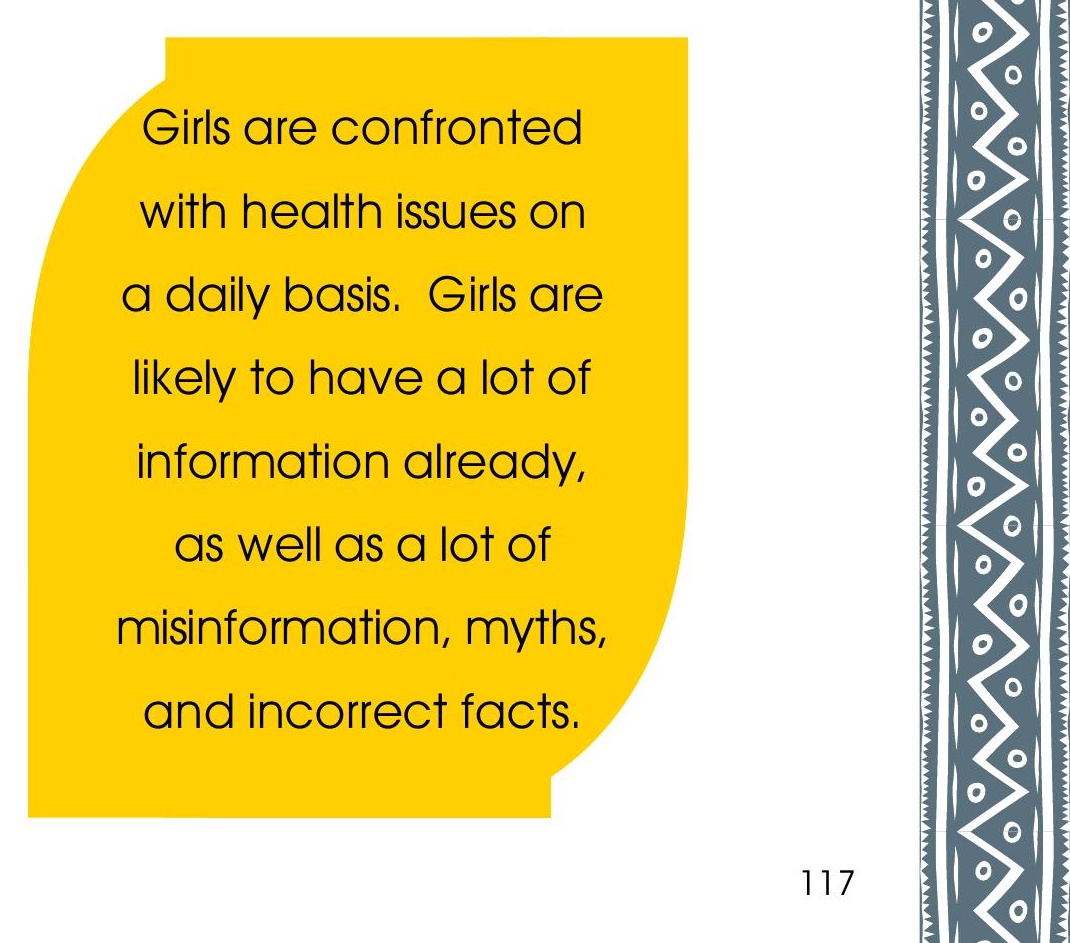


If you decide to provide health education, health issues are taught most effectively when they are presented in nonjudgmental ways and not in a lecture format. Girls are confronted with health issues on a daily basis. Girls are likely to have a lot of information already, as well as a lot of misinformation, myths, and incorrect facts. They also have a lot of questions. When preparing the content of what you want to teach girls and selecting a curriculum, carefully consider the importance of the setting for the sessions: Will it be comfortable for girls? Is there enough openness so that they feel that they can ask any question without being judged or laughed at AND get the accurate answers?

Review existing materials and learning tools. See the resource section for references to educational materials and curriculum on sexual and reproductive health and HIV.

The common topics that fall within sexual and reproductive health and HIV education include:

- Adolescent growth and development

- Sexuality

- How to access health services

- Contraception/family planning

- Teenage pregnancy

- Life skills - self esteem, communication skills, peer pressure, relationships

- Drugs and substance abuse

- Sexual and gender based violence (SGBV)

- Gender and harmful traditional practices, including early and child marriage and female genital mutilation (FGM)

- Counseling skills 
Remember, as with all activities, the content and delivery will change with the age range that you are targeting. Younger girls will be most interested in different topics (in-depth focus on adolescent growth and development and a basic introduction to the rest) than older girls (more focus on sexuality, teenage pregnancy, and family planning).

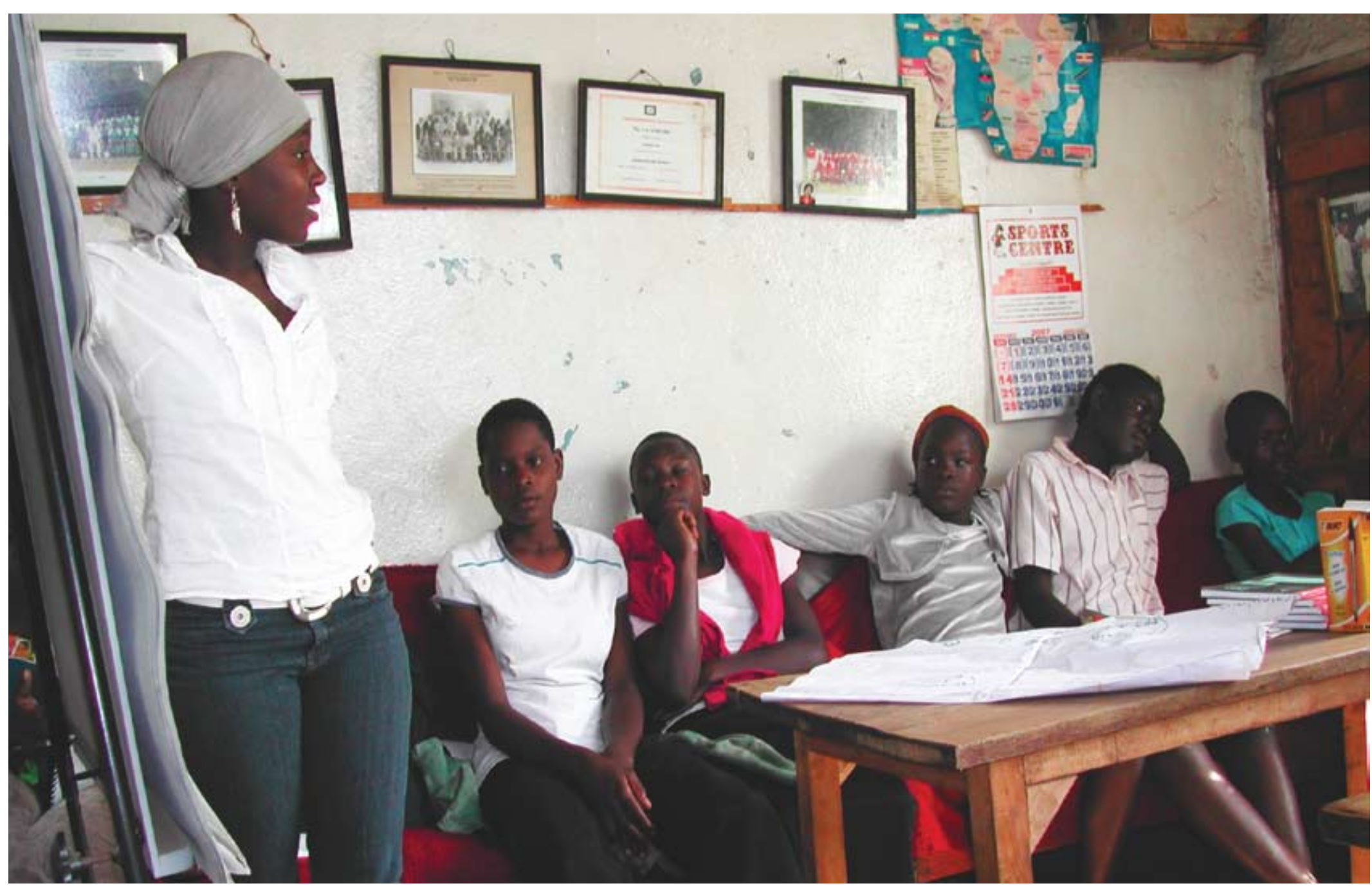


There are also a number of methods through which health information can be delivered. Here is a list of each of those methods along with their advantages and disadvantages

\section{Television and Radio}

\section{How Do We Do It?}

Two common uses of television and radio are 1) educational show/soap operas and 2) informational public service announcements/commercials.

\section{(3) PROs}

- can reach a wide audience

- uses technologies that are already common/people use

CONs

- have to be watching/listening at the time of the show or announcement

- expensive

- doesn't allow for interaction, response from girls (unless it's a TV show that is watched and then discussed at the program)

Key Tips to Using This Method

- make sure that you are using TV channels and radio stations that are popular with the kind of girls you are trying to reach (local radio stations are great for this)

- make sure they are at times that girls are watching/listening

- consider having a call-in number/sms option so that girls can respond/interact/ask questions

- test your show/announcement with some members of the target group ahead of time to make sure that it carries a relevant message for them. 


\section{Drama/Poems}

How Do We Do It?

Role play, or acting out situations in which girls deal with various reproductive health/HIV issues, and

either solve them well or not well, can be a very educational tool for getting girls thinking about different $\mathrm{RH} / \mathrm{HIV}$ issues, the situations in which they occur, and possible solutions for the problem. In addition to dramas, these issues can be written about and performed in a poem, song or choral verse. This can be done within the program itself as a teaching tool for the girls, but girls can also rehearse a particular scene and go out and perform it in the community (a form of community outreach). They should be prepared to facilitate a conversation about the topic after the show!

\section{PROS}

- a way to make the girls loosen up and feel comfortable with a topic

- a good way to interact with the community

- a way for girls to also showcase their talent, express themselves creatively

\section{CONs}

- not all girls feel comfortable expressing themselves through drama

Key Tips to Using This Method

- it is important to guide the content of the drama so that it remains educational and accurate. The discussion is how girls (or the community) will process the information. 


\section{Peer Education}

How Do We Do It?

This involves training a subset of the girls to be trainers/facilitators so that they can pass on the information to other girls. Please see chapter 5 on Leadership Development for more information about this.

PROs

- can reach a wide number of girls

- girls may feel free with their peers

CONs

- it can be costly to train the peer educators

- other girls might not respond well/with respect if the peer educators are their own age

- if there is no structure in place to maintain the peer educators, you will constantly be needing to replace them with others

- peer educators must be very closely monitored and supported to ensure quality of the sessions

008 Key Tips to Using This Method

This is the most effective when the girls doing the training/facilitating are a bit older than the girls they are teaching. Also, supporting the girls doing the training is critical. See Chapter 5 for more guidance on this strategy. 


\section{Information, Education, and Communication (IEC) Material}

How Do We Do It?

Use written materials to transfer information - posters, comic books, brochures, fliers, etc. These can be developed by your program, and also often are available through local clinics, other NGOs, health/ education ministries, etc. that you can get these for free.

(3) PROS

- a quick, easy, cheap way to deliver information

- has a wide coverage

- accurate information

- something girls can take home with them

\section{CONs}

- the language isn't always appropriate for young girls (i.e. too complicated)

- if you have to produce it yourselves it can be costly

105 Key Tips to Using This Method

Make sure the IEC materials you distribute are appropriate for adolescent girls in terms of the content in them, the level of the language, and the key messages. Have enough copies on hand so girls can read, and if they want, take home. 


\section{Games}

B) How Do We Do It?

Games can take a wide range of forms-mostly reinforcing knowledge or facts about a certain topic that girls have been taught. These can be quiz games, matching games, etc. Many RH/HIV curricula will come with examples of these.

PROS

- entertaining and engaging

- illiterates can participate

- promotes active participation

CONs

- misinformation can come out without easily being corrected

- time consuming to prepare

- risk dominancy by stronger members

- risk of losing the theme as the game is played (i.e. girls more into the game than the topic)

aff Key Tips to Using This Method

For this to be both fun and educational the game will have to be tightly facilitated-to ensure that girls stay on target, misinformation is corrected, and all girls are given a chance to participate.

Prepare the games ahead of time! 


\section{Debates}

How Do We Do It?

Divide the girls into two teams and assign them each one-side of an argument - i.e. If her boyfriend refuses to use a condom, a girl should leave that relationship - agree/disagree, or if a girl's uncle abuses her she should go to the police - agree/disagree. Allow each team to make an opening argument, then they can go back and forth a couple of times, and then make a final, summary argument.

BROs

- it can be lively and engaging

- it presents both sides to an issue

- improves girls' public speaking skills

CONs

- it can be hard for accurate information to come out

- the arguments can get out of control

(IS) Key Tips to Using This Method

The facilitator must keep close control of the debates as the arguments can get heated! Also, at the end,

make sure to correct any misinformation that has been given so that girls leave knowing what were the facts and what was opinion. 


\section{Group Discussion}

(i) How Do We Do It?

Get the girls in a group together, ideally seated in a circle, and allow them the open space to ask any questions, present challenges they have been facing, etc.

\section{PROs}

- lets the girls decide the discussion topic

- relaxed, non-classroom environment

- can address misinformation that girls might have

CONs

- not all girls will feel comfortable to open up

of Key Tips to Using This Method

Give each girl a chance to ask or share - otherwise, the quiet girls might not participate. Also, you can let other girls in the group try to answer the questions - but always be prepared to correct misinformation! 


\section{Clinical services}

Getting clinical services is not always an easy task for girls. First going for services means a conscious acceptance that they are 1 ) sexually active, 2) at risk of a health problem/STD, and/or 3) experiencing some symptoms. This is often a big mental step for girls to make. Other barriers include cost (of transport to the clinic and services themselves), worry about being stigmatized at the clinic and treated poorly by the staff, or being seen by the community around the clinic and stigmatized that way.

Linkages to health services for girls

Unless you provide clinical services yourselves, your program is going to have to develop relationships with girl-friendly clinics and make referrals for the girls in your program. Perhaps you will need to provide transport for the girls. Perhaps you can work with the clinic to provide special fees or exemption from fees for your girls. Perhaps you can offer to work with the clinic to help them become more "girl-friendly" if they are interested.

One strategy that has worked with some girls programs is to take a "field trip" to a local clinic (who knows ahead of time that you are coming!) with the girls. Often girls have not had a positive experience with health services in the past, so taking them that first time, helping them get linked to the health service sector, will help her to continue going in the future. 
How do you know "Youth Friendly Services" are also GIRL friendly?

Youth friendly health care services have a number of qualities that are important for both girls and boys, and some qualities that make them particularly girl-friendly. Below is a general list of characteristics that make a clinic girlfriendly (GF), which also overlap with many qualities of general youth-friendly clinical services (YFS):

- Providers should embrace professionalism and confidentiality-as well as be non-judgmental (from the clinic manager to the watchmen). There are so many stories about nurses at clinics scolding girls for being sexually active when they seek STI testing instead of remaining professional, encouraging them for seeking medical treatment, and helping them to get the services and care they need. (GF + YFS)

- Services offered should be relevant to girls (and young people). For example treatment for a range of sexually transmitted infections that girls are vulnerable to and family planning methods that girls can use themselves (for example, offering injectables, emergency contraception, and oral contraceptive pills, not only the male condom) should be available (GF + YFS)

- Should provide girl-friendly recreation and education services as they wait for services (i.e. not just a pool table or a television set with a football game showing, but also girls group discussions or educational videos) $(\mathrm{GF}+\mathrm{YFS})$

- Counseling services should be free and to make them girl-friendly ensure that there are female counselors on hand (GF+YFS)

- Have female medical staff-some girls may prefer to talk to female service providers only (GF)

- Location of clinical services should be in a place where girls can walk in without it being obvious that they are walking into a building for clinical services-i.e. within the building of a broader program, or within a general health clinic so the problem could be malaria, diarrhea, etc-not only SRH related. In addition, if a clinic is located in an area that is unsafe for girls (i.e. near a bus stop where a lot of drunk men idle about), girls will be unlikely to go there. (GF) 
- Location of the clinic is important-some girls prefer to leave their community so that they are not recognized as they walk in. Therefore, an SRH clinic right in the heart of the community where they live is not always preferable. In our experience, girls are willing to travel quite a distance for quality, affordable, and girl-friendly services $(G F+Y F)$

- Service providers should be youthful and knowledgeable on related youth issues. It important that the clinic have ongoing capacity building for staff so that they are always current with the issues relevant to girls (YF)

- Centre should be accessible-opening, closing hours should be times when girls are able to come for services, and should be posted and made well-known to girls (YF)

- Should provide comprehensive services (one-stop-shop)—not one single service: Example, counseling, testing, treatment and referral systems should be available so the girl doesn't have to shuttle around from place to place (YF)

Should have a good referral system (YF)

IEC materials such as brochures, fliers and posters should be available at clinic (YF)

(11,

- Access to interpreters (especially if that is a need in the particular community), and staff that understand youth "slang" (YF)

- Cost should be youth-friendly and affordable-or even FREE! (YF) 
Integrated model of care

One successful model of providing clinical services to girls is to provide the services at the same place your program activities happen. This is not possible for many programs, but if it is, it's worth exploring. Having the services on site eliminates the barriers of having to get to the clinic, or being worried what others will say when they see you walking in. Services do not have to be available every day.
K-MET's Sisterhood for Change (SFC) program is an example of the integrated model of care. Atthe same location where they conduct vocational training courses on tailoring, hairdressing and catering, the program established a room where clinical services are offered. Once a week, a youthful health provider whom the girls are comfortable speaking with is available to see girls from the program, as well as their peers from the community. Services are provided at one-fifth the cost for SFC members and are subsidized by the revenue from K-Met's general community clinic. Girls can receive family planning counseling and services, STD testing and treatment, HIV counseling and testing, and referrals for HIV treatment. For more general treatment (i.e. malaria, diarrhea, etc.) they are referred to K-MET's community clinic where their babies can also receive services. After about a year of operation the clinic was moved to a location about 100m from the training site to enhance access to services by girls who are not in the program, while maintaining the confidentiality and youth friendliness of the site. 
Do

- Make sure the content and methods for teaching RH/HIV topics is adapted to the age of the girls you are working with

- Make linkages to girl-friendly health services that the girls in your program can access and consider taking girls there for a first visit "field trip"

\section{Don't}

- Deliver information on RH/HIV in a judgmental way 


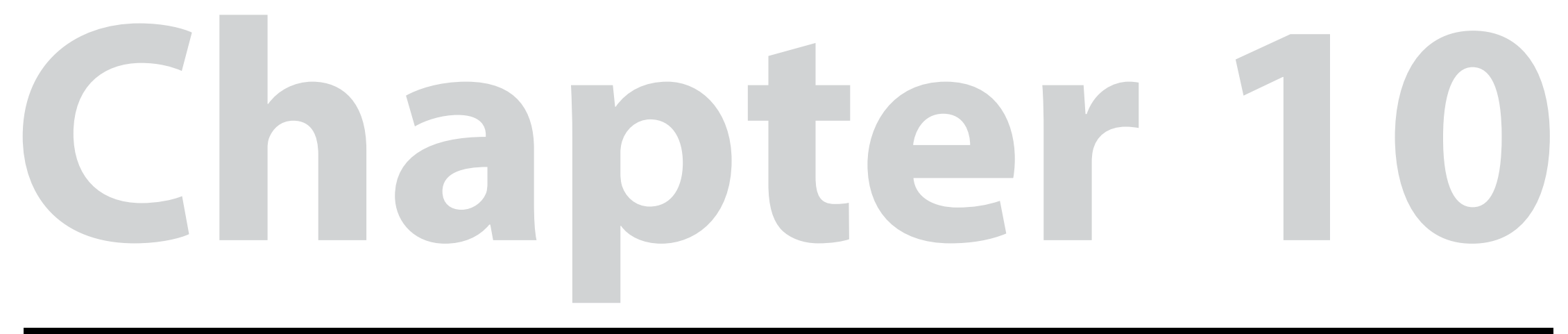

\section{Addressing sexual and gender based violence}

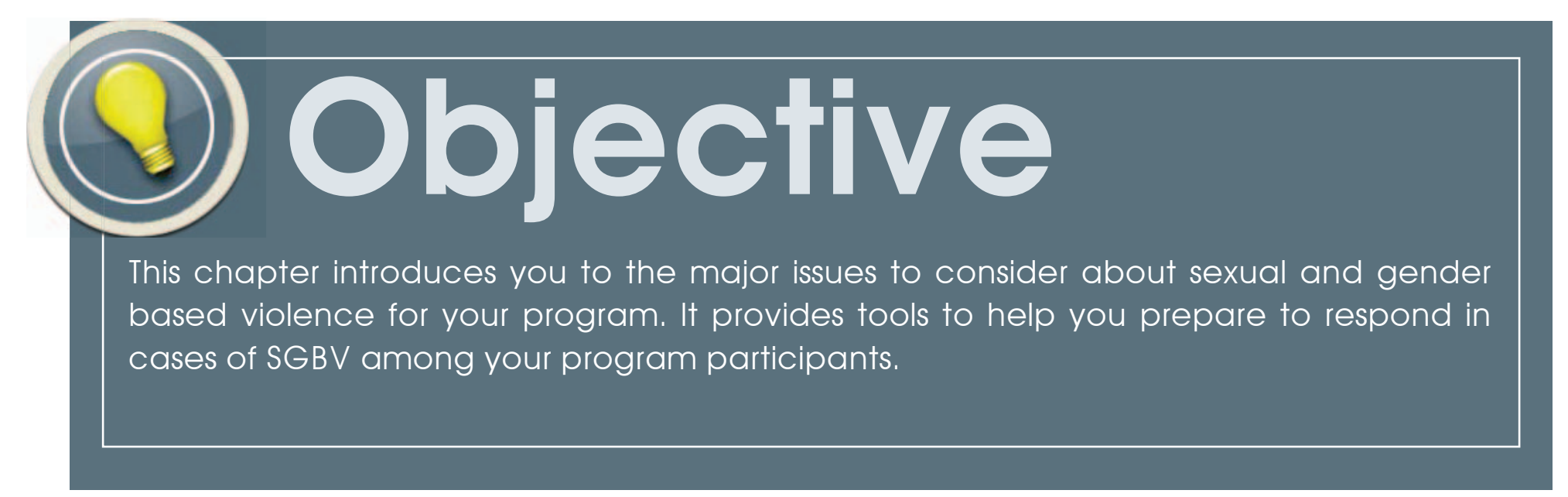


This chapter is a short overview of what a program could do to prevent and address sexual and gender based violence (SGBV). Much has been written about SGBV, both in terms of prevention and response (see resource booklet).

Also, each community will have a different set of resource providers-clinics where girls can go for medical services, the police station with a child desk or SGBV reporting unit, legal assistance, etc.

SGBV issues can be thought of in two categories: prevention and response. On the prevention side, we have already covered many of the things that you can do as a program to help girls prevent SGBV. Building girls' social, health, financial and physical assets gives them the skills, knowledge, self-esteem, and financial means to avoid those situations as best as possible. The Safety Scan Tools in Chapter 3 will help you work with the girls to understand what makes them safe and unsafe, not only in terms of physical locations to be avoided but seasons, times and situations that increase or decrease safety.

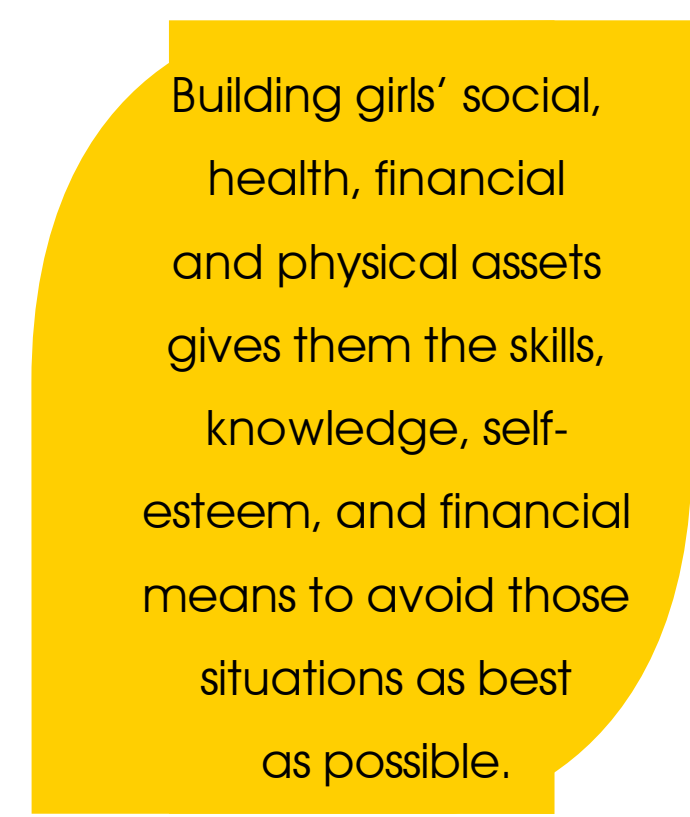


Through the results of the safety scans, your program can design strategies to protect girls in the places, seasons, and situations that they feel most unsafe. For example, if they have to pass through an unsafe place to get to the program, help them develop strategies to walk in groups. If they feel unprotected during the holiday season, consider maintaining your programming so that girls have a source of support during that risky period. If girls feel unsafe going to make requests of their teachers, perhaps you or your program staff can be available to go with them

Strategies to prevent SGBV will need to be developed within your program, and based on the terms and conditions of "non-safety" for the girls that you work with.

You can also include training sessions on SGBV in your program, so that girls are aware of the different kinds of gender based violence, what their rights are, what is and is not considered appropriate behavior, and what to do in the case that they, or a friend/relative is a victim of SGBV. There are many curricula available that have training sessions on these topics.

\section{Key Topics to Include on SGBV}

- What is SGBV

- What are different kinds of violence-physical, emotional/psychological, socio-economic,

sexual, verbal

- What is the cycle of violence and what triggers someone to behave in a violent way

- Effects of SGBV

- What are the rights in your country related to SGBV

- What are the key steps in responding to incidents of SGBV—medical, legal, social, law enforcement

\section{Responding to SGBV}

You will want to be prepared with information about where girls can go for assistance when they come to you reporting that they have been victims of an incidence of SGBV. You can fill-in the following preparedness worksheet that will help you as a program be equipped to assist girls. You may want to establish relationships or links with local resources and other organizations that have these specialties 


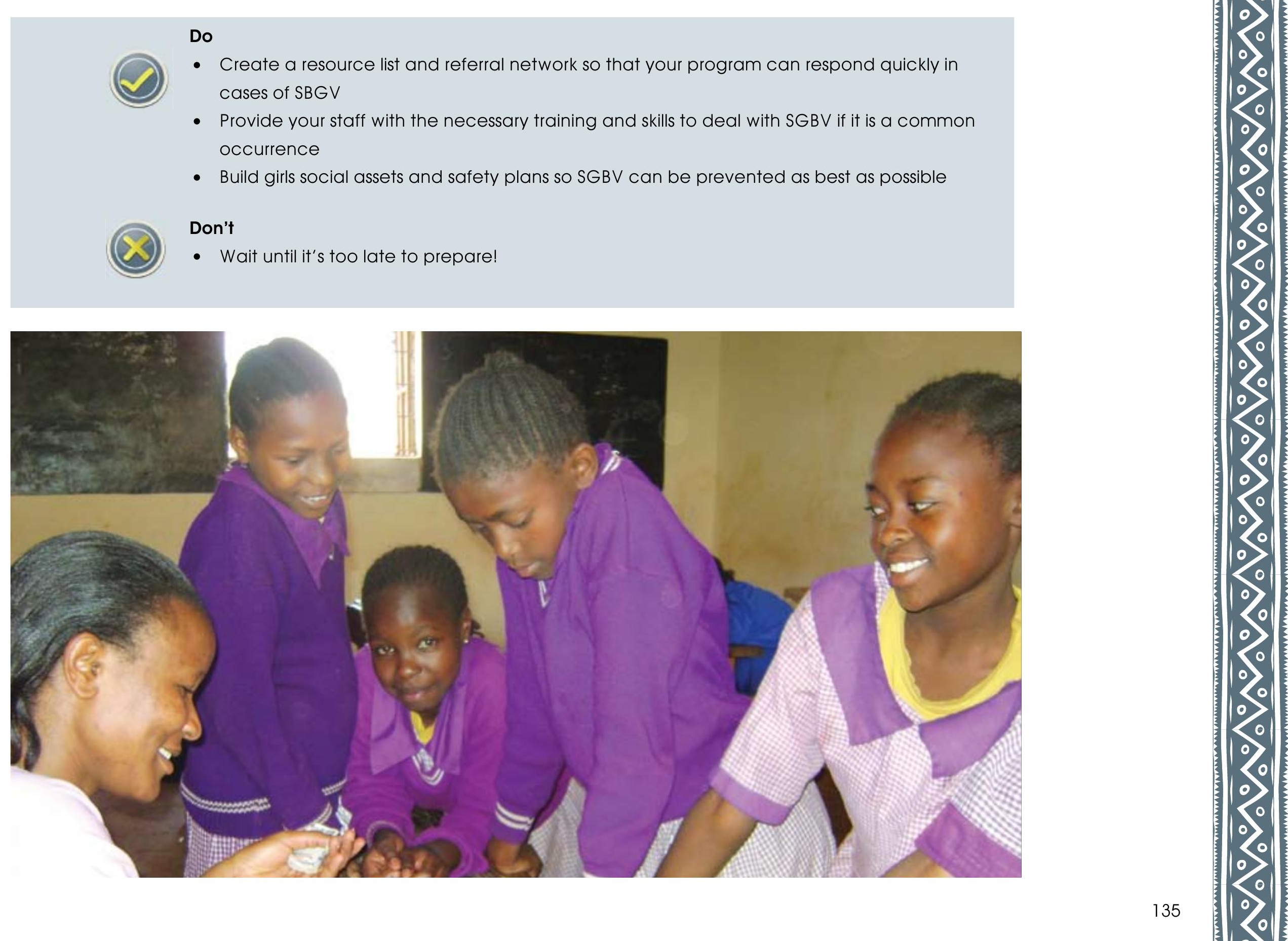


Responding to SGBV at a program level - A preparedness worksheet

This worksheet helps you collect information about all the local resources for girls who have experienced SGBV. That way, if you are approached by a girl in that situation, you can easily know where to refer her to. You can also print this sheet once it is complete and share it with girls in your program (in case they want to go on their own).

If this is a very common occurrence in your program, consider:

- having your staff trained in counseling of survivors of SGBV

- having a small emergency fund to assist girls with transport/bus fare to access local resources

- building relationships with the staff working in local resource organizations to ensure smooth provision of services.

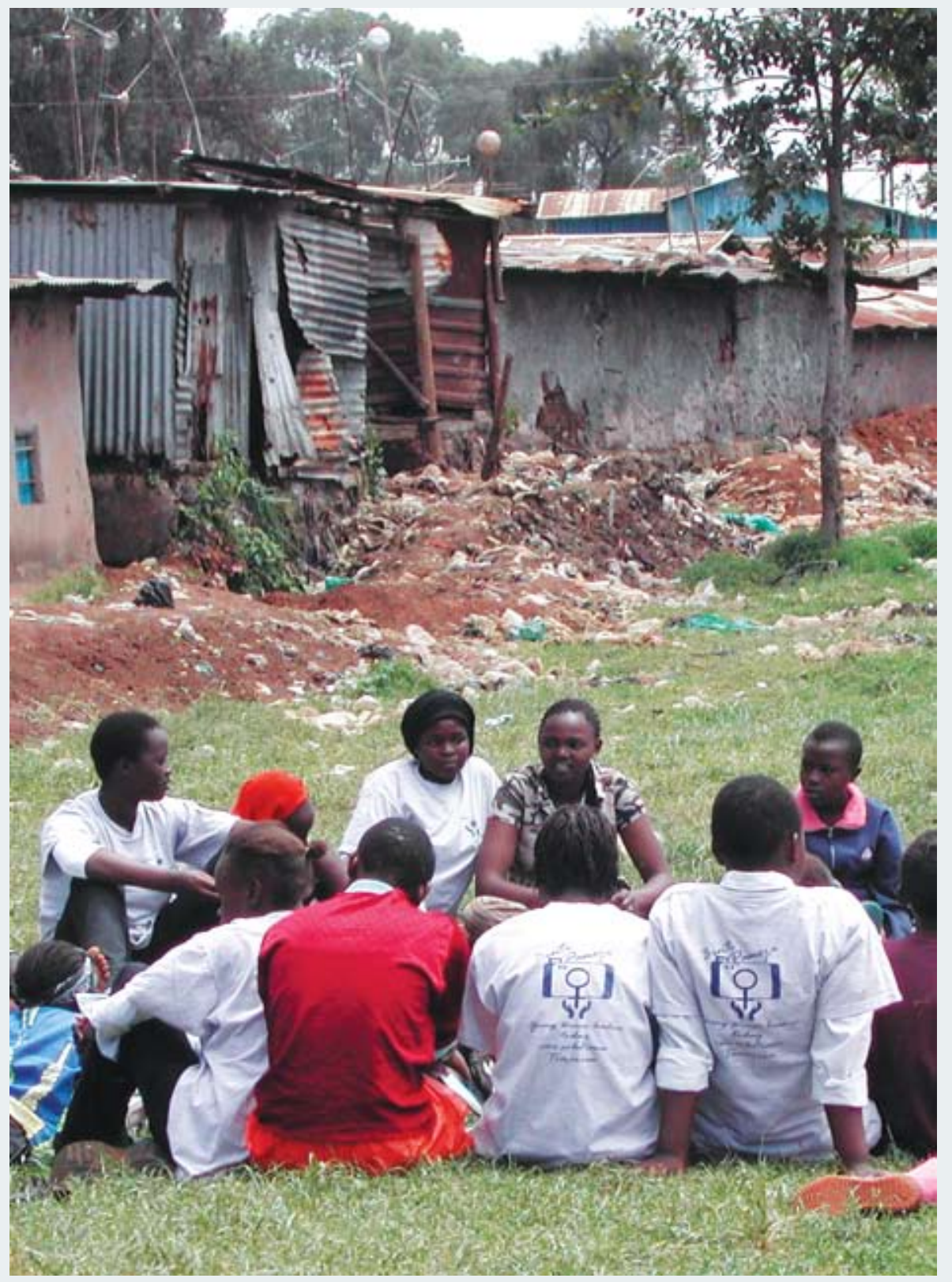


Medical response: Where are the three nearest facilities that can provide a medical response?

\begin{tabular}{|l|l|}
\hline LOCATION 1 & \\
\hline NAME & \\
\hline PHYSICAL ADDRESS & \\
\hline PUBLIC TRANSPORT & \\
\hline PHONE NUMBER & \\
\hline COST & \\
\hline $\begin{array}{l}\text { LIST OF SERVICES PROVIDED } \\
\text { (Emergency contraception/pregnancy prevention, } \\
\text { sexually transmitted infection testing and } \\
\text { treatment, PEP/HIV prevention, pain management, } \\
\text { evidence collection, counseling) }\end{array}$ & \\
\hline
\end{tabular}




\begin{tabular}{|l|l|}
\hline LOCATION 2 & \\
\hline NAME & \\
\hline PHYSICAL ADDRESS & \\
\hline PUBLIC TRANSPORT & \\
\hline PHONE NUMBER & \\
\hline COST & \\
\hline $\begin{array}{l}\text { LIST OF SERVICES PROVIDED } \\
\text { (Emergency contraception/pregnancy prevention, } \\
\text { sexually transmitted infection testing and treatment, } \\
\text { PEP/HIV prevention, pain management, evidence } \\
\text { collection, counseling) }\end{array}$ & \\
\hline
\end{tabular}

\begin{tabular}{|l|l|}
\hline LOCATION 3 & \\
\hline NAME & \\
\hline PHYSICAL ADDRESS & \\
\hline PUBLIC TRANSPORT & \\
\hline PHONE NUMBER & \\
\hline COST & \\
\hline $\begin{array}{l}\text { LIST OF SERVICES PROVIDED } \\
\text { (Emergency contraception/pregnancy prevention, } \\
\text { sexually transmitted infection testing and treatment, } \\
\text { PEP/HIV prevention, pain management, evidence } \\
\text { collection, counseling) }\end{array}$ & \\
\hline
\end{tabular}


Legal response - What are the two local resources where I can refer girls for legal services?

\begin{tabular}{|l|l|}
\hline LOCATION 1 & \\
\hline NAME & \\
\hline PHYSICAL ADDRESS & \\
\hline PUBLIC TRANSPORT & \\
\hline PHONE NUMBER & \\
\hline COST & \\
\hline $\begin{array}{l}\text { LIST OF SERVICES PROVIDED } \\
\text { (Legal counseling, legal representation, } \\
\text { assistance with police, etc.) }\end{array}$ & \\
\hline
\end{tabular}

\begin{tabular}{|l|l|}
\hline LOCATION 2 & \\
\hline NAME & \\
\hline PHYSICAL ADDRESS & \\
\hline PUBLIC TRANSPORT & \\
\hline PHONE NUMBER & \\
\hline COST & \\
\hline $\begin{array}{l}\text { LIST OF SERVICES PROVIDED } \\
\text { (Legal counseling, legal representation, } \\
\text { assistance with police, etc.) }\end{array}$ & \\
\hline
\end{tabular}


Law enforcement response - Where is the nearest police station that has a Child Desk or a SGBV Response Unit?

\begin{tabular}{|l|l|}
\hline LOCATION 1 & \\
\hline NAME & \\
\hline PHYSICAL ADDRESS & \\
\hline PUBLIC TRANSPORT & \\
\hline PHONE NUMBER & \\
\hline COST & \\
\hline LIST OF SERVICES PROVIDED & \\
\hline
\end{tabular}

\begin{tabular}{|l|l|}
\hline LOCATION 2 & \\
\hline NAME & \\
\hline PHYSICAL ADDRESS & \\
\hline PUBLIC TRANSPORT & \\
\hline PHONE NUMBER & \\
\hline COST & \\
\hline LIST OF SERVICES PROVIDED & \\
& \\
\hline
\end{tabular}




\begin{tabular}{|l|l|}
\hline LOCATION 3 & \\
\hline NAME & \\
\hline PHYSICAL ADDRESS & \\
\hline PUBLIC TRANSPORT & \\
\hline PHONE NUMBER & \\
\hline COST & \\
\hline LIST OF SERVICES PROVIDED & \\
\hline
\end{tabular}

\begin{tabular}{|l|l|}
\hline LOCATION 4 & \\
\hline NAME & \\
\hline PHYSICAL ADDRESS & \\
\hline PUBLIC TRANSPORT & \\
\hline PHONE NUMBER & \\
\hline COST & \\
\hline LIST OF SERVICES PROVIDED & \\
& \\
\hline
\end{tabular}


Psycho-social response - What are the local resources that provide professional counseling and guidance for survivors of SGBV?

\begin{tabular}{|l|l|}
\hline LOCATION 1 & Psycho-social response \\
\hline NAME & \\
\hline PHYSICAL ADDRESS & \\
\hline PUBLIC TRANSPORT & \\
\hline PHONE NUMBER & \\
\hline COST & \\
\hline LIST OF SERVICES PROVIDED & \\
\hline
\end{tabular}

\begin{tabular}{|l|l|}
\hline LOCATION 2 & \\
\hline NAME & \\
\hline PHYSICAL ADDRESS & \\
\hline PUBLIC TRANSPORT & \\
\hline PHONE NUMBER & \\
\hline COST & \\
\hline LIST OF SERVICES PROVIDED & \\
\hline
\end{tabular}




\begin{tabular}{|l|l|}
\hline LOCATION 3 & \\
\hline NAME & \\
\hline PHYSICAL ADDRESS & \\
\hline PUBLIC TRANSPORT & \\
\hline PHONE NUMBER & \\
\hline COST & \\
\hline LIST OF SERVICES PROVIDED & \\
\hline
\end{tabular}

\begin{tabular}{|l|l|}
\hline LOCATION 4 & \\
\hline NAME & \\
\hline PHYSICAL ADDRESS & \\
\hline PUBLIC TRANSPORT & \\
\hline PHONE NUMBER & \\
\hline COST & \\
\hline LIST OF SERVICES PROVIDED & \\
\end{tabular}


Safe houses - Where are there safe houses/places where girls can spend the night in case of an emergency?

\begin{tabular}{|l|l|}
\hline LOCATION 1 & \\
\hline NAME & \\
\hline PHYSICAL ADDRESS & \\
\hline PUBLIC TRANSPORT & \\
\hline PHONE NUMBER & \\
\hline COST & \\
\hline LIST OF SERVICES PROVIDED & \\
\end{tabular}

\begin{tabular}{|l|l|}
\hline LOCATION 2 & \\
\hline NAME & \\
\hline PHYSICAL ADDRESS & \\
\hline PUBLIC TRANSPORT & \\
\hline PHONE NUMBER & \\
\hline COST & \\
\hline LIST OF SERVICES PROVIDED & \\
& \\
\hline
\end{tabular}




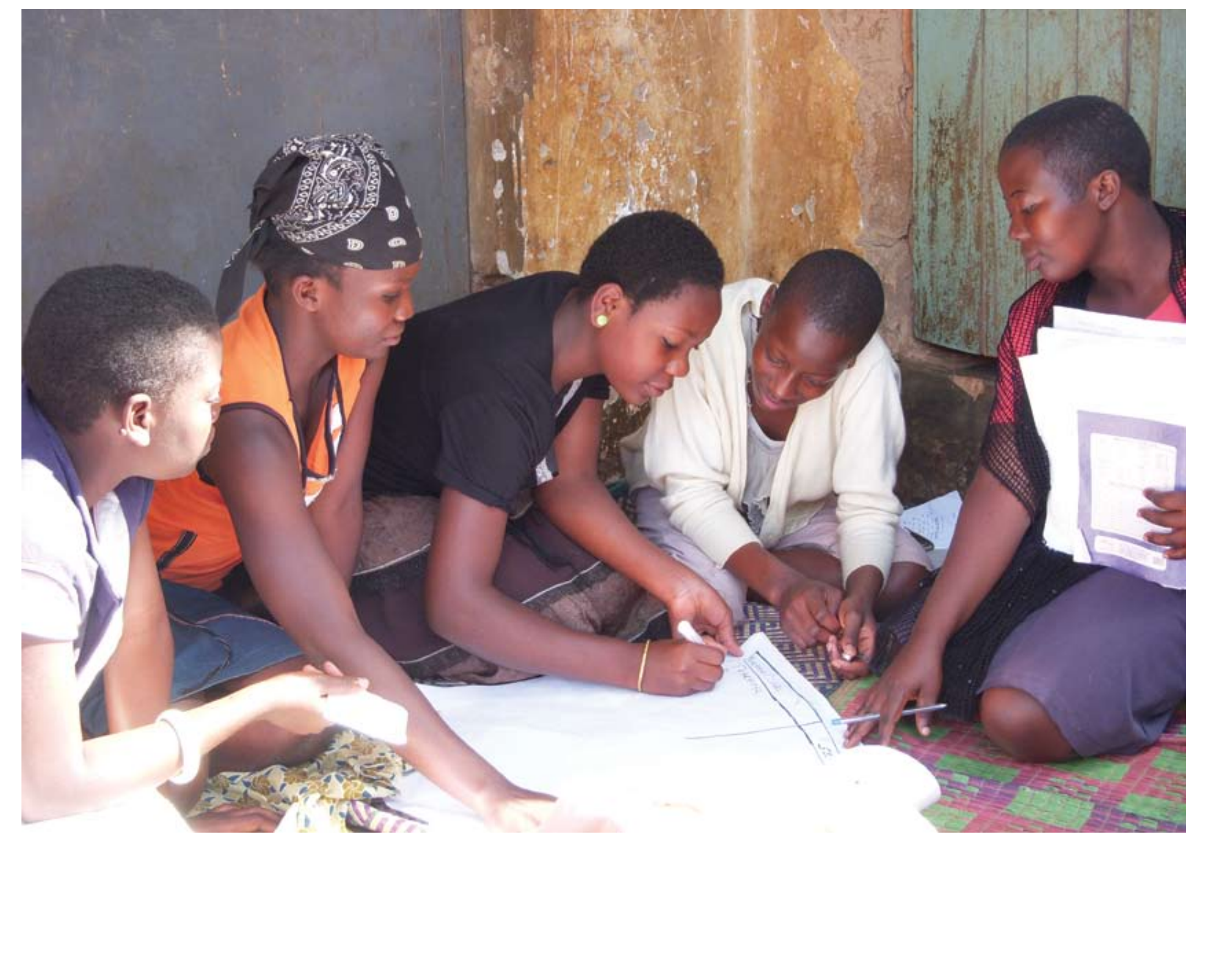



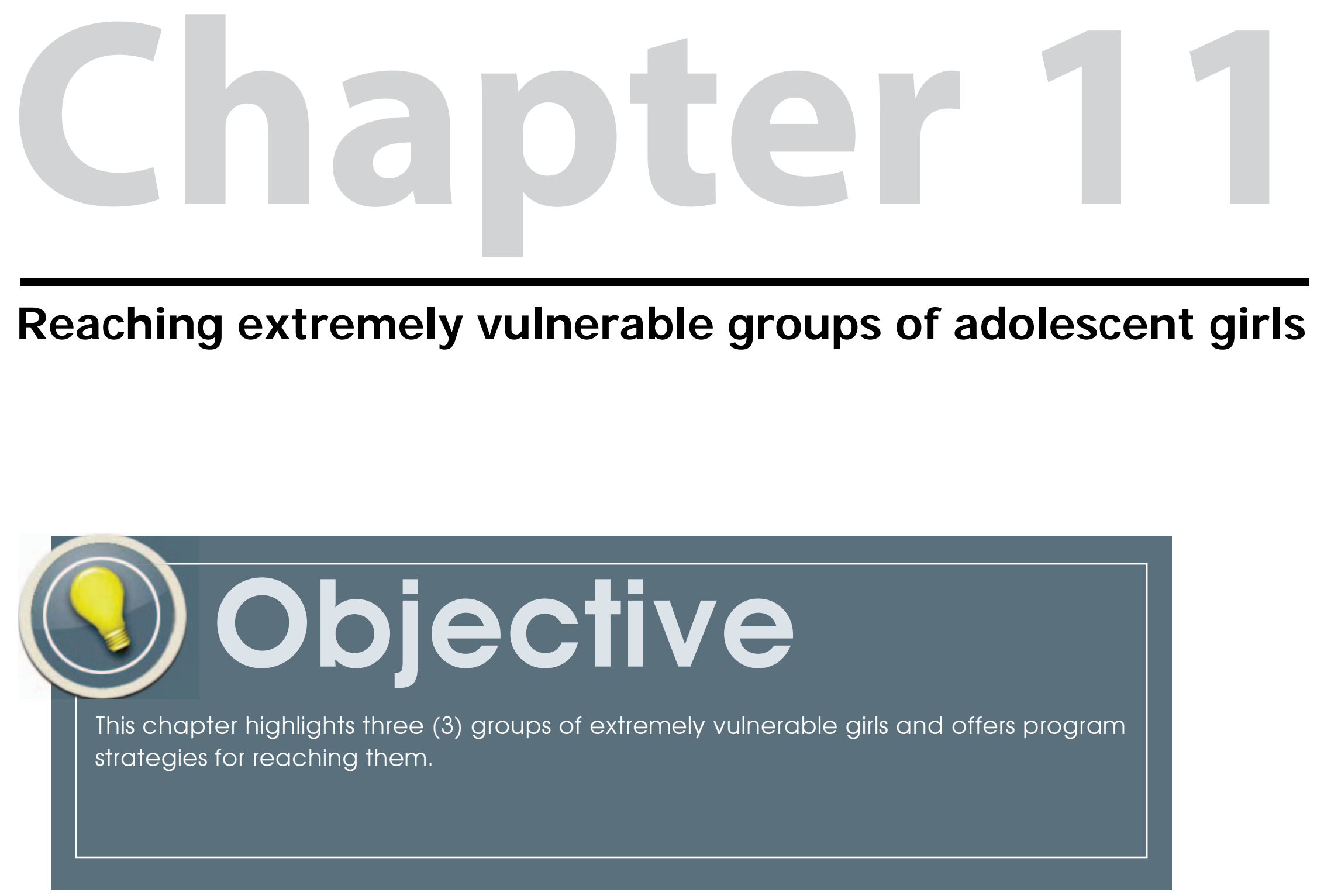
While most girls in low-income settings are vulnerable, there are certain groups of girls that tend to be very vulnerable and may need special attention and consideration when planning your program and engaging them in program activities.

These extremely vulnerable girls will not likely just show up at your programs-if you really want to reach them you will have to engage in intensive and targeted recruitment (see Chapter 4). In this chapter three highly vulnerable groups are highlighted-domestic workers, married adolescents and girls with disabilities. In the context where you are working it is quite possible that there are additional or different groups. The key is to be aware of who the most vulnerable are and to take the necessary steps to engage them in your program.

Extremely vulnerable girls will not likely just show up at your programs - if you really want to reach them you will have to engage in intensive and targeted recruitment. 


\section{Domestic workers}

Girls in domestic service are very vulnerable because they are usually out-of-school, have just migrated (perhaps out of a dangerous situation) from the rural to the urban areas, and are living with their employer (in often quite unfriendly working conditions, with limited social supports and freedom, and at high risk of abuse and sexual violence'). Due to their long work hours, they tend to be excluded from general youth, or even girls programs ${ }^{2}$.

Some successful program strategies have created programs specifically for domestic workers ${ }^{3}$ and others have tried to integrate them into existing programs. A few tips to keep in mind when trying to integrate domestic workers into your programs ${ }^{4}$ :

- You will have to engage with their employer to gain permission for their participation. This can be a time-consuming, multi-stage process, but it is necessary.

- Perhaps even more than other girls (because they are dependent on their employers), domestic workers have very weak social networks and will need the program for help in making friends, meeting mentors, and being referred to other institutions in society-such as clinics and other government offices/services. 


\section{Married adolescents}

Girls who are married are also extremely vulnerable. Once they are married, they often go and live with their husband, or with his family. Therefore, they are now even less in control of their lives than before,

unable to disobey their husband AND their mother-in-law. Another known vulnerability is that married adolescents are more at risk of HIV infection than sexually active, unmarried adolescent girls ${ }^{5}$. This is likely because they have sex more frequently, and with marriage, have less ability to negotiate for condom use. Additionally, their husbands are more likely to be older and have a greater risk of being infected with HIV.

When considering program strategies, keep in mind the following:

- Married adolescents still need the same social support as other girls - so having girls groups, mentors, safe places for them to meet is important. However, they might feel their issues are different from unmarried girls, so they might need their own groups to meet in.

- Key adults to engage as well will be their husbands and their mothers-in-law.

- Consider engaging the husbands in HIV testing and counseling, as well as other educational programming - for their own benefit, as well as that of the girls. 


\section{Girls with disabilities}

Girls with disabilities face increased vulnerability that often leaves them quite invisible_to communities and programs. Some girls with disabilities are kept in the home, hidden, and not allowed to participate in the public sphere-whether school, youth programs, income generation, or general day-to-day activities such as going to the market. Furthermore, they are often wrongly seen as not having sexual health needs, but as one disability activist in Kenya said, "My leg doesn't work properly, not the rest of my body!" As a result, girls with disabilities typically miss out on sexual health information that is passed on from aunties or other women in the community. Even more so, they are often taken advantage of and suffer very high rates of sexual abuse and rape. In some settings such abuse is not seen as a crime, but often the response would be that "whoever did that was doing her a favor."

There are typically two strategies for engaging girls with disabilities in programming. The first is to create special programs for them and the second is to integrate them into existing girls programs. Programs that seek to work only with girls with disabilities must be sure that they have the proper assistance-i.e. people who can sign, material in Braille, staff trained in working with those who have mental disabilities, etc. However, otherwise, they are girls who need training on sexual and reproductive health, HIV, financial education, entrepreneurship and more - just like any other girls programs. They need the chance to build friendships and develop their self esteem. 
For programs that want to integrate girls with disabilities into their current programming - that is very much encouraged. A couple of tips:

- You will need to directly recruit these girls - going door to door in the community to find where these girls are living, talk to their guardians so that they consent to their participation, and understand what their needs are so you will be able to accommodate them.

- Think carefully about the certain kinds of disabilities of the girls that you can recruit and make sure that you have the capacity to properly absorb girls with that kind of disability before you recruit them. For example, a girl who is deaf will need a sign language translator; a girl who is blind will need materials in Braille; a girl in a wheelchair might need help getting to the program. Programs have run into problems bringing in girls with the best of intentions to integrate them into the program, but then not having the ability to translate or work with their specific disability.

- At the very least, even if there aren't any girls with disabilities in your program, you can discuss the issue of disabilities in your program so as to reduce the stigma on girls with disabilities among the girls that you work with.

See the Mobility International website - http://www.miusa.org/ - for more information on disability issues.

Do

- Identify the extremely vulnerable groups of girls in the context where you are working

- Plan and take steps in each step of your program design to reach the extremely vulnerable girls

\section{Don't}

- Assume that extremely vulnerable girls will participate in your program without you taking extra steps to recruit and include them appropriately 


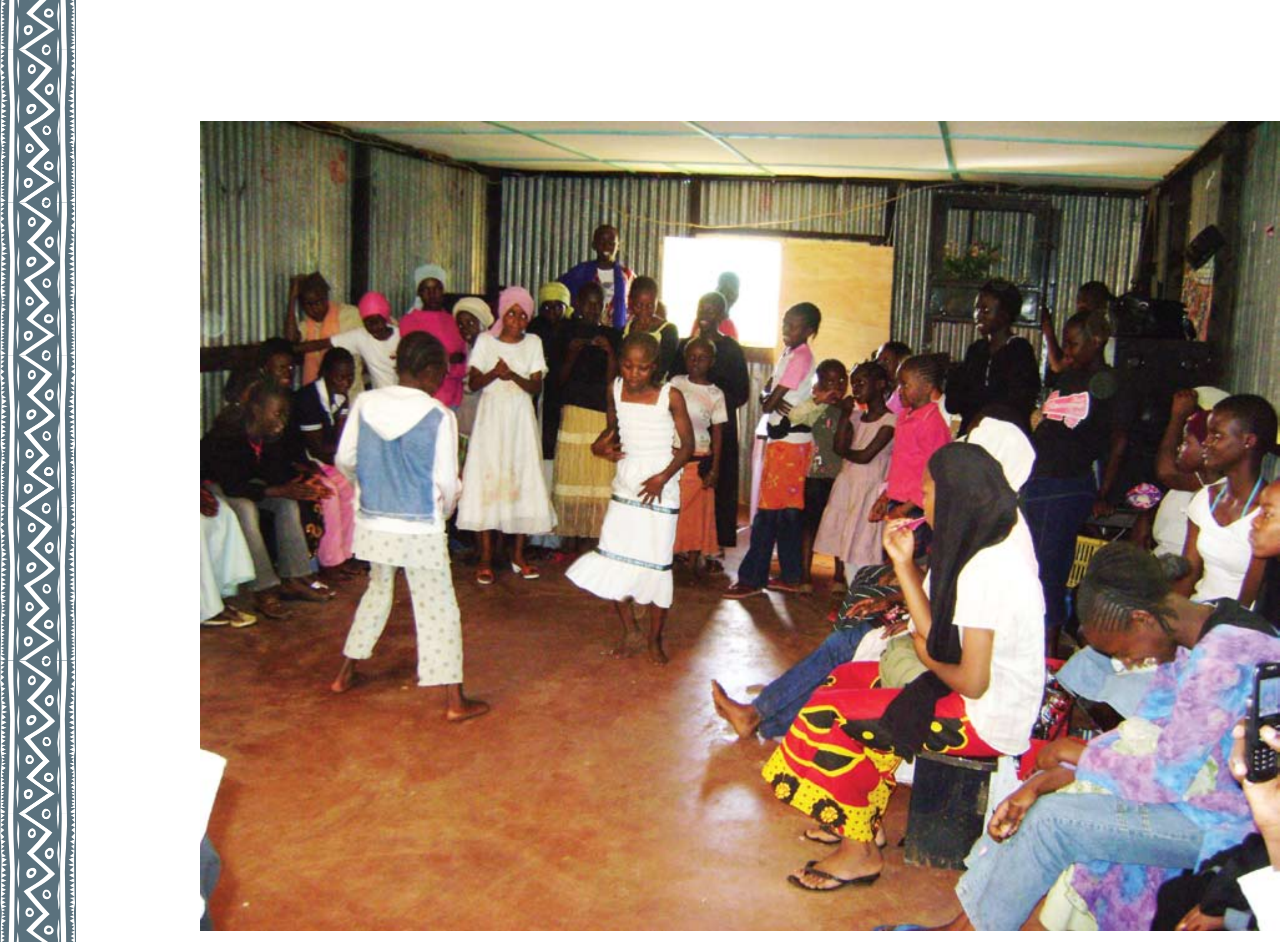




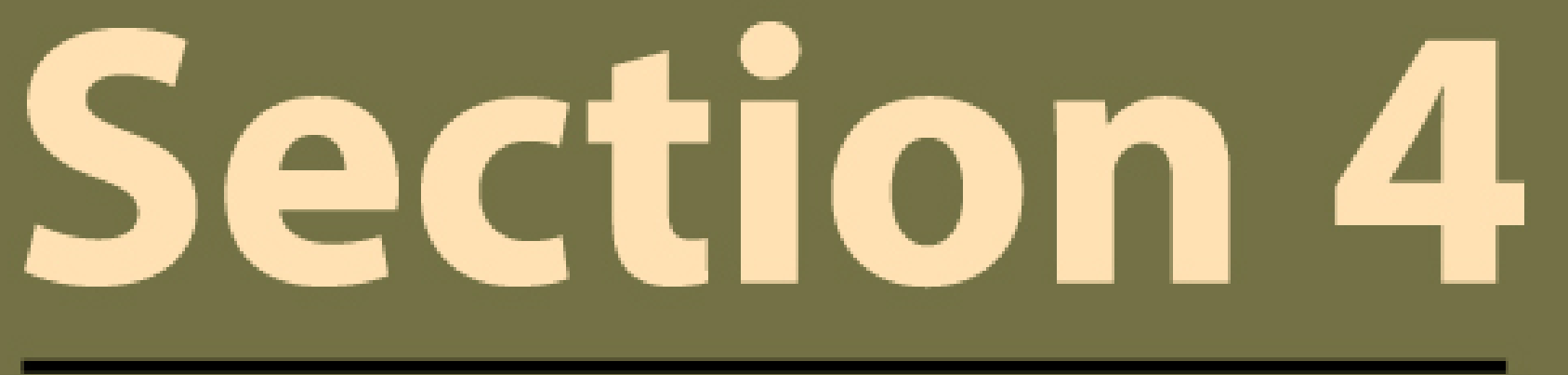

\section{Monitoring \& Evaluation}

Chapter 12

Monitoring

\section{Chapter 13}

Evaluation

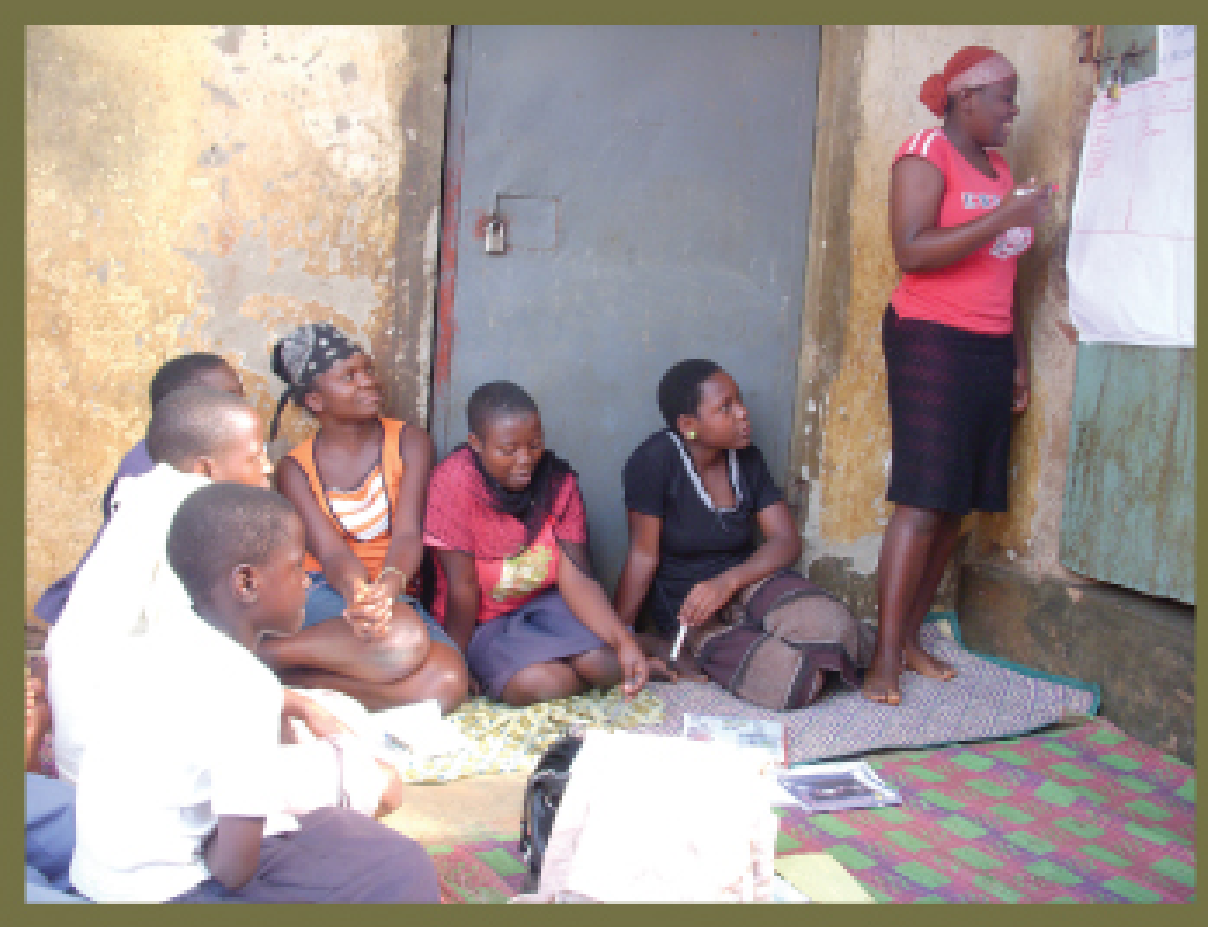

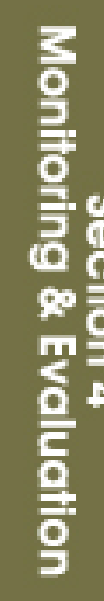




\section{Monitoring \& Evaluation}




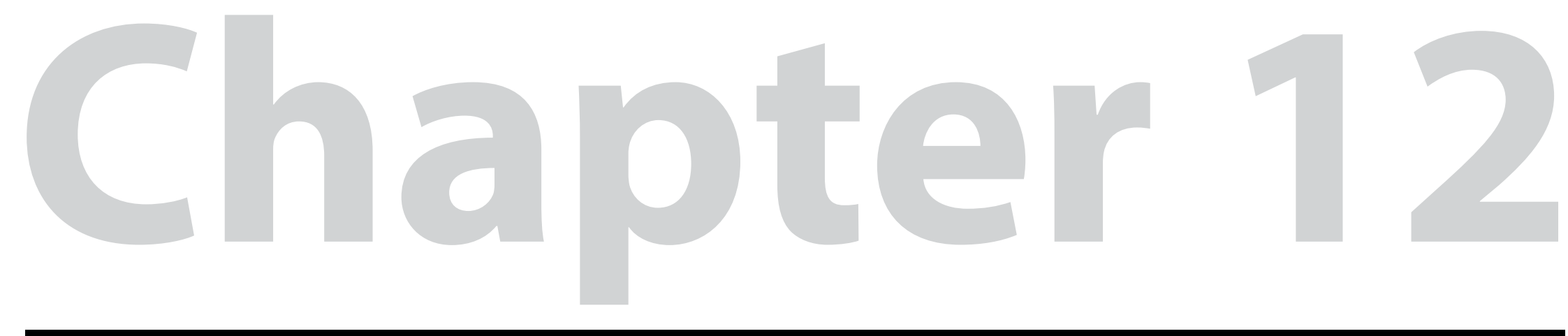

Monitoring

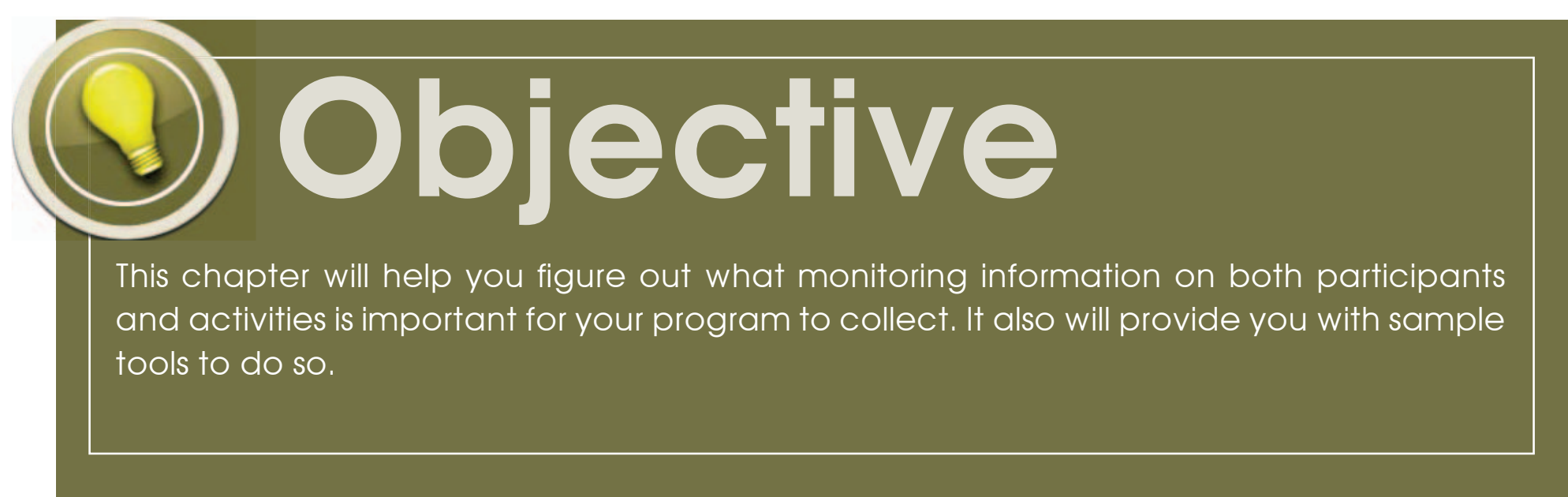


This chapter and the next will focus on monitoring and evaluation. While the term "M\&E" gets used a lot, it is often not clear what is meant, how the two are different, and what programs themselves can do without too much complexity or prior experience.

Overall, good monitoring and evaluation helps you to chart the success of your program - to tell the story of how girls benefit from participating in your program.

This chapter will focus on monitoring and Chapter 13 on evaluation.

Monitoring answers two basic questions:

- Who are we reaching?

- What are we doing?

It can also be seen as a process to help keep you on track by thinking of the questions as:

- Are we reaching who we said we would reach?

- Are we doing the activities we said we would do?

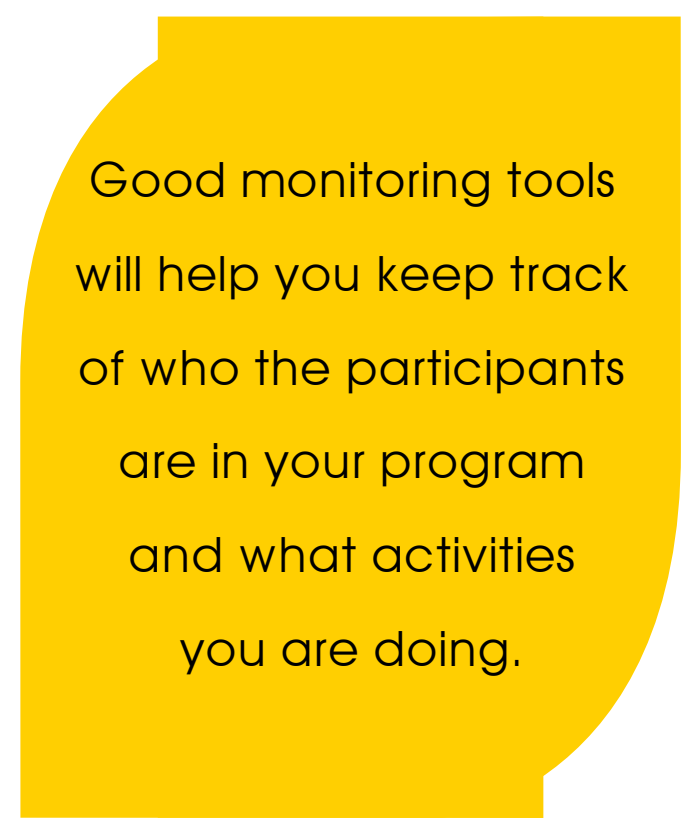


Good monitoring tools will help you keep track of who the participants are in your program and what activities you are doing. There are two kinds of monitoring tools we will discuss-one that helps you keep track of participants and another that helps you keep track of activities.

Participant Register This helps you keep track of the girls in the program and their critical characteristics. Some sample participant registers are included at the end of this chapter, but the critical work for you will be to decide which characteristics are important for you to include in this register. For example, if you are working with in-school girls, you do not need to ask if they are in school or out of school, but instead what level they are in school. Ask yourself, do you need to know what school they go to? If your program has a component of school visits, then perhaps yes. Similarly, if you are working with teenage mothers, you do not need to ask if they do or do not have kids, but instead how many children they have. You will have to decide if you want to also ask who they live with or their level of education.

Note You may have already thought through the important characteristics for your program with the coverage exercise described in Chapter 1. Depending on the purpose of your coverage exercise (for example if you are using it at the intake stage), it may overlap with the participant register.

Remember! Too much information is not helpful. It usually just overwhelms program staff with data and makes them less likely to prepare summary reports. 
Here is a list of sample characteristics that can be included in a monitoring register. You have to decide for your program which characteristics are the most critical.

\begin{tabular}{|c|c|}
\hline CHARACTERISTIC & $\begin{array}{l}\text { QUESTION } \\
\text { (Depends on which piece of information you want to collect) }\end{array}$ \\
\hline Age & How old are you? \\
\hline Living Arrangements & Who do you live with? \\
\hline Living Location & What neighborhood do you live in? \\
\hline Schooling Status & Are you currently in school? \\
\hline Education Level & $\begin{array}{l}\text { What grade/class/level are you in? } \\
\text { What is the highest level of schooling you reached? }\end{array}$ \\
\hline School Attended & What school do you go to? \\
\hline Parenthood Status & $\begin{array}{l}\text { Do you have any children? } \\
\text { How many children do you have? }\end{array}$ \\
\hline Marital Status & $\begin{array}{l}\text { Are you currently married? How many children do you have? } \\
\text { Do you currently live with your boyfriend or husband? }\end{array}$ \\
\hline Migration Status & $\begin{array}{l}\text { Were you born in the neighborhood where you live? } \\
\text { At what age did you move there? } \\
\text { From where did you move? }\end{array}$ \\
\hline Work Status & $\begin{array}{l}\text { Are you currently engaged in any form of income generating activity? } \\
\text { What income generating activities are you involved in? }\end{array}$ \\
\hline
\end{tabular}


The other important monitoring tool is an activity register. This will help you document the meetings, activities, events that you hold in your program, how many girls come and what the attendance levels are. This information not only helps you to be able to report on the activities in your program, but also helps you monitor trends to see if you need to make any changes. For example: Are attendance levels dropping? Are we covering all of the topics we said we would?

Like the participant register, you need to develop an activity register to meet the needs of your program, match the structure of your program, and the kinds of information that is relevant to you.

\section{ID Cards}

While counting and tracking girls is critical within your own program, it is also critical on a municipal, state,

and national level. Officially counting and identifying vulnerable girls is typically a missed opportunity. Lack of birth certificates, immunization cards, or other kinds of official, recognized identification contributes significantly to this problem. This can affect girls when they go to access work opportunities, health services, financial services, or other formal institutions where identification is required.

Your program can help girls be counted officially - or obtain identification - either through 1) assisting with obtaining formal documents such as birth certificates or national IDs or 2) providing program IDs that are recognized locally that can help girls access formal institutions of society and perhaps at a later stage be used to obtain official ID. Some programs have reached agreements with local government to stamp their program ID cards which has added a level of formal recognition, and then the ID cards are used by the girls in the program to access health and other services. 
Here is a list of kinds of information you might want to capture. Again, you will have to choose what is right for you.

Information for Activity Register

- Date

- Time

- Number of girls attended

- Topics covered (i.e. family planning, entrepreneurship, how to make a budget, HIV prevention)

- Type of activity (i.e. group meeting, lecture, family event, community outreach)

- Name of group mentor/facilitator/leader

- Girls who have been absent the last three meetings in a row

- Referrals made

- Material distributed

Again, tailor these registers to meet your needs.

Finally, there is no point in collecting the data if you are not going to do anything with it. So, before you get started developing your monitoring plan and tools, answer the following questions for yourselves:

- Who will create/finalize the registers \& by when?

- When will these registers be used?

- Who is responsible for ensuring they get completed?

- Who is responsible for analysis/reporting?

- How often/when will the analysis/reporting be done?

- Do you need a monthly/quarterly summary form?

Don't forget - sometimes those funding your program are also interested in specific kinds of details or ask for certain information on their reports. Think about what you will have to report on to your donors ahead of time and make sure this information will be captured through your registers. 
Do

- Develop and use monitoring tools that collect information that is important for your
program

- Develop and use monitoring tools that collect information that is important for your
program

- Use monitoring tools that collect information on participants and activities

(1)

- Assign responsibilities to staff responsible for the different monitoring tasks

(2) Don't

- Collect more information than you will use
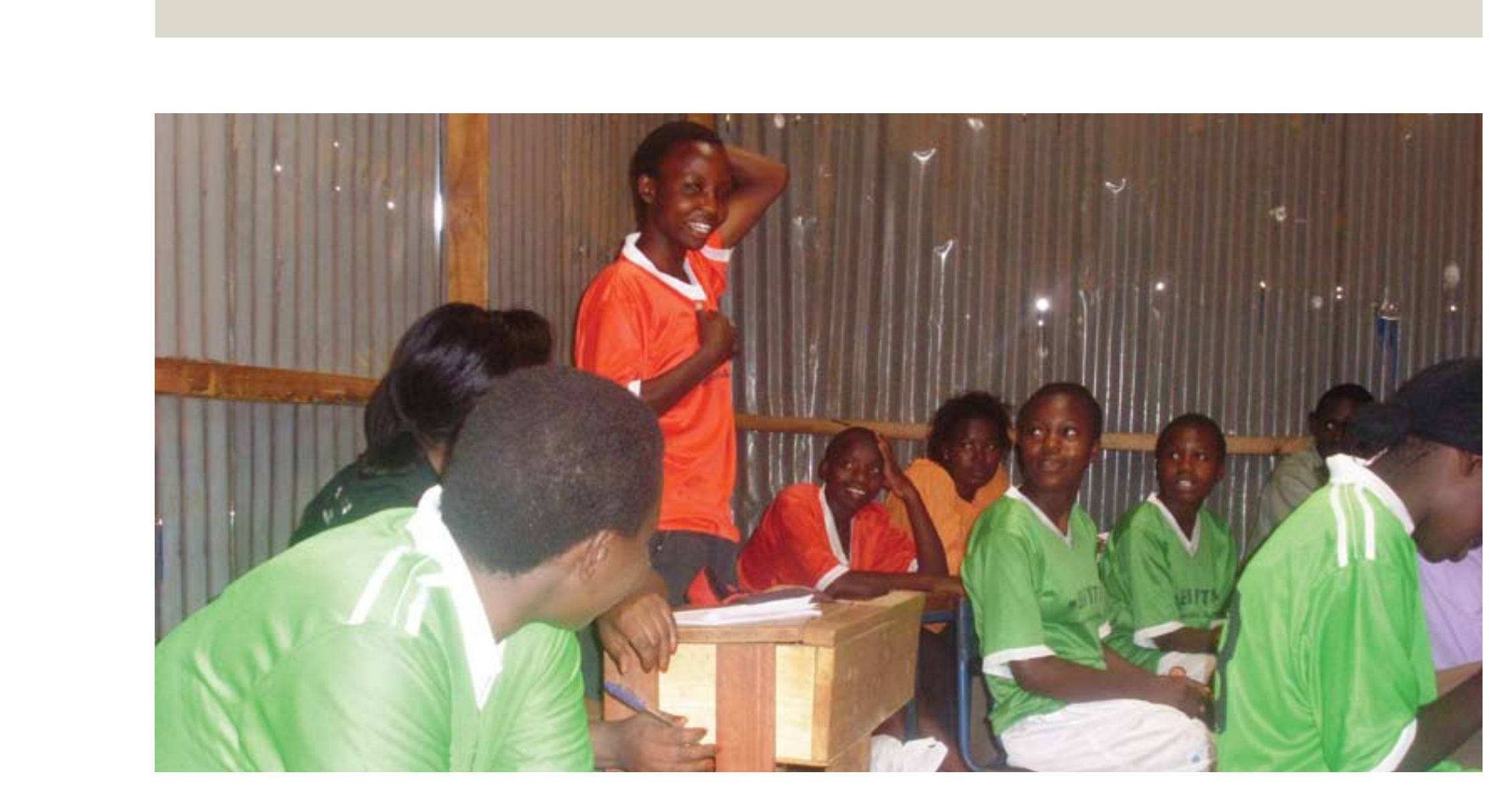

\section{(1)}

Don't

-

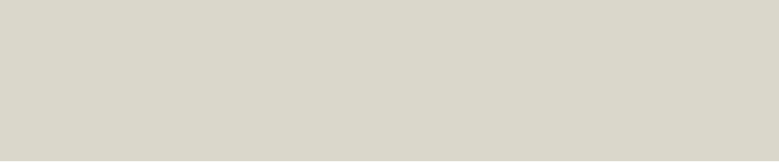

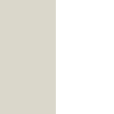

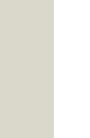

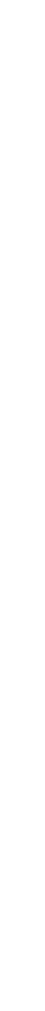

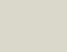

.

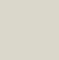

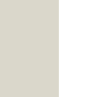
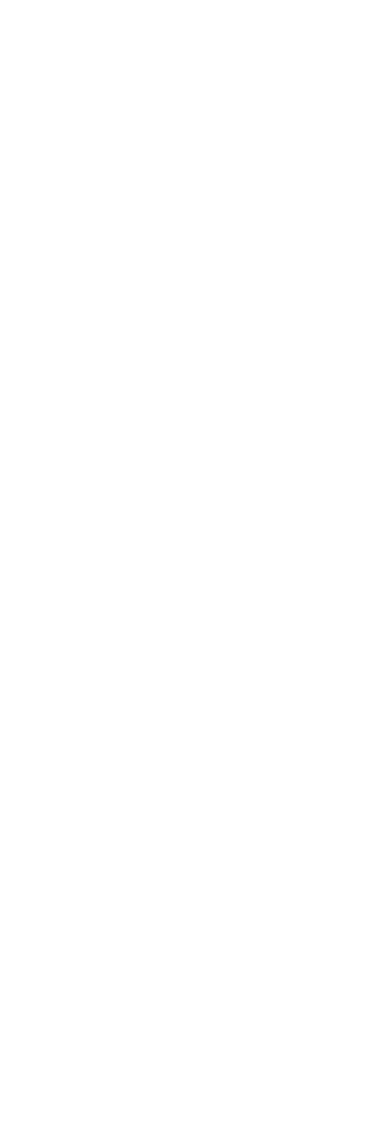


\begin{tabular}{|c|c|c|c|c|c|c|c|c|c|}
\hline & \multirow{2}{*}{$\begin{array}{l}\text { SAMPLE INTAKE REGISTER } 1 \\
\text { DATE }\end{array}$} & \multicolumn{8}{|c|}{ **This is for a program that reaches a wide range of adolescent girls in the Kibera slum in Nairobi Kenya } \\
\hline & & & & & & & & & \\
\hline & Name & Age & Village & $\begin{array}{l}\text { School } \\
\text { Status? }\end{array}$ & $\begin{array}{l}\text { Class/ } \\
\text { Form }\end{array}$ & $\begin{array}{l}\text { Lives With: } \\
\text { ** }\end{array}$ & $\begin{array}{l}\text { Has } \\
\text { Child? }\end{array}$ & Married? & $\begin{array}{l}\text { How did you } \\
\text { hear about the } \\
\text { program? }\end{array}$ \\
\hline \multicolumn{10}{|l|}{1} \\
\hline \multicolumn{10}{|l|}{2} \\
\hline \multicolumn{10}{|l|}{3} \\
\hline \multicolumn{10}{|l|}{4} \\
\hline \multicolumn{10}{|l|}{5} \\
\hline \multicolumn{10}{|l|}{6} \\
\hline \multicolumn{10}{|l|}{7} \\
\hline \multicolumn{10}{|l|}{8} \\
\hline \multicolumn{10}{|l|}{9} \\
\hline \multicolumn{10}{|c|}{10} \\
\hline \multicolumn{10}{|c|}{11} \\
\hline \multicolumn{10}{|c|}{12} \\
\hline \multicolumn{10}{|c|}{13} \\
\hline \multicolumn{10}{|c|}{14} \\
\hline \multicolumn{10}{|c|}{15} \\
\hline \multicolumn{10}{|l|}{16} \\
\hline \multicolumn{10}{|l|}{17} \\
\hline \multicolumn{10}{|l|}{18} \\
\hline \multicolumn{10}{|l|}{19} \\
\hline \multicolumn{10}{|l|}{20} \\
\hline & $\begin{aligned} & * \star \text { Lives With: } 1=\text { Both Parents; } 2=1 \\
& 6=\text { Friends; } 7=\text { Other }\end{aligned}$ & $\begin{array}{l}\text { Iy; } 3=\mathrm{Fat} \\
8=\mathrm{Other}\end{array}$ & $\begin{array}{l}\text { ner Only; } 4 \\
\text { Non-Relati }\end{array}$ & $\begin{array}{l}\text { oyfriend } / \mathrm{Hu} \\
\text { s; } 9=\text { Employ }\end{array}$ & $\begin{array}{l}\text { Dand; } 5=A \\
r ; 10=\text { Oth }\end{array}$ & & & & \\
\hline & ${ }^{* *}$ Has Child: $0=N O ; 1=$ Yes $\quad{ }^{*} \mathrm{M}$ & No; $1=Y \epsilon$ & s $\quad * *$ Sch & l: $0=$ out of & chool; $1=i$ & & & & \\
\hline
\end{tabular}




\begin{tabular}{|c|c|c|c|c|c|c|c|c|c|}
\hline & \multirow{2}{*}{$\begin{array}{l}\text { SAMPLE INTAKE REGISTER } 2 \\
\text { DATE }\end{array}$} & \multicolumn{8}{|c|}{${ }^{* *}$ This is a register of a program targeting young mothers who are working in a certain market in Kampala, Uganda } \\
\hline & & & & & & & & & \\
\hline & Name & Age & Neighborhood & \# of Kids & \begin{tabular}{|l} 
Highes $\dagger$ \\
Level of \\
Education
\end{tabular} & $\begin{array}{l}\text { Lives With: } \\
\text { ** }\end{array}$ & $\begin{array}{l}\text { Date started } \\
\text { working in } \\
\text { Market }\end{array}$ & Migration Status & Notes \\
\hline \multicolumn{10}{|l|}{1} \\
\hline \multicolumn{10}{|l|}{2} \\
\hline \multicolumn{10}{|l|}{3} \\
\hline \multicolumn{10}{|l|}{4} \\
\hline \multicolumn{10}{|l|}{5} \\
\hline \multicolumn{10}{|l|}{6} \\
\hline \multicolumn{10}{|l|}{7} \\
\hline \multicolumn{10}{|l|}{8} \\
\hline \multicolumn{10}{|l|}{9} \\
\hline \multicolumn{10}{|l|}{10} \\
\hline \multicolumn{10}{|l|}{11} \\
\hline \multicolumn{10}{|l|}{12} \\
\hline \multicolumn{10}{|l|}{13} \\
\hline \multicolumn{10}{|l|}{14} \\
\hline \multicolumn{10}{|l|}{15} \\
\hline \multicolumn{10}{|l|}{16} \\
\hline \multicolumn{10}{|l|}{17} \\
\hline \multicolumn{10}{|l|}{18} \\
\hline \multicolumn{10}{|l|}{19} \\
\hline \multicolumn{10}{|l|}{20} \\
\hline \multicolumn{10}{|c|}{$\begin{aligned} \text { ** Lives With: } 1=\text { Both Parents; } 2=\text { Mother Only; } 3=\text { Father Only; } 4=\text { Boyfriend/Husband; } 5=\text { Alone; } \\
6=\text { Friends; } 7=\text { Other Relatives; } 8=\text { Other Non-Relatives; } 9=\text { Employer; } 10=\text { Other }\end{aligned}$} \\
\hline \multicolumn{5}{|c|}{ ** Migration Status: 0=Born in Kampala; l=Migrated from Rural Area } & \multicolumn{5}{|c|}{$\begin{array}{l}\star \star * \text { Education Level: } 1=\text { Some Primary; } 2=\text { Finished Primary; 3=Some Secondary; } \\
4=\text { Completed Secondary; } 5=\text { =Some Post-Secondary; } 6=\text { Other (specify in notes) }\end{array}$} \\
\hline \multicolumn{10}{|c|}{$\begin{aligned} \text { Neighborhood: } & 1=\text { Kisenyi; } 2=\text { Katwe; } 3=\text { Wandegya; } 4=\text { Bwaise; } 5=\text { Kivulu; } 6=\text { Kamwokya; } 7=\text { Makerere; } 8=\text { Ndeba; } 9=\text { Kawempe; } \\
& \text { 10=Kibuye; } 11=\text { Gayaza; } 12=\text { Nakulabye; } 13=\text { Kikoni; } 14=\text { Owino; } 15=\text { Old Kampala; 16=Kasubi; } 17=\text { =ther in Kampala (specify in notes) }\end{aligned}$} \\
\hline
\end{tabular}




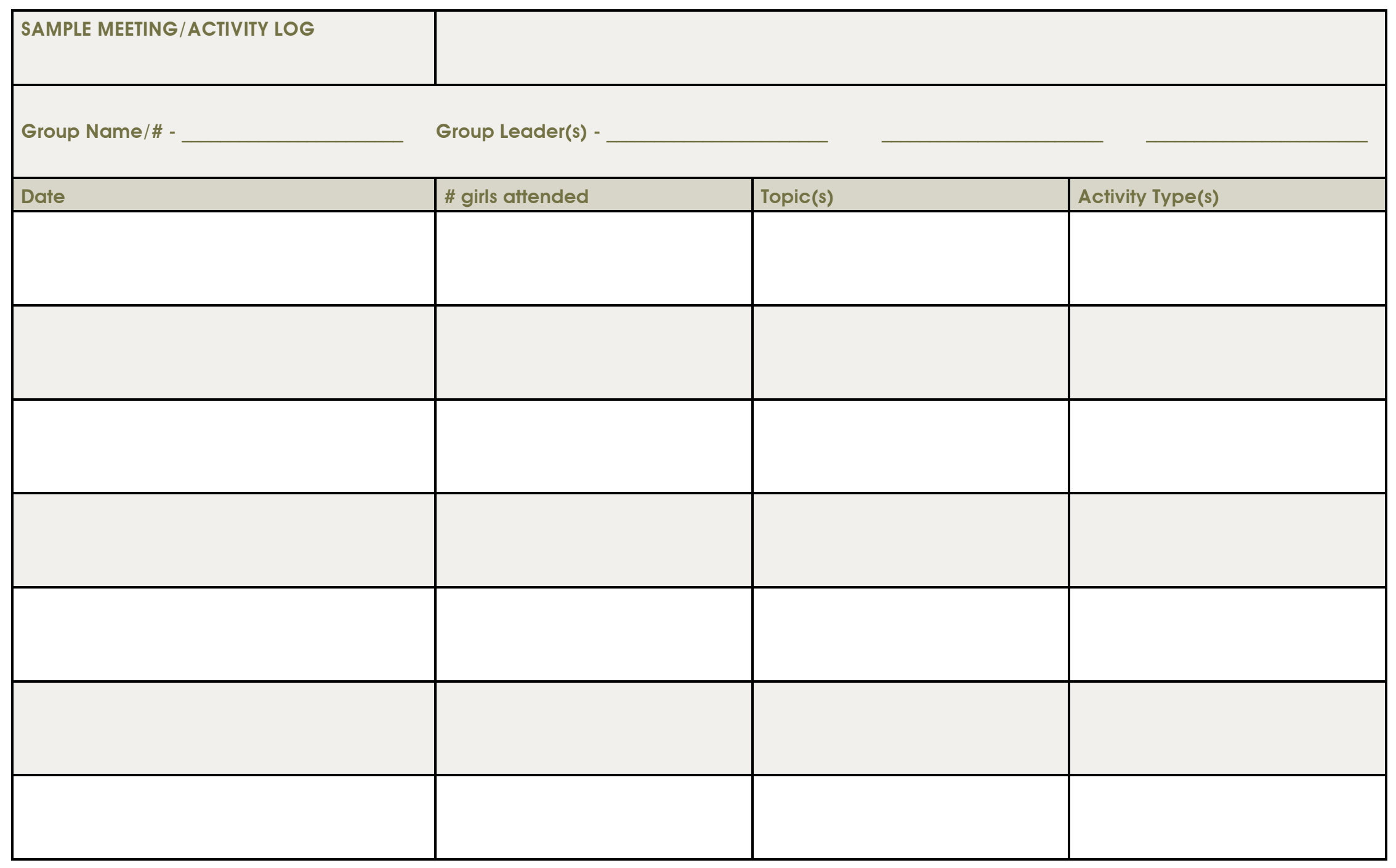




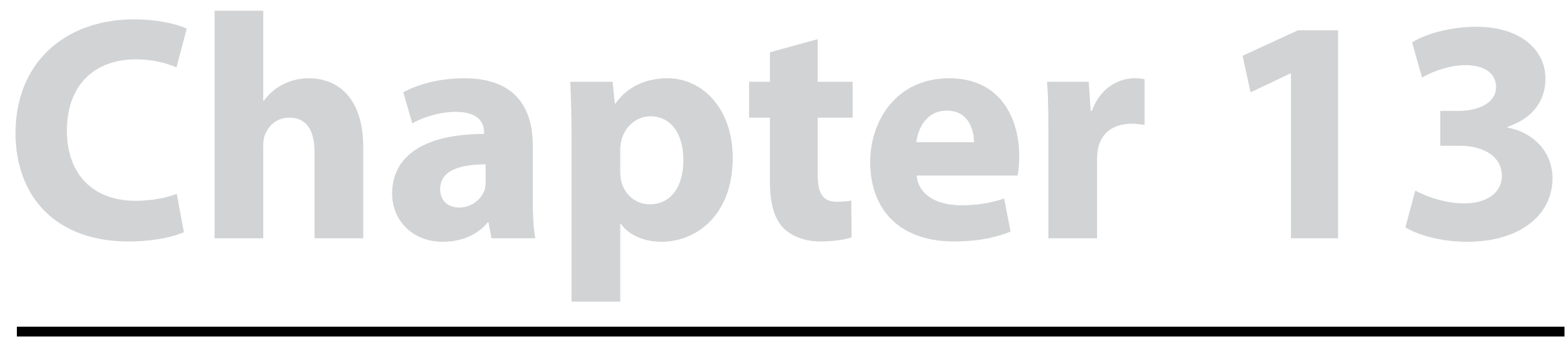

\section{Evaluation}

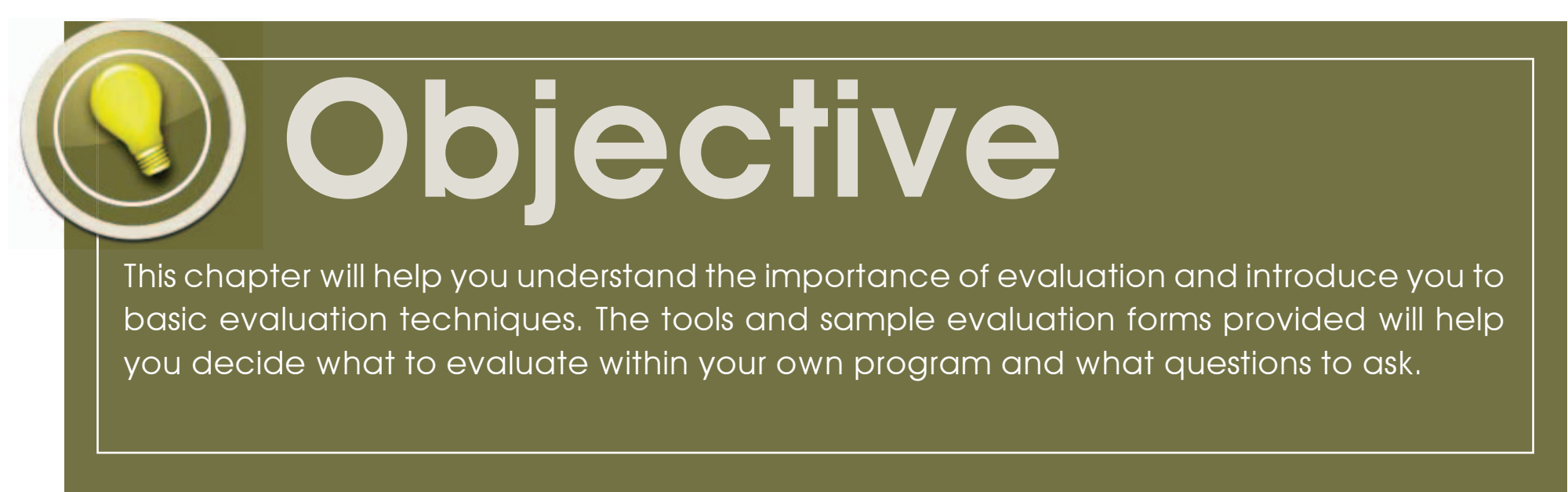


Monitoring, discussed in Chapter 12, can be the first step in

evaluation because it provides a solid base of information about the girls in your program and what you are doing with them from which to evaluate your program.

Evaluation then helps you answer the questions:

- Is my program making a difference?

- What kinds of changes take place in girls because they participate in my program?

Many programs back away from evaluation because they find it overwhelming, they do not know where to start, or because it is not valued as a management or decision-making tool. Sometimes, just the day-to-day tasks of keeping a program running can keep you so busy that there never seems to be any time for it. However, evaluation is important because it helps you better understand what your program does and does not do for the girls who participate, and allows you to be able to tell that story with confidence and evidence to other people (whether they be parents, donors, or other partners).

Evaluation helps you answer the questions: Is my program making a difference? What kinds of changes take place in girls because they participate in my program? 
A key point about evaluation is that it is not something that should be left to the end of a project. Instead, it should be part of the overall work plan and project design. Your program should decide at the beginning of a project cycle what kind of evaluation you want to do and what will be evaluated.

One common challenge is that programs often do not know what to evaluate. This chapter will help you decide what in your program you want to evaluate and what questions you can ask in those areas. In addition, this chapter will briefly outline different kinds of evaluation, when they can be done effectively, and how you can plan for evaluation activities.

\section{Deciding What to Evaluate}

For most of us, our programs have a strong mission or vision—whether they focus specifically on one area or another, in general we want the adolescent girls in our program to make a successful transition into adulthood. We want them to become young women who do not have HIV, who are able to plan their pregnancies, who live lives free of violence, who have a successful livelihood and are able to financially support themselves, their children and their families. Even more so, we do not stop at wanting these outcomes only for the girls, but for their entire communities.

However, those goals are very difficult to measure. Often it would mean doing complicated and expensive tests, mostly because change rarely happens quickly. It takes a lot of time to follow the same girls until they reach adulthood. If a girl is 14 years old when she joins your program, for example, you would have to wait a minimum of ten years until she's an "adult" of 24 to see if she is HIV free, financially independent, etc. It's a serious commitment for your program to take on the task of evaluating whether or not your program has succeeded at these goals.

Therefore, when you begin to think about what to evaluate, two questions that will help get you started are:

- what are the "steps along the way"-or intermediate goals-you can measure to make sure that a girl is on the right track for a healthy transition into adulthood?

- what assets (knowledge, skills, attitudes, opportunities) is your program giving a girl to help her make that healthy transition? 
Assets (see Chapter 7) are things that you can measure and can use to chart the success of your program. The second is to keep focused on the changes that you want to see in the girl herself. Measuring things like "lower HIV in the community" is very vague, difficult, and does not speak directly to the impact of your program.

In Chapter 7, you made a list of assets that you think girls should have by a certain age, and then you chose the assets that you wanted girls in your program to have. This is a great list of things to measure. For example, if you wanted girls to have a savings account-you can measure that. If you wanted them to know where to have an HIV testyou can measure that.

At the end of this chapter is a set of tools that will take you through a process of figuring out what you want to, and realistically can, measure. We have also included a sample list of questions that you can ask that will help you measure if girls have acquired those assets.

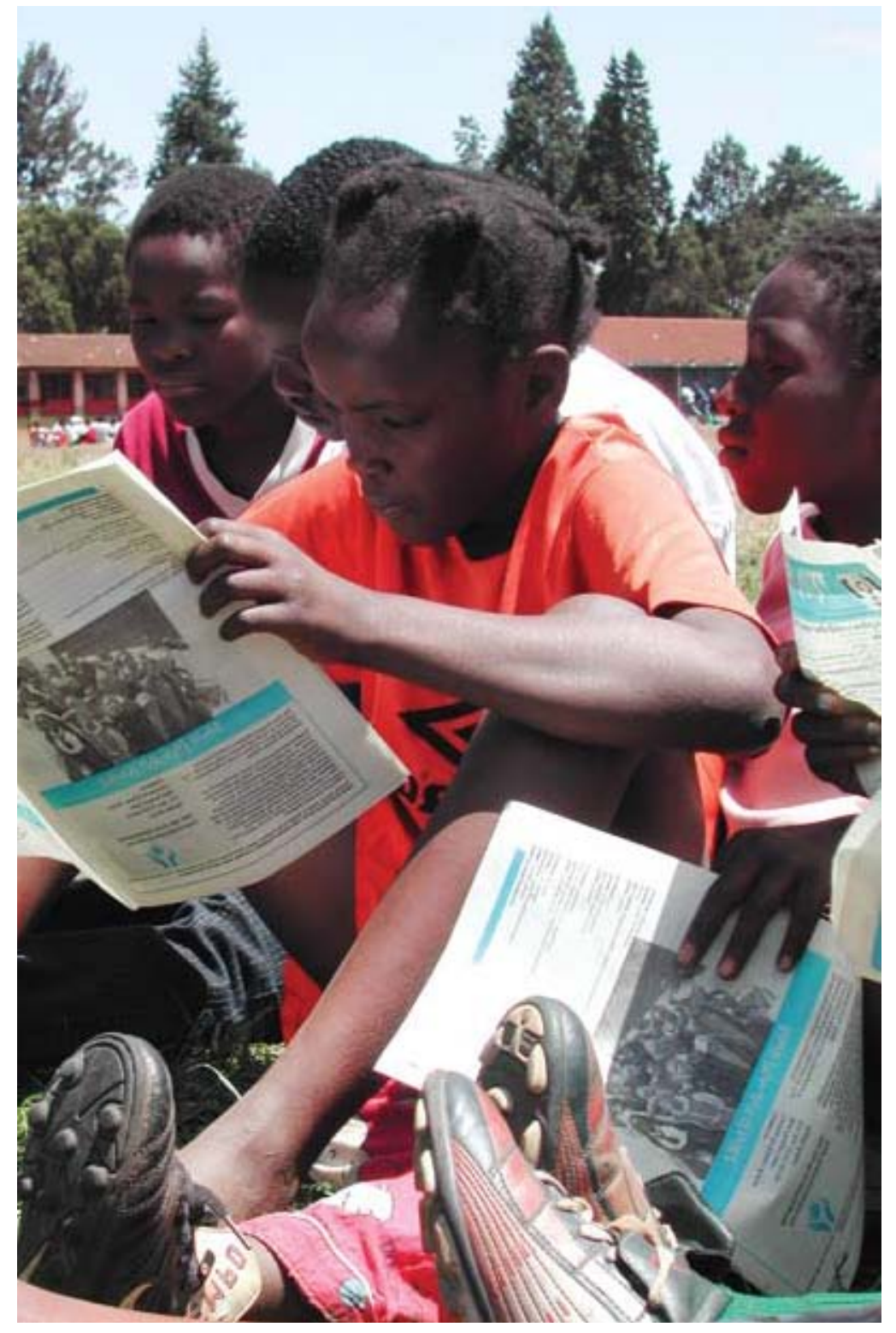




\section{Quantitative v. Qualitative}

Quantitative data is information that can be expressed in the form of a number-by a percent, a scale, or an average. The questions used to gather quantitative data are "closed-ended questions" meaning that they can be answered with a number or typically one word (yes or no; true or false; agree or disagree). The tools used to collect quantitative data are typically surveys or questionnaires and this kind of data is good for giving an overall picture or summary. It often answers the questions what, how much or how many?

Qualitative data is better at answering the questions how and why? The questions used are typically "open-ended", asking the participant to describe, explain and elaborate. The tools often used are the in-depth one-on-one interview using open-ended questions and the focus group discussion-typically a group of 6-10 people with common characteristics who are guided by an experienced facilitator through a series of questions on the topic you are exploring. Another common qualitative tool is the case study-where you follow a small number of participants in the program over time and capture information on their life history, the changes they have experienced through the program, their challenges and successes. This is often a nice way to highlight the impact of your program.

For example - let's look at a couple of different scenarios:

\section{Condom Use}

- How difficult is it for your partner to agree to use a condom every time you have sex?
a) Very Difficult;
b) Somewhat Difficult;
c) Somewhat Easy or;
d) Very Easy

This kind of question will collect QUANTITATIVE DATA

- Why is it difficult for your partner to agree to use a condom every time you have sex?

(Then the interviewer will ask further: "Explain a bit more," "Describe what you do in those situations".)

This kind of question will collect QUALITATIVE DATA 


\section{Safety}

- There is a lot of violence in the community where I live
a) Strongly Agree;
b) Somewhat Agree:
c) Somewhat Disagree; or
d) Strongly Disagree

\section{This kind of question will collect QUANTITATIVE DATA}

- Describe for me the kind of violence that occurs in this community?

(The interviewer will ask further - what are the areas with the most violence and why do you think that is so? Who are the people who cause most of the violence and why? Who are the people who are the victims of the violence and why? What do you think can be done to improve the situation and reduce the amount of violence?)

\section{These kinds of questions will collect QUALITATIVE DATA}

Often, programs will use a combination of the two kinds of data collection. This gives a nice ability to describe the overall picture in numbers, as well as with in-depth explanations and stories.

Tips for Making an Evaluation Plan

- Make a timeline, just like for your program

- Be realistic about how long it will take

- Keep it simple and short

- Think about intermediate results

- Think about areas where you would expect to see improvement

- Make standard questions relevant for your context

- But make sure you record the critical information

- Measure what you are trying to change

- Timing: Before, during, and after

- Only collect data as often as you are willing to do something about it 
A word about ongoing evaluation of activities

In addition to measuring the effect that your program is having on the girls themselves, it is important to engage in process evaluation - how is the program itself going? What do the girls think of the program activities? What do they like the most about the program? What changes would they make to the program? This can be done at certain time intervals (you can decide to do this every six months, once a year, etc.) or after major events (i.e. evaluating a specific training that the girls just went through or a community event that was held).

Doing this kind of evaluation regularly is important so that you have an up-to-date understanding about what works and what doesn't work in terms of your program activities, what the girls like and dislike, what they want more of or less of, etc. It can help you makes changes in the program activities throughout the course of the program. See the tools section for a sample event evaluation form.

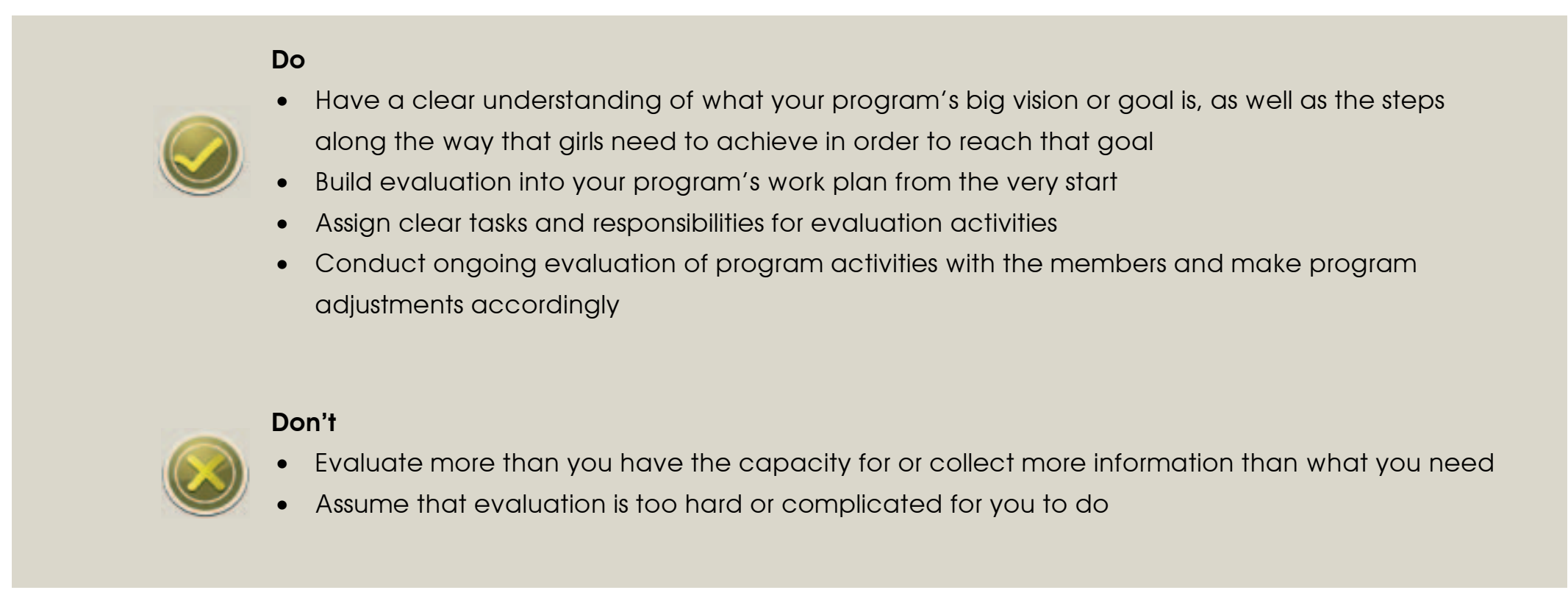


As you think about the kind of evaluation that you are planning, one of the first steps is to decide what you want to measure. As we discussed, being able to differentiate between the overall goal and vision that you have for the girls in you program, and the steps along the way that will let you know that they are on the path to reaching that goal will simplify your evaluation work and allow you to get meaningful information.

\section{First:}

What is the overall goal and vision of your organization? What is the big, long-term goal that you have for the girls in your program?

\section{Second:}

What are the assets that you are trying to build within the girls themselves? 
Third: What questions will you ask to measure each asset? (Use the list on page 174-181 to help you)

\begin{tabular}{|l|l|}
\hline ASSET/INDICATOR & QUESTION \\
\hline & \\
\hline & \\
\hline & \\
\hline & \\
\hline & \\
\hline & \\
\hline
\end{tabular}

Fourth: Think about what tools you will use to gather the information about each of these changes that you would like to measure. Will you use a short survey and include several questions? Will you have some focus groups? Use the next chart to think through the different tools:

\begin{tabular}{|l|l|l|}
\hline TOOL & ASSET/INDICATOR TO BE MEASURED & QUESTION TO BE ASKED \\
\hline Eg. Quantitative Survey & Has Savings & $\begin{array}{l}\text { Do you have money put aside or in your } \\
\text { savings? (Yes/No) }\end{array}$ \\
\hline Eg. Focus Group Discussion & Understands the Importance of Saving & $\begin{array}{l}\text { What are some of the reasons that girls } \\
\text { like yourselves save, or put money aside } \\
\text { for future use? }\end{array}$ \\
\hline & & \\
\hline & & \\
\hline & & \\
\hline
\end{tabular}


Fifth: Now you can assign responsibilities and timelines for getting these evaluation activities in place. It is also important to think about a) how much money this will cost and if it is in your budget and b) do you have the in-house skills to complete these tasks or if you will need to engage someone external (and the cost implications of that):

\begin{tabular}{|l|l|l|l|l|l|}
\hline TASK & $\begin{array}{l}\text { WHO WILL BE } \\
\text { RESPONSIBLE ? }\end{array}$ & $\begin{array}{l}\text { DO WE NEED } \\
\text { EXTERNAL } \\
\text { EXPERTISE \& IN } \\
\text { WHAT AREA? }\end{array}$ & $\begin{array}{l}\text { HOW MUCH } \\
\text { MONEY WILL IT } \\
\text { COST? }\end{array}$ & $\begin{array}{l}\text { HOW MUCH STAFF } \\
\text { TIME WILL IT TAKE? }\end{array}$ & BY WHT DATE? \\
\hline $\begin{array}{l}\text { Finalize list of } \\
\text { assets/indicators }\end{array}$ & & & & & \\
\hline $\begin{array}{l}\text { Finalize list of } \\
\text { questions }\end{array}$ & & & & & \\
\hline $\begin{array}{l}\text { Develop Evaluation } \\
\text { Tools (surveys, } \\
\text { interview guides, } \\
\text { etc.) }\end{array}$ & & & & & \\
\hline $\begin{array}{l}\text { Organize the Data } \\
\text { Collection* }\end{array}$ & & & & & \\
\hline $\begin{array}{l}\text { Collect the Data* } \\
\text { (doing the actual } \\
\text { interviewing) }\end{array}$ & & & & & \\
\hline Analyze the Data & & & & & \\
\hline Compile Reports & & & & & \\
\hline
\end{tabular}

*Note Data collection might happen at several points during the program cycle

Use the information in this chart to assess what can be done internally and what you will need external assistance with.

Calculate the total budget costs and assess if you have the funds and staff time available.

Finally, you can use all of this information to integrate the evaluation activities into your overall program work plan/timeline. 
Sample questions

Below is a list of questions that can be used to measure different assets. This list was initially compiled by Eva Roca and was drawn

from various Population Council surveys including Siyakha Nentsha (South Africa), Berhane Hewan (Ethiopia), TAP (Kenya), Biruh Tesfah (Ethiopa), SEWA (India), Safe and Smart Savings Products for Vulnerable Adolescent Girls (Kenya/Uganda).

Note - This list will help you to pick and choose questions that are relevant for YOUR program. We are not suggesting that you must ask all of these questions.

\begin{tabular}{|c|c|}
\hline CATEGORY OF INQUIRY & ILLUSTRATIVE QUESTIONS \\
\hline Basic demography & $\begin{array}{l}\text { - What is your age? } \\
\text { - What is your ethnicity? } \\
\text { - Who do you live with? (options given, with multiple responses possible-e.g., mother, father, } \\
\text { - Is your birth/natural father/mother alive? (if yes, does he/she live with you; if no, what age were } \\
\text { - Wou when he/she passed away?) } \\
\text { - What is your marital status? (single/in a relationship/engaged/married/divorced, etc.) } \\
\text { - How long have you lived in the community where you currently reside? } \\
\text { - If you migrated from another area, what is your region of origin? } \\
\text { - Have you ever attended school? } \\
\text { - What is the highest grade you have completed? }\end{array}$ \\
\hline
\end{tabular}




\begin{tabular}{|c|c|}
\hline $\begin{array}{l}\text { Social Assets (social networks, } \\
\text { group membership, relations of } \\
\text { trust, access to wider institutions of } \\
\text { society, freedom from violence) }\end{array}$ & 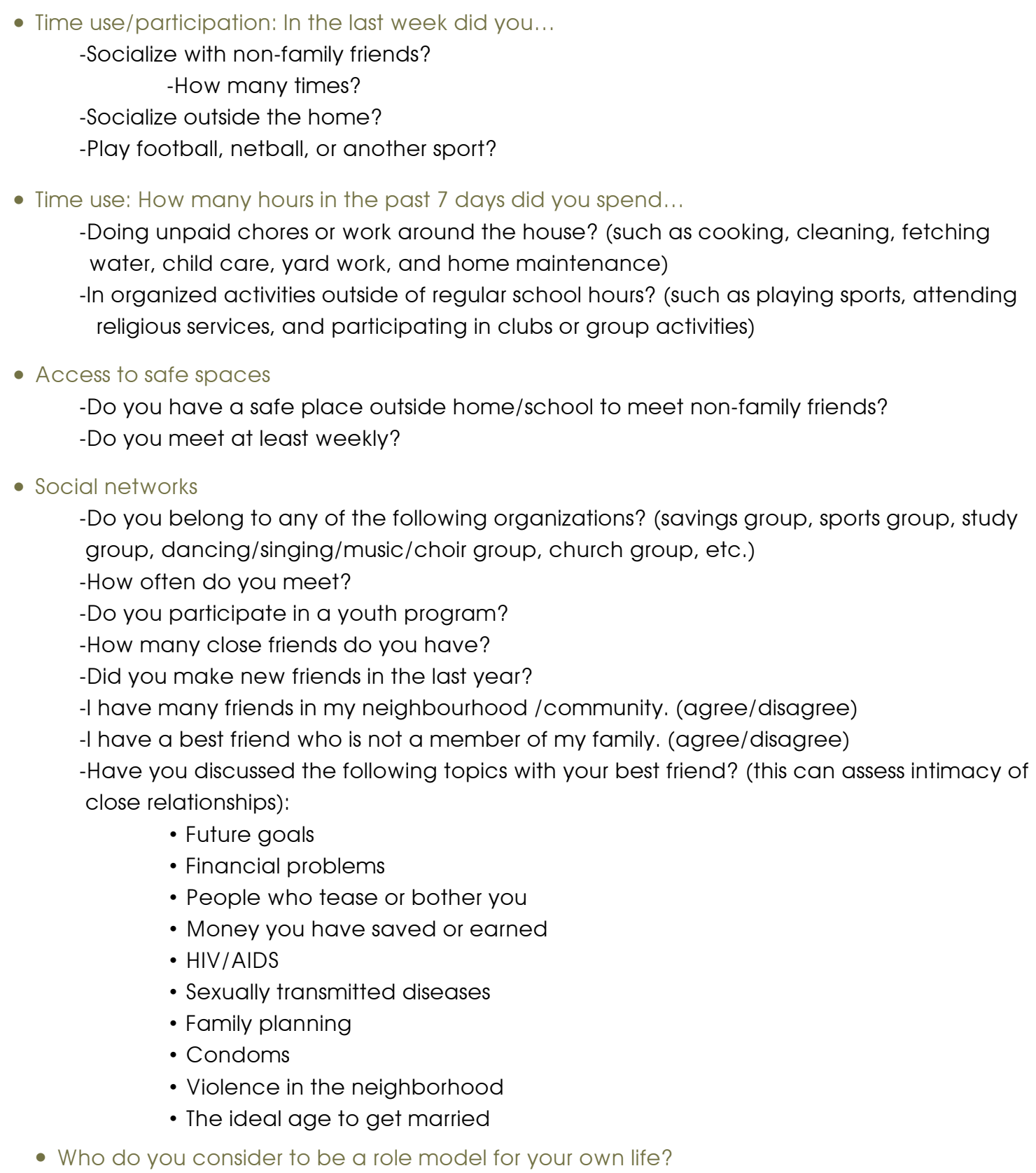 \\
\hline
\end{tabular}




\section{Social assets (social}

networks, group

membership, relations

of trust, access to wider

institutions of society,

freedom from violence)
- Safety/social cohesion Strongly agree/Agree/Disagree/Strongly disagree with the following statements: -I feel safe walking around in my neighbourhood/community during the day.

-The adults in my neighbourhood/community will help me if I am in trouble.

-There is a lot of crime in my neighbourhood/community.

-There is a lot of violence among young people in my neighbourhood/community.

-I would be much happier if I lived in another community.

-I trust people in my community.

-In my neighborhood, people tease me as I go about my business.

- Safety nets

-If you didn't have a place to sleep, there is someone in the neighborhood who would take you in. -Do you have someone to turn to in difficulty?

-Do you have someone to borrow money from in an emergency? / If you needed money urgently, is there someone you could borrow from?

-How many non-family friends do you have?

-How often do you see them?

- Safety planning

-Do you have a plan to avoid harassment in the streets? (Yes/No)

-Is it OK for teachers to invite you to their home to get a grade? (Yes/No)

-Where is the nearest Police Station? (Is answer correct/incorrect)

-Where do you go if someone is trying to marry you off against your will? (Is answer correct/ incorrect)

- Has anyone ever (and when was the first/last time this happened?)

-Slapped you or thrown something at you that could hurt you?

-Pushed or shoved you?

-Twisted your arm or pulled your hair?

-Hit you with a fist or something else that could hurt?

-Threatened you with a gun or knife?

- The last time this happened, did you tell anyone about it? Who? (friend, family, an authority, a teacher, etc)

-Do you know a place you could go for help if something like this happened to you? 


\begin{tabular}{|c|c|}
\hline $\begin{array}{l}\text { Human assets } \\
\text { (skills and knowledge, } \\
\text { ability to work, good } \\
\text { health, self-esteem, } \\
\text { bargaining power, } \\
\text { autonomy, control } \\
\text { over decisions) }\end{array}$ & 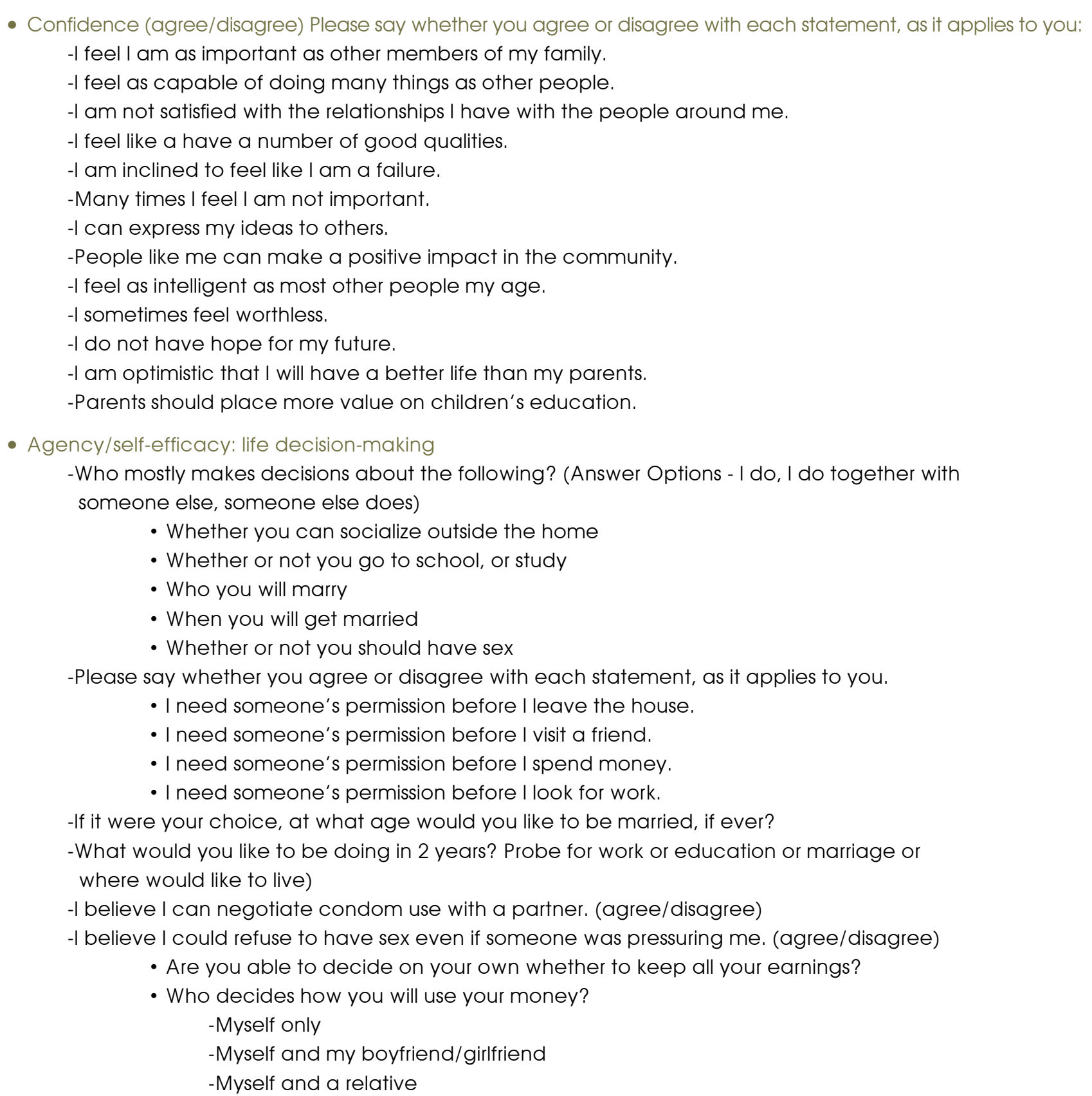 \\
\hline
\end{tabular}




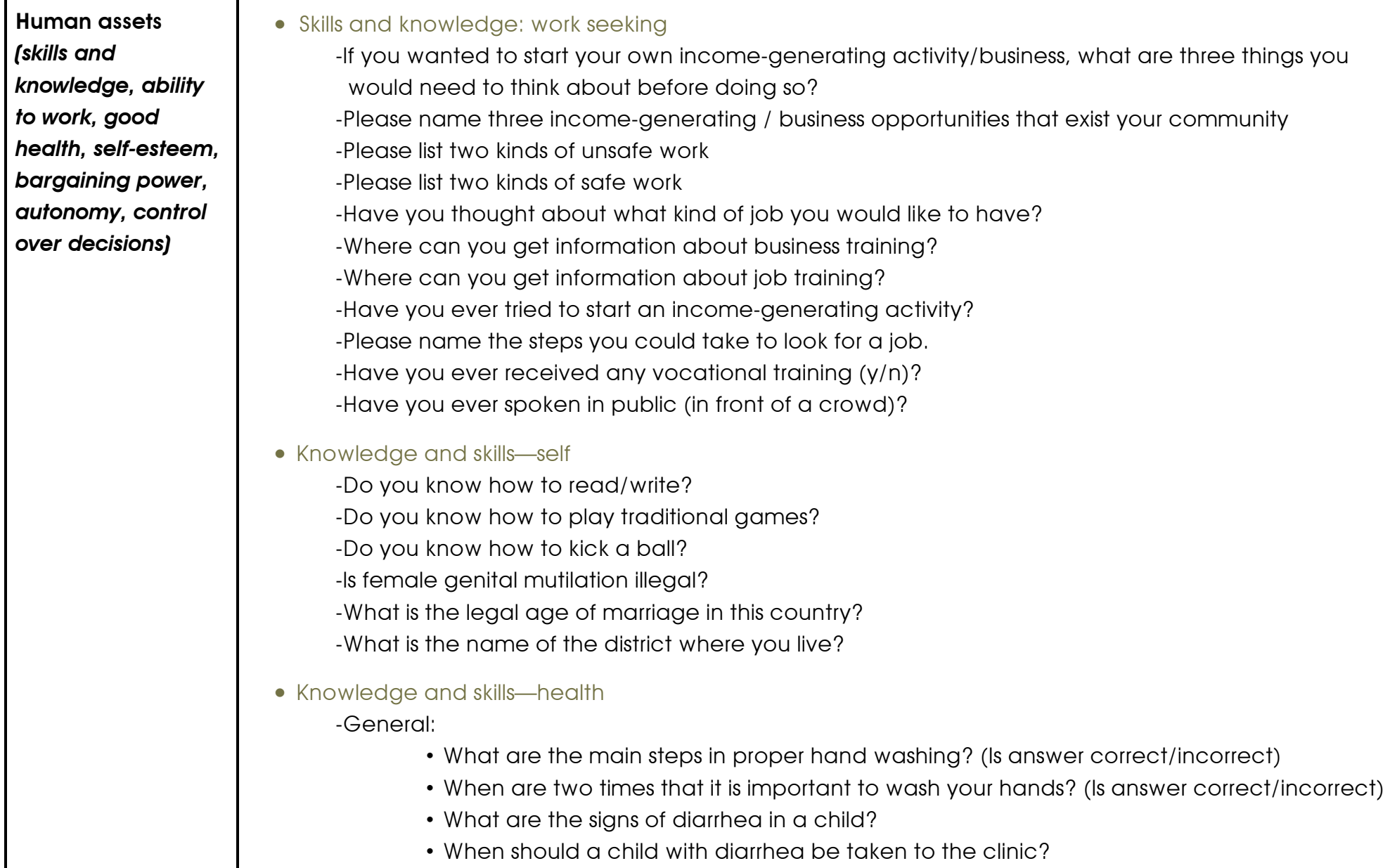

Human assets

(skills and

knowledge, ability

to work, good

health, self-esteem,

bargaining power,

autonomy, control

over decisions]

- Skills and knowledge: work seeking

-If you wanted to start your own income-generating activity/business, what are three things you would need to think about before doing so?

-Please name three income-generating / business opportunities that exist your community

-Please list two kinds of unsafe work

-Please list two kinds of safe work

-Have you thought about what kind of job you would like to have?

-Where can you get information about business training?

-Where can you get information about job training?

-Have you ever tried to start an income-generating activity?

-Please name the steps you could take to look for a job.

- Have you ever received any vocational training $(y / n)$ ?

-Have you ever spoken in public (in front of a crowd)?

- Knowledge and skills-self

-Do you know how to read/write?

-Do you know how to play traditional games?

-Do you know how to kick a ball?

-Is female genital mutilation illegal?

-What is the legal age of marriage in this country?

-What is the name of the district where you live?

- Knowledge and skills-health

-General:

- What are the main steps in proper hand washing? (Is answer correct/incorrect)

- When are two times that it is important to wash your hands? (Is answer correct/incorrect)

- What are the signs of diarrhea in a child?

- When should a child with diarrhea be taken to the clinic? 


\begin{tabular}{|c|c|}
\hline $\begin{array}{l}\text { Human assets } \\
\text { (skills and } \\
\text { knowledge, ability } \\
\text { to work, good } \\
\text { health, self-esteem, } \\
\text { bargaining power, } \\
\text { autonomy, control } \\
\text { over decisions) }\end{array}$ & 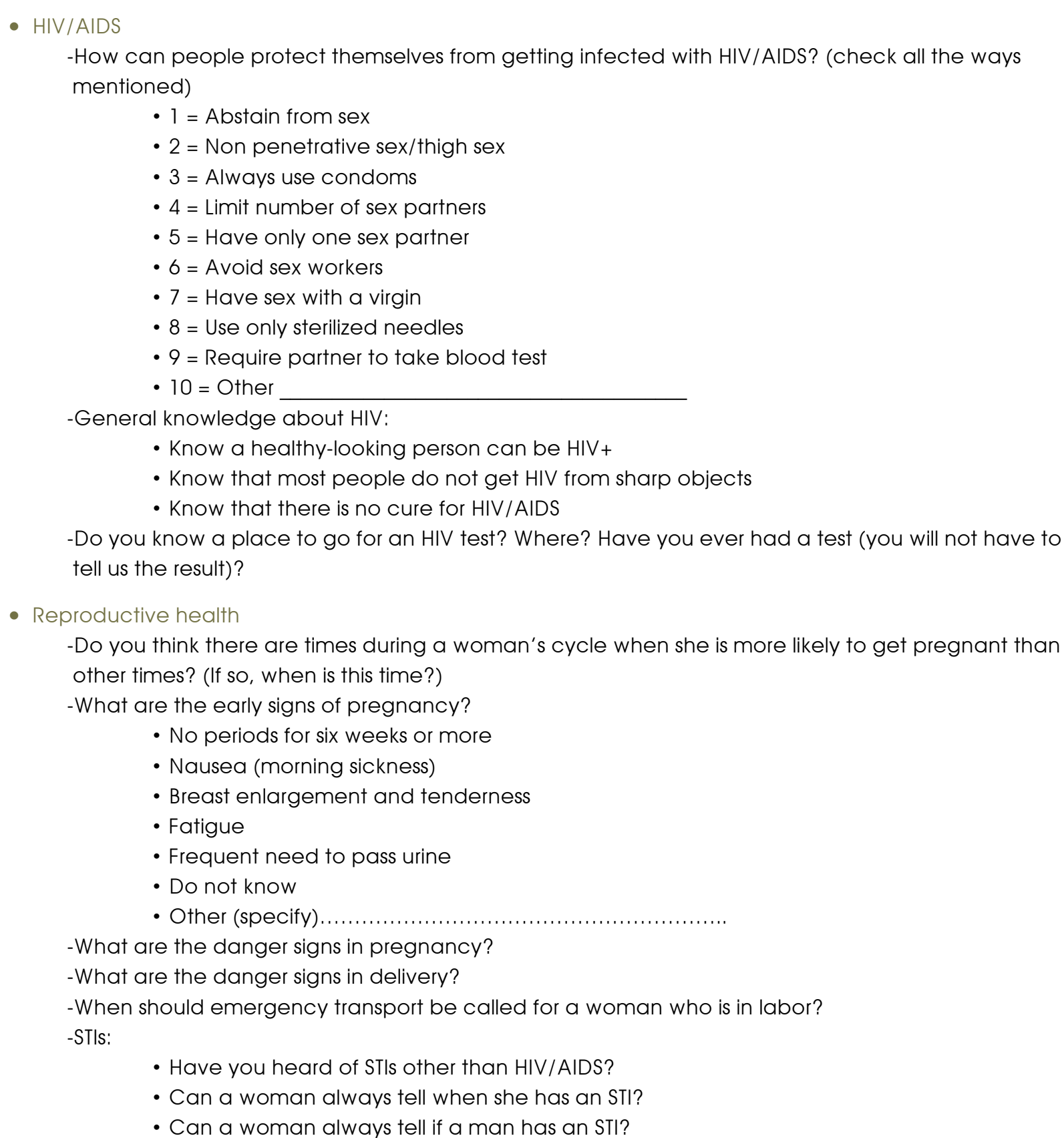 \\
\hline
\end{tabular}




\begin{tabular}{|c|c|}
\hline $\begin{array}{l}\text { Human assets } \\
\text { (skills and knowledge, ability to work, } \\
\text { good health, self-esteem, bargaining } \\
\text { power, autonomy, control over decisions) }\end{array}$ & $\begin{array}{l}\text { - Access knowledge } \\
\text { - What is the nearest emergency health service? (Is answer correct/incorrect) } \\
\text {-Do you know where to go if you wanted to get tested? } \\
\text {-Have you ever had a health check up? } \\
\text {-Have you had a visual/hearing screening? } \\
\text {-ls there a youth club in your neighborhood? } \\
\text {-Have you ever been there? } \\
\text { - Knowledge and skills - Financial Literacy } \\
\text {-Do you know where the nearest bank is? } \\
\text {-Have you ever been inside a bank? } \\
\text {-Have you ever kept track of how much money you make for a period of time? } \\
\text {-Have you ever kept track of how much money you spend for a period of time? } \\
\text {-What are two reasons why savings in important? } \\
\text {-What is one informal way to save money? } \\
\text {-What is one formal way to save money? } \\
\text {-Do you know where to go if you wanted more information on a financial service? } \\
\text {-What are two obligations of a loan? } \\
\text {-How often do you deposit money into your savings? }\end{array}$ \\
\hline $\begin{array}{l}\text { Financial assets } \\
\text { (cash, savings, loans and gifts, regular } \\
\text { remittances or entitlements) }\end{array}$ & $\begin{array}{l}\text { - Employment and earning } \\
\text {-Have you ever spent time actively looking for work? Last } 12 \text { months? Last month? } \\
\text {-Have you ever undertaken any kind of work, whether for yourself or for other } \\
\text { people, for which you have earned money? In the last } 12 \text { months? Last month? } \\
\text {-What type of work was this? (have locally relevant categories available) } \\
\text {-How much money did you earn? (per day, per hour, etc) } \\
\text {-Was this work a type you would have chosen? (or something to indicate } \\
\text { whether forced/coerced work) } \\
\text {-What are two characteristics of unsafe work? (Is answer correct/incorrect) }\end{array}$ \\
\hline
\end{tabular}




\begin{tabular}{|c|c|}
\hline $\begin{array}{l}\text { Financial assets } \\
\text { (cash, savings, loans and gifts, regular } \\
\text { remittances or entitlements) }\end{array}$ & $\begin{array}{l}\text { - Savings/ financial decision-making: } \\
\text {-I have a financial goal (yes/no) } \\
\text {-l am saving money in order to do or buy something specific (yes/no) } \\
\text {-When you have money, do you plan ahead for how to spend it? } \\
\text {-I have savings/ I am saving (yes/no) } \\
\text {-l am saving for something specific (yes/no)_or some other indication of having a } \\
\text { financial goal. } \\
\text {-l have some money I keep in case of an emergency (yes/no) } \\
\text {-How much money do you have in your savings? } \\
\text {-Have you ever tried to open a bank account? (if yes, were you successful?) } \\
\text {-Have you ever borrowed money? }\end{array}$ \\
\hline $\begin{array}{l}\text { Physical assets } \\
\text { (land, housing, jewelry, shoes, clothing, } \\
\text { productive assets, tools and equipment } \\
\text { for business activities) }\end{array}$ & $\begin{array}{l}\text { - Household level } \\
\text {-Does your household own any of the following assets? (Could also ask if } \\
\text { personally owned, as appropriate. Lists tailored for what is relevant in a } \\
\text { particular setting. For example, Kenya included: radio, television, kerosene lamp, } \\
\text { productive tools (i.e. sewing machine), mobile phone, refrigerator, furniture, } \\
\text { bicycle, motorcycle, automobile, house, land, small/large livestock, savings, } \\
\text { jewelry) } \\
\text { - Personal level } \\
\text {-Do you personally own any of the following: (above list tailored for what is } \\
\text { relevant in a particular setting) } \\
\text { - Citizenship: Do you have any of the following identification documents: Birth } \\
\text { certificate, ID card? } \\
\text {-Do you have a CV? } \\
\text {-Do you have any degrees/diplomas/certificates of achievement? }\end{array}$ \\
\hline
\end{tabular}




\section{SAMPLE TRAINING PARTICIPANT EVALUATION FORM}

\section{Participant Training Evaluation Form}

Date: Title of Training:

1. What was your favorite part of the training today?

2. Which topic was the most important to you in the training? Why?

3. Which topics need to be added to this training?

4. What was your least favorite part of the training?

5. What are three things that we can improve about this training?
A)
B)
C) 


\section{SAMPLE PROGRAM EVALUATION FORM}

\section{Member Evaluation Form}

Note This form is designed to be completed by the girls themselves in writing. Please adapt the questions to suit your specific program goals and activities. Also, it is generically called "this program". Feel free to fill in with your program's name.

1. What have you learned from (this program)?

2. What more would you like to learn at (this program) that you have not yet learned?

3. What is your favorite activity at (this program)?

4. What is your least favorite activity at (this program)?

5. What would you do to make (this program) better?

6. What would you do to make your life as a young woman better and that of other young woman in this community and (this program)?

7. What do you think is (this program)'s impact on this community?

8. How can (this program) better impact the community?

9. Has (this program) had an effect on your life? If so, how?

Any other comments 
*Note The two forms on pages 182 \& 183 (training evaluation and program evaluation) require girls to be able to read and write. If you would rather not rely on that, you can ask the girls the questions out loud either individually or as a group. You can use the following chart as a guide for a group discussion. Ask participants what about the program or training they love, like, want less of, or want no more of:

\begin{tabular}{|l|l|}
\hline LOVE IT & LIKE IT \\
\hline & \\
\hline LESS OF IT & \\
\hline IT & \\
\hline & LOSE IT \\
\hline & \\
\hline
\end{tabular}


Section 5

Annexes

Tools/Handouts

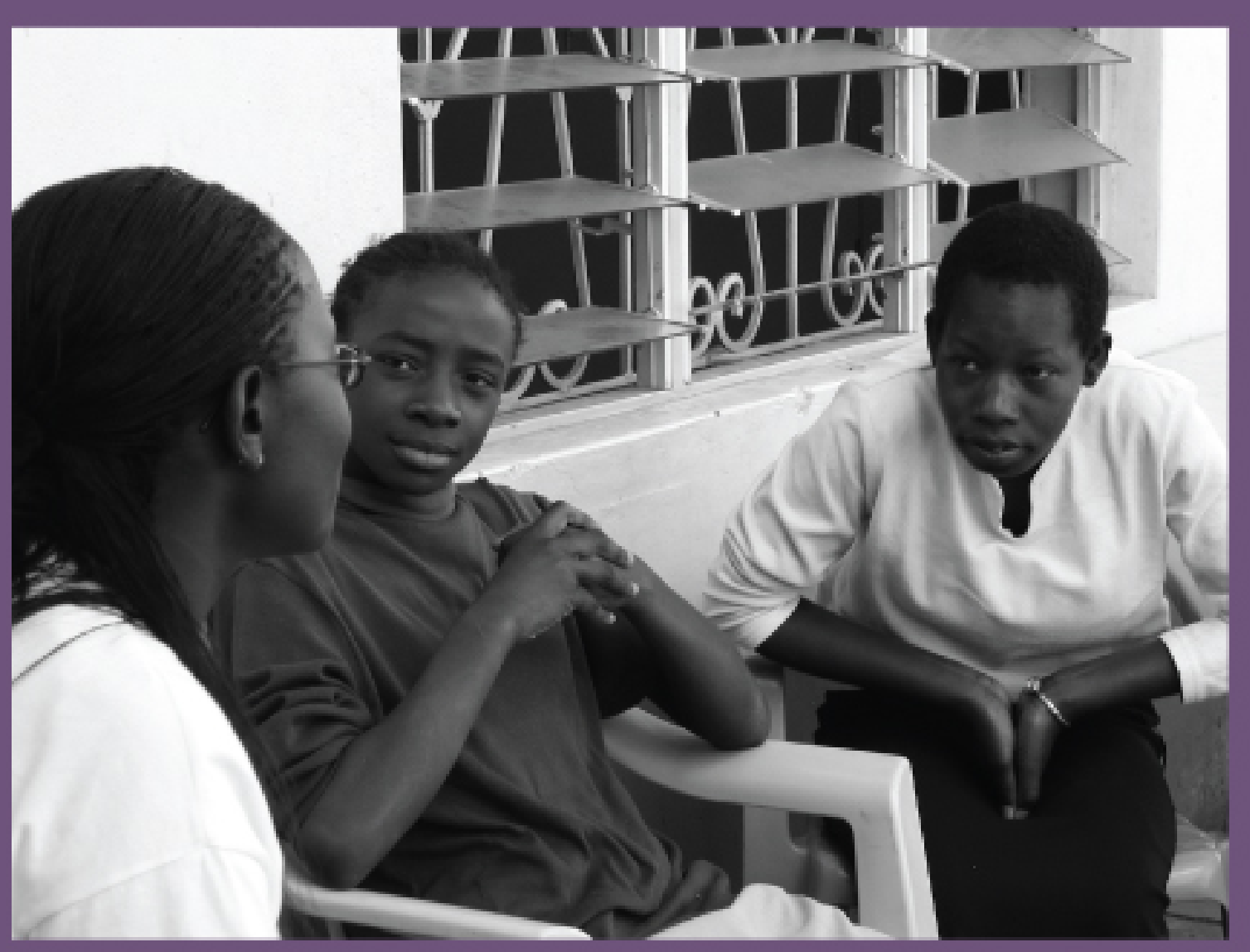

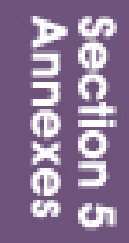




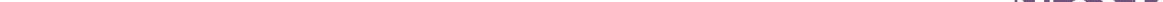


Chapter 1: Coverage exercise tool

Sample coverage exercise

Remember, you must choose the profile information that is important for your own program.

\begin{tabular}{|c|c|c|c|c|c|}
\hline & Male/female & Age & $\begin{array}{l}\text { In school/out of } \\
\text { school }\end{array}$ & $\begin{array}{l}\text { Neighbourhood that } \\
\text { you live in }\end{array}$ & $\begin{array}{l}\text { Do you live with one or } \\
\text { both of your parents? }\end{array}$ \\
\hline 1 & & & & & \\
\hline 2 & & & & & \\
\hline 3 & & & & & \\
\hline 4 & & & & & \\
\hline 5 & & & & & \\
\hline 6 & & & & & \\
\hline 7 & & & & & \\
\hline 8 & & & & & \\
\hline 9 & & & & & \\
\hline 10 & & & & & \\
\hline 11 & & & & & \\
\hline 12 & & & & & \\
\hline 13 & & & & & \\
\hline 14 & & & & & \\
\hline 15 & & & & & \\
\hline 16 & & & & & \\
\hline 17 & & & & & \\
\hline 18 & & & & & \\
\hline 19 & & & & & \\
\hline 20 & & & & & \\
\hline 21 & & & & & \\
\hline 22 & & & & & \\
\hline 23 & & & & & \\
\hline 24 & & & & & \\
\hline 25 & & & & & \\
\hline 26 & & & & & \\
\hline 27 & & & & & \\
\hline 28 & & & & & \\
\hline
\end{tabular}

In this coverage exercise tool you will learn about boys vs. girls, age, if they are in or out of school, where they live and with whom they live. You will not learn at what level they are in school, if they work, if they have children, and more. If you want to get different information, you will have to change the characteristics listed in this table. 


\section{Sample coverage exercise-summary sheet}

This table can be used to summarize the information collected with the coverage tool.

\begin{tabular}{|c|c|c|c|c|c|c|c|c|}
\hline & \multicolumn{2}{|c|}{ Schooling status } & \multicolumn{2}{|c|}{ Living status } & \multicolumn{4}{|c|}{ Location* } \\
\hline & In school & $\begin{array}{l}\text { Out of } \\
\text { school }\end{array}$ & $\begin{array}{l}\text { One or both } \\
\text { parents }\end{array}$ & $\begin{array}{l}\text { Neither } \\
\text { parent }\end{array}$ & Area 1 & Area 2 & Area 3 & Area 4 \\
\hline Girls 10-14 & & & & & & & & \\
\hline Girls 15-19 & & & & & & & & \\
\hline Girls $20+$ & & & & & & & & \\
\hline Boys 10-14 & & & & & & & & \\
\hline Boys 15-19 & & & & & & & & \\
\hline Boys $20+$ & & & & & & & & \\
\hline
\end{tabular}

* Personalize this based on the area where you are working 


\section{Chapter 3: Safety Scan Tools}

Safety by time of day

Fill out where you are during all 24 hours of the day. Then next to each time slot, check off one of the three columns.

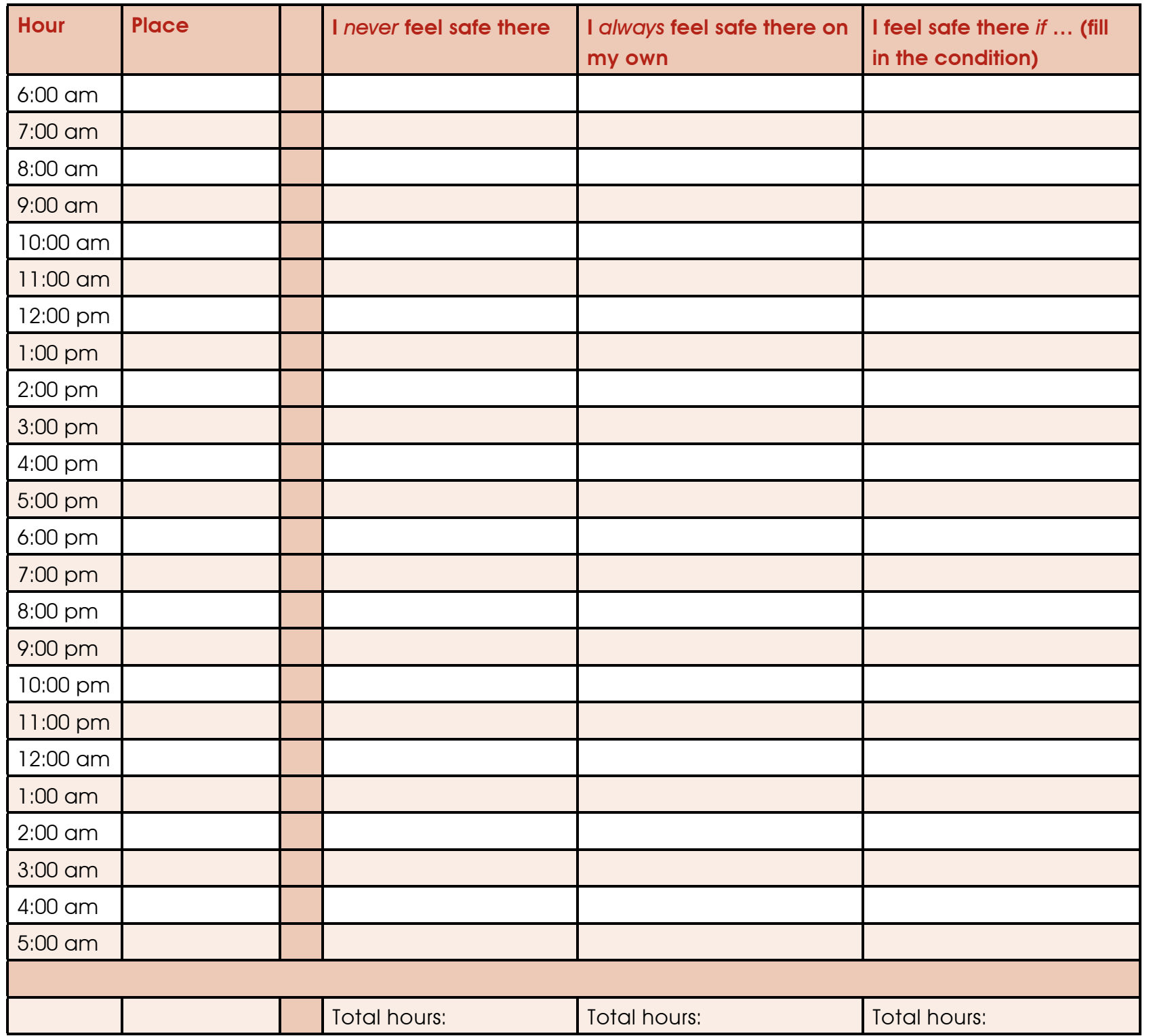


Safety in different places in the community

\begin{tabular}{|l|l|l|l|}
\hline Places & Never feel safe & Always feel safe & Sometimes feel safe \\
\hline Market & & & \\
\hline School & & & \\
\hline Home & & & \\
\hline Police station & & & \\
\hline Church, mosque & & & \\
\hline Clinic & & & \\
\hline Bus station & & & \\
\hline Friend's home & & & \\
\hline
\end{tabular}

Safety accessing services and opportunities

For situations where you sometimes feel safe, indicate what would make you feel safer.

\begin{tabular}{|l|l|l|l|l|}
\hline Situation & $\begin{array}{l}\text { Always safe to use, } \\
\text { access }\end{array}$ & $\begin{array}{l}\text { Sometimes safe to } \\
\text { use, access }\end{array}$ & $\begin{array}{l}\text { Never safe to use/ } \\
\text { access }\end{array}$ & $\begin{array}{l}\text { What would make } \\
\text { it safer? }\end{array}$ \\
\hline $\begin{array}{l}\text { Taking public } \\
\text { transportation }\end{array}$ & & & & \\
\hline Taking taxis & & & & \\
\hline Health service & & & & \\
\hline Going to school & & & & \\
\hline Going to the bank & & & & \\
\hline Going to the post office & & & & \\
\hline On a football pitch & & & & \\
\hline At the salon & & & & \\
\hline Church, mosque & & & & \\
\hline
\end{tabular}


Safety nets

\begin{tabular}{|l|l|l|l|l|}
\hline $\begin{array}{l}\text { In an emergency, do you } \\
\text { have ... }\end{array}$ & Yes & No & Not sure & Comment \\
\hline $\begin{array}{l}\text { Five non-family female } \\
\text { friends? }\end{array}$ & & & & \\
\hline $\begin{array}{l}\text { A place to meet female } \\
\text { friends at least once a } \\
\text { week? }\end{array}$ & & & & \\
\hline $\begin{array}{l}\text { Someone to turn to if you } \\
\text { have a sensitive personal } \\
\text { problem -your own or } \\
\text { someone else's? }\end{array}$ & & & & \\
\hline $\begin{array}{l}\text { Someone from whom you } \\
\text { can borrow money? }\end{array}$ & & & & \\
\hline $\begin{array}{l}\text { A safe place to stay for the } \\
\text { night? }\end{array}$ & & & & \\
\hline $\begin{array}{l}\text { Someone to turn to if you } \\
\text { have a health problem? }\end{array}$ & & & & \\
\hline $\begin{array}{l}\text { Someone to turn to if } \\
\text { you have an economic } \\
\text { problem? }\end{array}$ & & & & \\
\hline
\end{tabular}

\section{Safety by season}

\begin{tabular}{|l|l|l|}
\hline Seasons that bring risk & Does the season bring risk? Why? & What can be done to reduce risk \\
\hline Harvesting & & \\
\hline Rainy season & & \\
\hline Migration for work & & \\
\hline School fees are due & & \\
\hline Holidays & & \\
\hline School is in session & & \\
\hline Other (describe) & & \\
\hline Other (describe) & & \\
\hline Other (describe) & & \\
\hline
\end{tabular}


Safety by situation

\begin{tabular}{|l|l|l|}
\hline Situations that bring risk & Does the situation bring risk? Why? & What can be done to reduce risk \\
\hline Getting stopped by a policeman & & \\
\hline In a shop by myself & & \\
\hline Asking for a grade & & \\
\hline Being kept after school & & \\
\hline Negotiating to sell something & & \\
\hline Other (describe) & & \\
\hline Other (describe) & & \\
\hline Other (describe) & & \\
\hline
\end{tabular}

Safety by day

\begin{tabular}{|l|l|l|}
\hline Days of the week & $\begin{array}{l}\text { Times of the week I feel most safe and } \\
\text { relaxed }\end{array}$ & $\begin{array}{l}\text { Times of the week I feel least safe and } \\
\text { relaxed }\end{array}$ \\
\hline Monday & & \\
\hline Tuesday & & \\
\hline Wednesday & & \\
\hline Thursday & & \\
\hline Friday & & \\
\hline Saturday & & \\
\hline Sunday & & \\
\hline
\end{tabular}




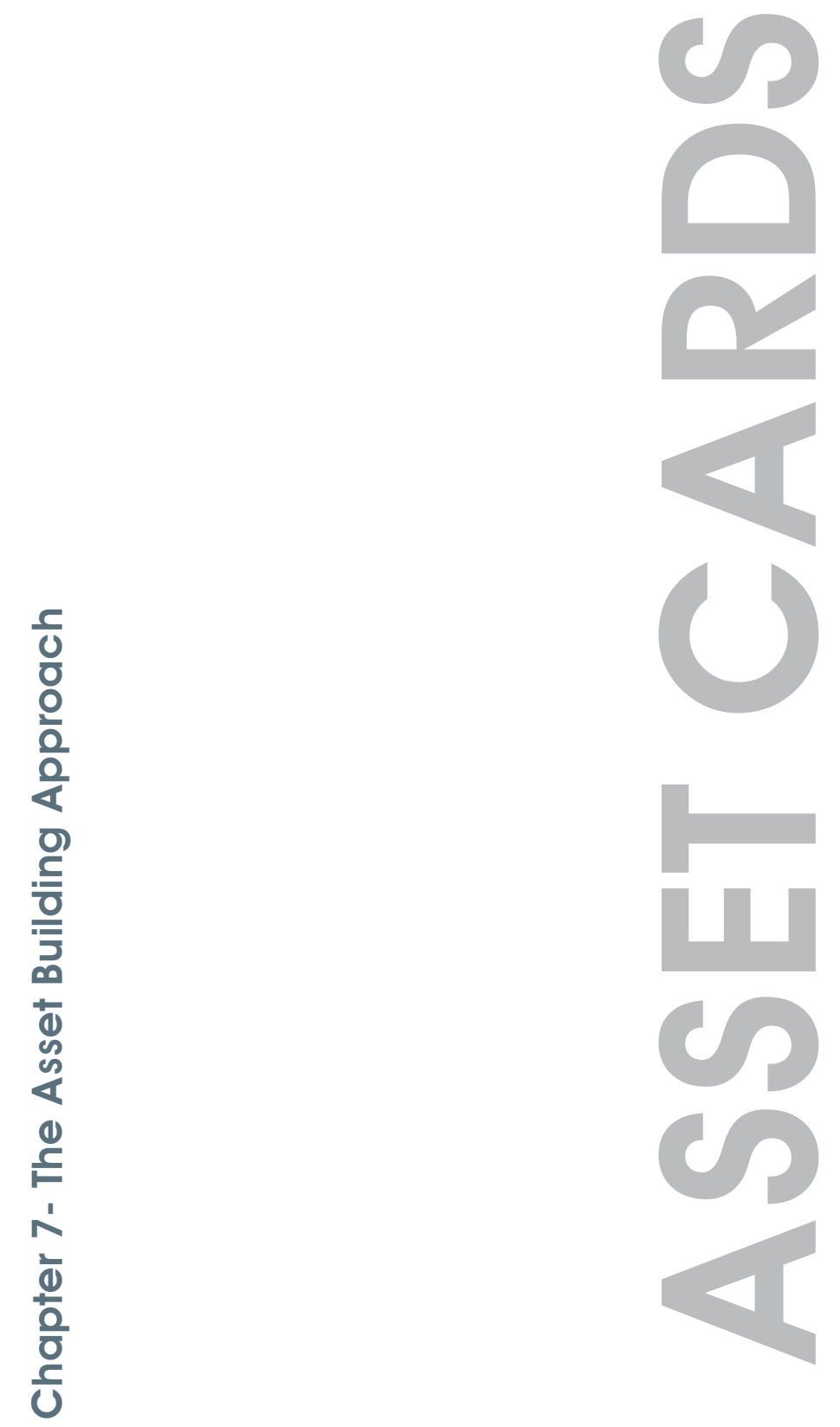




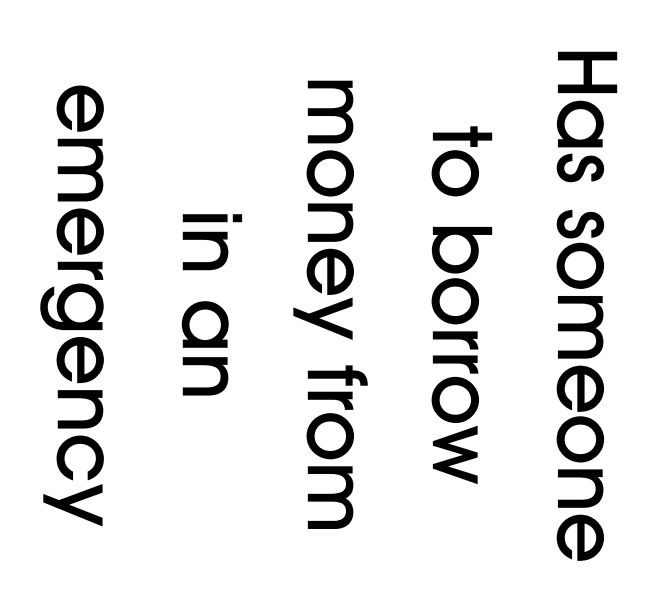

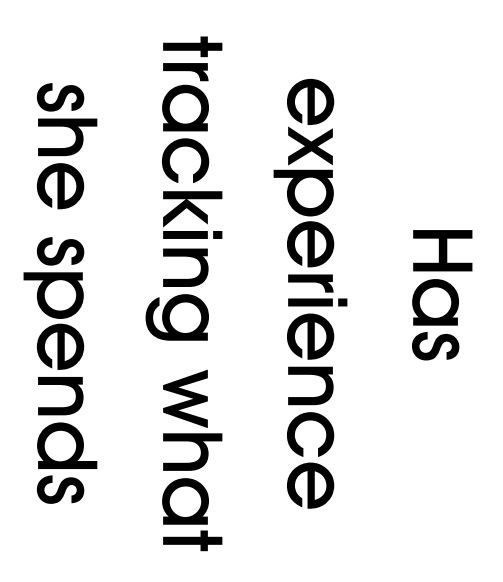

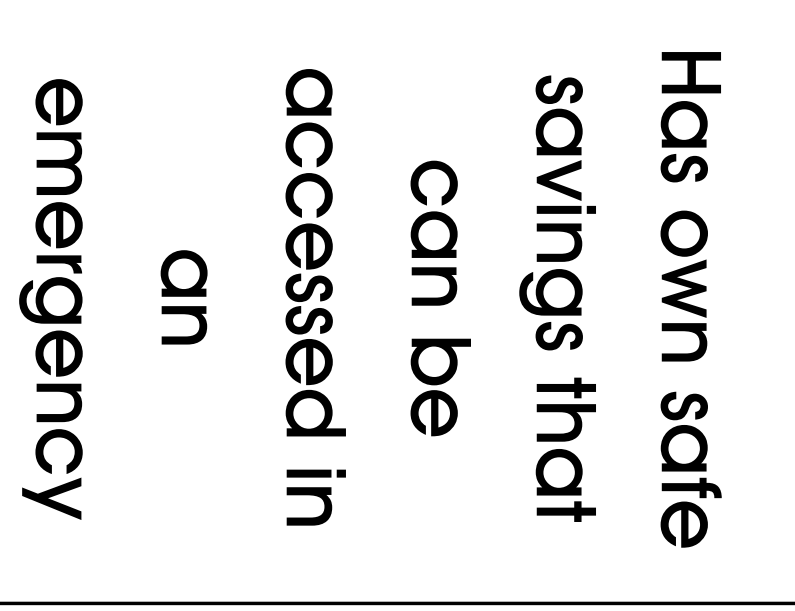

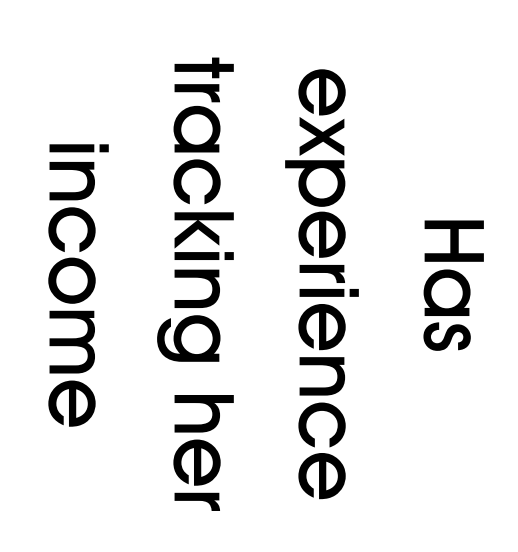

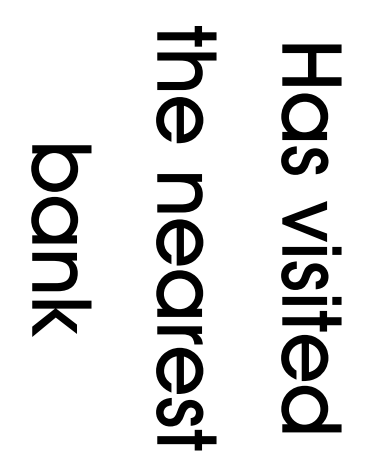

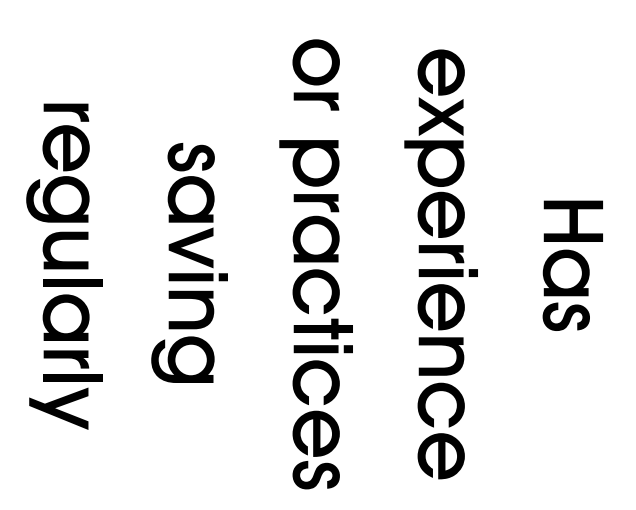

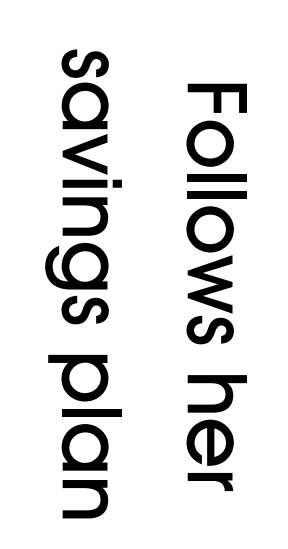

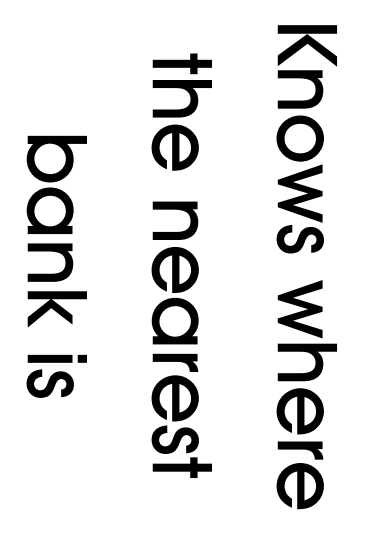



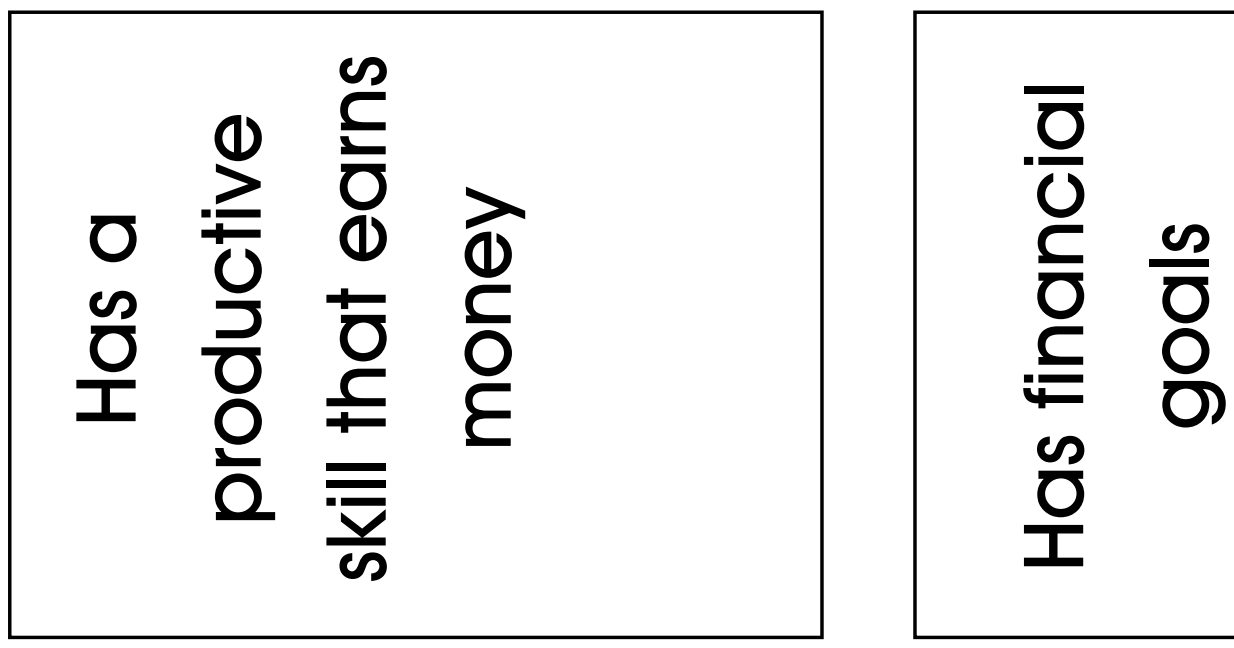

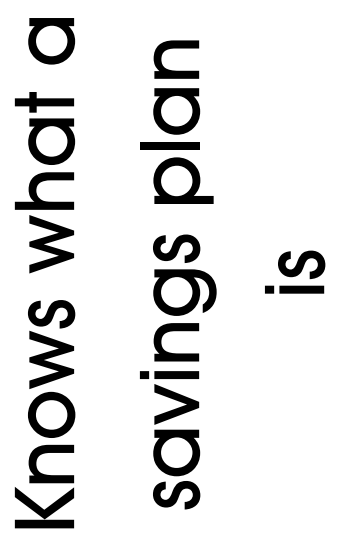

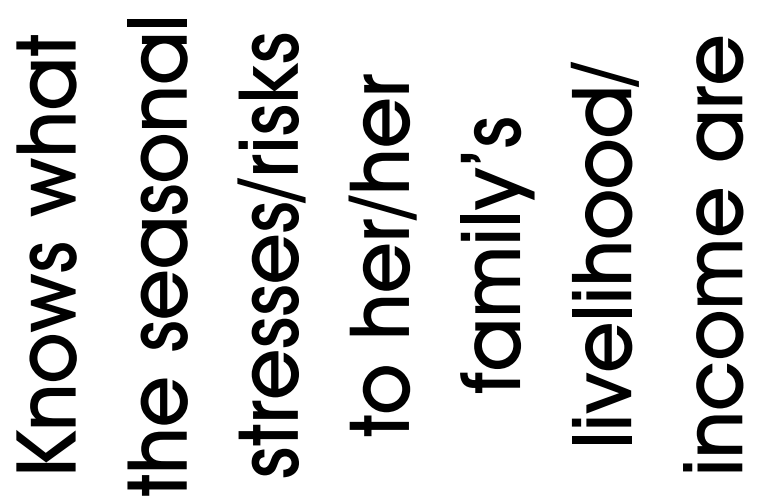

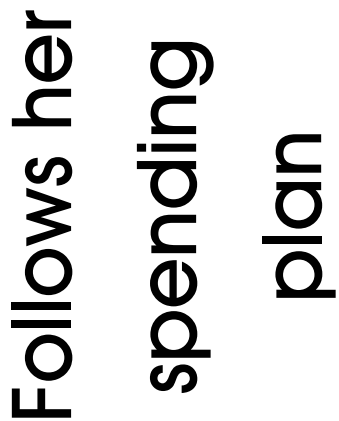

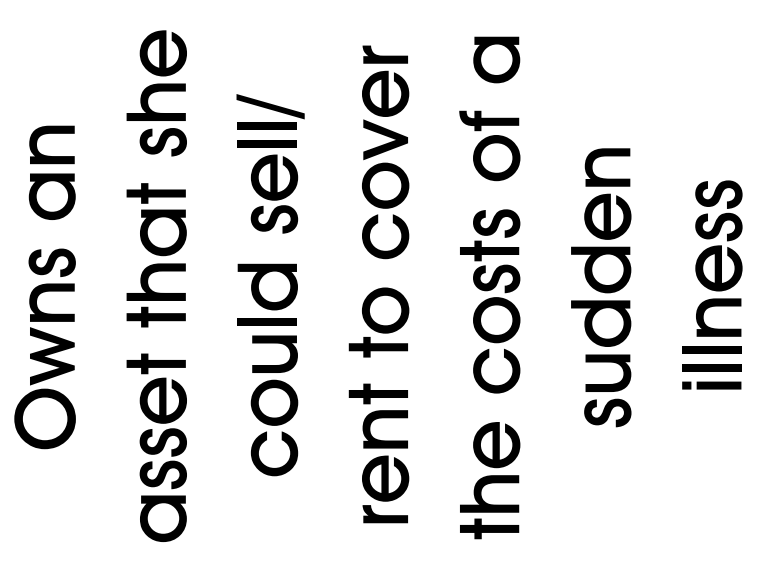

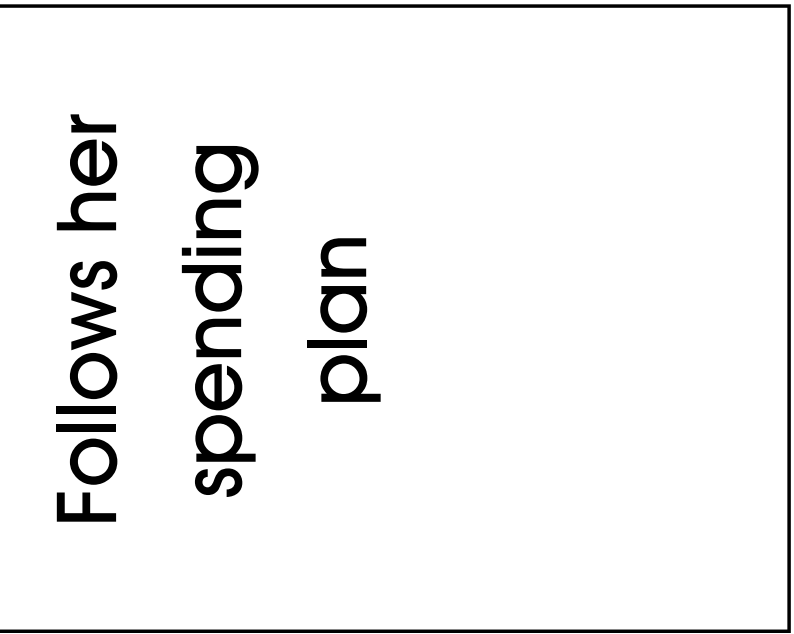

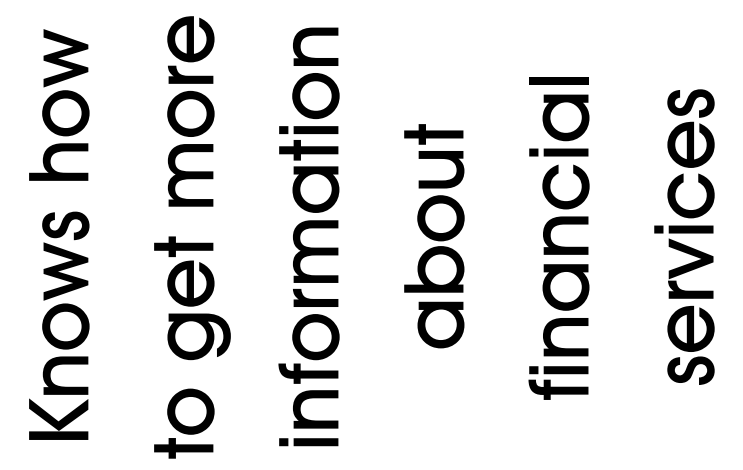




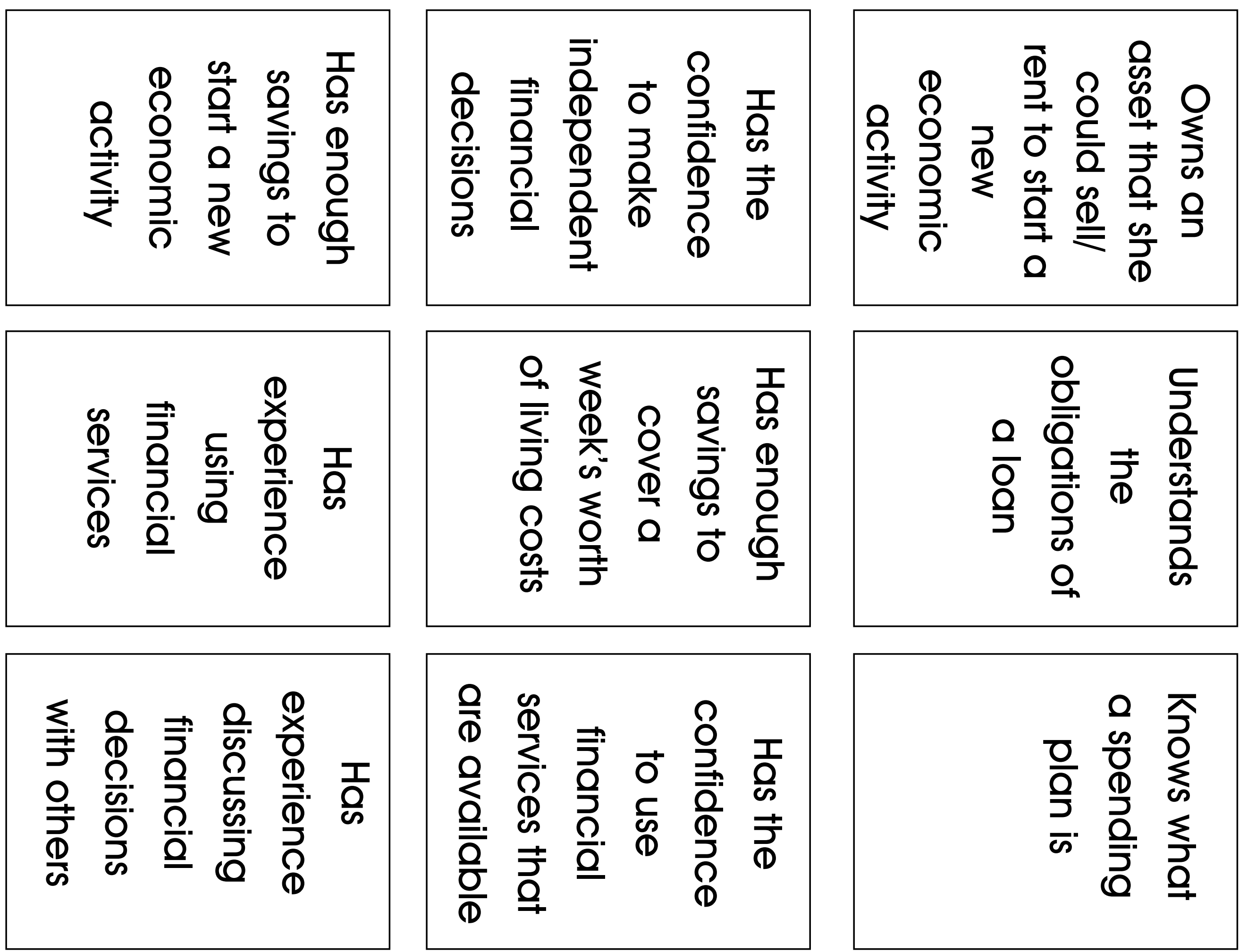




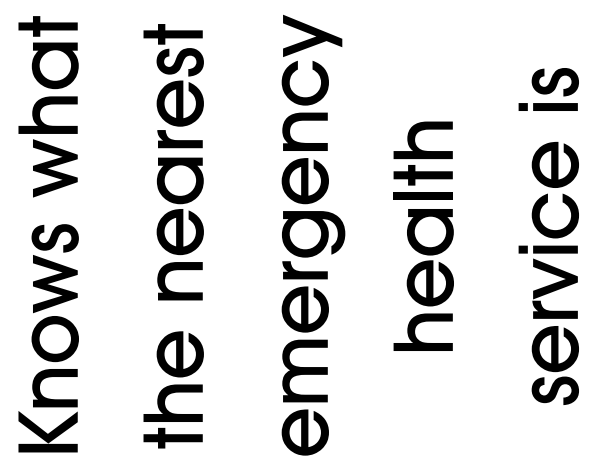

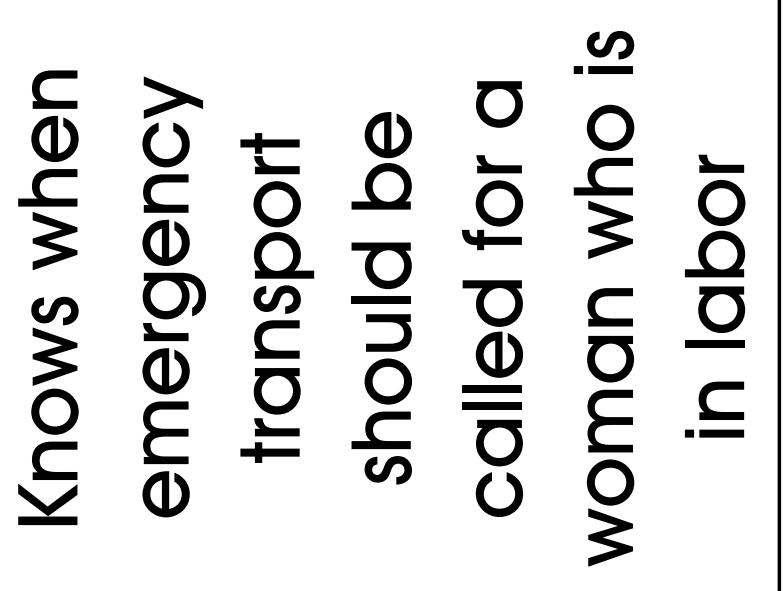

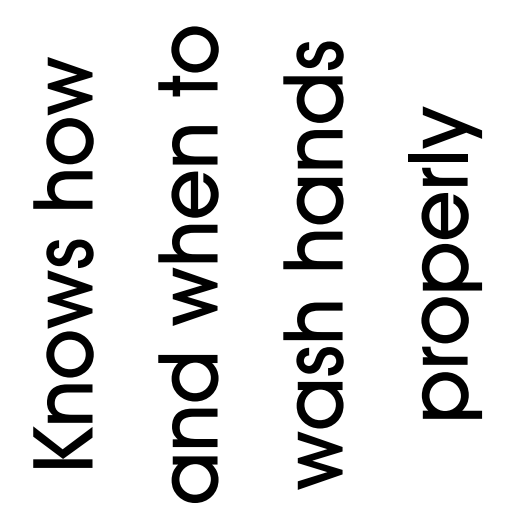

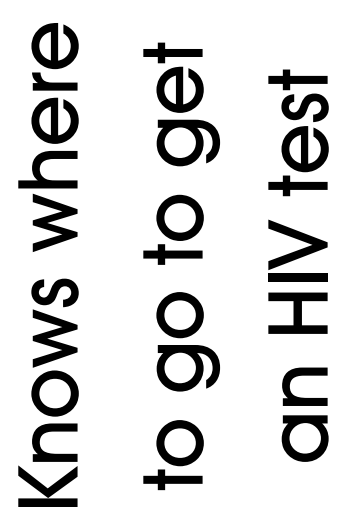

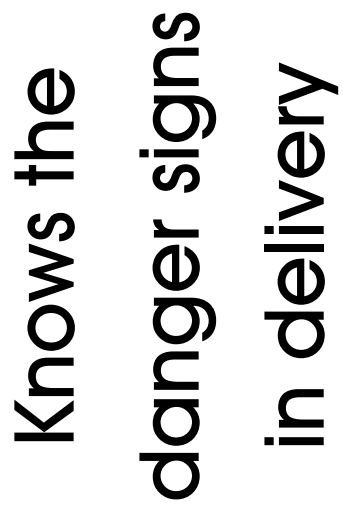

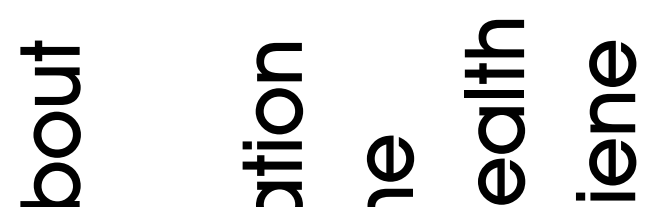

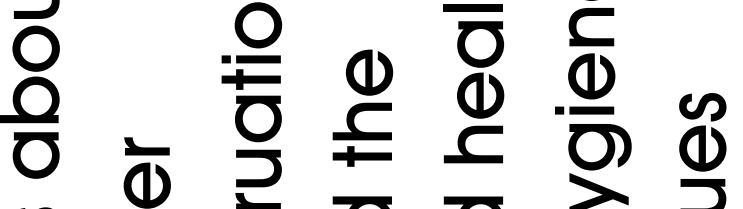

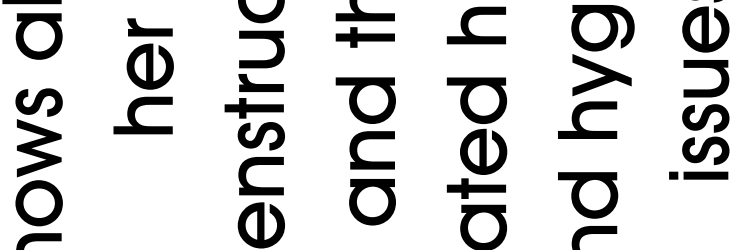

$$
\begin{aligned}
& \text { ₹ है } \frac{\bar{\sigma}}{\omega} \overline{0}
\end{aligned}
$$




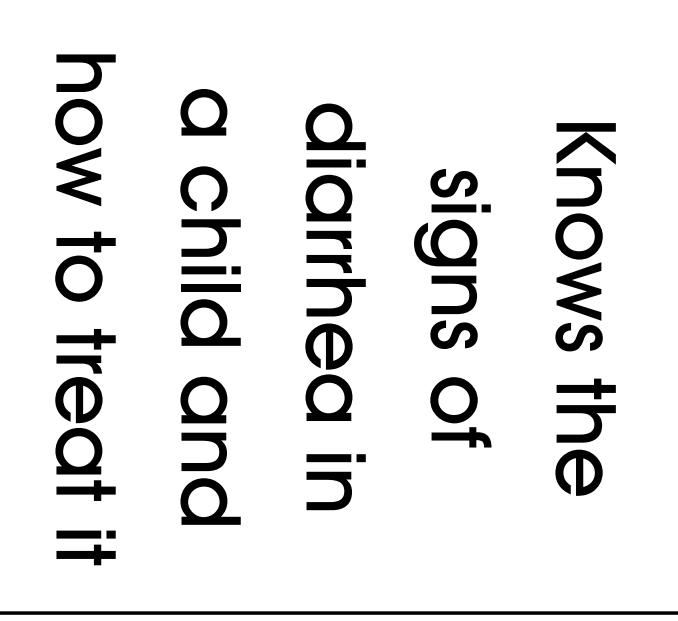

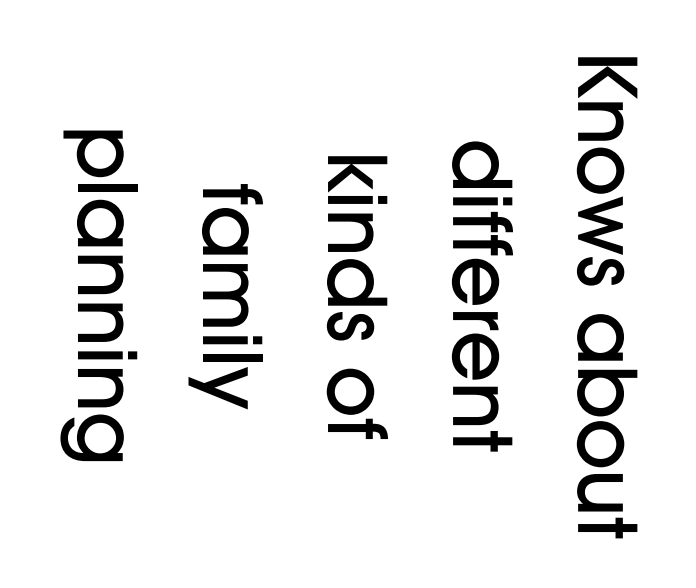

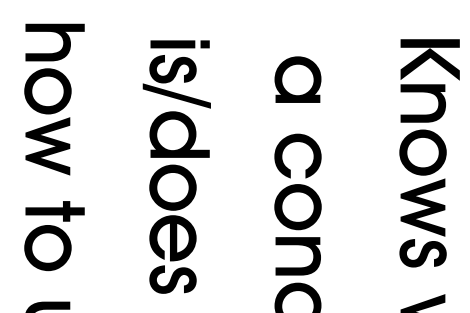

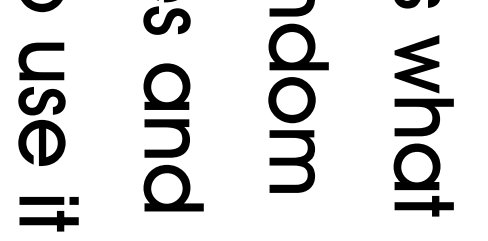




$$
\begin{aligned}
& \text { 造 } \frac{\bar{d}}{\frac{d}{3}} \frac{}{\frac{0}{\sigma}} \\
& \infty \stackrel{0}{c} \infty \\
& \text { 亭 }
\end{aligned}
$$

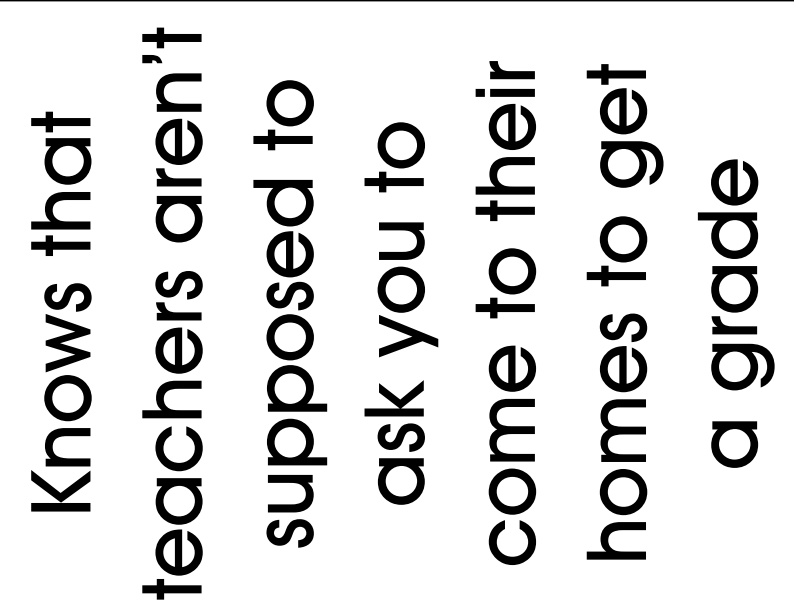

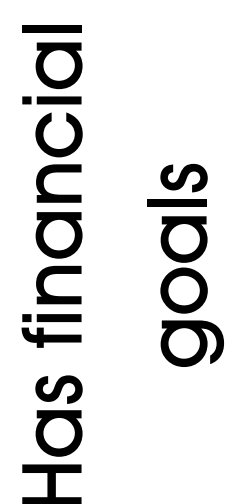

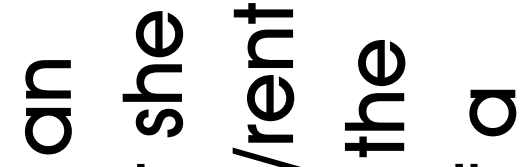

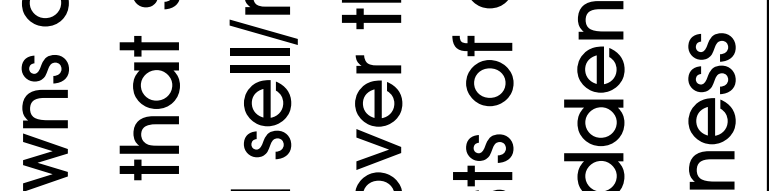

О 㐫

$$
\text { 잉 엉 으 }
$$

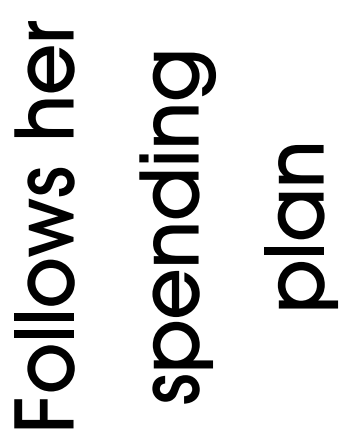

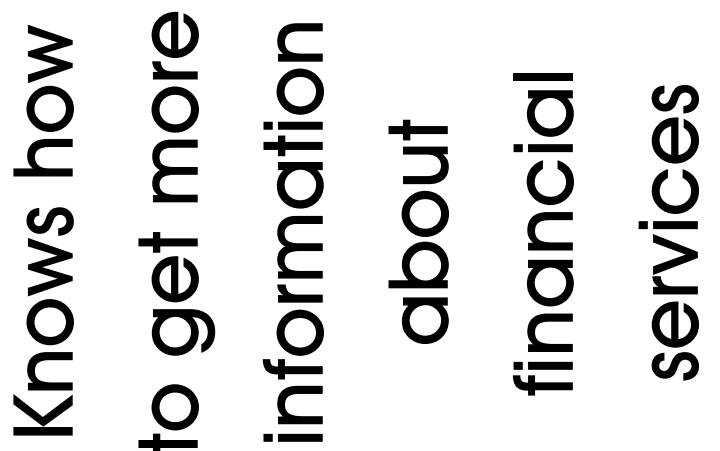

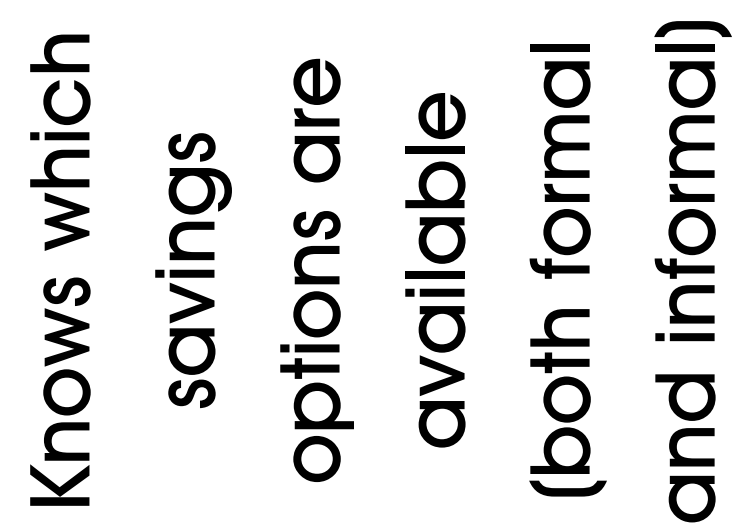




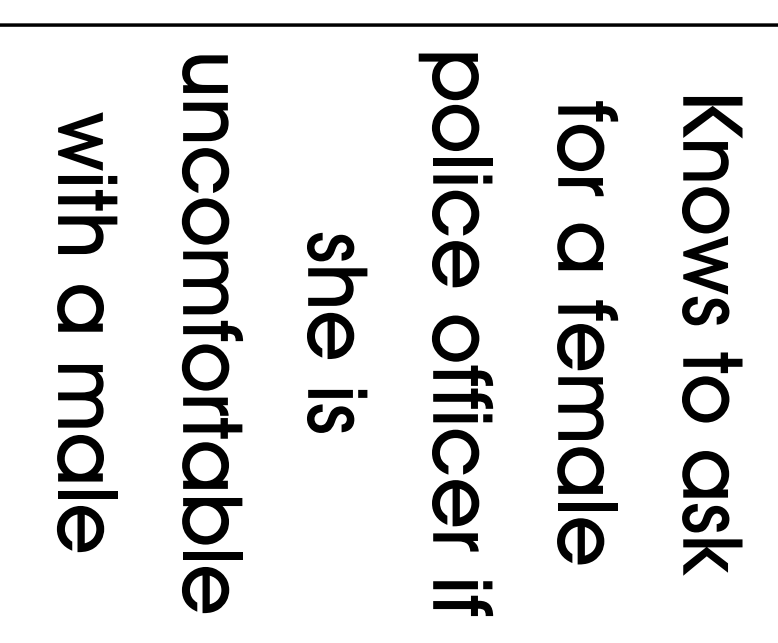

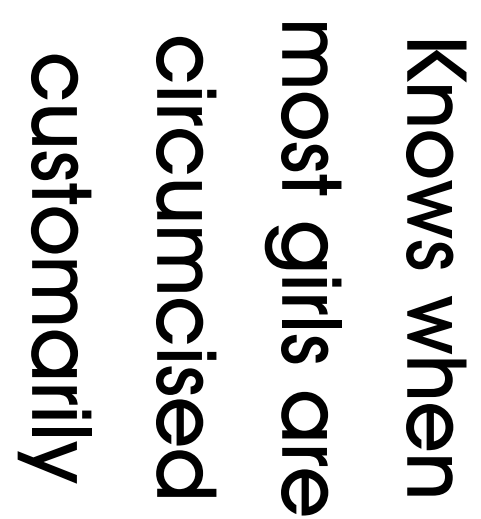

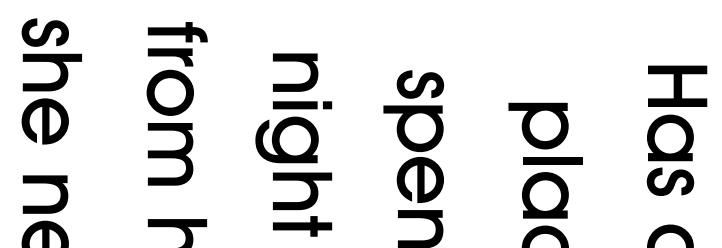$$
\text { ब }
$$

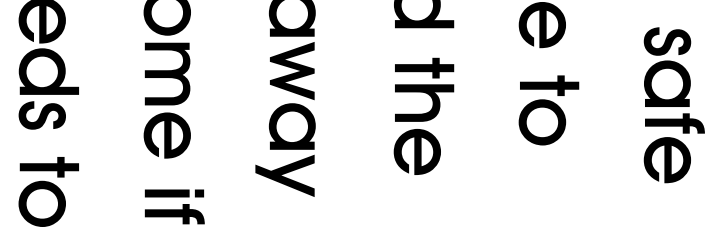

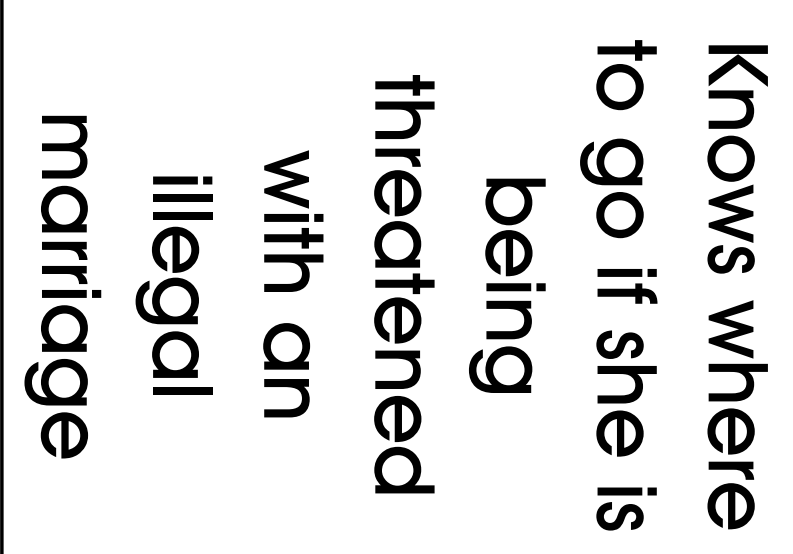




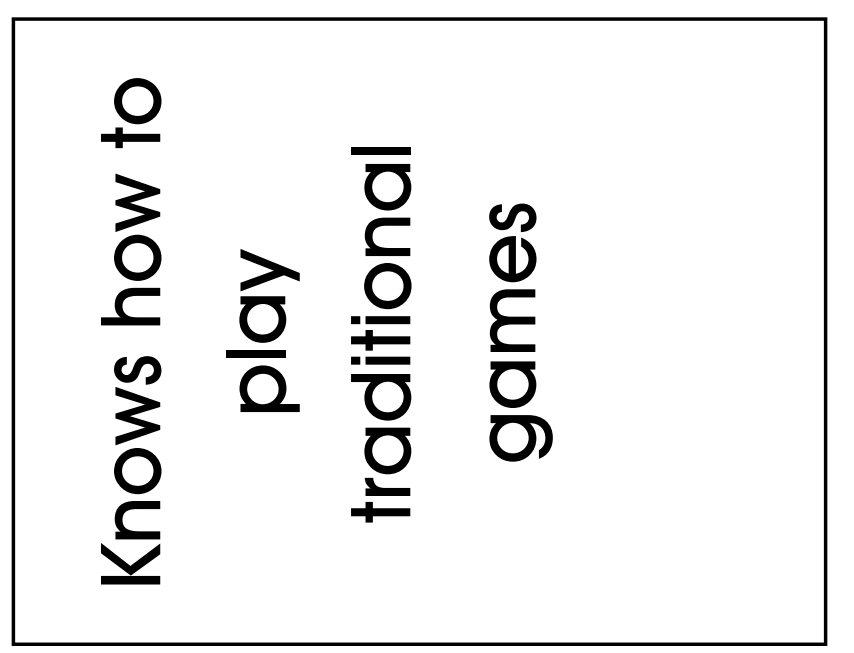

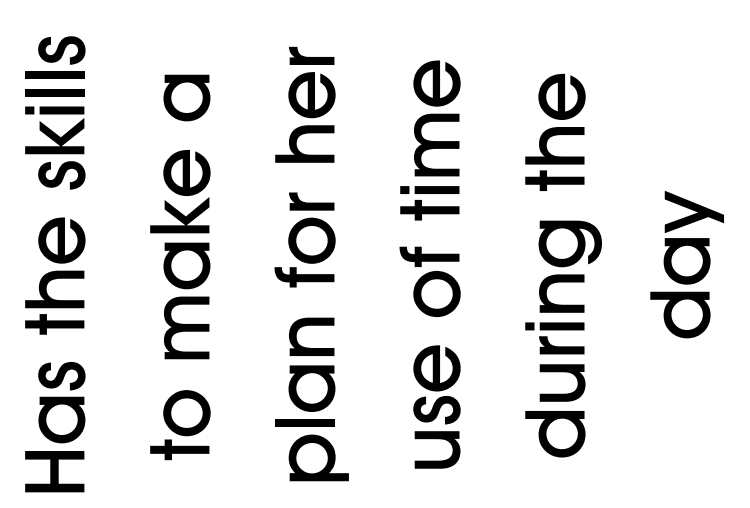

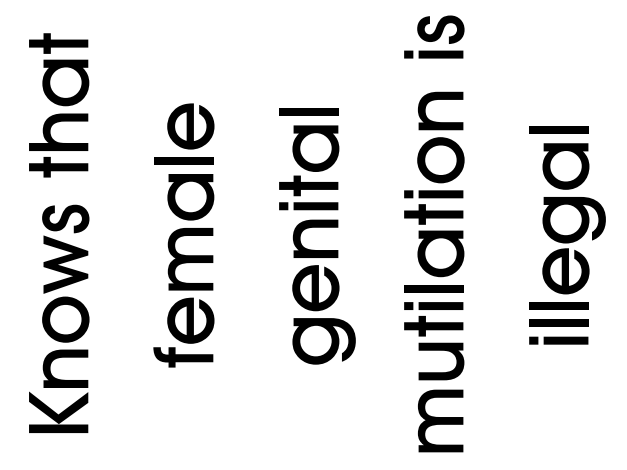

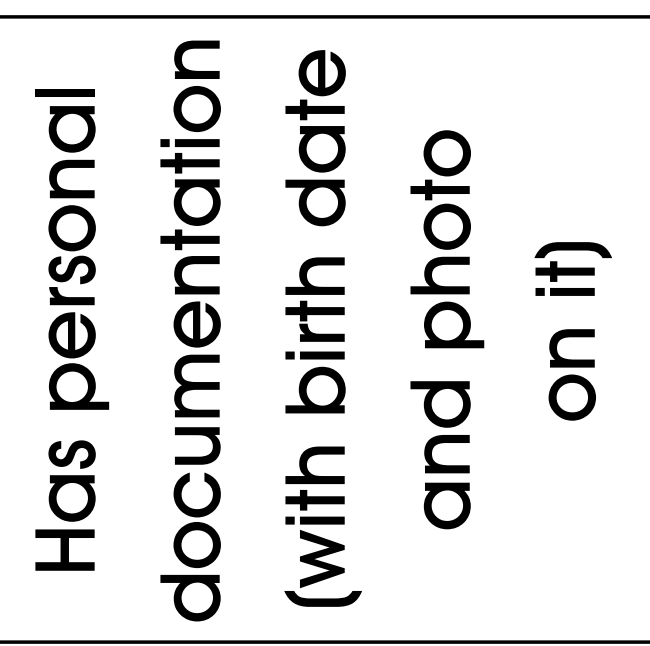

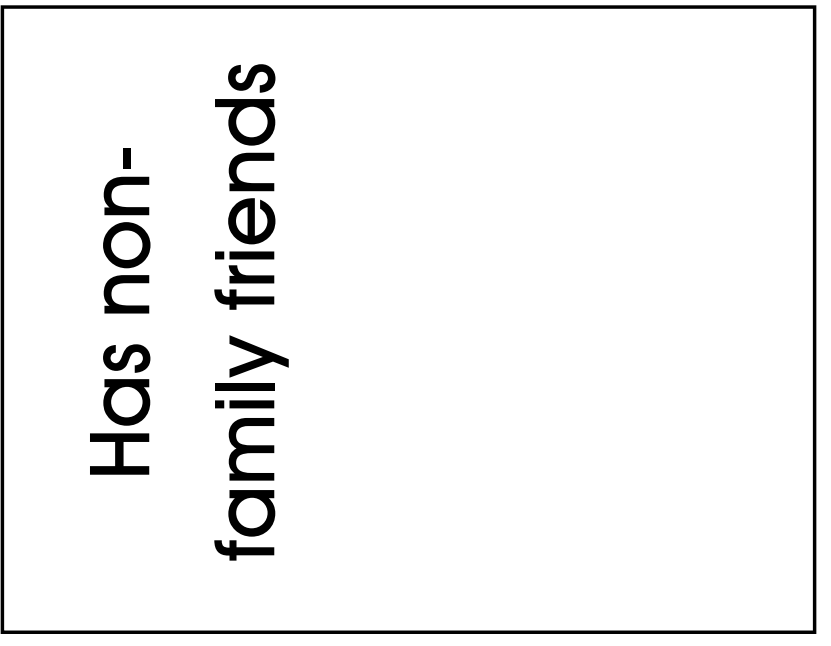

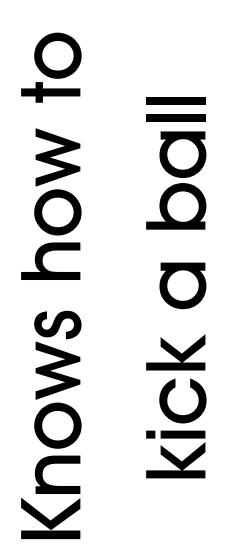

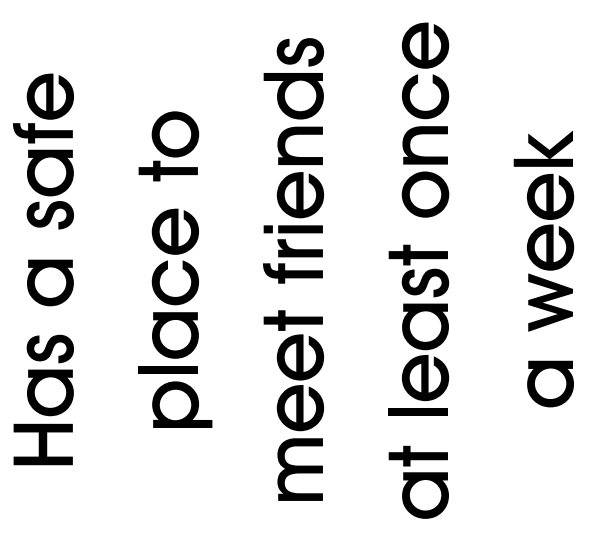

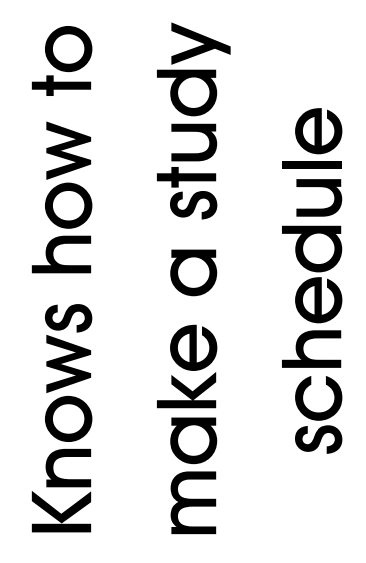




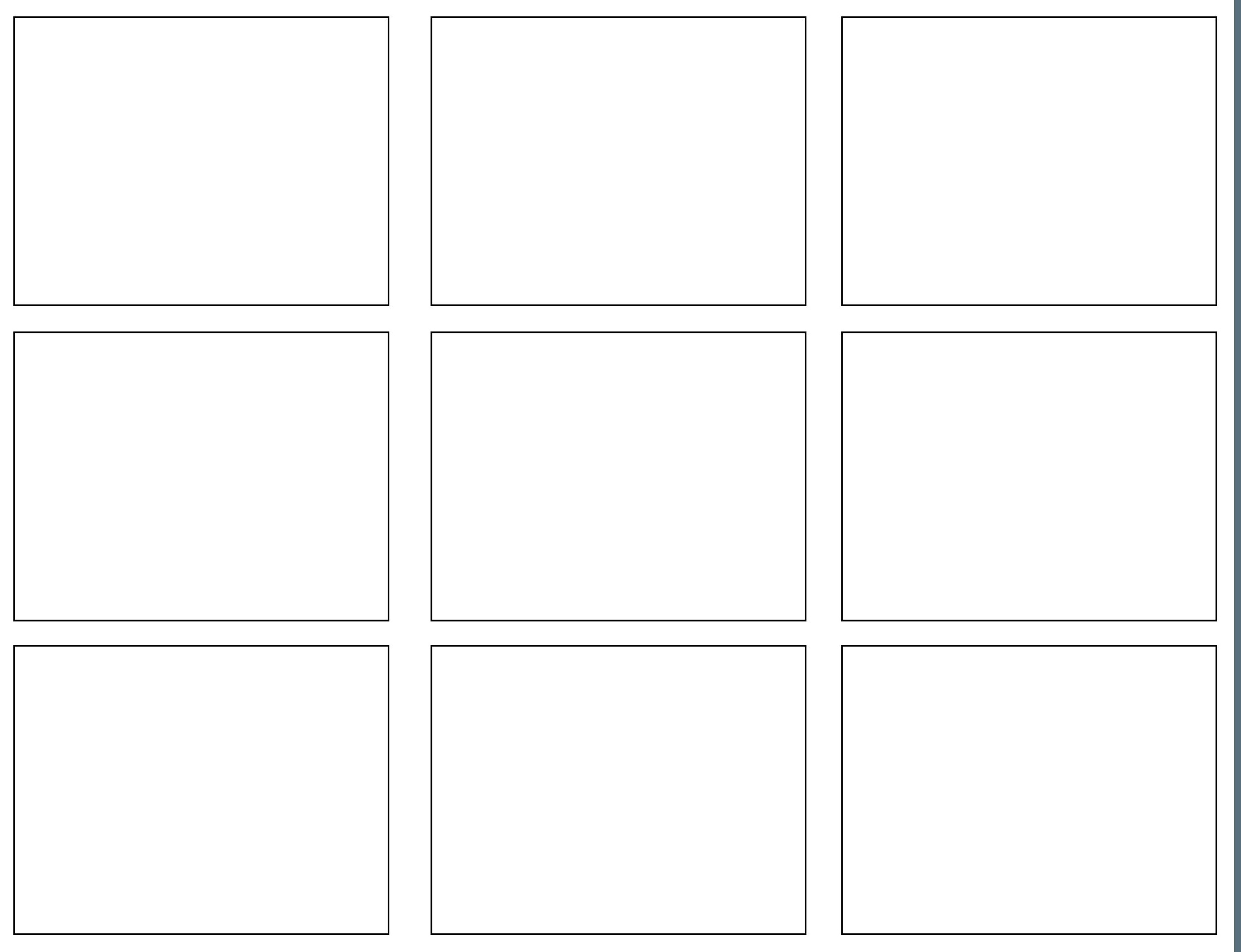


Chapter 10: Responding to SGBV at a program level - A preparedness worksheet

Medical response: Where are the three nearest facilities that can provide a medical response?

\begin{tabular}{|l|l|}
\hline LOCATION 1 & \\
\hline NAME & \\
\hline PHYSICAL ADDRESS & \\
\hline PUBLIC TRANSPORT & \\
\hline PHONE NUMBER & \\
\hline COST & \\
\hline $\begin{array}{l}\text { LIST OF SERVICES PROVIDED } \\
\text { (Emergency contraception/pregnancy prevention, } \\
\text { sexually transmitted infection testing and } \\
\text { treatment, PEP/HIV prevention, pain management, } \\
\text { evidence collection, counseling) }\end{array}$ & \\
\hline
\end{tabular}




\begin{tabular}{|l|l|}
\hline LOCATION 2 & \\
\hline NAME & \\
\hline PHYSICAL ADDRESS & \\
\hline PUBLIC TRANSPORT & \\
\hline PHONE NUMBER & \\
\hline COST & \\
\hline $\begin{array}{l}\text { LIST OF SERVICES PROVIDED } \\
\text { (Emergency contraception/pregnancy prevention, } \\
\text { sexually transmitted infection testing and treatment, } \\
\text { PEP/HIV prevention, pain management, evidence } \\
\text { collection, counseling) }\end{array}$ & \\
\hline
\end{tabular}

LOCATION 3

Medical response

NAME

PHYSICAL ADDRESS

PUBLIC TRANSPORT

PHONE NUMBER

COST

LIST OF SERVICES PROVIDED

(Emergency contraception/pregnancy prevention,

sexually transmitted infection testing and treatment,

PEP/HIV prevention, pain management, evidence

collection, counseling) 
Legal response - What are the two local resources where I can refer girls for legal services?

\begin{tabular}{|l|l|}
\hline LOCATION 1 & \\
\hline NAME & \\
\hline PHYSICAL ADDRESS & \\
\hline PUBLIC TRANSPORT & \\
\hline PHONE NUMBER & \\
\hline COST & \\
\hline $\begin{array}{l}\text { LIST OF SERVICES PROVIDED } \\
\text { (Legal counseling, legal representation, } \\
\text { assistance with police, etc.) }\end{array}$ & \\
\hline
\end{tabular}

\begin{tabular}{|l|l|}
\hline LOCATION 2 & \\
\hline NAME & \\
\hline PHYSICAL ADDRESS & \\
\hline PUBLIC TRANSPORT & \\
\hline PHONE NUMBER & \\
\hline COST & \\
\hline $\begin{array}{l}\text { LIST OF SERVICES PROVIDED } \\
\text { (Legal counseling, legal representation, } \\
\text { assistance with police, etc.) }\end{array}$ & \\
\hline
\end{tabular}


Law enforcement response - Where is the nearest police station that has a Child Desk or a SGBV Response Unit?

\begin{tabular}{|l|l|}
\hline LOCATION 1 & \\
\hline NAME & \\
\hline PHYSICAL ADDRESS & \\
\hline PUBLIC TRANSPORT & \\
\hline PHONE NUMBER & \\
\hline COST & \\
\hline LIST OF SERVICES PROVIDED & \\
\hline
\end{tabular}

\begin{tabular}{|l|l|}
\hline LOCATION 2 & \\
\hline NAME & \\
\hline PHYSICAL ADDRESS & \\
\hline PUBLIC TRANSPORT & \\
\hline PHONE NUMBER & \\
\hline COST & \\
\hline LIST OF SERVICES PROVIDED & \\
& \\
\hline
\end{tabular}




\begin{tabular}{|l|l|}
\hline LOCATION 3 & \\
\hline NAME & \\
\hline PHYSICAL ADDRESS & \\
\hline PUBLIC TRANSPORT & \\
\hline PHONE NUMBER & \\
\hline COST & \\
\hline LIST OF SERVICES PROVIDED & \\
\end{tabular}

\begin{tabular}{|l|l|}
\hline LOCATION 4 & \\
\hline NAME & \\
\hline PHYSICAL ADDRESS & \\
\hline PUBLIC TRANSPORT & \\
\hline PHONE NUMBER & \\
\hline COST: & \\
\hline LIST OF SERVICES PROVIDED & \\
& \\
\hline
\end{tabular}


Psycho-social response - What are the local resources that provide professional counseling and guidance for survivors of SGBV?

\begin{tabular}{|l|l|}
\hline LOCATION 1 & \\
\hline NAME & \\
\hline PHYSICAL ADDRESS & \\
\hline PUBLIC TRANSPORT & \\
\hline PHONE NUMBER & \\
\hline COST & \\
\hline LIST OF SERVICES PROVIDED & \\
\hline
\end{tabular}

\begin{tabular}{|l|l|}
\hline LOCATION 2 & \\
\hline NAME & \\
\hline PHYSICAL ADDRESS & \\
\hline PUBLIC TRANSPORT & \\
\hline PHONE NUMBER & \\
\hline COST & \\
\hline LIST OF SERVICES PROVIDED & \\
\hline
\end{tabular}


Psycho-social response - What are the local resources that provide professional counseling and guidance for survivors of SGBV?

\begin{tabular}{|l|l|}
\hline LOCATION 3 & Psycho-social response \\
\hline NAME & \\
\hline PHYSICAL ADDRESS & \\
\hline PUBLIC TRANSPORT & \\
\hline PHONE NUMBER & \\
\hline COST & \\
\hline LIST OF SERVICES PROVIDED & \\
\hline
\end{tabular}

\begin{tabular}{|l|l|}
\hline LOCATION 4 & \\
\hline NAME & \\
\hline PHYSICAL ADDRESS & \\
\hline PUBLIC TRANSPORT & \\
\hline PHONE NUMBER & \\
\hline COST & \\
\hline LIST OF SERVICES PROVIDED & \\
\hline
\end{tabular}


Safe houses - Where are there safe houses/places where girls can spend the night in case of an emergency?

\begin{tabular}{|l|l|}
\hline LOCATION 1 & \\
\hline NAME & \\
\hline PHYSICAL ADDRESS & \\
\hline PUBLIC TRANSPORT & \\
\hline PHONE NUMBER & \\
\hline COST & \\
\hline LIST OF SERVICES PROVIDED & \\
\hline
\end{tabular}

\begin{tabular}{|l|l|}
\hline LOCATION 2 & \\
\hline NAME & \\
\hline PHYSICAL ADDRESS & \\
\hline PUBLIC TRANSPORT & \\
\hline PHONE NUMBER & \\
\hline COST & \\
\hline LIST OF SERVICES PROVIDED & \\
& \\
\hline
\end{tabular}




\section{AGE CATEGORIES}

Put each asset listed above under the age by which you think a girl in your program should have this asset.
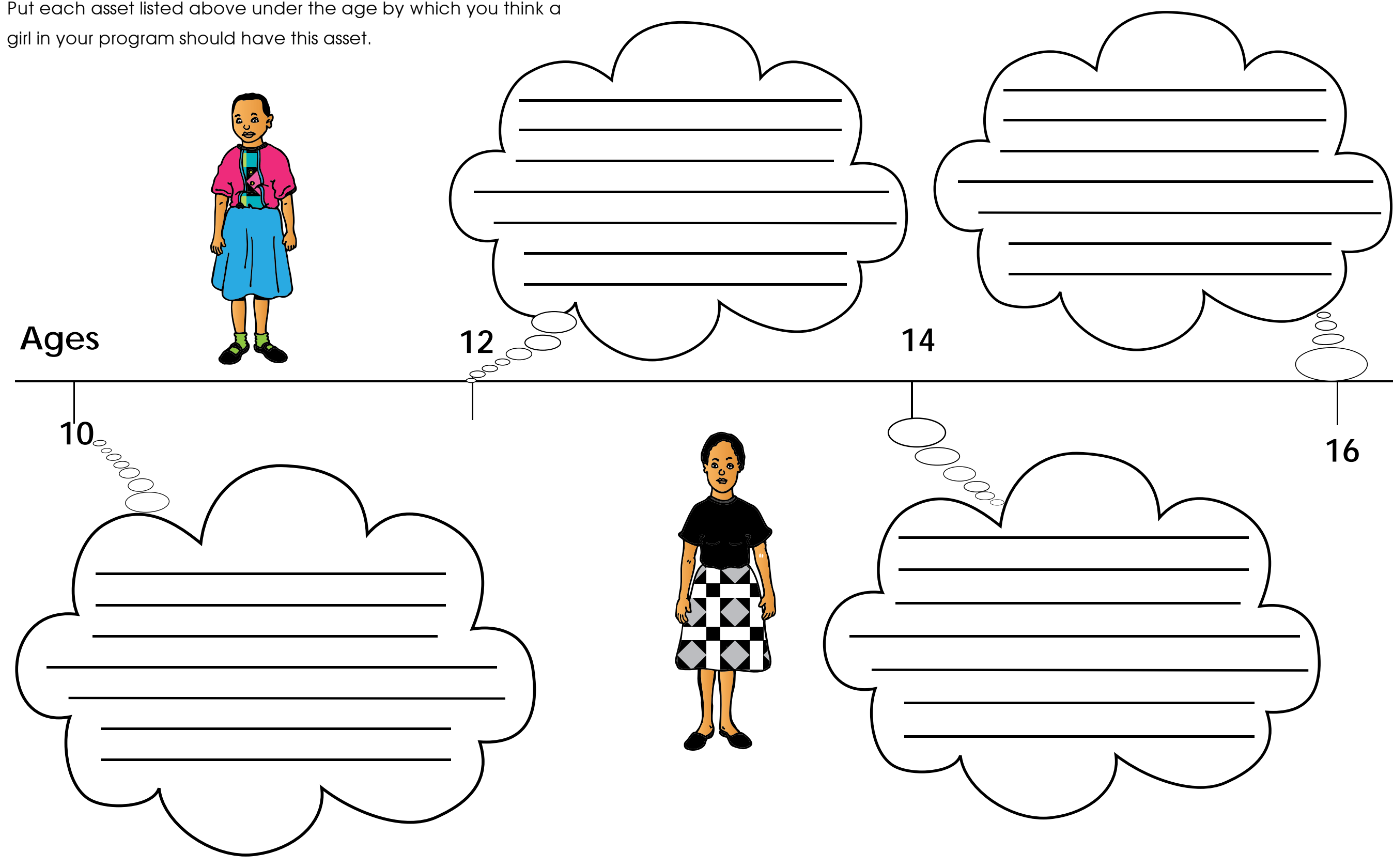


\section{Chapter 12}

Intake register questions

\begin{tabular}{|c|c|}
\hline CHARACTERISTIC & $\begin{array}{l}\text { QUESTION } \\
\text { (Depends on which piece of information you want to collect) }\end{array}$ \\
\hline Age & How old are you? \\
\hline Living Arrangements & Who do you live with? \\
\hline Living Location & What neighborhood do you live in? \\
\hline Schooling Status & Are you currently in school? \\
\hline Education Level & $\begin{array}{l}\text { What grade/class/level are you in? } \\
\text { What is the highest level of schooling you reached? }\end{array}$ \\
\hline School Attended & What school do you go to? \\
\hline Parenthood Status & $\begin{array}{l}\text { Do you have any children? } \\
\text { How many children do you have? }\end{array}$ \\
\hline Marital Status & $\begin{array}{l}\text { Are you currently married? How many children do you have? } \\
\text { Do you currently live with your boyfriend or husband? }\end{array}$ \\
\hline Migration Status & $\begin{array}{l}\text { Were you born in the neighborhood where you live? } \\
\text { At what age did you move there? } \\
\text { From where did you move? }\end{array}$ \\
\hline Work Status & $\begin{array}{l}\text { Are you currently engaged in any form of income generating activity? } \\
\text { What income generating activities are you involved in? }\end{array}$ \\
\hline
\end{tabular}




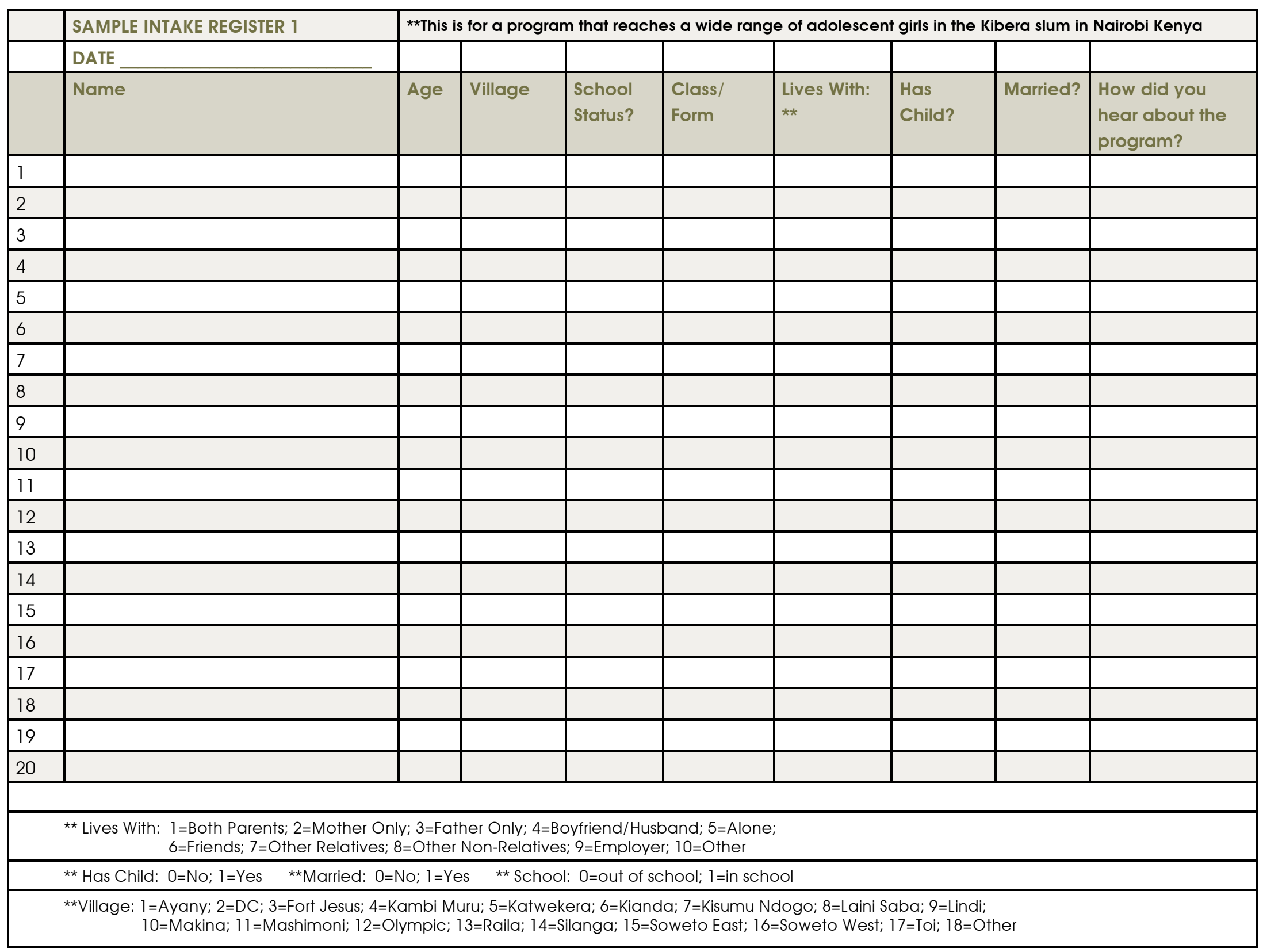




\begin{tabular}{|c|c|c|c|c|c|c|c|c|c|}
\hline & \multirow{2}{*}{$\begin{array}{l}\text { SAMPLE INTAKE REGISTER } 2 \\
\text { DATE }\end{array}$} & \multicolumn{8}{|c|}{${ }^{* *}$ This is a register of a program targeting young mothers who are working in a certain market in Kampala, Uganda } \\
\hline & & & & & & & & & \\
\hline & Name & Age & Neighborhood & \# of Kids & $\begin{array}{l}\text { Highest } \\
\text { Level of } \\
\text { Education }\end{array}$ & $\begin{array}{l}\text { Lives With: } \\
\text { ** }\end{array}$ & $\begin{array}{l}\text { Date started } \\
\text { working in } \\
\text { Market }\end{array}$ & Migration Status & Notes \\
\hline \multicolumn{10}{|l|}{1} \\
\hline \multicolumn{10}{|l|}{2} \\
\hline \multicolumn{10}{|l|}{3} \\
\hline \multicolumn{10}{|l|}{4} \\
\hline \multicolumn{10}{|l|}{5} \\
\hline \multicolumn{10}{|l|}{6} \\
\hline \multicolumn{10}{|l|}{7} \\
\hline \multicolumn{10}{|l|}{8} \\
\hline \multicolumn{10}{|l|}{9} \\
\hline \multicolumn{10}{|l|}{10} \\
\hline \multicolumn{10}{|l|}{11} \\
\hline \multicolumn{10}{|l|}{12} \\
\hline \multicolumn{10}{|l|}{13} \\
\hline \multicolumn{10}{|l|}{14} \\
\hline \multicolumn{10}{|l|}{15} \\
\hline \multicolumn{10}{|l|}{16} \\
\hline \multicolumn{10}{|l|}{17} \\
\hline \multicolumn{10}{|l|}{18} \\
\hline \multicolumn{10}{|l|}{19} \\
\hline \multicolumn{10}{|l|}{20} \\
\hline \multicolumn{10}{|c|}{$\begin{aligned} \text { ** Lives With: } 1=\text { Both Parents; } 2=\text { Mother Only; } 3=\text { Father Only; } 4=\text { Boyfriend/Husband; } 5=\text { Alone; } \\
6=\text { Friends; } 7=\text { Other Relatives; } 8=\text { Other Non-Relatives; } 9=\text { Employer; } 10=\text { Other }\end{aligned}$} \\
\hline \multicolumn{5}{|c|}{ ** Migration Status: 0=Born in Kampala; l=Migrated from Rural Area } & \multicolumn{5}{|c|}{\begin{tabular}{|l}
$* \star$ Education Level: $1=$ Some Primary; 2=Finished Primary; $3=$ Some Secondary; \\
$4=$ Completed Secondary; $5=$ Some Post-Secondary; $6=$ Other (specify in notes) \\
\end{tabular}} \\
\hline \multicolumn{10}{|c|}{$\begin{aligned} \text { Neighborhood: } & 1=\text { Kisenyi; } 2=\text { Katwe; } 3=\text { Wandegya; } 4=\text { Bwaise; } 5=\text { Kivulu; } 6=\text { Kamwokya; } 7=\text { Makerere; } 8=\text { Ndeba; } 9=\text { Kawempe; } \\
& \text { 10=Kibuye; } 11=\text { Gayaza; } 12=\text { Nakulabye; } 13=\text { Kikoni; } 14=\text { Owino; } 15=\text { Old Kampala; 16=Kasubi; } 17=\text { =ther in Kampala (specify in notes) }\end{aligned}$} \\
\hline
\end{tabular}




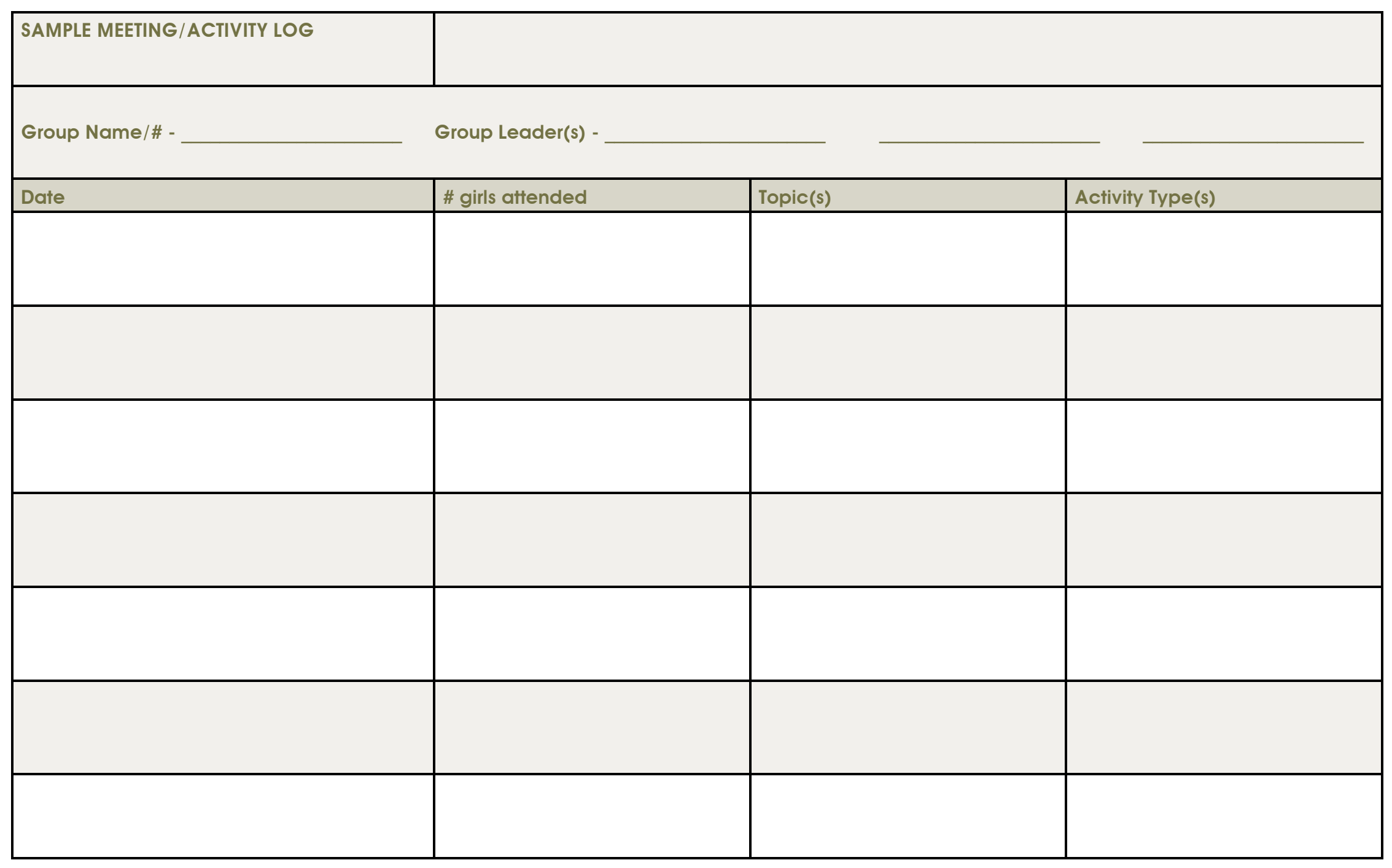




\section{Chapter 13}

What do you want to measure?

As you think about the kind of evaluation that you are planning, one of the first steps is to decide what you want to measure. As we discussed, being able to differentiate between the overall goal and vision that you have for the girls in you program, and the steps along the way that will let you know that they are on the path to reaching that goal will simplify your evaluation work and allow you to get meaningful information.

\section{First:}

What is the overall goal and vision of your organization? What is the big, long-term goal that you have for the girls in your program?

\section{Second:}

What are the assets that you are trying to build within the girls themselves? 
Third: What questions will you ask to measure each asset? (Use the list in 174-181 to help you)

\begin{tabular}{|l|l|}
\hline ASSET/INDICATOR & QUESTION \\
\hline & \\
\hline & \\
\hline & \\
\hline & \\
\hline & \\
\hline & \\
\hline & \\
\hline
\end{tabular}

Fourth: Think about what tools you will use to gather the information about each of these changes that you would like to measure. Will you use a short survey and include several questions? Will you have some focus groups? Use the next chart to think through the different tools:

\begin{tabular}{|l|l|l|}
\hline TOOL & ASSET/INDICATOR TO BE MEASURED & QUESTION TO BE ASKED \\
\hline Eg. Quantitative Survey & Has Savings & $\begin{array}{l}\text { Do you have money put aside or in your } \\
\text { savings? (Yes/No) }\end{array}$ \\
\hline Eg. Focus Group Discussion & Understands the Importance of Saving & $\begin{array}{l}\text { What are some of the reasons that girls } \\
\text { like yourselves save, or put money aside } \\
\text { for future use? }\end{array}$ \\
\hline & & \\
\hline & & \\
\hline & & \\
\hline
\end{tabular}


Fifth: Now you can assign responsibilities and timelines for getting these evaluation activities in place. It is also important to think about a) how much money this will cost and if it is in your budget and b) do you have the in-house skills to complete these tasks or if you will need to engage someone external (and the cost implications of that):

\begin{tabular}{|l|l|l|l|l|l|}
\hline TASK & $\begin{array}{l}\text { WHO WILL BE } \\
\text { RESPONSIBLE ? }\end{array}$ & $\begin{array}{l}\text { DO WE NEED } \\
\text { EXTERNAL } \\
\text { EXPERTISE \& IN } \\
\text { WHAT AREA? }\end{array}$ & $\begin{array}{l}\text { HOW MUCH } \\
\text { MONEY WILL IT } \\
\text { COST? }\end{array}$ & $\begin{array}{l}\text { HOW MUCH STAFF } \\
\text { TIME WILL IT TAKE? }\end{array}$ & BY WHAT DATE? \\
\hline $\begin{array}{l}\text { Finalize list of } \\
\text { assets/indicators }\end{array}$ & & & & & \\
\hline $\begin{array}{l}\text { Finalize list of } \\
\text { questions }\end{array}$ & & & & & \\
\hline $\begin{array}{l}\text { Develop Evaluation } \\
\text { Tools (surveys, } \\
\text { interview guides, } \\
\text { etc.) }\end{array}$ & & & & & \\
\hline $\begin{array}{l}\text { Organize the Data } \\
\text { Collection* }\end{array}$ & & & & & \\
\hline $\begin{array}{l}\text { Collect the Data* } \\
\text { (doing the actual } \\
\text { interviewing) }\end{array}$ & & & & & \\
\hline Analyze the Data & & & & & \\
\hline Compile Reports & & & & & \\
\hline
\end{tabular}

*Note Data collection might happen at several points during the program cycle

Use the information in this chart to assess what can be done internally and what you will need external assistance with

Calculate the total budget costs and assess if you have the funds and staff time available.

Finally, you can use all of this information to integrate the evaluation activities into your overall program work plan/timeline. 


\section{SAMPLE TRAINING PARTICIPANT EVALUATION FORM}

\section{Participant training evaluation form}

Date: Title of Training:

1. What was your favorite part of the training today?

2. Which topic was the most important to you in the training? Why?

3. Which topics need to added to this training?

4. What was your least favorite part of the training?

5. What are three things that we can improve about this training?
A)
B)
C) 


\section{SAMPLE PROGRAM EVALUATION FORM}

\section{Member evaluation form}

Note This form is designed to be completed by the girls themselves in writing. Please adapt the questions to suit your specific program goals and activities. Also, it is generically called "this program". Feel free to fill in with your program's name.

1. What have you learned from (this program)?

2. What more would you like to learn at (this program) that you have not yet learned?

3. What is your favorite activity at (this program)?

4. What is your least favorite activity at (this program)?

5. What would you do to make (this program) better?

6. What would you do to make your life as a young woman better and that of other young woman in this community and (this program)?

7. What do you think is (this program)'s impact on this community?

8. How can (this program) better impact the community?

9. Has (this program) had an effect on your life? If so, how?

Any other comments 
*Note The two forms on pages 221 \& 222 (training evaluation and program evaluation) require girls to be able to read and write. If you would rather not rely on that, you can ask the girls the questions out loud either individually or as a group. You can use the following chart as a guide for a group discussion. Ask participants what about the program or training they love, like, want less of, or want no more of:

\begin{tabular}{|l|l|}
\hline LOVE IT & LIKE IT \\
\hline & \\
\hline & \\
\hline LESS OF IT & \\
\hline & LOSE IT \\
\hline & \\
\hline
\end{tabular}




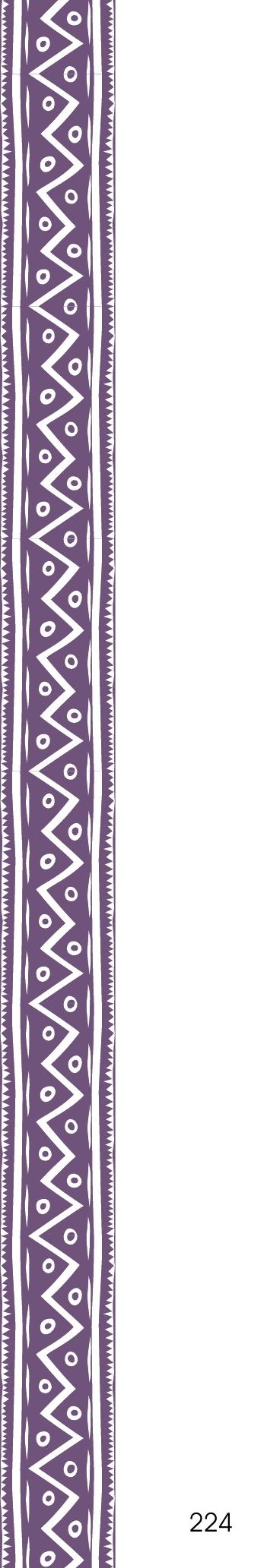




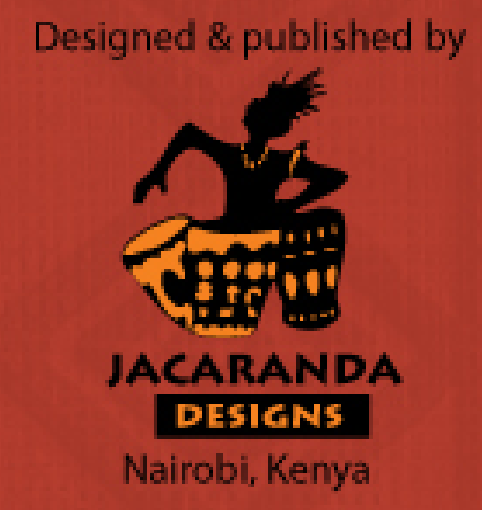

